\title{
Implementation of a Helicopter Flight Simulator with Individual Blade Control
}

Andrew G. Zinchiak

West Virginia University

Follow this and additional works at: https://researchrepository.wvu.edu/etd

\section{Recommended Citation}

Zinchiak, Andrew G., "Implementation of a Helicopter Flight Simulator with Individual Blade Control" (2011). Graduate Theses, Dissertations, and Problem Reports. 2235.

https://researchrepository.wvu.edu/etd/2235

This Thesis is protected by copyright and/or related rights. It has been brought to you by the The Research Repository @ WVU with permission from the rights-holder(s). You are free to use this Thesis in any way that is permitted by the copyright and related rights legislation that applies to your use. For other uses you must obtain permission from the rights-holder(s) directly, unless additional rights are indicated by a Creative Commons license in the record and/ or on the work itself. This Thesis has been accepted for inclusion in WVU Graduate Theses, Dissertations, and Problem Reports collection by an authorized administrator of The Research Repository @ WVU. For more information, please contact researchrepository@mail.wvu.edu. 


\title{
Implementation of a Helicopter Flight Simulator with Individual Blade Control
}

\author{
Andrew G. Zinchiak \\ Thesis submitted to the \\ College of Engineering and Mineral Resources \\ at West Virginia University \\ in partial fulfillment of the requirements \\ for the degree of \\ Master of Science \\ in \\ Aerospace Engineering \\ Committee: \\ Mario G. Perhinschi, Ph.D., Chair \\ Marcello R. Napolitano, Ph.D. \\ Larry E. Banta, Ph.D. \\ Department of Mechanical and Aerospace Engineering \\ Morgantown, WV \\ 2011
}

Keywords: Helicopter Flight Dynamics, Individual Blade Control 


\section{Abstract \\ Implementation of a Helicopter Flight \\ Simulator with Individual Blade Control}

\section{Andrew G. Zinchiak}

Nearly all modern helicopters are designed with a swashplate-based system for control of the main rotor blades. However, the swashplate-based approach does not provide the level of redundancy necessary to cope with abnormal actuator conditions. For example, if an actuator fails (becomes locked) on the main rotor, the cyclic inputs are consequently fixed and the helicopter may become stuck in a flight maneuver. This can obviously be seen as a catastrophic failure, and would likely lead to a crash.

These types of failures can be overcome with the application of individual blade control (IBC). IBC is achieved using the blade pitch control method, which provides complete authority of the aerodynamic characteristics of each rotor blade at any given time by replacing the normally rigid pitch links between the swashplate and the pitch horn of the blade with hydraulic or electronic actuators. Thus, IBC can provide the redundancy necessary for subsystem failure accommodation. In this research effort, a simulation environment is developed to investigate the potential of the IBC main rotor configuration for fault-tolerant control.

To examine the applications of IBC to failure scenarios and fault-tolerant controls, a conventional, swashplate-based linear model is first developed for hover and forward flight scenarios based on the UH-60 Black Hawk helicopter. The linear modeling techniques for the swashplate-based helicopter are then adapted and expanded to include IBC. Using these modified techniques, an IBC based mathematical model of the UH-60 helicopter is developed for the purposes of simulation and analysis. The methodology can be used to model and implement a different aircraft if geometric, gravimetric, and general aerodynamic data are available.

Without the kinetic restrictions of the swashplate, the IBC model effectively decouples the cyclic control inputs between different blades. Simulations of the IBC model prove that the primary control functions can be manually reconfigured after local actuator failures are initiated, thus preventing a catastrophic failure or crash. Furthermore, this simulator promises to be a useful tool for the design, testing, and analysis of fault-tolerant control laws. 


\section{Acknowledgements}

First and foremost, I would like to thank my research advisor and committee chairman, Dr. Mario Perhinschi, for giving me the opportunity to work on this project. His guidance and support opened me up to the wonderful world of rotorcraft, and I don't know if I will ever look back. I would also like to thank Sergio Tamayo for dedicating his time to helping with my research while very busy with his own work. Fortunately, Sergio had already met, and overcome, many of the obstacles that I encountered during my studies. His experience was invaluable and I can't thank him enough. In addition, I would like to thank my committee members, Dr. Larry Banta and Dr. Marcello Napolitano, for assisting me on this journey as well as helping to provide me with the skills and knowledge needed to reach this point in my academic career.

I would like to dedicate this thesis to my family who have stood by and supported me in all of my educational endeavors. Thank you to my parents, Zeke and Janie, for supporting my decision to return to school. The two of you taught me the true value of hard work. Thank you to my two brothers, Tommy and Timmy, for always keeping me in check. The two of you both know that I am not nearly as smart as I pretend to be, but that secret can remain between us. And a special thanks to my sister, Valerie. Who knows where I would be if you hadn't been so in love with "playing school" as a child. By the time I was in kindergarten I already knew second grade math, and I definitely owe that jump start in the world of academia to you. And thank you to my mother, Lynn, for forcing me to take advanced math and science courses in middle school and high school. You kept me on the path, and you will remain in my heart, always.

Finally, I would like to thank all of my friends and loved ones at WVU. Sarah, I couldn't have done this without you. You are my rock, and I love you. And, as always, LET'S GO MOUNTAINEERS!!!! 


\section{Table of Contents}

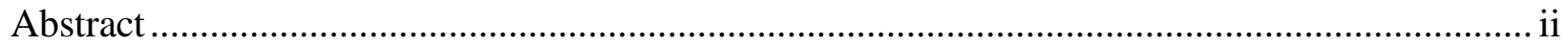

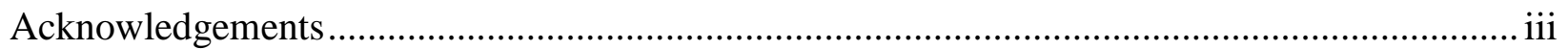

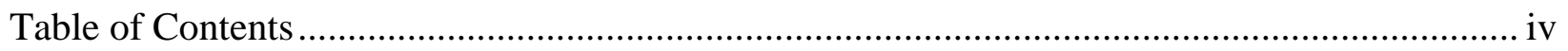

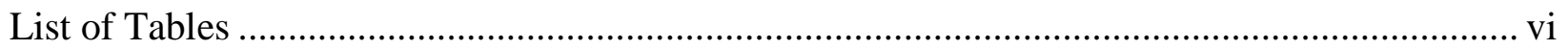

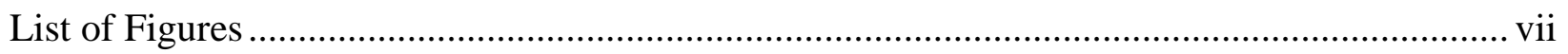

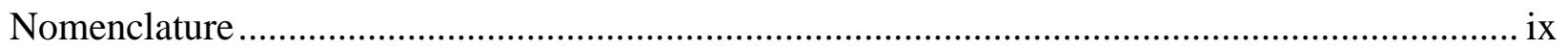

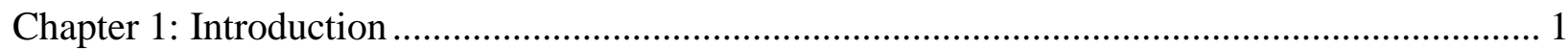

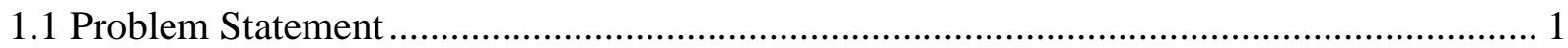

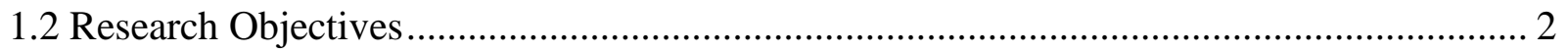

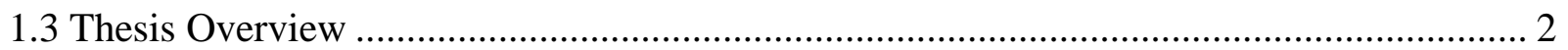

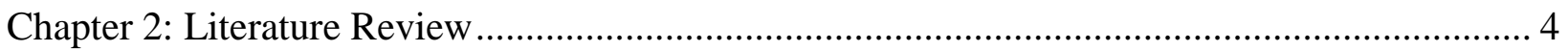

2.1 Review of Helicopter Flight Controls .................................................................. 4

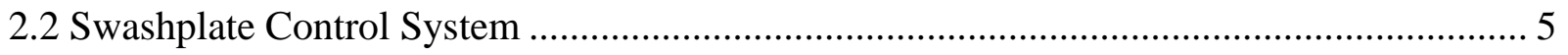

2.3 Individual Blade Control System................................................................................ 8

2.4 Helicopter Mathematical Model ......................................................................... 13

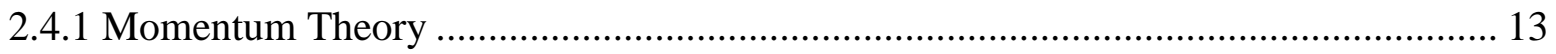

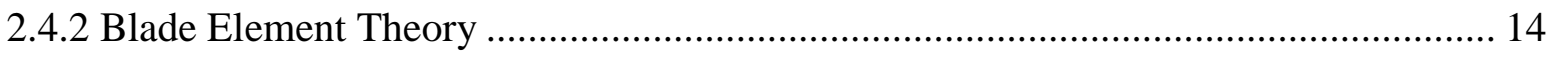

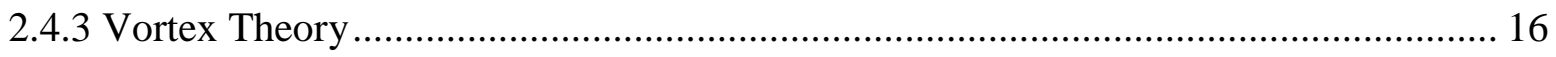

Chapter 3: Modeling a Swashplate-Based Helicopter ........................................................... 19

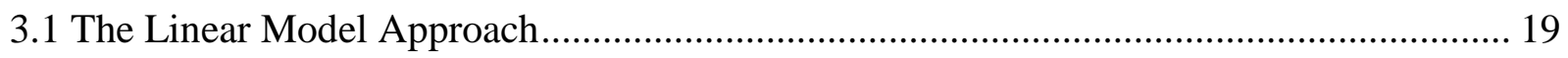

3.1.1 The Helicopter in Trim .............................................................................. 19

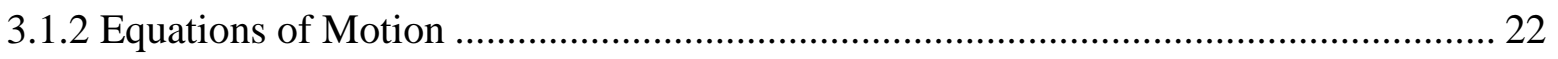

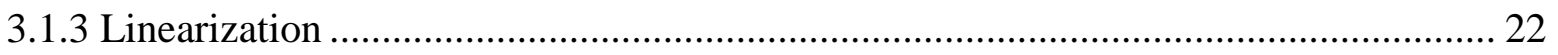

3.2 UH-60 Black Hawk Linear Model: Hover................................................................... 26

3.2.1 Overview of Modeling Structure and Assumptions .............................................. 26

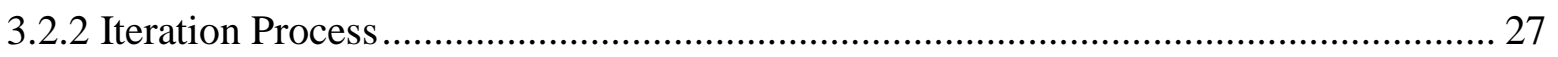

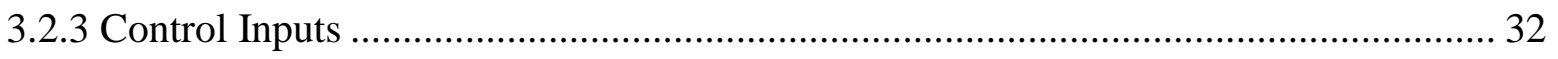

3.2.4 Stability and Control Derivatives and State-Space Representation .......................... 34

3.3 UH-60 Black Hawk Linear Model: Forward Flight ................................................... 35

3.3.1 Overview of Modeling Structure and Assumptions ............................................ 35

3.3.2 Main Rotor Calculations for Forward Flight .................................................... 36

3.3.3 Fuselage Calculations for Forward Flight........................................................ 40 
3.3.4 Empennage Calculations for Forward Flight ....................................................... 42

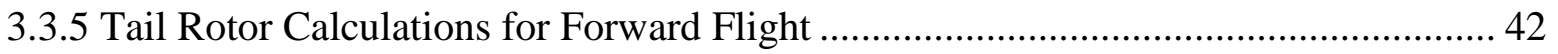

3.3.6 Calculations of Euler Angles for Forward Flight .................................................. 46

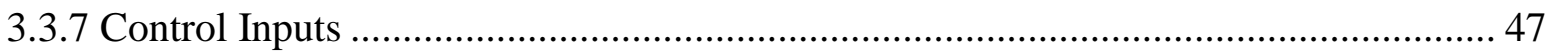

3.3.8 Stability and Control Derivatives and State-Space Representation ............................. 47

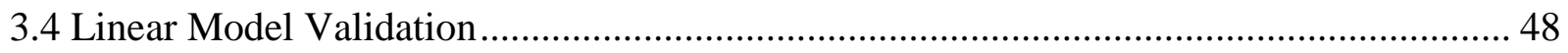

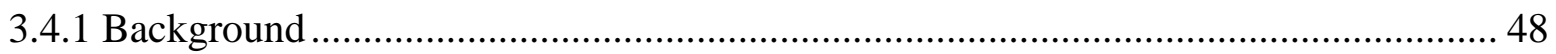

3.4.2 Comparison \#1: Hilbert Model (Ames - 1984) ………........................................... 48

3.4.3 Comparison \#2: Gen Hel Model (Ames - 1987) ……………………...................... 54

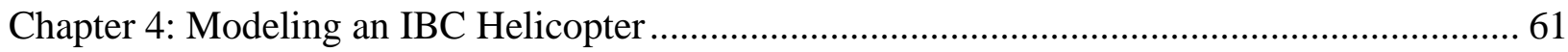

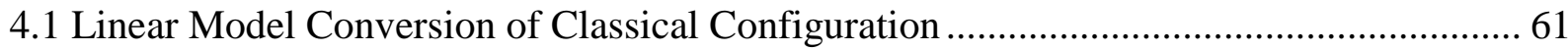

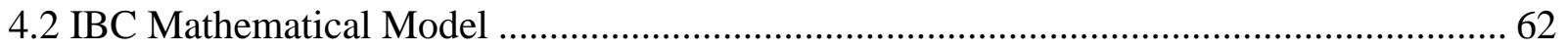

Chapter 5: General Architecture of Simulation Environment .................................................... 65

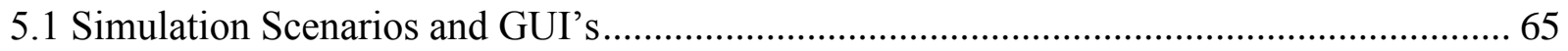

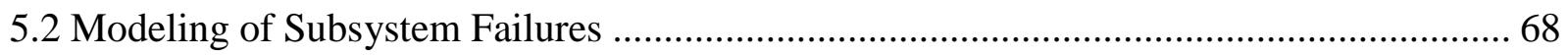

Chapter 6: Simulation Results and Discussion ...................................................................... 70

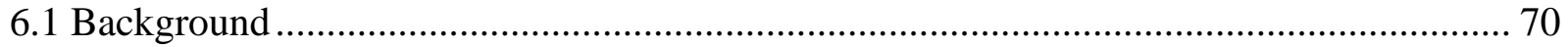

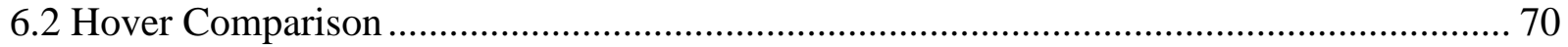

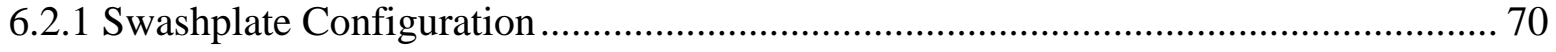

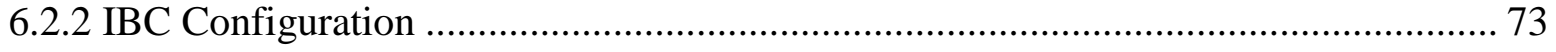

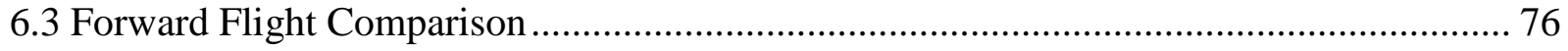

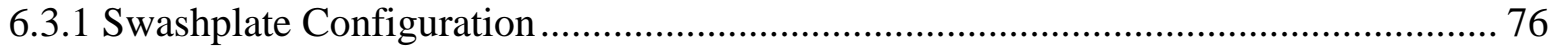

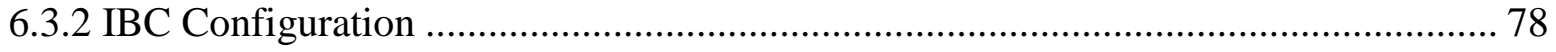

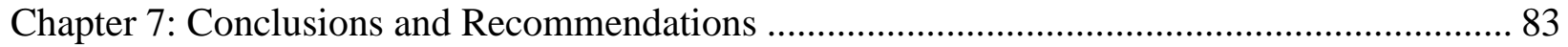

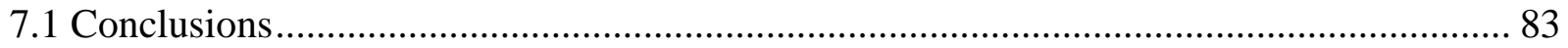

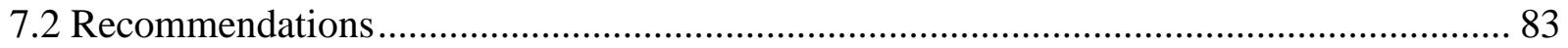

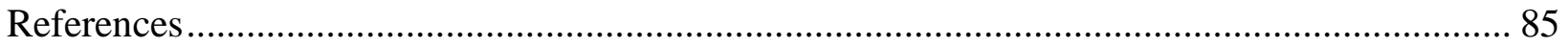

Appendix A: UH-60 Helicopter Constants ....................................................................... A-1

Appendix B: Stability and Control Derivatives .................................................................. B-1

Appendix C: WVU UH-60 Black Hawk Flight Simulator User Guide ....................................... C-1 


\section{List of Tables}

Table 3.1: Level Flight Trim Characteristics (Hilbert UH-60 Math Model) ............................. 49

Table 3.2: Level Flight Trim Characteristics (Boeing-Vertol UH-60 Math Model) .................. 49

Table A.1: UH-60 Helicopter Constants (Aircraft Mass and Inertias) .................................. A-1

Table A.2: UH-60 Helicopter Constants (Main Rotor) ..................................................... A-1

Table A.3: UH-60 Helicopter Constants (Tail Rotor) ............................................................. A-2

Table A.4: UH-60 Helicopter Constants (Fuselage) .......................................................... A-3

Table A.5: UH-60 Helicopter Constants (Horizontal Stabilizer)............................................ A-3

Table A.6: UH-60 Helicopter Constants (Vertical Stabilizer) ............................................ A-3

Table A.7: UH-60 Helicopter Control System Characteristics ............................................... A-4

Table B.1: Stability and Control Derivative Comparison (Hover) ....................................... B-1

Table B.2: Stability and Control Derivative Comparison (20 Knots) ................................... B-3

Table B.3: Stability and Control Derivative Comparison (40 Knots) ..................................... B-5

Table B.4: Stability and Control Derivative Comparison (60 Knots) .................................... B-7

Table B.5: Stability and Control Derivative Comparison (100 Knots) ................................... B-9

Table B.6: Stability and Control Derivative Comparison (140 Knots) ................................ B-11 


\section{List of Figures}

Figure 2.1: Example of Yaw Control Using Tail Rotor......................................................... 5

Figure 2.2: Schematic of Swashplate Control System ........................................................ 6

Figure 2.3: Detailed Schematic of Swashplate Control System ............................................. 6

Figure 2.4: Collective Pitch of M.R. Blades by Means of Swashplate Vertical Movement .......... 7

Figure 2.5: Cyclic Pitch of M.R. Blades by Means of Swashplate Tilt ..................................... 7

Figure 2.6: Trailing-Edge Flap with Aerodynamic Balance................................................ 8

Figure 2.7: Schematic of Flap Actuation Mechanism ...................................................... 8

Figure 2.8: Kaman Aircraft Featuring Active Servo Flaps .............................................. 9

Figure 2.9: Blade Camber Control Using Smart Materials.................................................. 10

Figure 2.10: Principle of the Adaptive Blade Camber Variation........................................... 10

Figure 2.11: Active Blade Twist Rotor Concept .................................................................. 11

Figure 2.12: Examples of Circulation Control (Boundary Layer Control) ............................... 12

Figure 2.13: Schematic IBC Architecture Using Blade Pitch Control ...................................... 13

Figure 2.14: Hovering Flight Flow Model for Momentum Theory Analysis ............................. 14

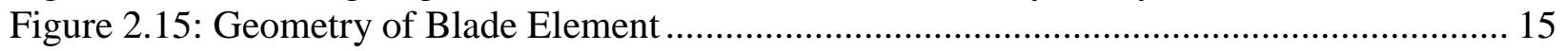

Figure 2.16: Example of Fixed Wing Aircraft Vortices ....................................................... 16

Figure 2.17: Rotor Vortex Wake in Vertical Flight ......................................................... 17

Figure 2.18: Vortex Theory - Actuator Disk Model ........................................................... 18

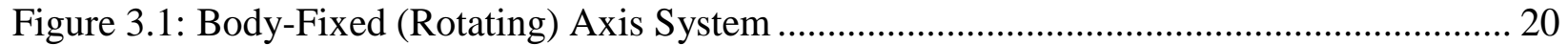

Figure 3.2: Forces and Moments Acting on Helicopter in Trim........................................... 21

Figure 3.3: Flowchart for the Swashplate-Based Linear Model (Hover) ................................... 27

Figure 3.4: OGE Induced Velocities for Hovering Rotor................................................... 28

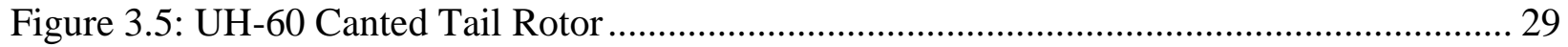

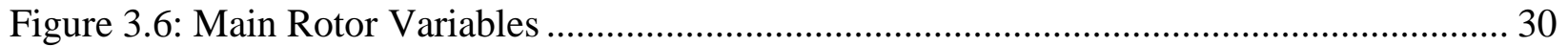

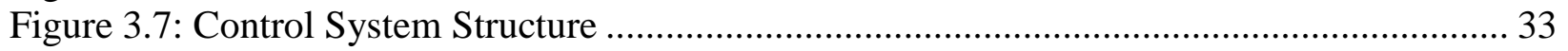

Figure 3.8: Flowchart for the Swashplate-Based Linear Model (Forward Flight) ..................... 36

Figure 3.9: Reverse Flow Region ................................................................................. 37

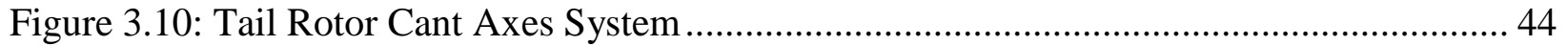

Figure 3.11: Tail Rotor Mechanical Control System............................................................... 45

Figure 3.12: Hilbert Model Comparison (Aircraft Pitch Attitude) ........................................... 50

Figure 3.13: Hilbert Model Comparison (Aircraft Roll Angle).............................................. 51

Figure 3.14: Hilbert Model Comparison (Cockpit Controls)..................................................... 52

Figure 3.15: Gen Hel Model Comparison (Aircraft Pitch Attitude) .......................................... 56

Figure 3.16: Gen Hel Model Comparison (Aircraft Roll Angle) ................................................ 56

Figure 3.17: Gen Hel Model Comparison (Aircraft Sideslip Angle)........................................ 57

Figure 3.18: Gen Hel Model Comparison (Horizontal Stabilizer Incidence Angle) ................... 57

Figure 3.19: Gen Hel Model Comparison (Cockpit Controls) ............................................... 58

Figure 4.1: Flowchart for IBC Linear Model Conversion ................................................ 61

Figure 5.1: WVU Helicopter Simulator - Main Menu ...................................................... 65

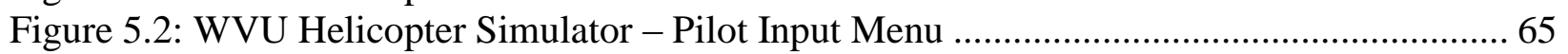

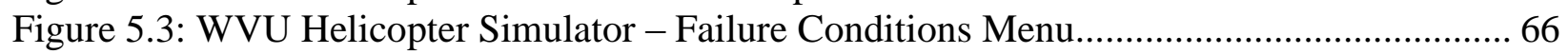

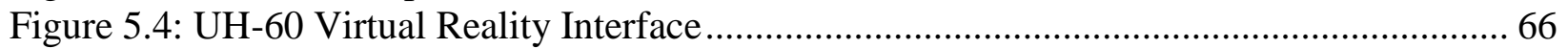


Figure 5.5: General Schematic of Simulation Environment (Swashplate) .............................. 66

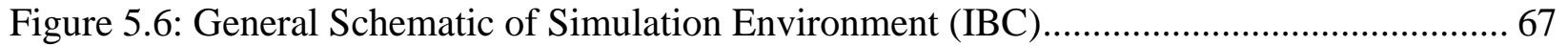

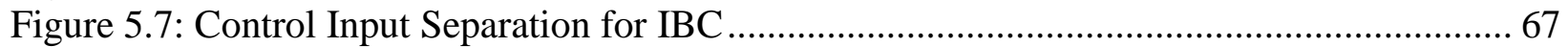

Figure 5.8: Flowchart for Cyclic Actuator Failure (Swashplate) .......................................... 68

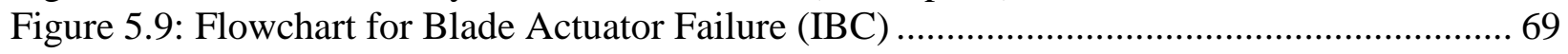

Figure 6.1: Control Inputs at the Rotor Hub (Lateral Cyclic Failure at Hover) ........................ 71

Figure 6.2: Aircraft Euler Angles (Lateral Cyclic Failure at Hover) ...................................... 71

Figure 6.3: Helicopter Flight Path Relative to the Earth (Lateral Cyclic Failure at Hover)......... 72

Figure 6.4: Blade Pitch Angles at the Rotor Hub (Blade \#1 Failure Scenario at Hover) ............ 73

Figure 6.5: Cyclic Response of IBC Blade at Hover Trim Conditions .................................... 74

Figure 6.6: Aircraft Euler Angles (Blade \#1 Failure Scenario at Hover) ................................... 74

Figure 6.7: Helicopter Flight Path Relative to the Earth (Blade \#1 Failure at Hover) ................ 75

Figure 6.8: Control Inputs at the Rotor Hub (Lateral Cyclic Failure at 80 Knots)..................... 76

Figure 6.9: Aircraft Euler Angles (Lateral Cyclic Failure at 80 Knots) ................................... 77

Figure 6.10: Helicopter Flight Path Relative to the Earth (Lateral Cyclic Failure at 80 Knots) .. 78

Figure 6.11: Blade Pitch Angles at the Rotor Hub (Blade \#4 Failure at 80 Knots).................... 79

Figure 6.12: Aircraft Euler Angles (Blade \#4 Failure at 80 Knots)....................................... 80

Figure 6.13: Lateral Cyclic Joystick Input (Blade \#4 Failure at 80 Knots).............................. 81

Figure 6.14: Helicopter Flight Path Relative to the Earth (Blade \#4 Failure at 80 Knots).......... 81

Figure A.1: UH-60 Horizontal Stabilator Control System ............................................. A-5

Figure C.1: WVU Helicopter Simulator - Folder Navigation ........................................... C-1

Figure C.2: WVU Helicopter Simulator - Main Menu ...................................................... C-2

Figure C.3: WVU Helicopter Simulator - Main Menu Drop-Down List................................ C-2

Figure C.4: WVU Helicopter Simulator - Main Menu Simulation Scenarios ......................... C-3

Figure C.5: WVU Helicopter Simulator - Pilot Input Menu.............................................. C-4

Figure C.6: WVU Helicopter Simulator - Examples of Pre-Recorded Input........................... C-5

Figure C.7: WVU Helicopter Simulator - Failure Conditions Menu (Current Deflection) ....... C-6

Figure C.8: WVU Helicopter Simulator - Failure Conditions Menu (Imposed Deflection)...... C-7

Figure C.9: WVU Helicopter Simulator - Command Window Data .................................... C-8

Figure C.10: WVU Helicopter Simulator - Simulation Features .......................................... C-9

Figure C.11: WVU Helicopter Simulator - VR Interface ............................................... C-10

Figure C.12: WVU Helicopter Simulator - Vizualization Menu ........................................ C-10

Figure C.13: WVU Helicopter Simulator - Play Button ................................................. C-11

Figure C.14: WVU Helicopter Simulator - Plots ......................................................... C-12

Figure C.15: WVU Helicopter Simulator - RTBlock ...................................................... C-12

Figure C.16: WVU Helicopter Simulator - RTBlock Parameters ........................................ C-13 


\section{Nomenclature}

Symbol

\section{English}

$a$

$a_{0}$

$a_{0}, a_{1}, b_{1}$

$a_{1_{S}}$

$b$

$b_{1 s}$

$c$

$c_{d}$

$c_{l}$

$e$

$e^{\prime}$

$f$

$g$

h

$i$

$l$

m

$n$

$p, q, r$

$q$

$r$

$t$

$\mathbf{u}, u(t)$

$u, v, w$

$v$

$\mathbf{x}, x(t)$

$x, y, z$

$y$

A, B

A

$A_{b}$

$A_{1}$

$B$

$B_{1}$

C

$C_{A_{1 S}}, C_{B_{1_{S}}}$

$C_{P}$

\section{Description}

Slope of lift curve

Coning angle

Fourier coefficients

First harmonic coefficient of longitudinal blade flapping w/ respect to shaft

Span of wing

First harmonic coefficient of lateral blade flapping w/ respect to shaft

Chord of blade

Coefficient of drag; two-dimensional

Coefficient of lift; two-dimensional

Hinge offset

Spare length exposed

Equivalent flat plate area

Gravity

Vertical center of gravity offset

Incidence

Longitudinal center of gravity offset

Mass of aircraft

Number of...

Angular velocity components of aircraft about the body-fixed axes

Dynamic pressure

Radius of blade element

Time

Control vector

Translational velocity components of aircraft about the body-fixed axes

Induced velocity

State vector

Cartesian coordinate system

Lateral center of gravity offset

System and control matrices

Area of rotor disk

Area of blades

Lateral cyclic

Tip loss factor

Longitudinal cyclic

Constant

Cyclic control rigging constants

Coefficient of power 


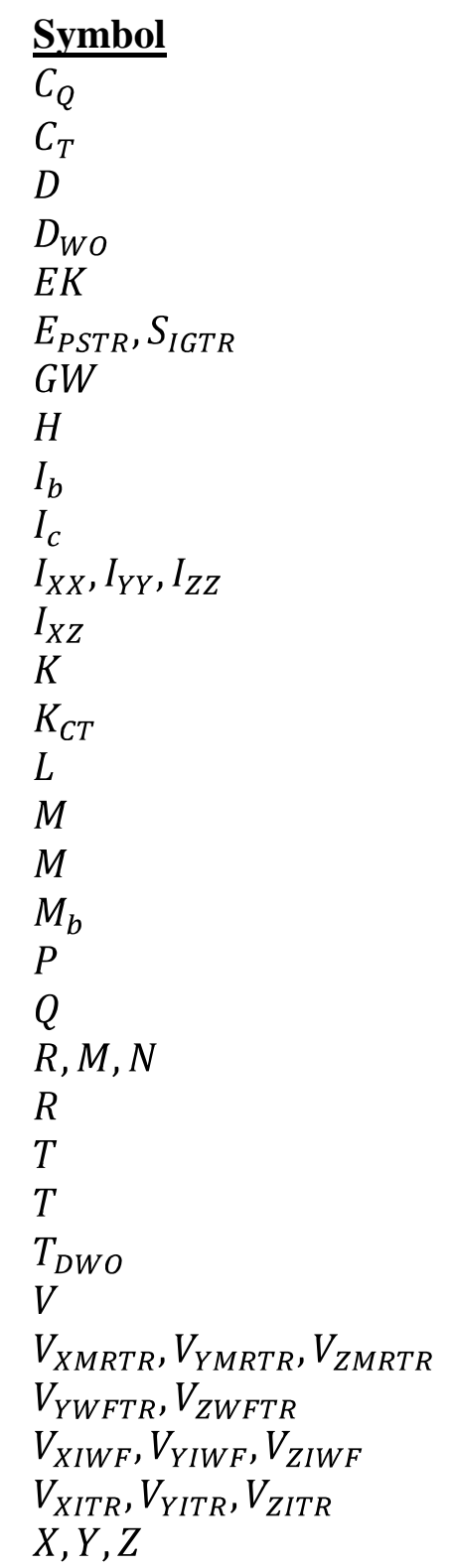

\section{$\underline{\text { Greek }}$}

$\alpha$

$\alpha_{L 0}$

$\beta$

$\beta$

$\gamma$

$\gamma_{C}$

$\delta_{3}$

$\delta_{a}, \delta_{e}, \delta_{c}, \delta_{p}$

$\delta_{a_{p}}, \delta_{e_{p}}, \delta_{c_{p}}, \delta_{p_{p}}$

$\mathcal{E}$

\section{Description}

Coefficient of torque

Coefficient of thrust

Drag

Uniform component of downwash at the rotor disk

Rotor wash interference factor

Fuselage downwash and sidewash at the tail rotor

Gross weight

Horizontal force on the rotor

Moment of inertia of blade about flapping hinge

Moment of inertia about the aircraft centroid

Moments of inertia of the aircraft about the body-fixed axes

Product of inertia of the aircraft about the $x$ - and $z$ - axes

Control system gains

Thrust gain for uniform downwash

Lift

Mach

Moment

Static moment of blade about flapping hinge

Power

Torque

External aerodynamic moments acting along the body-fixed axes

Rotor radius

Temperature

Thrust

Time constant for uniform downwash calculation

Forward velocity of aircraft

Main rotor wash velocities at the tail rotor

Fuselage wash velocities at the tail rotor

Main rotor wash interference velocities on the fuselage

Main rotor and fuselage interference velocities at the tail rotor

External aerodynamic forces acting along the body-fixed axes

Angle of attack

Angle of attack for zero lift

Blade flapping angle

Sideslip angle

Blade lock number

Climb angle

Pitch-flap coupling angle

Lateral, longitudinal, collective, and pedal control inputs (postmixing)

Lateral, longitudinal, collective, and pedal control inputs (pre-

mixing/pilot)

Downwash angle 


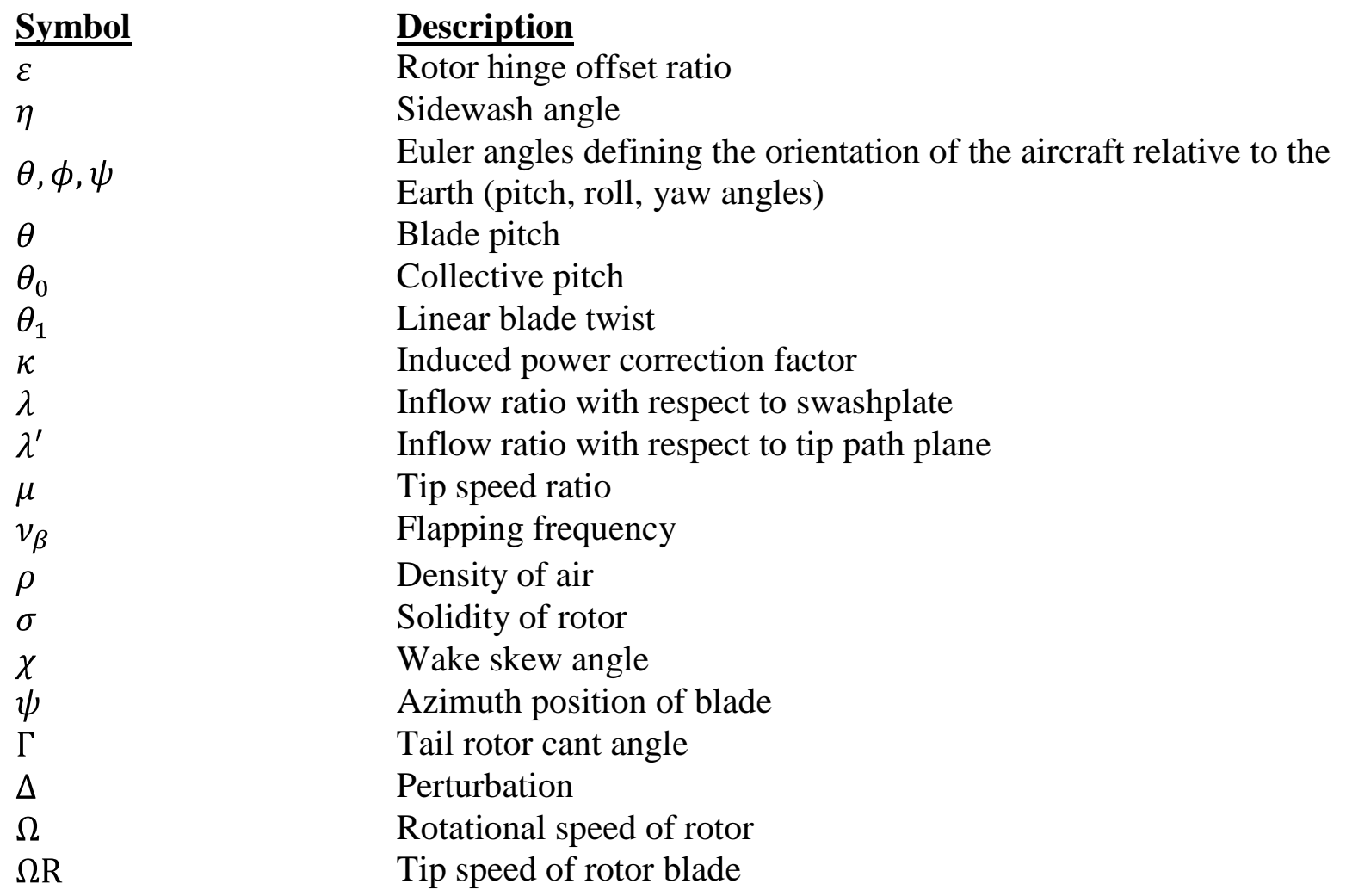

\section{Subscript}

c

$c$

$e$

hov

$p$

$t$

$B$

C

F

$H$

$M, M R$

$T, T R$

$T P P$

V

V

$X G W F, Y G W F, Y G W F$

$X T R, Y T R, Z T R$

$X W F, Y W F, Z W F$

\section{Centroid}

Climb

Equilibrium or trim condition

Hover

Pilot input

Tip

Body axes system

Cant axis system

Fuselage

Horizontal stabilizer

Main rotor

Tail rotor

Tip path plane

Vertical

Vertical stabilizer

Fuselage gust components

Tail rotor components in the body-fixed axis sys.

Fuselage components in the body-fixed axis sys.

\section{Acronym}

AKA

BEMT

BET
Also known as

Blade element momentum theory

Blade element theory 


Symbol
CFD
DOF
GUI
IBC
NASA
PBA
RPM
SAS
USAAEFA, AEFA
VR
VTOL
WVU

\section{Description}

Computational fluid dynamics

Degrees of freedom

Graphical user interface

Individual blade control

National Aeronautics and Space Administration

Pitch bias actuator

Revolutions per minute

Stability augmentation system

United States Army Aviation Engineering Flight Activity

Virtual reality

Vertical takeoff and landing

West Virginia University 


\section{Chapter 1: Introduction}

\subsection{Problem Statement}

Nearly all modern helicopters are designed with a swashplate-based system for control of the main rotor blades. This has been an industry standard for nearly a hundred years. However, the swashplate-based approach does not provide the level of redundancy necessary to cope with abnormal actuator conditions. For example, control of a helicopter becomes very difficult, and sometimes impossible, under certain system failures. If an actuator fails (becomes locked) on the main rotor, the cyclic inputs are consequently fixed and the helicopter may become stuck in a flight maneuver. This can obviously be seen as a catastrophic failure, and would likely lead to a crash.

Helicopter actuator failures can be overcome with individual blade control (IBC). Unlike the swashplate-based control system, individual blade control allows complete authority of the aerodynamic characteristics of each rotor blade at any given time. In other words, IBC can provide the additional redundancy for fault-tolerant control purposes that swashplate systems lack. An extensive amount of research has been performed in the field of individual blade control over the past 20 years. Specifically, in the areas of gust alleviation, stall flutter suppression, lag damping augmentation, vertical vibration alleviation, in-plane vibration alleviation, flapping stabilization, stall alleviation, flying qualities enhancement, performance enhancement, and automatic blade tracking [1]. However, very little research has been performed in the area of fault-tolerant controls for IBC helicopters.

The first step in examining the effects of IBC on fault-tolerant controls is to create a conventional, swashplate-based, mathematical model of a helicopter for simulation. A UH-60 Black Hawk helicopter was selected for this purpose because an extensive amount of data for this helicopter is available for public use. Additionally, IBC research is currently being performed on the UH-60 at the NASA Ames Research Center in Moffett Field, California. The linear modeling technique was chosen for this aircraft because it can be conveniently used for control law design and it provides accurate data for the purposes of simulation. The linear approach is based mainly on the modeling process for swashplate-based helicopters outlined in the textbook Helicopter Performance, Stability, and Control by Raymond W. Prouty [2]. The linear modeling techniques for the swashplate-based helicopter are then adapted and expanded to 
include individual blade control. Using these modified techniques, an IBC based mathematical model of the UH-60 Black Hawk helicopter is developed for the purposes of simulation and future control law development.

\subsection{Research Objectives}

The research effort presented in this thesis was designed to achieve to following objectives:

- In the Matlab/Simulink ${ }^{\circledR}$ programming environment, design and implement an algorithm for the computation of state space linear models for single rotor helicopters at hover and forward flight scenarios based on the classic swashplate control system. Integrate aircraft parameters for the UH-60 Black Hawk into the swashplate-based state space linear model algorithm.

- In the Matlab/Simulink ${ }^{\circledR}$ programming environment, design and implement an algorithm for the computation of state space linear models for single rotor helicopters at hover and forward flight scenarios based on individual blade control. Integrate aircraft parameters for the UH-60 Black Hawk into the IBC-based state space linear model algorithm.

- Incorporate both sets of linear models into the Matlab/Simulink ${ }^{\circledR}$ based WVU Helicopter Flight Simulator.

- Incorporate subsystem failures within each model for the purposes of examining the effects of IBC on fault-tolerant controls.

\subsection{Thesis Overview}

The chapter structure throughout this thesis is organized in the following manner:

- Chapter 2 consists of the literature review, which presents background information on swashplate control systems and individual blade control. Additionally, this chapter outlines helicopter mathematical modeling techniques based on Momentum Theory, Blade Element Theory, and Vortex Theory.

- Chapter 3 describes the linear model approach for the swashplate-based UH-60 Black Hawk helicopter. Both hover and forward flight models are outlined in this section. Additionally, multiple validations are presented in this chapter to confirm the accuracy of the models. 
- Chapter 4 describes the linear model approach for the UH-60 Black Hawk helicopter based on individual blade control. Both hover and forward flight models are outlined in this section.

- Chapter 5 introduces/discusses the WVU Helicopter Flight Simulation Environment which includes the Graphical User Interface, Simulink® model, and the WVU 6-DOF Flight Simulator.

- Chapter 6 presents and compares the simulation results for swashplate control system and the IBC system. Data for both hover and forward flight models is presented at normal conditions and in the presence of actuator failures.

- Chapter 7 concludes the thesis. Closing remarks are made about what can be drawn from this research effort. Recommendations are made with regards to future aspects that need to be investigated in the field of individual blade control. 


\section{Chapter 2: Literature Review}

\subsection{Review of Helicopter Flight Controls}

A typical rotary wing aircraft (helicopter) has five separate control inputs: the longitudinal and lateral cyclic, the main rotor collective, the tail rotor collective (anti-torque pedals), and the throttle.

The longitudinal and lateral cyclic input, or cyclic joystick, controls the pitch of the main rotor blades cyclically. In other words, the pitch, or feathering angle, of each rotor blade changes depending upon their position as they rotate around the hub of the main rotor. Each of the blades will change their angle the same amount at the same point in the cycle. The change in cyclic pitch is controlled by means of a mechanical swashplate. The change in cyclic pitch causes the rotor disk to slant, effectively tilting the helicopter in the desired direction. The end result is that roll or pitch can be produced for the helicopter. For example, if the pilot pushes the cyclic joystick forward, the rotor disk tilts forward, and the rotor produces a thrust vector in the forward direction.

The collective pitch control, or collective lever, changes the pitch angle of all the main rotor blades collectively (i.e., all at the same time) and independent of their position. Therefore, if a collective input is made, all the blades change their angle of attack equally, and the result is the helicopter increases or decreases its total lift derived from the rotor. In level flight this would cause a climb or descent, while with the helicopter pitched forward an increase in total lift would produce acceleration together with a given amount of ascent. Similar to the cyclic pitch, the collective pitch is controlled by means of a mechanical swashplate.

The anti-torque pedals, which are similar to the rudder pedals in an airplane, control the direction that the nose of the aircraft is pointed. In other words, they control the yaw or heading angle of the aircraft. In a typical helicopter design, the torque of the main rotor needs to be offset by the force produced by a tail rotor. A helicopter creates lift by spinning its main rotor blades in one direction. Based on Newton's third law, for every action there is an equal and opposite reaction, it can be seen that this spinning action has an equal and opposite effect on the helicopter fuselage, making it "want" to spin in the opposite direction. Obviously, this isn't a problem when the helicopter is on the ground. When the helicopter lifts off, however, tail rotor thrust is necessary to counteract the force produced by the main rotor. 


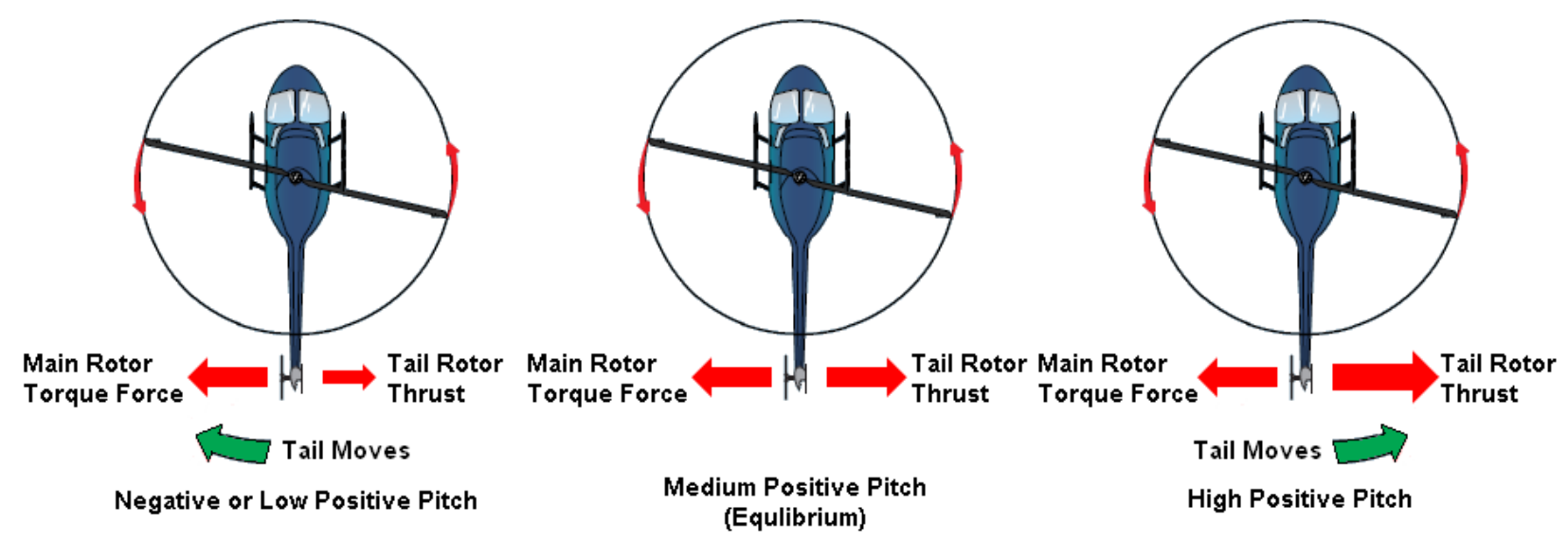

Figure 2.1: Example of Yaw Control Using Tail Rotor [3]

By increasing or decreasing the pitch of the tail rotor blades (by means of the anti-torque pedals) the tail rotor thrust can be altered. In effect, the heading angle of the helicopter can be adjusted.

Lastly, the throttle controls the power produced by the engine. Helicopter rotors are designed to operate within a very specific RPM range. Typically, the RPM's are kept relatively constant after liftoff and changes in altitude are managed through collective pitch control. So, the purpose of the throttle is to maintain enough engine power (RPM's) to keep the rotor producing enough lift for flight. Governors, or other electro-mechanical control systems, are often used in today's modern helicopters to maintain rotor RPM and relieve the pilot of routine responsibility for that task.

\subsection{Swashplate Control System}

The main rotor of a typical helicopter is controlled by a mechanical swashplate. The main purpose of the swashplate is to transmit inputs from the collective and cyclic controls to the main rotor blades. A swashplate consists of two main parts: the stationary swashplate and the rotating swashplate (see Figure 2.2 and Figure 2.3). 


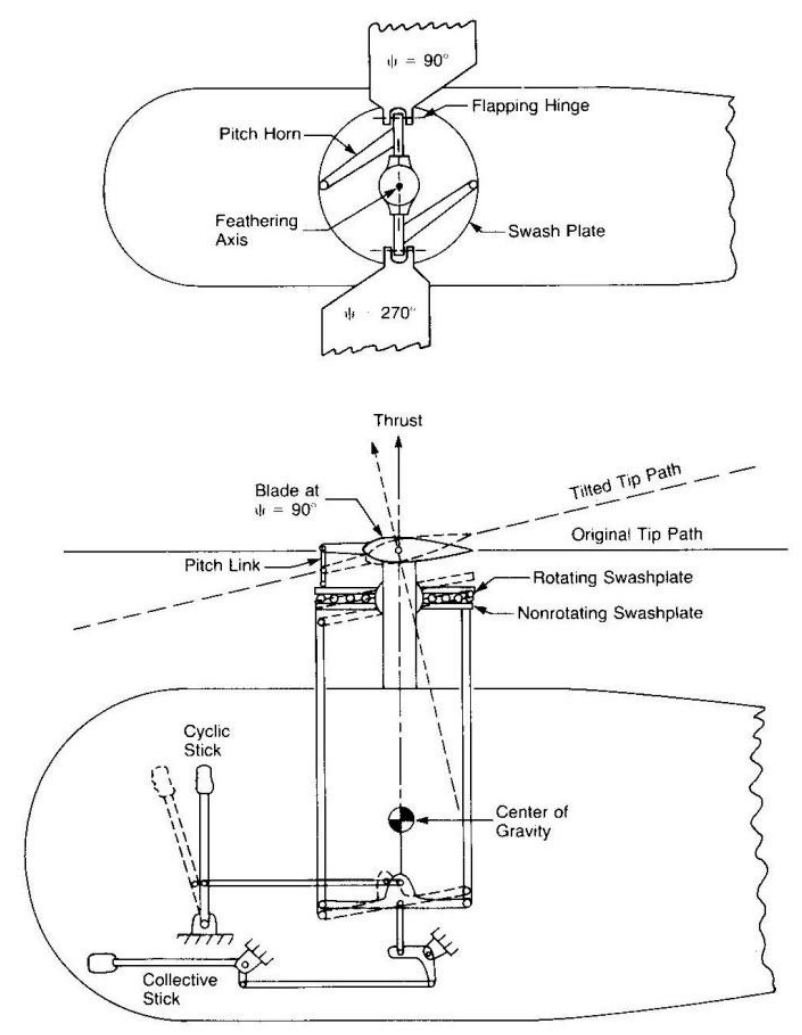

Figure 2.2: Schematic of Swashplate Control System [2]

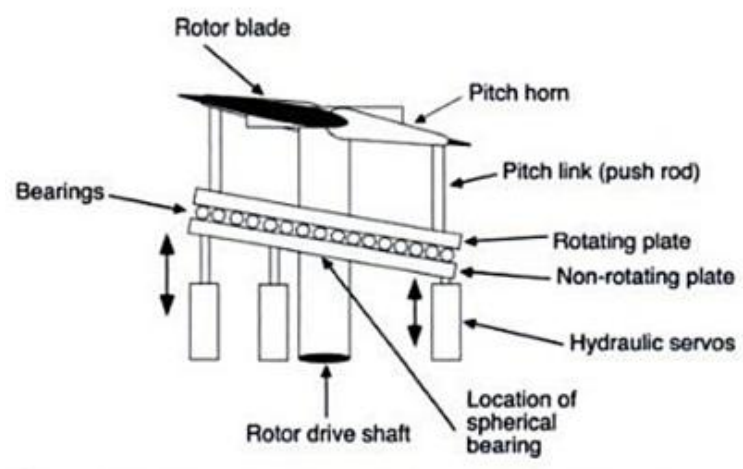

Figure 2.3: Detailed Schematic of Swashplate Control System [4]

The stationary swashplate is mounted around the main rotor drive shaft and connected to the cyclic and collective controls by a series of rods, linkages, and actuators (hydraulic servos). It is restrained from rotating but is able to tilt in all directions and move vertically. The rotating swashplate is mounted to the stationary swashplate using a set of bearings and is permitted to rotate with the main rotor drive shaft. Both swashplates move as one unit with the ability to uniformly slide up and down, or tilt in any direction. The rotating swash plate is connected to the pitch horns by the pitch links. The pitch horns then alter the angle of attack of the main rotor blades. In order to control the collective pitch of the main rotor blades, the entire swashplate must be moved up or down along its axis without changing the orientation of the cyclic controls. Moving the entire swashplate causes all of the pitch linkages to move simultaneously. As a result, the rotor blades all adjust their pitch at the same time, as shown in Figure 2.4. 


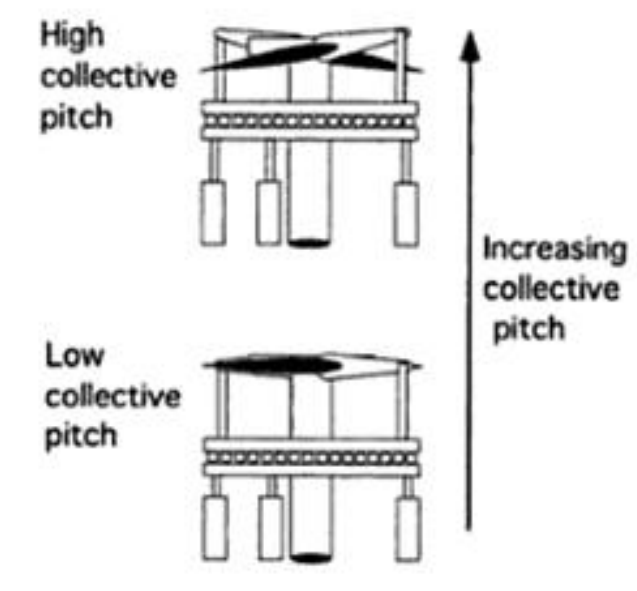

Figure 2.4: Collective Pitch of M.R. Blades by Means of Swashplate Vertical Movement [4]

Cyclic pitch is controlled through a similar process. Essentially, when the stationary swashplate is tilted, the rotor blades will go through a pitch cycle (increasing and decreasing pitch throughout a single revolution). In other words, if the pilot pushes the stick forward, the swashplate is tilted forward (as shown in Figure 2.5). Since the pitch horn is attached to the swashplate $90^{\circ}$ ahead of the rotor blade, the blade pitch is reduced when it is on the right side and increased when it is on the left side. This will produce a tilt of the rotor disk forward due to the phase lag of the flapping. When the blade is over the nose or the tail, the forward tilt of the swashplate has no effect on the blade pitch.

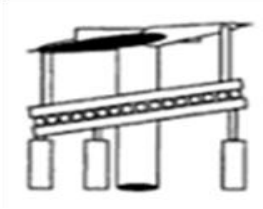

Swashplate tilted forward

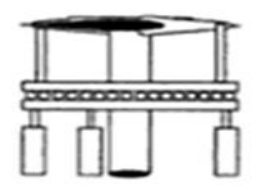

Stationary swashplate

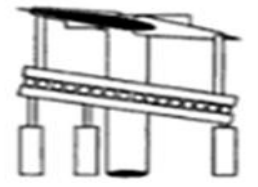

Swashplate tilted rearward

Figure 2.5: Cyclic Pitch of M.R. Blades by Means of Swashplate Tilt [4] 


\subsection{Individual Blade Control System}

Unlike the swashplate-based control system, individual blade control allows complete authority of the aerodynamic characteristics of each rotor blade at any given time. IBC can be achieved through a variety of mechanical systems, such as active plain trailing-edge flaps [5,6,7], active servo flaps [8], blade camber control [9,10], blade twist control [10,11] circulation control $[12,13,14]$, and blade pitch control $[1,15,16]$.

Active plain trailing edge flaps are flaps integrated within the main lifting section of the blade (as shown in Figure 2.6 and Figure 2.7). The flaps are deflected cyclically in order to change the lift and/or moment characteristics of the blade section [7].

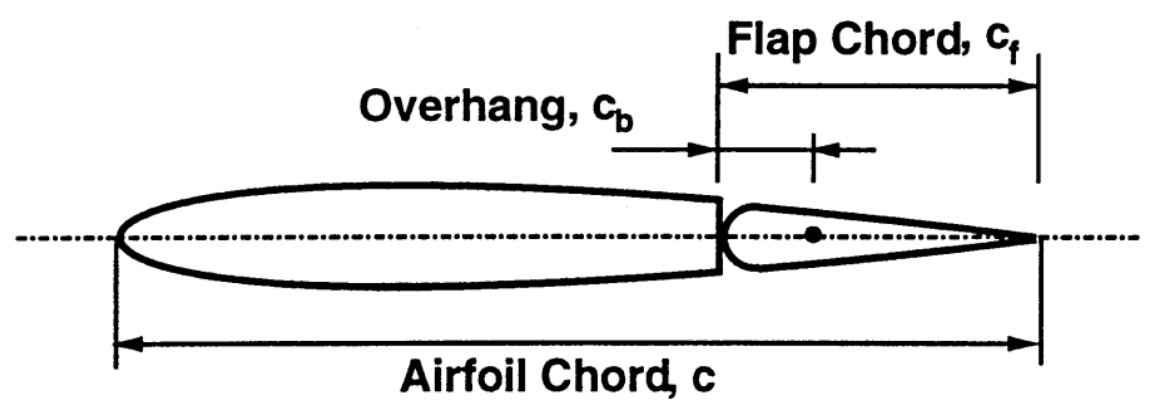

Figure 2.6: Trailing-Edge Flap with Aerodynamic Balance [7]

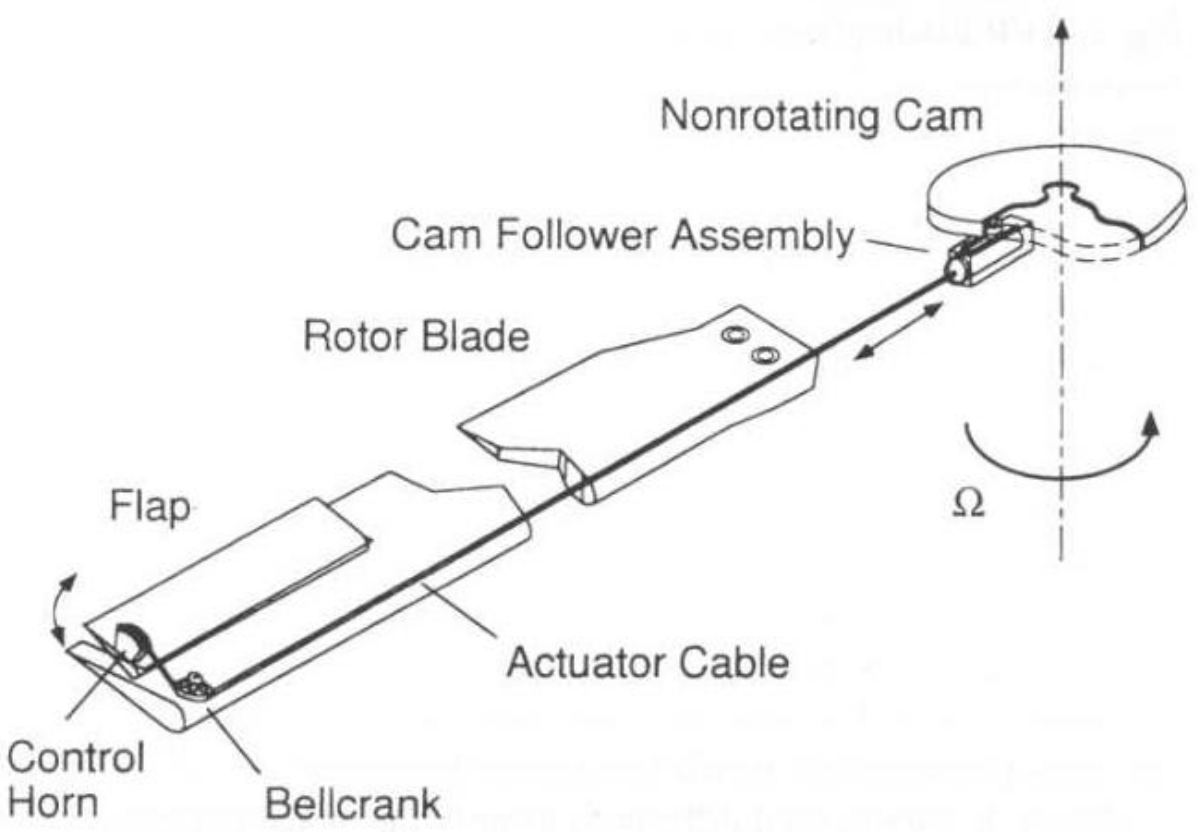

Figure 2.7: Schematic of Flap Actuation Mechanism [5]

The concept of using trailing edge flaps on rotorcraft is not entirely new. This system was first explored in the early 1920's by Pescara and has been a feature of Kaman aircraft since the 
1940's [5]. However, due to the inherent mechanical complexity, the trailing-edge flap was used scarcely by the rotorcraft industry. With the emergence of lightweight, smart material actuators in the late 1980's, trailing edge flaps began being explored for their applications to IBC. Currently, most of the IBC research performed with trailing-edge flaps focuses on the reduction of helicopter vibration and noise $[5,6,7]$. These research projects typically use trailing-edge flaps in coordination with a conventional swashplate control system. In other words, the swashplate control system is still used for primary control of the aircraft, while trailing-edge flaps are implemented to reduce noise and vibration of the overall system.

Active servo flaps are supplementary airfoil sections that are fitted to the trailing edge of the main rotor blades. Invented by Kaman in 1946, these secondary airfoils (shown in Figure 2.8) are operated by a servo embedded in the main rotor blade.

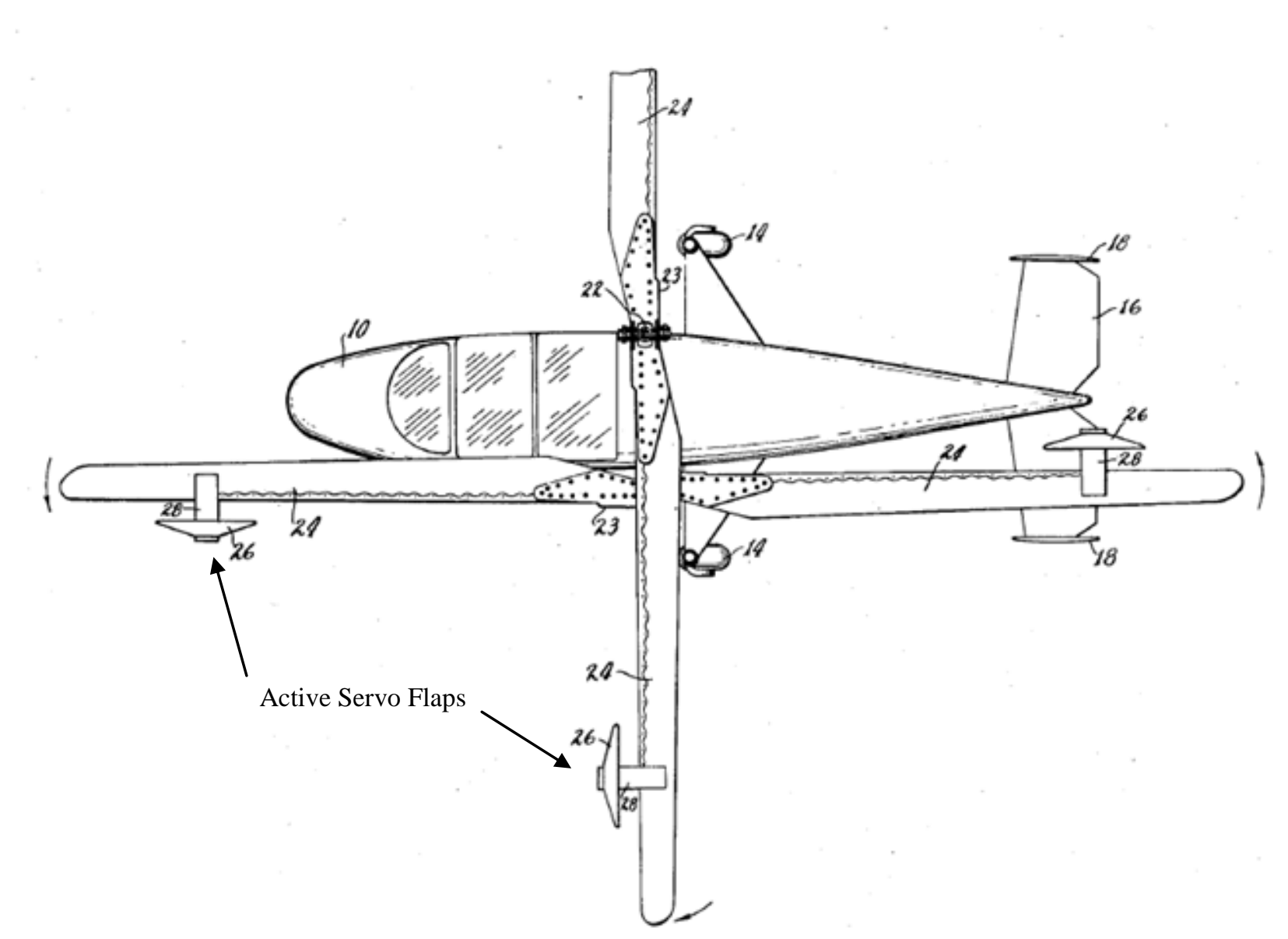

Figure 2.8: Kaman Aircraft Featuring Active Servo Flaps [8] 
Similar to trailing-edge flaps, the primary benefit of active servo flaps in rotorcraft is vibration and noise reduction. However, the exposed flaps produce the undesirable disadvantage of increased drag [6].

Blade camber control is a system that alters the camber, or shape of the cross-section, of the rotor blade, a shown in Figure 2.9. The adjustment in blade camber can be achieved mechanically or through the use of piezoelectric "smart" materials. Piezoelectric materials are attached to the skin on each side of the blade, which are then stretched or stiffened by applying a voltage to the material. The end result is that the overall shape of the blade can be altered.

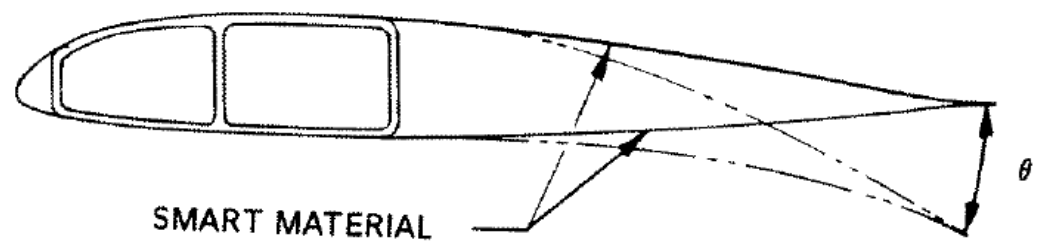

Figure 2.9: Blade Camber Control Using Smart Materials [9]

A similar approach developed by Büter, achieves the desired change of camber using tension-torsion-coupling in the outer cells (of a rotor blade separated into three cells) that are activated by piezoelectric stack-actuators integrated into the blade tip [10] :

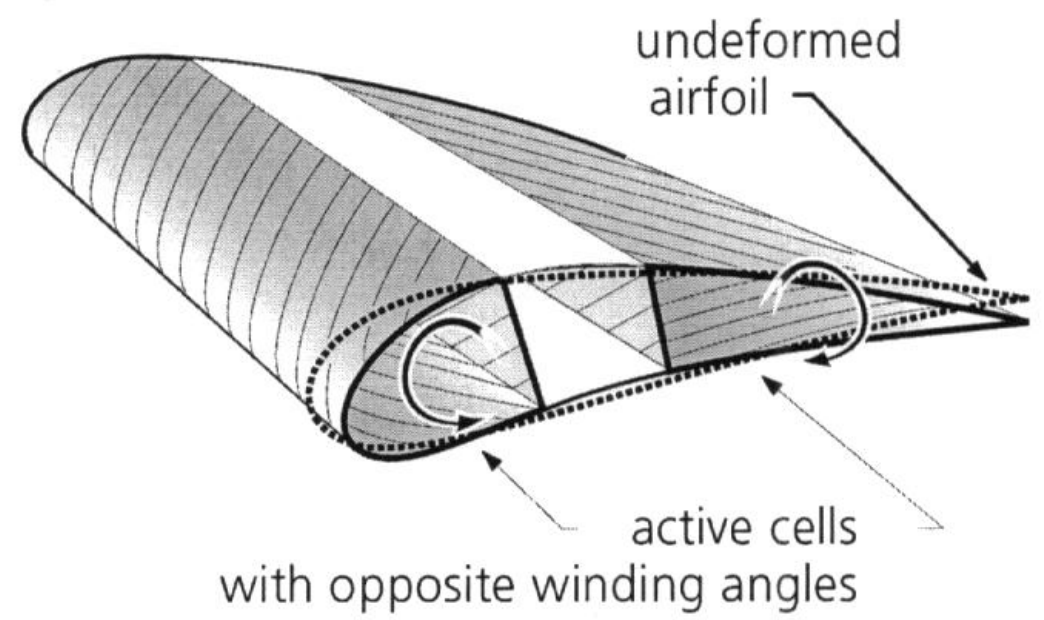

Figure 2.10: Principle of the Adaptive Blade Camber Variation [10]

One of the advantages of the blade camber control system is that no flaps or other moving parts are used so that the aerodynamic surface in the deformed state remains smooth without any gaps, edges, or dents [10]. Once again, the primary benefit of blade camber control as it applies to rotorcraft is vibration reduction, noise suppression, and an increase in the aerodynamic efficiency 
of the blade. Currently, much of the research in this field has only been performed on scaled rotor models. The actuation concepts are presently difficult to build at full-scale without excessive weight and power penalties, but this will change as further research is conducted [4].

Blade twist control is achieved in a similar manner to that of blade camber control. Piezoelectric materials are attached to the skin on each side of the blade, which are then operated by applying a differential voltage to the material.

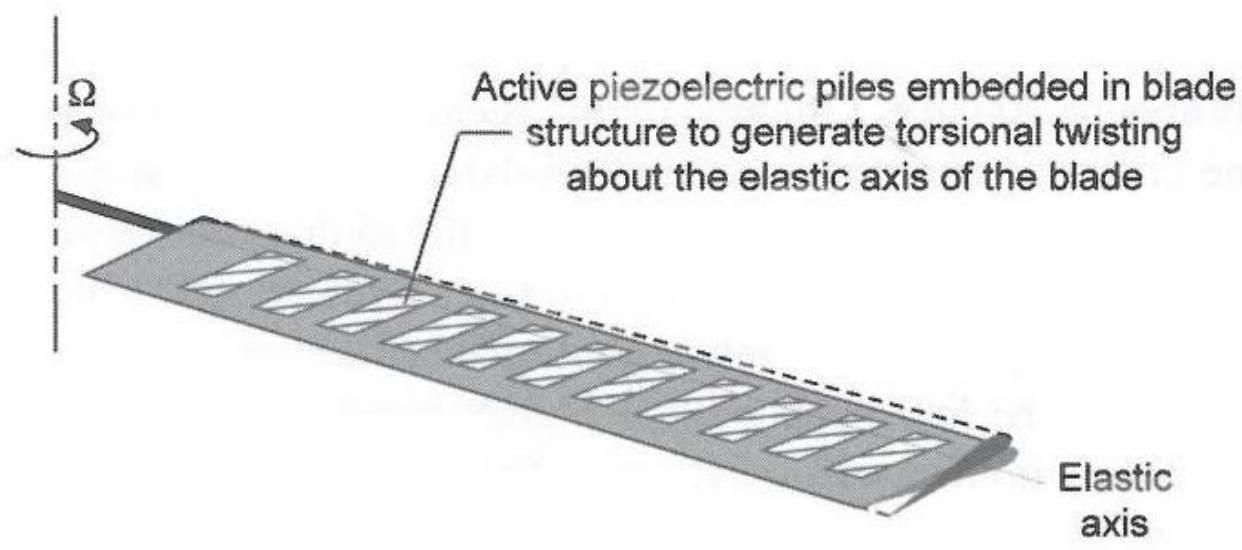

Figure 2.11: Active Blade Twist Rotor Concept [4]

As with the previous design approaches, the primary benefits of blade twist control are vibration reduction and noise suppression. Although this system involves no moving parts, it incurs a significant weight penalty and gives an undesirable increase to blade stiffness [4]. Structural integrity is also an issue with this design.

Circulation control, or boundary layer control, is an aerodynamic method of altering rotor blade characteristics by blowing air out of strategically placed jets along the surface of the airfoil, as shown in Figure 2.12. As a result, pressure around the airfoil changes generating an increase or decrease in lift (depending upon the application of the jets). 


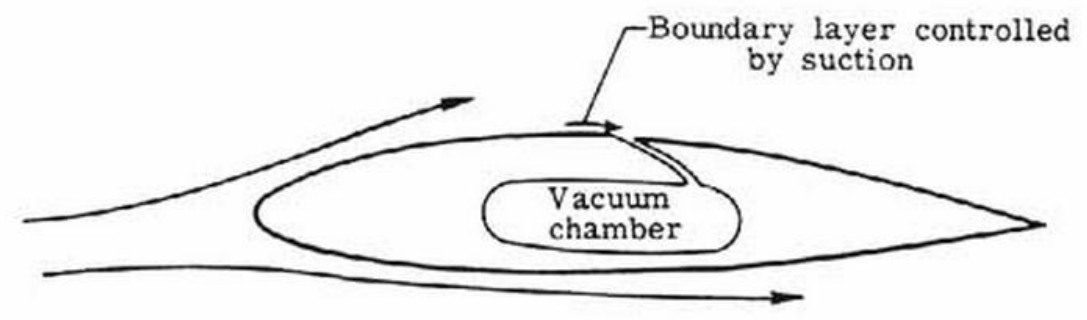

(a) Suction of boundary layer.

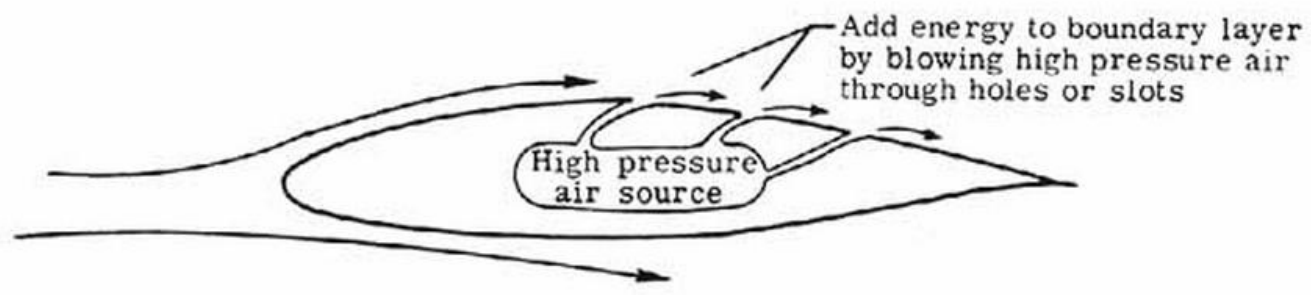

(b) Reenergizing the boundary layer.

Figure 2.12: Examples of Circulation Control (Boundary Layer Control) [17]

Circulation controlled airfoils rely upon the Coanda effect to generate the changes in the aerodynamic characteristics. The Coanda effect is the tendency of a fluid to travel close to a surface contour, even if the surface curvature diverges from the jet axis [4]. This effect can be of significant importance when applied to the blades of a rotorcraft. During forward flight, a large area of flow separation is produced on the retreating side of the rotor disk, which greatly reduces the efficiency of the blade. Circulation control can help reduce this flow separation and improve the efficiency of rotor blades in forward flight [14]. However, this creates a highly unsteady aerodynamics problem where jet blowing would need to be applied based on azimuth position so that the flow around the rotor is only being altered on the retreating side of the rotor disk. While circulation control is clearly attractive because of the potentially high lift capability, the behavior of circulation controlled airfoils in an unsteady rotor environment is still being explored at this time [4].

Blade pitch control is an approach that adjusts the pitch of individual blades at the hub by replacing the normally rigid pitch links between the swashplate and the pitch horn of the blade with hydraulic or electronic actuators [15]. These actuators allow the pitch of each blade to be changed independently of each other. Due to this fact, a rotating swashplate with actuators below it is no longer necessary. 


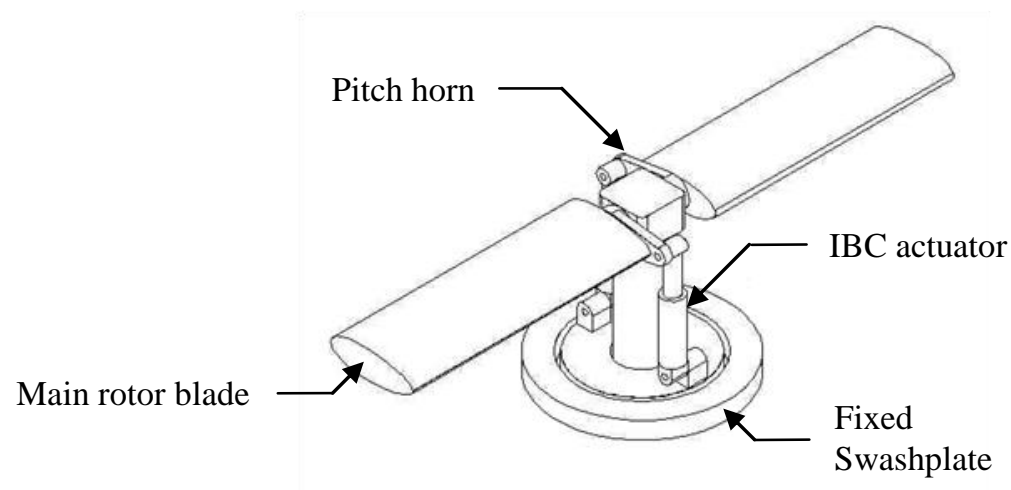

Figure 2.13: Schematic IBC Architecture Using Blade Pitch Control [18]

Since very few additional parts are required for this method, it has been deemed a very cost and weight effective solution for individual blade control [16]. Furthermore, this approach can be used as the primary control system for the main rotor to produce both collective and cyclic control. Once again, the majority of research for this method has focused primarily on noise suppression and vibration reduction, as well as improving overall rotor performance [15]. However, it has also been shown that the blade pitch control method can be applied to faulttolerant controls. Without the kinetic restrictions of the swashplate it is possible to decouple the cyclic control inputs between different blades. Thus, the primary control functions can be reconfigured after local failures (partial blade damage or single blade actuator degradation) $[16,19]$. For this reason, the blade pitch control method is used in the current study with the hopes of examining the effects of IBC on fault-tolerant controls.

\subsection{Helicopter Mathematical Model}

\subsubsection{Momentum Theory}

Momentum Theory, also known as actuator disk theory, is based on the application of the three basic laws of conservation (conservation of mass, momentum, and energy). The conservation laws are applied to a quasi-one-dimensional flow field of air surrounding the rotor and its wake. This approach permits a first level analysis of the rotor performance (e.g., its thrust and power), but without actually having to consider the details of the flow environment [4].

In the general form of this theory, the main rotor is assumed to be an infinitely thin actuator disk. The rotor-disk plane can be considered to be a simple input/output system that adds momentum and energy to the flow of air that passes through it. Using Newton's $3^{\text {rd }}$ law of motion, which states "for every action, there is an equal and opposite reaction," the system is 
modeled using the action of the thrust force of the air on the blades and the reaction of the wake of air that is accelerated downwards, as seen in Figure 2.14:

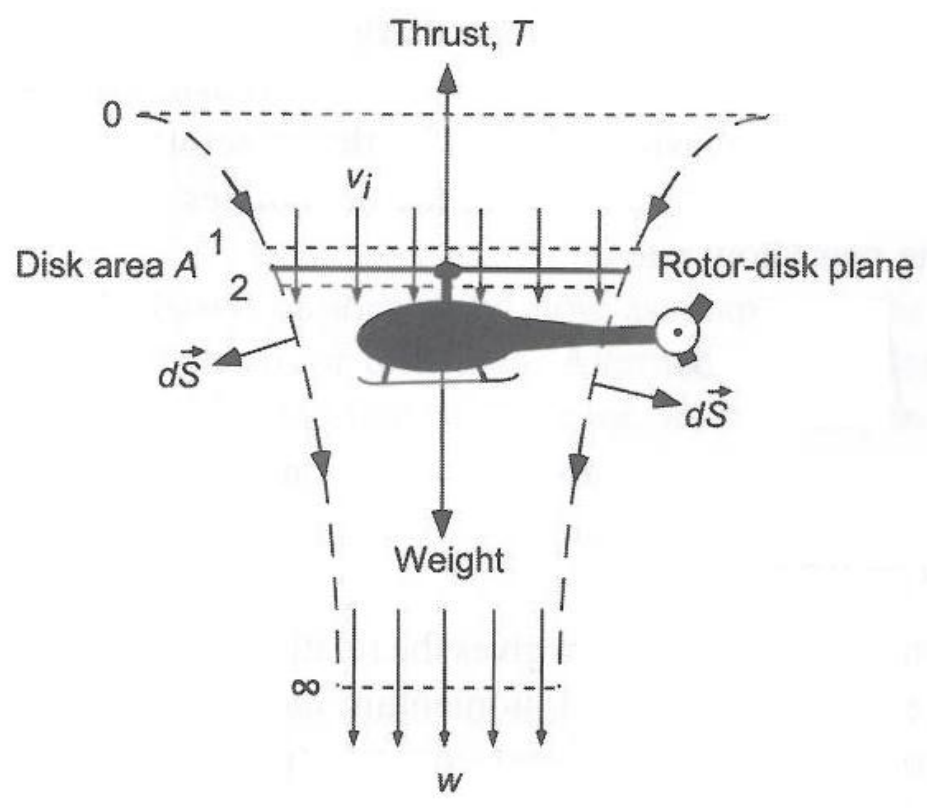

Figure 2.14: Hovering Flight Flow Model for Momentum Theory Analysis

By applying the basic laws of conservation to the flow model for the hovering rotor described in Figure 2.14, expressions can be derived for the induced velocity $\left(v_{1}\right)$ at the rotor disk, thrust $(T)$, and power $(P)$. Furthermore, momentum theory can be used to provide similar expressions for the helicopter in axial climb, axial descent, and forward flight by examining the corresponding flow fields.

\subsubsection{Blade Element Theory}

In contrast to the generalized approach provided by momentum theory, blade element theory (BET) relies on a detailed examination of the lift and drag forces produced by the rotor blades. This approach separates the rotor blade into individual blade elements, as seen in Figure 2.15 (denoted by $\Delta r$ ): 


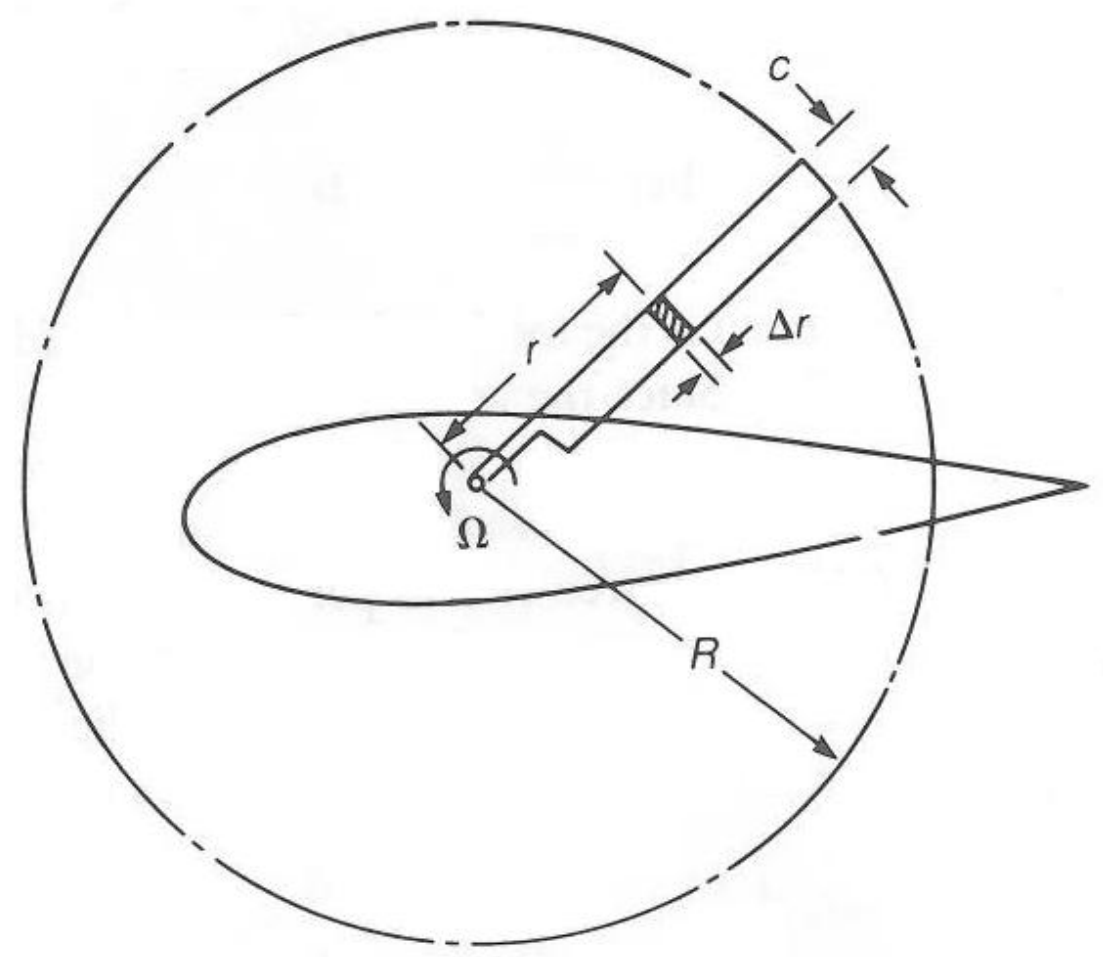

Figure 2.15: Geometry of Blade Element

The forces acting on each individual element are calculated using two-dimensional lift and drag data as a function of angle of attack and rotor wake. These forces are then integrated along the entire blade span and averaged over the course of one rotor revolution to obtain the forces and moments produced by the entire rotor. Unlike momentum theory, blade element theory can be used as a basis to help design the rotor blade in terms of blade twist, the planform distribution and perhaps also the airfoil shape to provide a specified overall rotor performance [4].

Since it is somewhat difficult to accurately model the nonuniform induced velocities for each blade element along the span of the main rotor, momentum theory is often combined with BET to estimate the induced velocities along each blade. This hybrid concept is known as blade element momentum theory (BEMT). The combined BEMT approach is flexible for a variety of airfoil types and rotor configurations. While very flexible, the BEMT approach can also be very tedious. Fortunately, modern computers make this normally tedious approach much more manageable.

Guidelines for setting up a BEMT computer program often vary from textbook to textbook. Prouty recommends separating each rotor blade into at least five elements, but no more than fifteen [2]. Leishman states that a minimum of 20 elements must be used to ensure an 
adequate numerical resolution of the inflow and spanwise loading, but 40 elements or more is desirable [4]. With a basic understanding of integrals, one can assume that more accurate results are produced with a greater number of elements.

\subsubsection{Vortex Theory}

In order to understand vortex theory for a helicopter, one must first examine vorticity as it applies to a typical fixed wing aircraft. For a two-dimensional airfoil, lift is created through a difference in air pressure created by the airfoil's shape. Air must move faster over the top of an airfoil when compared to air passing below an airfoil, which creates a difference in pressure. If this theory is expanded to a three-dimensional airfoil, it can be seen that these effects also occur at an airfoils wingtip. Due to the differences in air pressure, air flows from below the wing and out around the tip to the top of the wing in a circular fashion. This circular flow is known as vorticity. As seen in Figure 2.16, vortices extend laterally from the rear of the aircraft, and can descend up to 900 feet at distances of 5 miles behind it [20]. Vorticity may reduce airfoil efficiency, particularly in shorter wings, and produces a wake that can affect control surfaces behind the wings.

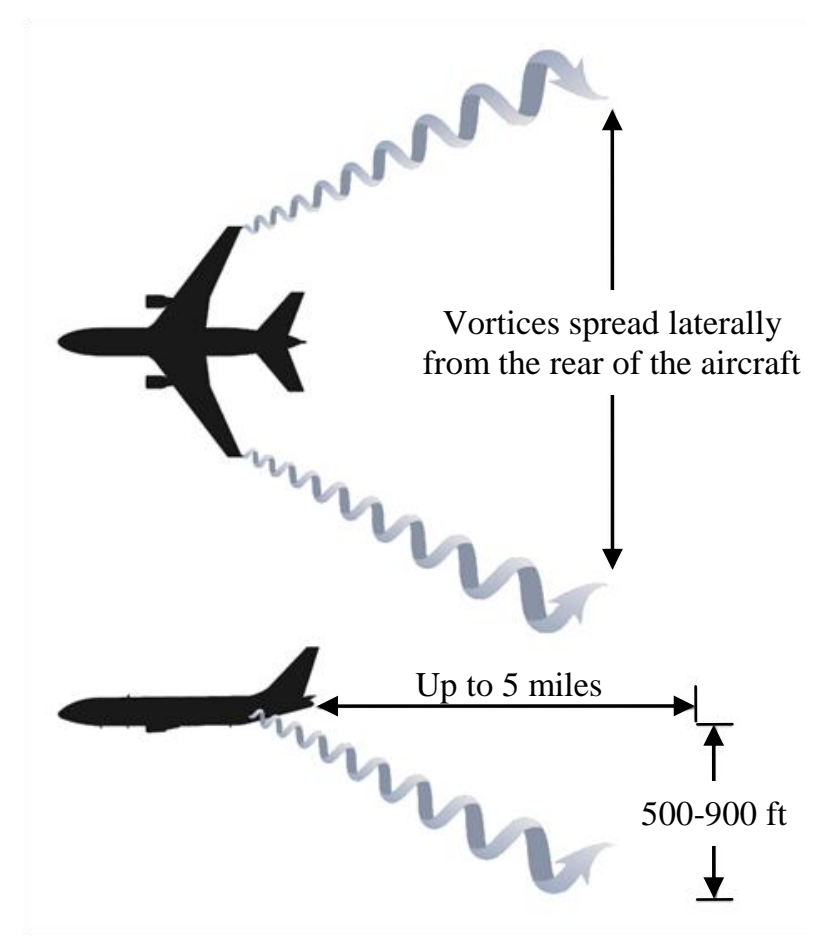

Figure 2.16: Example of Fixed Wing Aircraft Vortices [20] 
Similar vortex flows are found in helicopter rotors. Rotor wake vorticity is concentrated in tip vortices that lie in helices below the rotor disk (Figure 2.17).

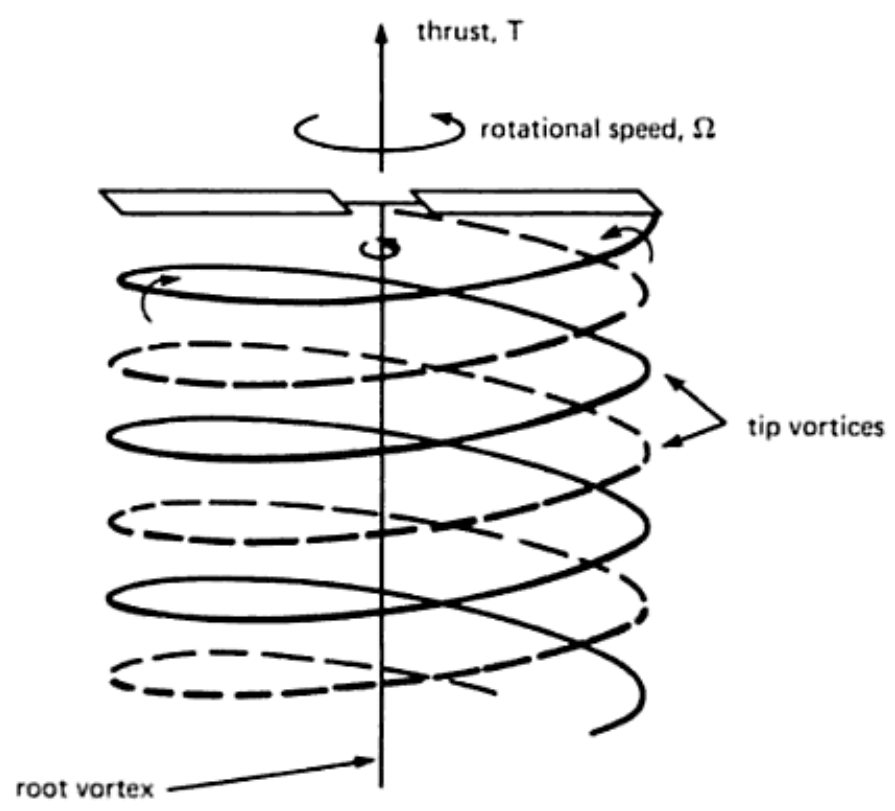

Figure 2.17: Rotor Vortex Wake in Vertical Flight [21]

In contrast to the fixed wing aircraft, the rotary wing has close interactions with its own wake and the wake from preceding blades. These interactions have a significant effect on the induced velocity and blade loads. Vortex theory is a rotor analysis that calculates the flow field of the rotor wake. More specifically, it calculates the induced velocity at the rotor disk using fluid dynamics laws for vorticity.

The simplest form of vortex theory uses an actuator disk model and assumes an infinite number of blades for hover conditions. The bound vorticity of the blades is distributed in a sheet over the rotor disk. Instead of being concentrated in helical sheets or lines, as in Figure 2.17, the wake vorticity is distributed throughout the volume of the wake (refer to Figure 2.18). This simplified form of vortex theory generally assumes no wake contraction for vortex sheets. In practice, the wake does contract producing a local distortion of the induced velocity near the blade tips [2], as shown in Figure 2.18: 


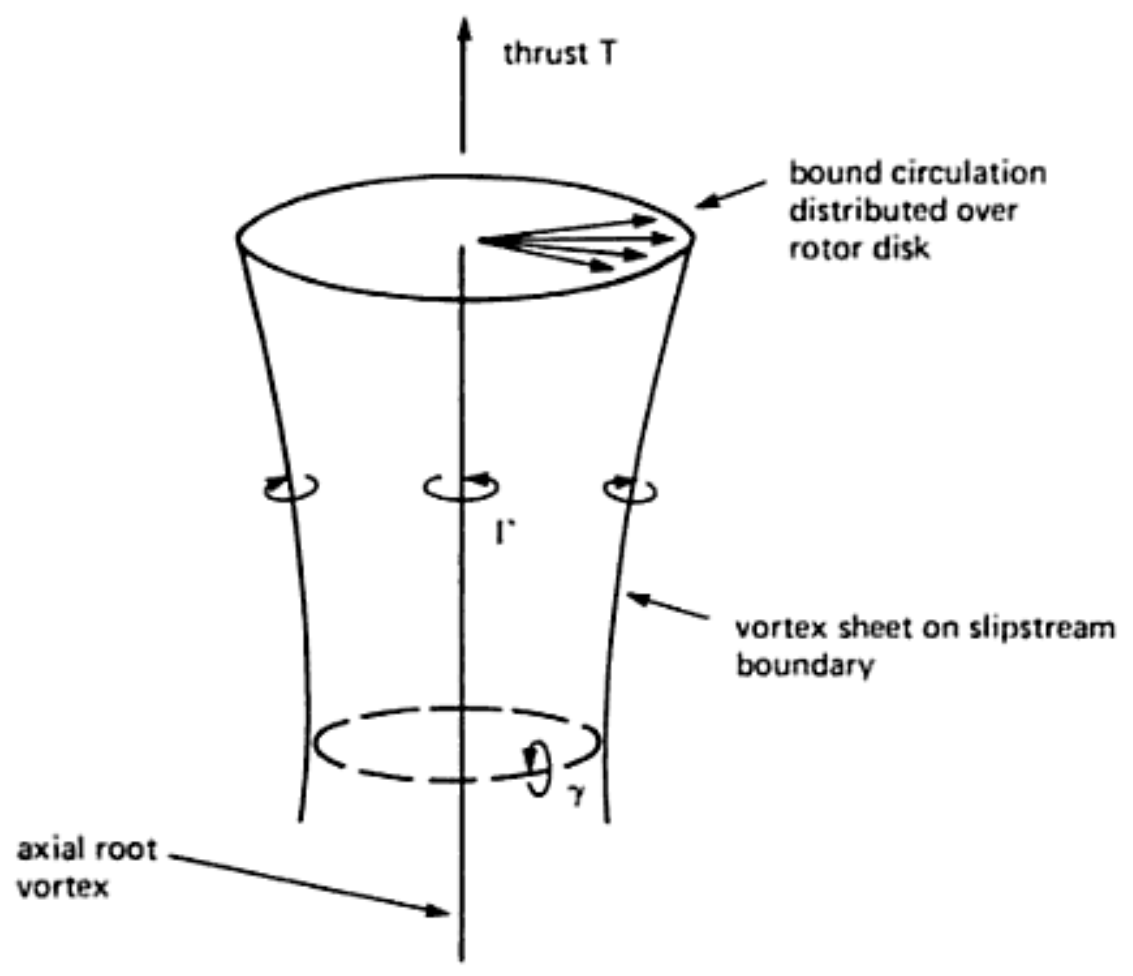

Figure 2.18: Vortex Theory - Actuator Disk Model [21]

This model allows for relatively simple calculations of the induced velocities created by the wake. These calculations are covered by momentum theory analysis, as previously described.

Vortex theory can also be applied to a finite number of blades. In this scenario, the wake can be modeled by vortex lines and sheets trailed in helices behind each blade, as shown in Figure 2.17. This scenario is much more difficult from a mathematical perspective, but some analytical solutions are still possible. The primary application of this model is calculating the loading near the blade tip. These calculations are covered in Prandtl's Tip Loading Solution and Goldstein's Propeller Analysis [21]. It is important to note that neither of the analyses applies to low inflow rotors (both neglect the blade-wake interactions).

The most modern form of vortex theory is a numerical solution for the rotor induced velocity, loads, and performance that uses a detailed model of the vortex wake. This analysis is so complex that it can only be performed using a combination of computational fluid dynamics and high-speed computers. Obviously, a more detailed, complex model can produce much more accurate results. Sometimes the improvements to accuracy are minimal when compared to the results produced by the previous vortex theory models. However, these minimal gains are often of critical importance for aerodynamic analyses. 


\section{Chapter 3: Modeling a Swashplate-Based Helicopter}

\subsection{The Linear Model Approach}

\subsubsection{The Helicopter in Trim}

A helicopter is said to be in trim when the forces and moments acting through its centerof-gravity (CG) are at equilibrium. Using this baseline assumption, as described by Prouty [2], the linear model of the UH-60 Black Hawk helicopter can be derived for both hover and forward flight scenarios. This approach uses the equations of equilibrium to solve for the aircraft Euler angles: roll $(\phi)$, pitch $(\theta)$, and yaw $(\psi)$, as well as the control inputs at trim: lateral cyclic $\left(A_{1}\right)$, longitudinal cyclic $\left(B_{1}\right)$, main rotor collective $\left(\theta_{0}\right)$, and tail rotor collective $\left(\theta_{0_{T}}\right)$. The six equations of equilibrium are:

Longitudinal

Force

$$
X_{M}+X_{T}+X_{H}+X_{V}+X_{F}=G W \sin \theta
$$

Lateral Force

$$
Y_{M}+Y_{T}+Y_{V}+Y_{F}=-G W \sin \phi \cos \theta
$$

Vertical Force

$$
Z_{M}+Z_{T}+Z_{H}+Z_{V}+Z_{F}=-G W \cos \phi \cos \theta
$$

Rolling Moment

$$
R_{M}+Y_{M} h_{M}+Z_{M} y_{M}+Y_{T} h_{T}+Y_{V} h_{V}+Y_{F} h_{F}+R_{F}=0
$$

Pitching Moment

$$
M_{M}-X_{M} h_{M}+Z_{M} l_{M}+M_{T}-X_{T} h_{T}+Z_{T} l_{T}-X_{H} h_{H}+Z_{H} l_{H}
$$

Yawing Moment

$$
-X_{V} h_{V}+M_{F}+Z_{F} l_{F}-X_{f} h_{f}=0
$$

$$
N_{M}-Y_{M} l_{M}-Y_{T} l_{T}-Y_{V} l_{V}+N_{F}-Y_{F} l_{F}=G W \sin \theta
$$

Note: $R$ is used instead of the standard $L$ to define the rolling moment. This helps differentiate between the lift coefficient $\left(C_{L}\right)$, and the roll moment coefficient $\left(C_{L}\right.$ or $\left.C_{R}\right)$. 
The following axis system is used in conjunction with the equation of equilibrium:

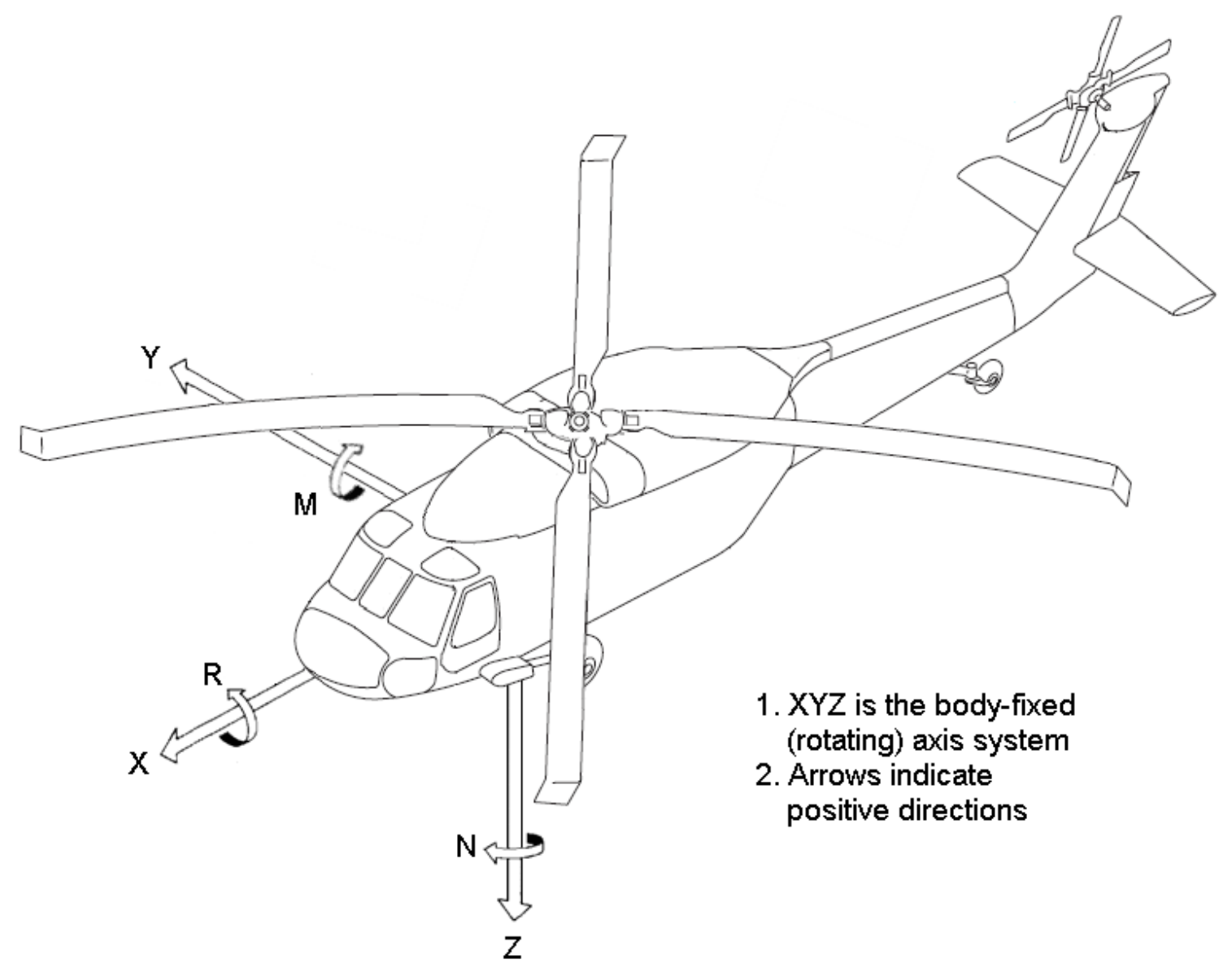

Figure 3.1: Body-Fixed (Rotating) Axis System

By defining each of the aerodynamic forces and moments for a given helicopter at a specific flight condition, the Euler angles can be found using the equations of equilibrium. The aerodynamic forces and moments acting on the helicopter (in the body-fixed axis system) are shown in Figure 3.2. The forces and moments are separated according to helicopter subsystems: the main rotor, the tail rotor, the horizontal stabilizer, the vertical stabilizer, and the fuselage. The values of the forces and moments for each helicopter section are found using the approaches outlined by Prouty [2] and Howlett [22]. These approaches are further investigated in Section 3.2 . 

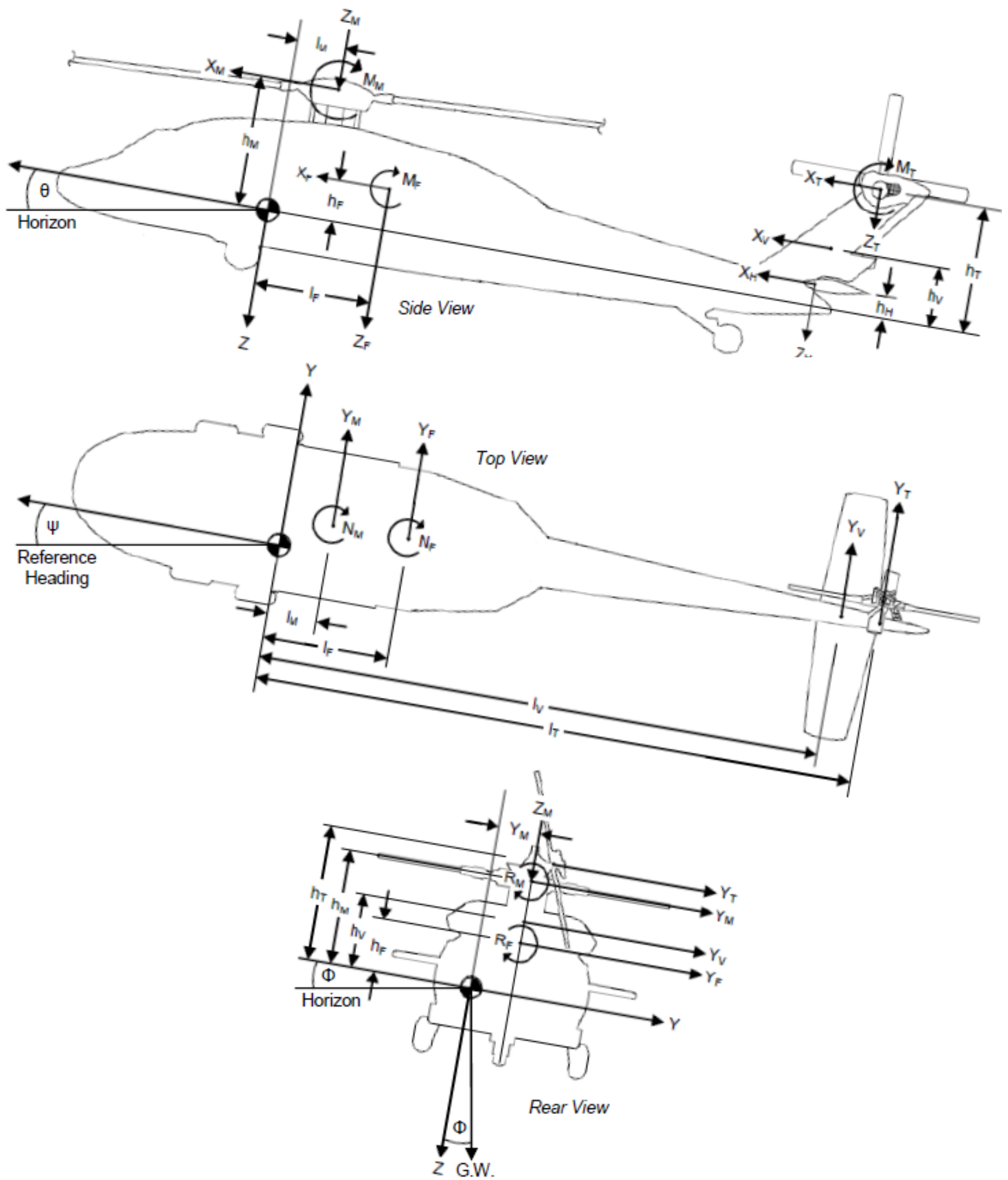

Figure 3.2: Forces and Moments Acting on Helicopter in Trim

It is important to note that the center-of-gravity locations in Figure 3.2 have been greatly exaggerated to help define the positive directions of forces and moments, and their associated distances with respect to the CG. 


\subsubsection{Equations of Motion}

Dynamic equations of motion are obtained using the linear and angular momenta theorems. Refer to Prouty [2] for a more detailed analysis of this process. The equations of motion are now in the following form:

$$
\begin{gathered}
X=G W \sin \theta+\frac{G W}{g}(\dot{u}-v r+w q) \\
Y=-G W \sin \phi \cos \theta+\frac{G W}{g}(\dot{v}+u r-w p) \\
Z=-G W \cos \phi \cos \theta+\frac{G W}{g}(\dot{w}-u q+v p) \\
R=I_{x x} \dot{p}-q r\left(I_{y y}-I_{z z}\right) \\
M=I_{y y} \dot{q}-p r\left(I_{z z}-I_{x x}\right) \\
N=I_{z z} \dot{r}-p q\left(I_{x x}-I_{y y}\right)
\end{gathered}
$$

Note that the separate aircraft components for the forces and moments on the left hand side of the equations of equilibrium have been grouped together into a singular term for each equation of motion (e.g. $X, Y, Z$, etc.).

\subsubsection{Linearization}

Next, the equations of motion can be linearized by converting them into linear differential small perturbation equations for six degrees of freedom (6 DOF). A fundamental assumption of linearization is that the external forces and moments acting on an aircraft can be represented as analytic functions of the disturbed motion variables and their derivatives.[23] In other words, Taylor's theorem can be applied if the force and moment functions, as well as all the associated derivatives, are known at any single point in time (the trim condition). However, this assumption is only valid for very small deviations, or "small perturbations," from the trim values of the known variables. Small perturbations will be defined in the following form:

$$
\mathbf{x}=\mathbf{x}_{e}+\Delta \mathbf{x}
$$

where the subscript, $e$, denotes the trim, or equilibrium flight condition.

Since the helicopter is being evaluated at steady state conditions, the linear approximation is applicable for both hover and forward flight scenarios. Small perturbation theory can now be applied to the equations of motion. The left-hand sides of the equations of 
motion are rewritten in terms of the stability derivatives for six degrees of freedom $(u, v, w, p, q$, and $r$ ) and four control inputs $\left(A_{1}, B_{1}, \theta_{0}\right.$, and $\left.\theta_{0_{T}}\right)$, e.g.:

$$
X=X_{e}+\frac{\partial X}{\partial u} \Delta u+\frac{\partial X}{\partial v} \Delta v+\cdots+\frac{\partial X}{\partial \theta_{0}} \Delta \theta_{0}+\cdots, \text { etc. }
$$

All six equations of motion are expanded in this manner. The linear approximation also contains terms in the rates of change of motion and control variables, but these terms will be neglected. Additionally, the stability derivatives will be referenced by their associated DOF or control input variable for all future analysis. The derivatives will take the following form:

$$
\frac{\partial X}{\partial u}=X_{u}, \quad \frac{\partial R}{\partial \theta_{0}}=R_{\theta_{0}}, \quad \text { etc. }
$$

Thus far the linearized system has been characterized by the translational and rotational equations of motion. However, these equations are not enough to fully define the system. The kinematic equations must also be implemented as functions of the Euler angles:

$$
\begin{gathered}
\dot{\phi}=p+q \sin \phi \tan \theta+r \cos \phi \tan \theta \\
\dot{\theta}=q \cos \phi-r \sin \phi \\
\dot{\psi}=q \sin \phi \sec \theta+r \cos \phi \sec \theta
\end{gathered}
$$

The linear differential equations of motion for small perturbations can now be rearranged into the vector-matrix shorthand form:

$$
\frac{d \mathbf{x}}{d t}-\mathbf{A x}=\mathbf{B u}+f(t)
$$

where

$$
\begin{gathered}
\mathbf{x}=\{u, w, q, \theta, v, p, \phi, r, \psi\}^{T} \\
\mathbf{u}=\left\{\theta_{0}, B_{1}, A_{1}, \theta_{0_{T}}\right\}^{T}
\end{gathered}
$$

$\mathbf{A}$ and $\mathbf{B}$ are the matrices of stability and control derivatives, identified in Eq. (3.14) and Eq. (3.15), while $f(t)$ represents external disturbances (e.g. gusts). For this simulation, external disturbances will be ignored and the vector-matrix shorthand form of the equations of motion can be rewritten in the standard state-space format:

$$
\dot{\mathbf{x}}=\mathbf{A x}+\mathbf{B u}
$$

In $6 \mathrm{DOF}$ form, the state vector, $\mathbf{x}$, is comprised of the aircraft component velocities $(u, v$, and $w)$, the aircraft Euler angles $(\phi, \theta$, and $\psi)$, and the aircraft angular rates $(p, q$, and $r)$. The control 
vector, $\mathbf{u}$, is comprised of the control inputs for the main rotor and tail rotor: the main rotor lateral cyclic pitch $\left(A_{1}\right)$, the main rotor longitudinal cyclic pitch $\left(B_{1}\right)$, the main rotor collective pitch $\left(\theta_{0}\right)$, and the tail rotor collective pitch $\left(\theta_{0_{T}}\right)$. In the fully expanded generic form, the contents of the system and control matrices, $\mathbf{A}$ and $\mathbf{B}$, for steady, level flight are defined by Eq. (3.23) and Eq. (3.24): 


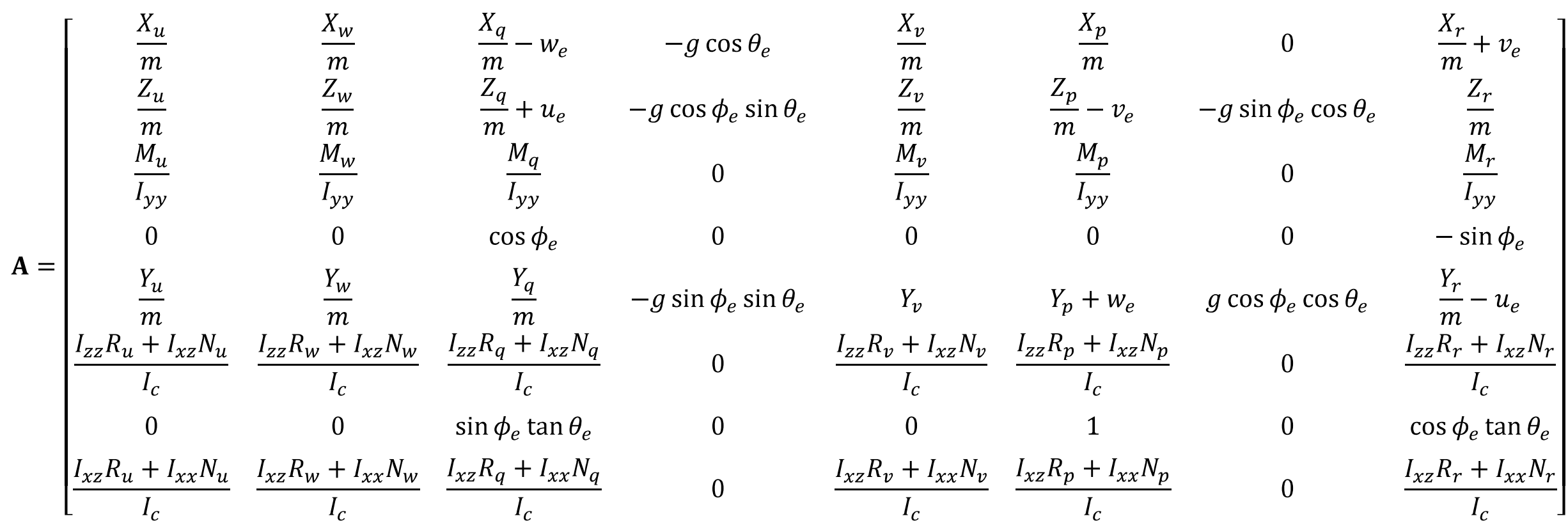

$$
\begin{aligned}
& \mathbf{B}=\left[\begin{array}{cccc}
\frac{X_{\theta_{0}}}{m} & \frac{X_{B_{1}}}{m} & \frac{X_{A_{1}}}{m} & \frac{X_{\theta_{0_{T}}}}{m} \\
\frac{Z_{\theta_{0}}}{m} & \frac{Z_{B_{1}}}{m} & \frac{Z_{A_{1}}}{m} & \frac{Z_{\theta_{0_{T}}}}{m} \\
\frac{M_{\theta_{0}}}{I_{y y}} & \frac{M_{B_{1}}}{I_{y y}} & \frac{M_{A_{1}}}{I_{y y}} & \frac{M_{\theta_{0_{T}}}}{I_{y y}} \\
0 & 0 & 0 & 0 \\
\frac{Y_{\theta_{0}}}{m} & \frac{Y_{B_{1}}}{m} & \frac{Y_{A_{1}}}{m} & \frac{Y_{r}}{m} \\
\frac{I_{z z} R_{\theta_{0}}+I_{x z} N_{\theta_{0}}}{I_{c}} & \frac{I_{z z} R_{B_{1}}+I_{x z} N_{B_{1}}}{I_{c}} & \frac{I_{z z} R_{A_{1}}+I_{x z} N_{A_{1}}}{I_{c}} & \frac{I_{z z} R_{\theta_{0_{T}}}+I_{x z} N_{\theta_{0_{T}}}}{I_{c}} \\
0 & 0 & \sin \phi_{e} \tan \theta_{e} & \cos \phi_{e} \tan \theta_{e} \\
\frac{I_{x z} R_{\theta_{0}}+I_{x x} N_{\theta_{0}}}{I_{c}} & \frac{I_{x z} R_{B_{1}}+I_{x x} N_{B_{1}}}{I_{c}} & \frac{I_{x z} R_{A_{1}}+I_{x x} N_{A_{1}}}{I_{c}} & \frac{I_{x z} R_{\theta_{0_{T}}}+I_{x x} N_{\theta_{0_{T}}}}{I_{c}}
\end{array}\right]
\end{aligned}
$$

where $I_{c}=\left(I_{x x} I_{z z}-I_{x z}{ }^{2}\right)$ 
It is important to note that at straight and level flight, $p_{e}=q_{e}=r_{e}=0$. For this reason, these variables were excluded from the A and $\mathbf{B}$ matrices in Eq. (3.23) and Eq. (3.24). Additionally, the heading angle, $\psi$, has been omitted from the $\mathbf{A}$ matrix because the direction of flight in the horizontal plane has no effect on the aerodynamic or dynamic forces and moments [23]. In other words, the psi equation is decoupled from the corresponding linear differential equations of motion for small perturbations.

Now that the helicopter system is defined in state-space format, the matrices can be incorporated into the WVU Flight Simulator for further analysis.

\subsection{UH-60 Black Hawk Linear Model: Hover}

\subsubsection{Overview of Modeling Structure and Assumptions}

Using the linear model approach described in Section 3.1, a mathematical model for the UH-60 Black Hawk helicopter can be developed in Matlab ${ }^{\circledR}$ for a hover flight scenario. The first step in this process is defining the atmospheric conditions. The helicopter is assumed to be flying out of ground effect (OGE) at standard sea-level conditions. Therefore, the density $(\rho)$ is 0.002377 slugs per cubic foot and the temperature is $59^{\circ} \mathrm{F}$. Next, a wide variety of helicopter constants must be defined for the UH-60 Black Hawk. The majority of the helicopter constants, shown in Appendix A:, have been extracted from Howlett [22]. However, some constants and relating data have also been extracted from Hilbert [24] and Ballin [25]. Additionally, since the helicopter is flying at hover, the following conditions can be assumed:

- $p=q=r=0$

- $u=v=w=0$

- $\beta=\gamma_{c}=0$

Next, a loop is built within the Matlab ${ }^{\circledR}$ code to solve for the main rotor thrust and Euler angles. The following flowchart describes the iteration process, as well as the overall modeling scheme: 


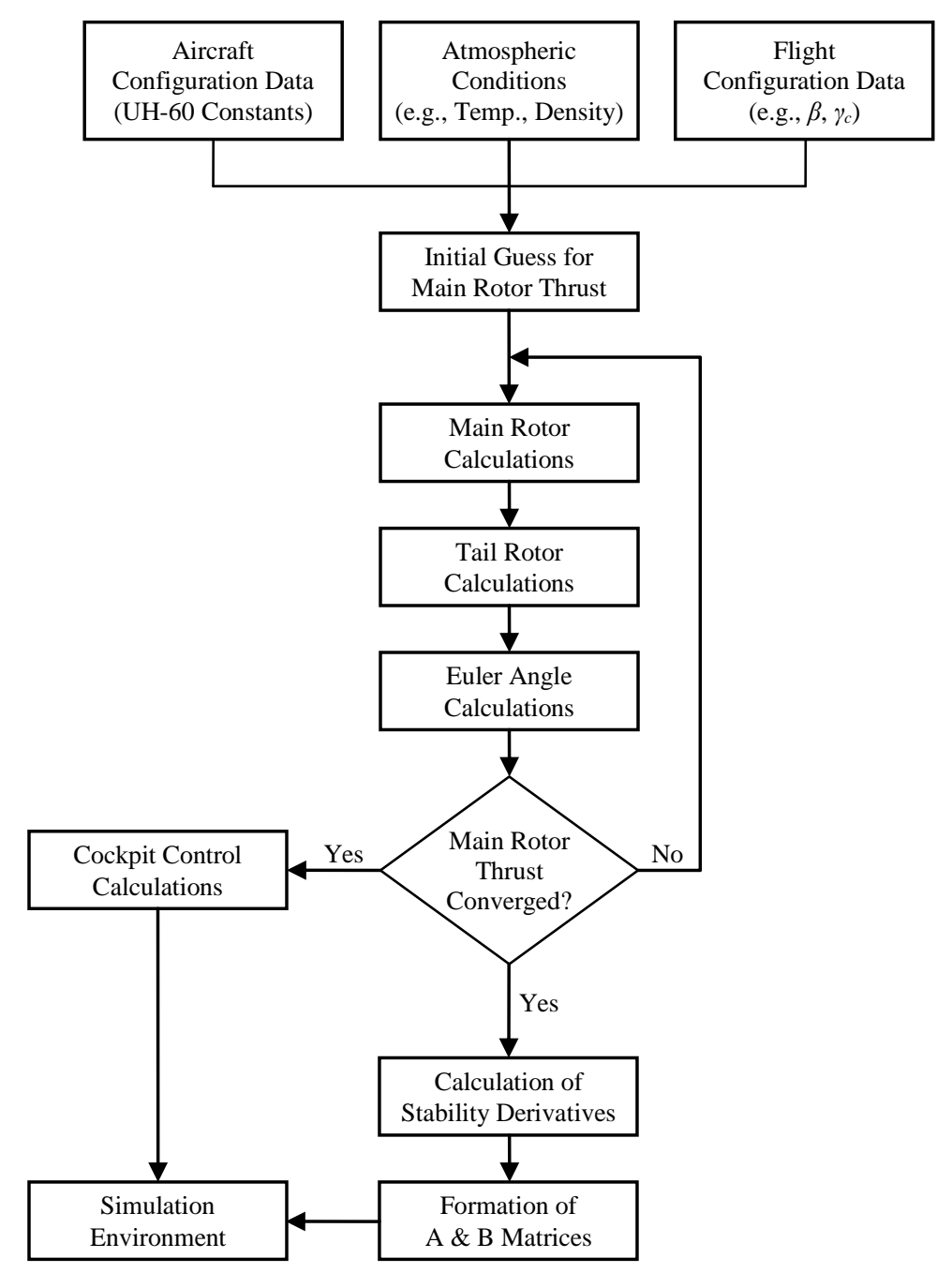

Figure 3.3: Flowchart for the Swashplate-Based Linear Model (Hover)

\subsubsection{Iteration Process}

The initial guess for the main rotor thrust is derived from the assumption that, at hover, the rotor thrust must offset the gross weight of the helicopter $(T=G W)$. This baseline assumption can be improved by accounting for the vertical drag $\left(D_{V}\right)$ of the helicopter, which will slightly increase the required thrust of the main rotor. The rotor thrust is now expressed as:

$$
T=\left(1+\frac{D_{V}}{G W}\right) G W
$$

Prouty recommends an average value of $4 \%$ for the vertical drag ratio of most helicopters, but more extensive research revealed that the vertical drag ratio of the UH-60 is actually 3.4\% [26].

Next, calculations are performed for the main rotor and tail rotor. These are the only two helicopter subsystems required to accurately model the aircraft at hover. Since the aircraft is 
assumed to be relatively stationary during hover, the main rotor produces little to no downwash onto the empennage and tail rotor, as seen in Figure 3.4:

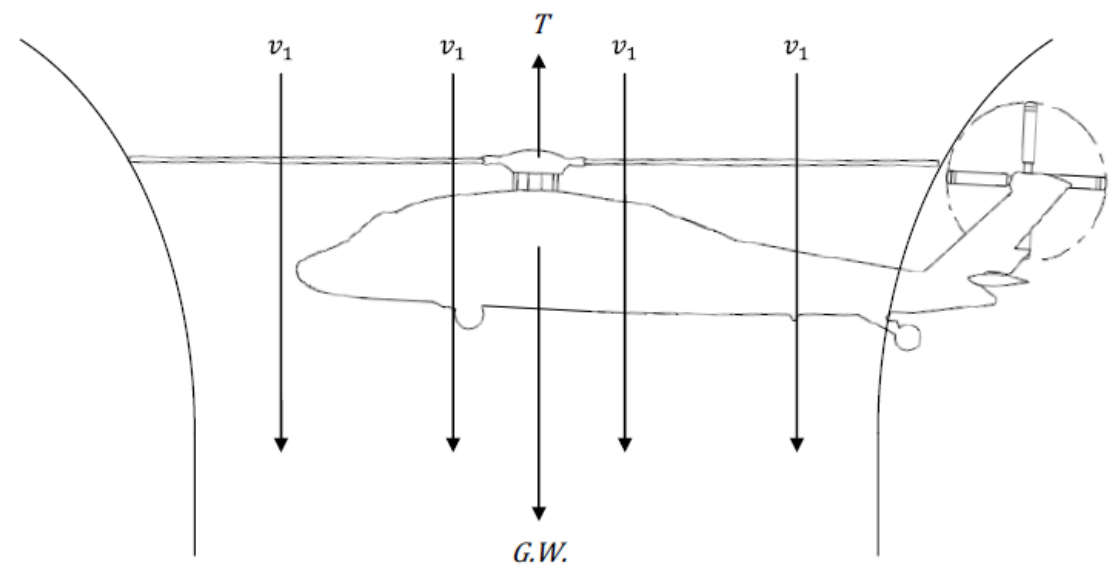

Figure 3.4: OGE Induced Velocities for Hovering Rotor

Therefore, the empennage yields negligible forces and moments and the tail rotor calculations become much more simplified. The fuselage is the only subsystem that is affected by the main rotor downwash during hover, and this component has been accounted for with the vertical drag of Eq. (3.25).

The next step in modeling the system at hover consists of defining the main rotor thrust and torque coefficients. Similar to aircraft aerodynamics, it is convenient to work with nondimensional coefficients to define rotor characteristics in a form that is independent of rotor size [2]. Therefore, the thrust, torque, and power coefficients will be defined in the following manner:

$$
\begin{gathered}
C_{T}=\frac{T}{\rho A(\Omega R)^{2}} \\
C_{Q}=\frac{Q}{\rho A(\Omega R)^{2} R} \equiv C_{P}=\frac{P}{\rho A(\Omega R)^{3}}
\end{gathered}
$$

where $T$ is the rotor thrust, $Q$ is the rotor torque, $P$ is the rotor power, $A$ is the area of the rotor, $\Omega R$ is the tip speed of the rotor, and $R$ is the rotor radius.

Note that since power is related to torque by $P=\Omega Q$, then numerically $C_{P} \equiv C_{Q}$. The torque coefficient can also be expressed as a function of the main rotor thrust:

$$
C_{Q}=\frac{\kappa C_{T}^{3 / 2}}{\sqrt{2}}+\frac{c_{d} \sigma}{8}
$$


where $\kappa$ is the induced power correction factor, $c_{d}$ is the drag coefficient of the rotor blade, and $\sigma$ is the solidity of the rotor blade.

The first term in Eq. (3.28) is known as the induced torque coefficient and it is derived from simple momentum theory. The induced power correction factor $(\kappa)$ accounts for a number of nonideal physical effects, such as nonuniform inflow, tip losses, wake swirl, less than ideal wake contraction, finite number of blades, and so on [4]. The second term in Eq. (3.28) is known as the profile torque coefficient, and it is only a function of the drag on the blade elements.

Next, the tail rotor thrust can be calculated as a function of the main rotor torque. For steady, level flight the tail rotor thrust must offset the torque produced by the main rotor, as described in Section 2.1. For a standard helicopter, a simple examination of the yaw moment at equilibrium will yield the required tail rotor force:

$$
Q_{M}-l_{T} Y_{T}=Q_{M}-l_{T} T_{T}=0
$$

where $Y_{T}$ is the side force component of the tail rotor thrust and $l_{T}$ is the distance between the helicopter CG location and the tail rotor, as seen in Figure 3.2. Note that the subscripts $M$ and $T$ have been introduced to help distinguish between the main rotor and tail rotor.

The tail rotor of the UH-60 helicopter, however, is canted at an angle of $20^{\circ}$, as seen in Figure 3.5:

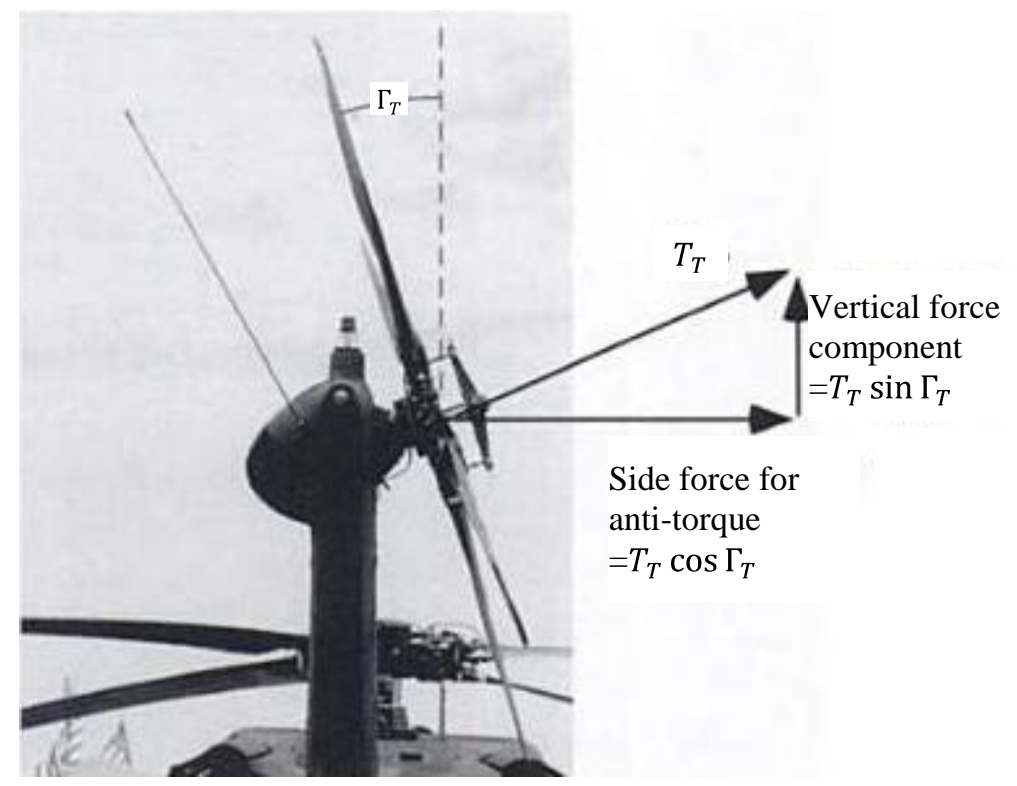

Figure 3.5: UH-60 Canted Tail Rotor [4] 
A canted tail rotor design provides some key advantages, such as more efficient use of hover power since the tail rotor thrust vector has an upward component, the ability to trim with a center-of-gravity position behind the main rotor, and the alleviation of unsteadiness in the vortex ring state in forward flight [2]. However, the underlying disadvantage of this design is that it produces an adverse coupling between pitch and yaw. This control coupling will be explored further in Section 3.2.3.

Upon examining the yaw moment at equilibrium for the UH-60, it becomes evident that a greater amount of tail rotor thrust is required to offset the torque produced by the main rotor. Accounting for the cant angle, the tail rotor thrust at hover is recalculated by examining the yaw moment at equilibrium:

$$
\begin{gathered}
Q_{M}-l_{T} Y_{T}=Q_{M}-l_{T} T_{T} \cos \Gamma_{\mathrm{T}}=0 \\
T_{T}=\frac{Q_{M}}{l_{T} \cos \Gamma_{\mathrm{T}}}
\end{gathered}
$$

In nondimensional form, the tail rotor thrust coefficient is:

$$
C_{T_{T}}=\frac{C_{Q_{M} R_{M}}}{l_{T} \cos \Gamma_{\mathrm{T}}} \frac{A_{M}}{A_{T}} \frac{(\Omega R)_{M}{ }^{2}}{(\Omega R)_{T}{ }^{2}}
$$

Next, the longitudinal trim calculations can be performed to solve for the aircraft pitch angle $(\theta)$, the longitudinal blade flapping coefficient $\left(a_{1_{S}}\right)$, and the main rotor thrust $\left(T_{M}\right)$. The longitudinal flapping coefficient, along with a variety of other main rotor variables, is defined in Figure 3.6.

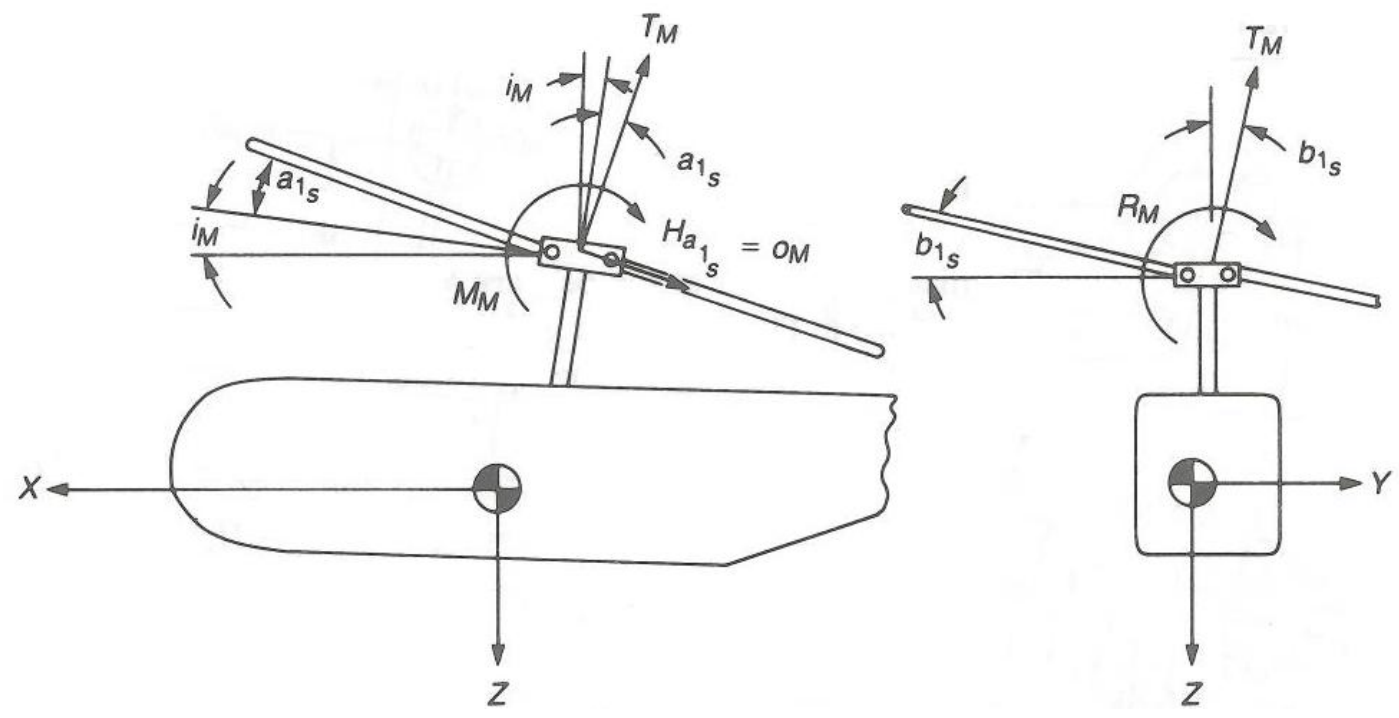

Figure 3.6: Main Rotor Variables [2] 
As mentioned previously, the aerodynamics of the empennage can be ignored at hover. Therefore, the equilibrium equations for longitudinal trim reduce to:

$$
\begin{gathered}
X_{M}=G W \sin \theta_{e} \\
Z_{M}+Z_{T}+Z_{F}=-G W \cos \theta_{\mathrm{e}} \\
M_{M}-X_{M} h_{M}+Z_{M} l_{M}+M_{T}+Z_{T} l_{T}+Z_{F} l_{F}=0
\end{gathered}
$$

Rewriting these equations in terms of the three independent variables $\left(\theta_{e}, a_{1_{S}}\right.$, and $\left.T_{M}\right)$ and applying the small-angle assumption yields the following:

$$
\begin{gathered}
-T_{M}\left(i_{M}+a_{1_{s}}\right)=G W\left(\theta_{e}\right) \\
-T_{M}-T_{T} \sin \left(\Gamma_{T}\right)+T_{M}\left(\frac{D_{V}}{G W}\right)_{F}=-G W \\
\left(\frac{d M_{M}}{d a_{1_{s}}}\right) a_{1_{s}}+T_{M}\left(i_{m}+a_{1_{s}}\right) h_{m}-T_{M} l_{M}-Q_{T}-T_{T} \sin \left(\Gamma_{T}\right) l_{T}+T_{M}\left(\frac{D_{V}}{G W}\right)_{F} l_{F}=0
\end{gathered}
$$

where $i_{M}$ is the incidence angle of the main rotor, $d M_{M} / d a_{1_{s}}$ is the uniform blade mass distribution, and $h$ and $l$ are the heights and lengths of the corresponding helicopter subsystems, as seen in Figure 3.2.

Solving the three equations with respect to the three unknowns:

$$
\begin{gathered}
\theta_{e}=\frac{-T_{M}\left(i_{M}+a_{1_{s}}\right)}{G W} \\
T_{M}=\frac{G W-T_{T} \sin \left(\Gamma_{T}\right)}{1-0.034} \\
a_{1_{s}}=\frac{T_{M} l_{M}-T_{M} i_{M} h_{m}+Q_{T}+T_{T} \sin \left(\Gamma_{T}\right) l_{T}-0.034 T_{M} l_{F}}{\left(\frac{d M_{M}}{d a_{1_{s}}}\right)+T_{M} h_{M}}
\end{gathered}
$$

Similarly, the lateral trim calculations can be performed to solve for the aircraft roll angle $\left(\phi_{e}\right)$ and the lateral blade flapping $\left(b_{1_{s}}\right)$. By once again neglecting the aerodynamics of the empennage, the equilibrium equations for lateral trim reduce to:

$$
\begin{gathered}
Y_{M}+Y_{T}=-G W \sin \phi_{\mathrm{e}} \cos \theta_{e} \\
R_{M}+Y_{M} h_{M}+Z_{M} y_{M}+Y_{T} h_{T}=0 \\
N_{M}-Y_{T} l_{T}=0
\end{gathered}
$$


The yaw equilibrium equation can be ignored since it was already used to calculate $T_{T}$ in Eq. (3.31). Rewriting the remaining equations in terms of the two independent variables $\left(\phi_{e}\right.$ and $\left.b_{1_{s}}\right)$ and applying the small-angle assumption yields the following:

$$
\begin{gathered}
T_{M} b_{1_{s}}+T_{T} \cos \left(\Gamma_{T}\right)=-G W \phi_{e} \\
\left(\frac{d R_{M}}{d b_{1_{s}}}\right) b_{1_{s}}+T_{M} b_{1_{s}} h_{m}-T_{M} y_{M}+T_{T} \cos \left(\Gamma_{T}\right) h_{T}=0
\end{gathered}
$$

where $d R_{M} / d b_{1_{s}}=d M_{M} / d a_{1_{s}}$. Solving the two equations with respect to the two unknowns:

$$
\begin{gathered}
\phi_{e}=\frac{T_{M} b_{1_{s}}+T_{T} \cos \left(\Gamma_{T}\right)}{-G W} \\
b_{1_{s}}=\frac{T_{M} y_{M}-T_{T} \cos \left(\Gamma_{T}\right) h_{T}}{\left(\frac{d M_{M}}{d a_{1_{s}}}\right)+T_{M} h_{M}}
\end{gathered}
$$

The system can now be iterated with the new, more accurate, value for thrust, which accounts for the vertical thrust component produced by the canted tail rotor. The system is iterated until convergence can be achieved for the main rotor thrust.

\subsubsection{Control Inputs}

Next, the control inputs can be calculated at the rotor hubs, which are then converted to inputs for the cockpit controls. The control inputs at the rotor hubs, identified in the control

matrix $\mathbf{u}=\left\{\theta_{0}, B_{1}, A_{1}, \theta_{0_{T}}\right\}^{T}$, are calculated using approaches outline by Prouty [2]. The main rotor collective pitch angle $\left(\theta_{0}\right)$ is found using the following equations:

$$
\begin{aligned}
& \theta_{t}=\frac{4}{a} \frac{C_{T}}{\sigma}+\sqrt{\frac{C_{T}}{2}} \\
& \theta_{0}=\frac{3}{2} \theta_{t}-\frac{3}{4} \theta_{1}
\end{aligned}
$$

where $\theta_{t}$ is the pitch at the blade tip and $\theta_{1}$ is the linear blade twist between the center of rotation and the blade tip. This approach also provides a relatively good approximation for the tail rotor collective pitch $\left(\theta_{0_{T}}\right)$ at hover.

The longitudinal and lateral cyclic pitch can be calculated using an approach derived by Leishman for blade flapping with a hinge offset [4]:

$$
A_{1}=\frac{8}{\gamma} a_{1_{s}}\left(v_{\beta}^{2}-1\right)+b_{1_{s}}
$$




$$
B_{1}=\frac{8}{\gamma} b_{1_{s}}\left(v_{\beta}^{2}-1\right)-a_{1_{s}}
$$

where $\gamma$ is the blade Lock number defined by rotor parameters and $v_{\beta}$ is the nondimensional flapping frequency in terms of the rotational speed:

$$
\begin{gathered}
\gamma=\frac{\rho a c R^{4}}{I_{b}} \\
v_{\beta}=\sqrt{1+\frac{3 \varepsilon}{2(1-\varepsilon)}}
\end{gathered}
$$

where $a$ is the lift curve slope of the main rotor blade, $c$ is the main rotor blade chord length, $I_{b}$ is the inertia of the blade about the hinge, and $\varepsilon$ is main rotor hinge offset ratio.

Next, the rotor control inputs can be converted into cockpit control inputs. As mentioned previously, the canted tail rotor design of the UH-60 helicopter produces an adverse coupling between pitch and yaw. As a result, control mixing becomes a somewhat complicated process for the Black Hawk helicopter. Fortunately, Talbot, et al. [27] have developed a straight forward approach to control mixing, and Hilbert [24] has adapted this approach for the UH-60. The control system used to derive the cockpit control inputs can be seen in Figure 3.7:

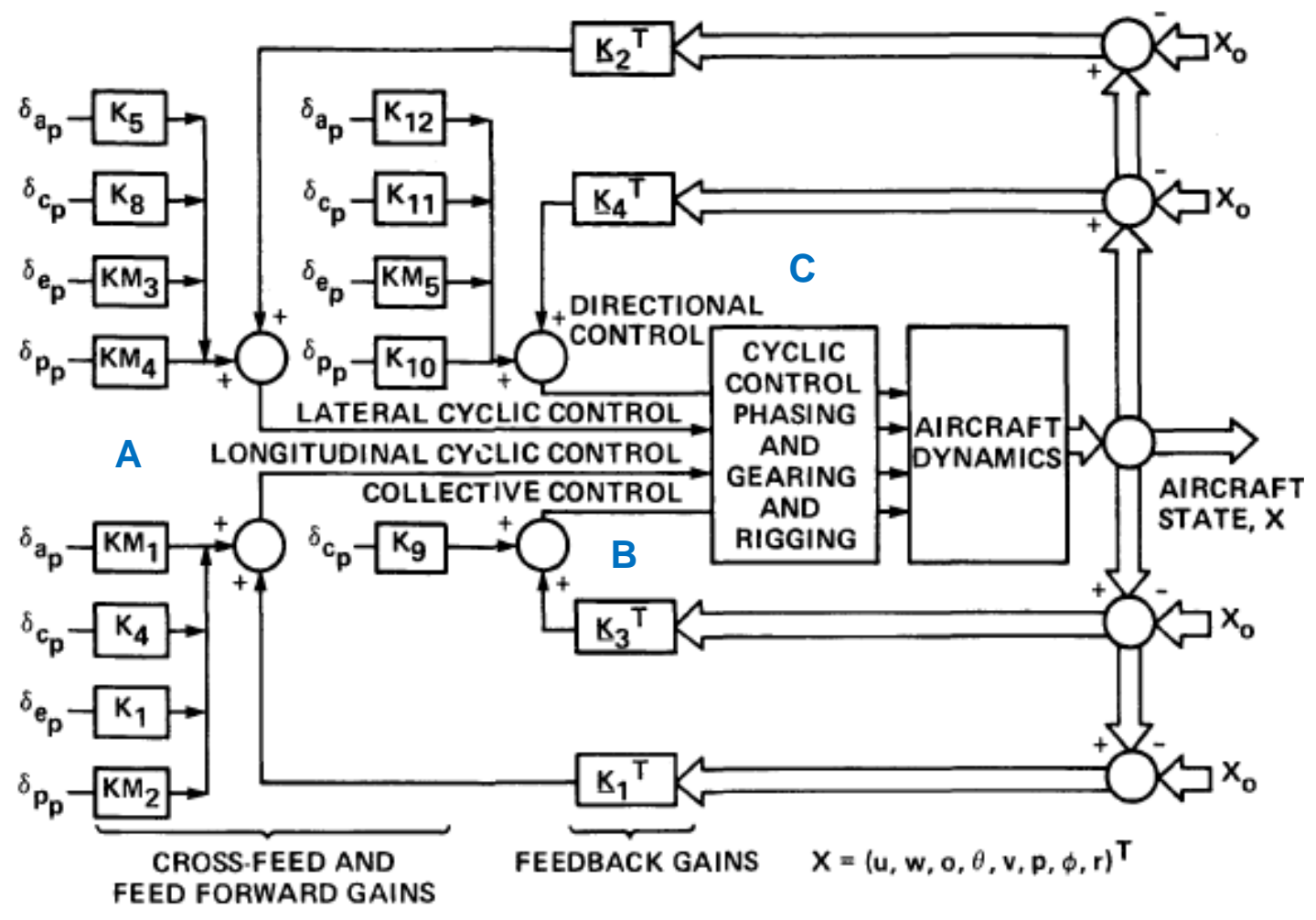

Figure 3.7: Control System Structure [27] 
The associated UH-60 gain values are presented in Appendix A.: Using the previously derived rotor control inputs (Part C in Figure 3.7), the post-mixing control inputs (Part B in Figure 3.7) can be found using:

$$
\begin{gathered}
\delta_{a}=\frac{A_{1}-C_{3} \delta_{e}-C_{A_{1}}}{C_{1}} \\
\delta_{e}=\frac{B_{1}-C_{2} \delta_{a}-C_{B_{1}}}{C_{4}} \\
\delta_{c}=\frac{\theta_{0}-C_{5}}{C_{6}} \\
\delta_{p}=\frac{\theta_{0_{T}}-C_{7}}{C_{8}}
\end{gathered}
$$

$C_{A_{1}}, C_{B_{1}}, C_{5}$, and $C_{7}$ are the constant or rigging terms for each control input. $C_{1}-C_{4}$ are the constants used to adjust for the phase angle between the cyclic control input and the resulting flapping.

The pre-mixing control inputs (Part A in Figure 3.7), or cockpit controls, can be found by arranging the post-mixing control inputs in a matrix format, along with the feed forward and cross-feed gains defined in Appendix A:

$$
\left[\begin{array}{l}
\delta_{a_{p}} \\
\delta_{e_{p}} \\
\delta_{c_{p}} \\
\delta_{p_{p}}
\end{array}\right]=\left[\begin{array}{cccc}
K_{5} & 0 & K_{8} & 0 \\
0 & K_{1} & K_{4} & K M_{2} \\
0 & 0 & K_{9} & 0 \\
0 & 0 & K_{11} & K_{10}
\end{array}\right]^{-1}\left[\begin{array}{c}
\delta_{a} \\
\delta_{e} \\
\delta_{c} \\
\delta_{p}
\end{array}\right]
$$

Note that the feedback gains have been ignored because the pitch rate and roll rate are assumed be zero at trim conditions.

\subsubsection{Stability and Control Derivatives and State-Space Representation}

The stability and control derivatives are calculated using the formulas developed by Prouty [2]. As mentioned previously, only two subsystems (main rotor and tail rotor) are necessary to accurately model the helicopter at hover. The subsystem stability and control derivatives are then combined to form the total derivatives, as described in Section 3.1.3. Lastly, the total derivatives are inserted into the state-space matrices defined by Eq. (3.23) and Eq. (3.24). Now that the helicopter system is defined in state-space format, the matrices can be incorporated into the WVU Flight Simulator for further analysis. 


\subsection{UH-60 Black Hawk Linear Model: Forward Flight}

\subsubsection{Overview of Modeling Structure and Assumptions}

The linear model approach described in Section 3.1 is once again used to develop a mathematical model in Matlab ${ }^{\circledR}$ for the UH-60 Black Hawk helicopter at forward flight conditions. The forward flight model is designed to be used at any forward speed in the UH-60 flight envelope, which approximately ranges from 0-160 knots. However, at very low forward speeds many of the main rotor calculations are expected to be less accurate. The induced velocity distribution becomes very complex at low speeds, and this complex flow is what makes helicopters vibrate when going from hover to forward flight. The actual speed that this transition occurs is debatable and will vary depending on the helicopter being examined. Padfield considers the low-speed regime for forward flight to be at airspeeds less than roughly 45 knots, while Prouty has recommended that his forward flight program only be used for airspeeds above 30 knots. Contrary to the expected less accurate results, the forward flight model coincides rather well with the validation data presented in Section 3.4. For this reason, the forward flight model is used throughout the full flight envelope of the Black Hawk helicopter.

The following assumptions are used for the forward flight model, which are almost identical to the assumptions used in the hover model:

- The helicopter is assumed to be flying out of ground effect (OGE) at standard sea-level conditions ( $\rho=0.002377$ slugs per cubic foot, $\mathrm{T}=59^{\circ} \mathrm{F}$.)

- $p=q=r=0$

- $\beta=\gamma_{c}=0$, and since $\beta=0$, it is safe to assume that $v \approx 0$.

The only difference in these assumptions, when compared to hover, is that the velocity components ( $u$ and $w$ ) are no longer zero for forward flight.

Once again, a wide variety of helicopter constants must be defined for the UH-60 Black Hawk. The majority of the helicopter constants, shown in Appendix A:, have been extracted from Howlett [22]. Next, a forward velocity is defined. The WVU Flight Simulator requires the forward speed to be input in knots, but within the Matlab ${ }^{\circledR}$ code the velocity can also be entered in feet per second. Next, a loop is built within the Matlab ${ }^{\circledR}$ code to calculate the main rotor thrust and the Euler angles. The following flowchart describes the iteration process, as well as the overall modeling scheme: 


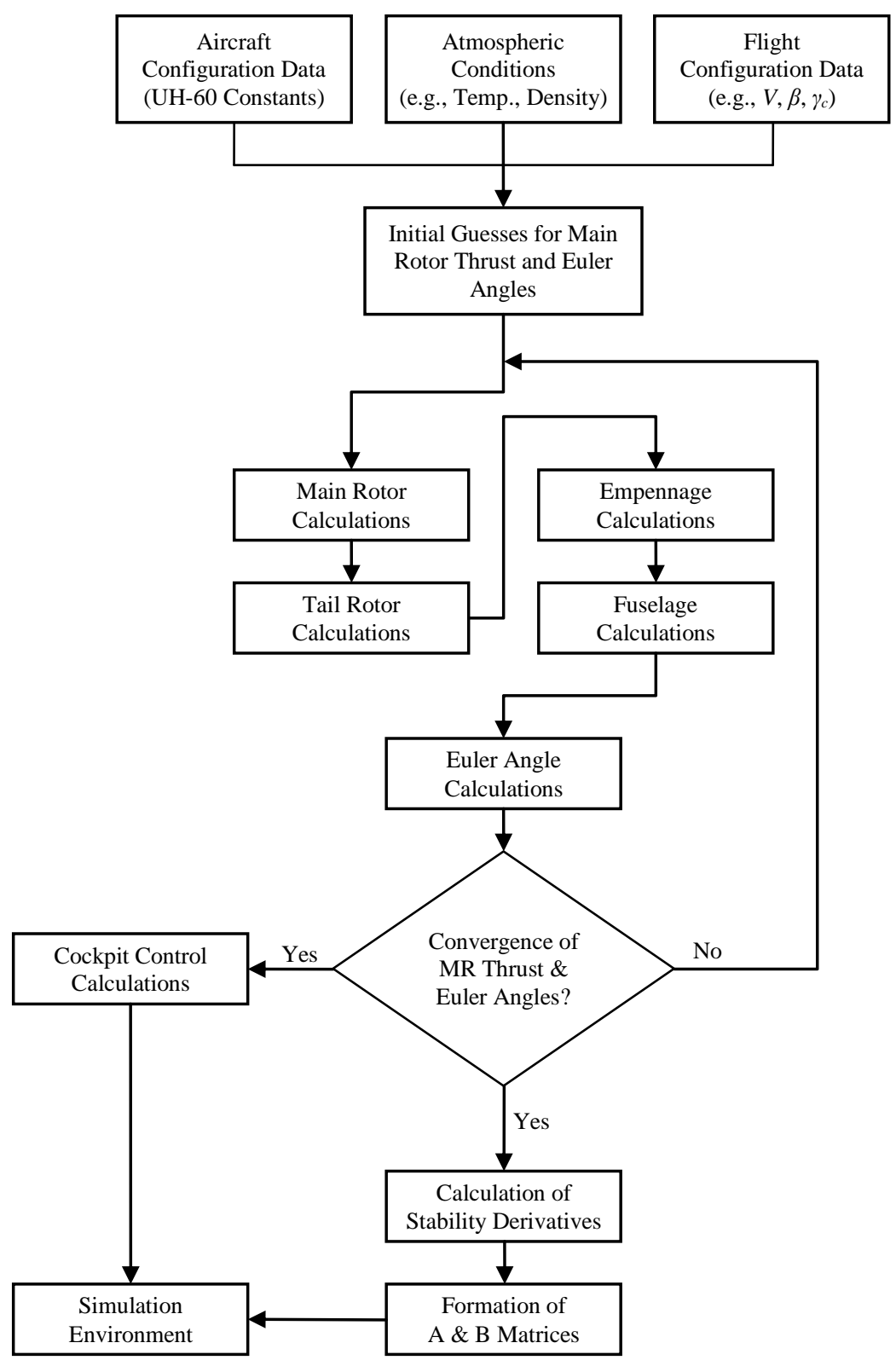

Figure 3.8: Flowchart for the Swashplate-Based Linear Model (Forward Flight)

\subsubsection{Main Rotor Calculations for Forward Flight}

The main rotor calculations are performed using the following assumptions:

- Tip loss and root cutout are ignored.

- Compressibility losses and tip relief are ignored.

- A constant blade element drag coefficient is used.

- Uniform inflow is assumed across the main rotor disk. 
Each of the above assumptions has an influence on the accuracy of the overall model. Prouty outlines methods to eliminate the assumptions one at a time, but does not outline a process to eliminate the combined assumptions. Prouty instead uses a look-up table process based on isolated rotor performance charts. The charts, originally designed for a NACA 0012 airfoil, can be modified for use with any airfoil. While look-up table data can readily be built for the Black Hawk helicopter based on these charts, the process is tedious and is only valid for a single flight condition. The look-up table data would have to be rebuilt each time the helicopter configuration or aerodynamic conditions are altered. So instead of using the isolated rotor performance charts, a step-by-step equation process will be outlined using the above assumptions, which still provide reasonable accuracy for the aircraft.

It is also important to note that the reverse flow region is being included in this analysis. The reverse flow region, illustrated in gray in Figure 3.9, is an area on the retreating side of the rotor disk where air flows over the blades from trailing to leading edge (the opposite direction).

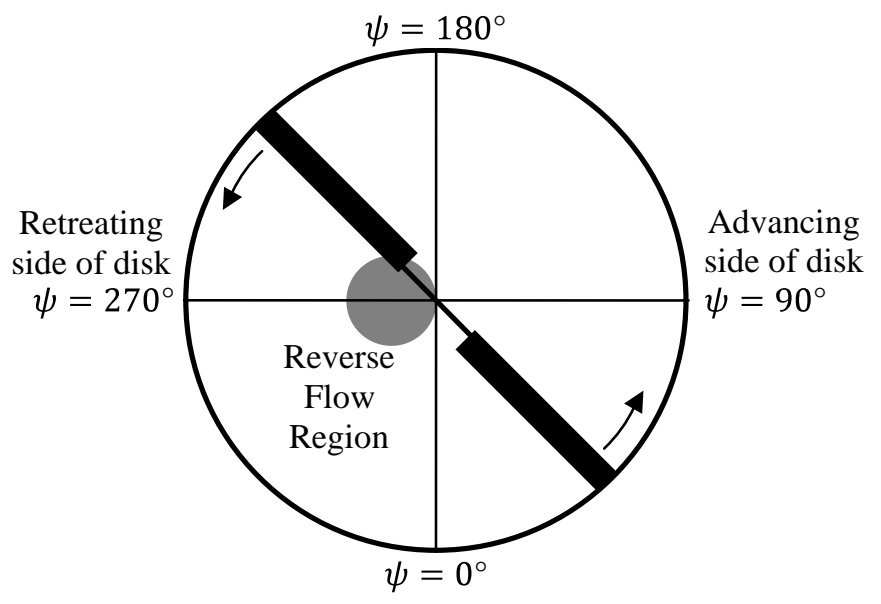

Figure 3.9: Reverse Flow Region

This phenomenon produces a negative lift distribution in the reverse flow region. At low forward speeds (approximately less than $\mu=0.25$ ) the negative lift distribution is small in comparison to the thrust produced by the main rotor. Therefore, the effects of the reverse flow region can be ignored without much consequence. However, at higher forward speeds (greater than $\mu=0.25$ ) the reverse flow region grows in diameter and the effects can no longer be ignored. Preliminary analysis of the WVU UH-60 linear model showed that ignoring the reverse region created significant errors in the calculation of Euler angles at high forward speeds. For this reason, the reverse flow region is included in all relevant main rotor calculations. 
First, the main rotor induced velocity is calculated using the equation for constant momentum induced velocity:

$$
v_{1}=\sqrt{-\frac{V^{2}}{2}+\sqrt{\left(\frac{V^{2}}{2}\right)^{2}+v_{1_{\text {hov }}}}}
$$

where $V$ is the forward velocity of the aircraft in the earth-fixed axis system and $v_{1_{\text {hov }}}=$ $\sqrt{T / 2 \rho A} \mathrm{ft} / \mathrm{sec}$. As mentioned previously, the induced velocity at low forward speeds is far more complex than the above equation depicts. The complexity is of great importance when studying blade loads and helicopter vibration, but it has been found that for most performance calculations the use of the constant momentum value - which represents the average of the complex velocity field - gives reasonable accurate results [2].

Next, the main rotor inflow is calculated in terms of the main rotor tip path plane:

$$
\lambda^{\prime}=\mu \alpha_{T P P}-\frac{v_{1}}{\Omega R}
$$

where $\mu$ is the tip speed ratio:

$$
\mu=\frac{V}{\Omega R}
$$

and $\alpha_{T P P}$ is the angle of attack of the tip path plane:

$$
\alpha_{T P P}=-\tan ^{-1} \frac{D_{F}}{G W}(1 \text { st approx. })
$$

The angle of attack of the tip path plane is approximated using the fuselage drag, $D_{F}$ (based on the initial guess for fuselage angle of attack). $D_{F}$ is found using a look-up table derived from Howlett [22]. A more accurate calculation for the angle of attack of the tip path plane will be presented later.

Next the average drag coefficient can be obtained using look-up tables developed by Howlett [22]:

$$
\overline{c_{d}}=f\left(\bar{\alpha}, 0.75 * M_{t}\right)
$$

An average value is found using the Mach number corresponding to $75 \%$ of the tip speed and calculating the average angle of attack for the main rotor blades. Prouty has derived the average two-dimensional lift coefficient of the main rotor in terms of the thrust coefficient [2]:

$$
\overline{c_{l}}=6 \frac{C_{T}}{\sigma}
$$


The average lift coefficient can also be defined in terms of the average angle of attack. Therefore, the two equations can be equated to one another to solve for the angle of attack:

$$
\begin{gathered}
\overline{c_{l}}=a \bar{\alpha} \\
\bar{\alpha}=\frac{6 C_{T} / \sigma}{a}
\end{gathered}
$$

Next, the main rotor coning angle and main rotor collective pitch angle are calculated using:

$$
\begin{gathered}
a_{0}=\frac{2}{3} \gamma \frac{C T / \sigma}{a}-\frac{\frac{3}{2} g R}{(\Omega R)^{2}} \\
\theta_{0}=\frac{\frac{4 C_{T}}{a \sigma}\left(1+\frac{3}{2} \mu^{2}-\frac{5}{24} \mu^{4}\right)-\frac{1}{2} \theta_{1}\left(1-\frac{3}{2} \mu^{2}+\frac{\mu^{4}}{6}-\frac{9}{16} \mu^{6}-\frac{3}{192} \mu^{8}\right)-\lambda^{\prime}\left(1+\frac{13}{24} \mu^{4}+\frac{\mu^{6}}{48}\right)}{\frac{2}{3}-\frac{2}{3} \mu^{2}-\frac{8}{9 \pi} \mu^{3}+\frac{25}{36} \mu^{4}-\frac{92}{45 \pi} \mu^{5}-\frac{5}{24} \mu^{6}+\frac{\mu^{7}}{135 \pi}}
\end{gathered}
$$

The horizontal force perpendicular to the rotor shaft, also known as the H-force, can be calculated using the following:

$$
\begin{gathered}
\frac{C_{H}}{\sigma}=\frac{\overline{c_{d}}}{4}\left(\mu+\frac{\mu^{3}}{4}\right)-\frac{a}{4}\left\{\frac { \mu \lambda ^ { \prime } } { 1 + \frac { 3 \mu ^ { 2 } } { 2 } - \frac { 5 \mu ^ { 4 } } { 2 4 } } \left[\frac{\theta_{0}}{3}\left(-1-\frac{4 \mu}{\pi}+\frac{3 \mu^{2}}{2}-\frac{106 \mu^{3}}{15 \pi}-\frac{5 \mu^{4}}{8}+\frac{\mu^{5}}{30 \pi}\right)\right.\right. \\
\left.+\frac{\theta_{1}}{2}\left(-1-\frac{\mu^{2}}{4}-\frac{2}{3} \mu^{4}-\frac{\mu^{6}}{96}\right)+\lambda^{\prime}\left(\mu^{2}-\frac{\mu^{4}}{48}\right)\right]+\frac{C_{T}}{\sigma} a_{1_{s}} \\
+\frac{-\mu}{1+\frac{\mu^{2}}{2}-\frac{\mu^{4}}{4}}\left\{\frac{a_{0}^{2}}{2}\left[\frac{1}{9}+\frac{\mu^{2}}{4}-\frac{64}{135 \pi} \mu^{3}-\frac{\mu^{4}}{6}-\left(\frac{128}{45^{2} \pi^{2}}-\frac{1}{96}\right) \mu^{6}\right]\right. \\
\left.\left.+a_{0} \frac{v_{1}}{\Omega R} \frac{\mu}{3}\left[1-\frac{8 \mu}{5 \pi}-\frac{\mu^{2}}{6}-\frac{8}{15 \pi} \mu^{3}+\frac{\mu^{5}}{45 \pi}\right]+\frac{1}{8}\left(\frac{v_{1}}{\Omega R}\right)^{2}\left[1-\frac{\mu^{2}}{2}-\frac{\mu^{4}}{8}+-\frac{\mu^{6}}{144}\right]\right)\right\} \\
H=C_{H} \rho A(\Omega R)^{2}
\end{gathered}
$$

It is important to perform two calculations for the H-force: one calculation as shown in Eq. (3.70) and one calculation with the lateral flapping, $a_{1_{s}}$, set to zero. The calculation with the lateral flapping set to zero is required for later use within the equilibrium equations (refer to Section 3.3.6). 
The main rotor torque coefficient is calculated using:

$$
\begin{aligned}
\frac{C_{Q}}{\sigma} & =\frac{\overline{c_{d}}}{8}\left(1+\mu^{2}-\frac{\mu^{4}}{8}\right)-\frac{a}{4}\left\{\frac { \lambda ^ { \prime } } { 1 + \frac { 3 \mu ^ { 2 } } { 2 } - \frac { 5 \mu ^ { 4 } } { 2 4 } } \left[\frac{\theta_{0}}{3}\left(2-\mu^{2}+\frac{4 \mu^{3}}{3 \pi}+\frac{7 \mu^{4}}{12}+\frac{14 \mu^{5}}{15 \pi}-\frac{\mu^{7}}{135 \pi}\right)\right.\right. \\
& \left.+\frac{\theta_{1}}{2}\left(1-\frac{\mu^{2}}{2}+\frac{5}{12} \mu^{4}+\frac{5}{48} \mu^{6}-\frac{1}{192} \mu^{8}\right)+\lambda^{\prime}\left(1-\frac{11}{24} \mu^{4}+\frac{\mu^{6}}{24}\right)\right] \\
& +\frac{\mu^{2}}{1+\frac{\mu^{2}}{2}-\frac{\mu^{4}}{24}}\left\{\frac{a_{0}^{2}}{2}\left[\frac{1}{9}+\frac{\mu^{2}}{4}-\frac{64}{135 \pi} \mu^{3}-\frac{\mu^{4}}{6}-\left(\frac{128}{45^{2} \pi^{2}}-\frac{1}{96}\right) \mu^{6}\right]\right. \\
& \left.\left.+a_{0} \frac{v_{1}}{\Omega R} \frac{\mu}{3}\left[1-\frac{8 \mu}{5 \pi}-\frac{\mu^{2}}{6}-\frac{8}{15 \pi} \mu^{3}+\frac{\mu^{5}}{45 \pi}\right]+\frac{1}{8}\left(\frac{v_{1}}{\Omega R}\right)^{2}\left[1-\frac{\mu^{2}}{2}-\frac{\mu^{4}}{8}+-\frac{\mu^{6}}{144}\right]\right\}\right\}
\end{aligned}
$$

Next, the combinations of cyclic pitch and flapping are calculated using:

$$
\begin{gathered}
B_{1}+a_{1_{s}}=\frac{\mu\left[\theta_{0}\left(\frac{8}{3}+\frac{32 \mu^{3}}{45 \pi}\right)+\theta_{1}\left(2+\frac{\mu^{4}}{12}\right)+\lambda^{\prime}\left(2-\frac{\mu^{2}}{2}\right)\right]}{1+\frac{3}{2} \mu^{2}-\frac{5 \mu^{4}}{24}} \\
A_{1}-b_{1_{s}}=-\frac{\left[a_{0}\left(\frac{4}{3} \mu+\frac{16}{45 \pi} \mu^{4}\right)+\frac{v_{1}}{\Omega R}\left(1+\frac{\mu^{4}}{24}\right)\right]}{1+\frac{\mu^{2}}{2}-\frac{\mu^{4}}{24}}
\end{gathered}
$$

Lastly, downwash produced by the main rotor must be accounted for. The main rotor wake skew angle is calculated using the following approximation:

$$
\chi=\tan ^{-1} \frac{V}{v_{1}}
$$

The main rotor uniform downwash is calculated using the following:

$$
D_{W O}=\frac{K_{C T} C_{T}}{2 \mu}\left[\frac{1}{1+\left(\frac{T_{D W O}}{\mu}\right) S}\right]
$$

where $K_{C T}$ is a gain factor of the harmonic inflow, $T_{D W O}$ is a time factor of the harmonic inflow, and $S$ is the area of an individual blade. The skew angle and uniform downwash are necessary for use with a variety of look-up tables in Section 3.3.3 through Section 3.3.5.

\subsubsection{Fuselage Calculations for Forward Flight}

The majority of the calculations performed for the fuselage are bypassed in favor of more accurate look-up tables derived from Howlett [22]. Using the look-up tables, the fuselage lift 
$\left(L_{F} / q_{F}\right)$, drag $\left(D_{F} / q_{F}\right)$, and pitching moment $\left(M_{F} / q_{F}\right)$ with respect to fuselage dynamic pressure are all extracted based on the fuselage angle of attack and assuming no fuselage sideslip ( $\beta_{F}=$ $0)$. Additionally, look-up tables are used to find the main rotor wash interference factors $\left(E K_{X W F}, E K_{Y W F}, E K_{Z W F}\right)$. The rotor wash at the fuselage is calculated using:

$$
\begin{gathered}
V_{X I W F}=E K_{X W F} D_{W O}(\Omega R) \\
V_{Y I W F}=0 \\
V_{Z I W F}=E K_{Z W F} D_{W O}(\Omega R)
\end{gathered}
$$

The fuselage velocity components are calculated in the following manner:

$$
\begin{aligned}
& V_{X W F}=u+V_{X G W F}+V_{X I W F} \\
& V_{Y W F}=v+V_{Y G W F}+V_{Y I W F} \\
& V_{Z W F}=w+V_{Z G W F}+V_{Z I W F}
\end{aligned}
$$

where $u, v$, and $w$ the aircraft velocity components in the body axes $(v \approx 0)$, and the gust components are assumed to be zero $\left(V_{X G W F}=V_{Y G W F}=V_{Z G W F}=0\right)$.

The dynamic pressure at the fuselage is calculated using:

$$
q_{F}=\frac{1}{2} \rho\left(V_{X W F}^{2}+V_{Y W F}^{2}+V_{Z W F}^{2}\right)
$$

The angle of attack at the fuselage is recalculated using:

$$
\alpha_{F}=\tan ^{-1}\left(\frac{V_{Z W F}}{\left|V_{X W F}\right|}\right)
$$

Lastly, the fuselage forces and moments can now be calculated using the following matrix format:

$$
\left[\begin{array}{c}
X_{F} \\
Y_{F} \\
Z_{F}
\end{array}\right]=\left[\begin{array}{ccc}
\cos \alpha_{F} \cos \beta_{F} & \cos \alpha_{F} \sin \beta_{F} & -\sin \alpha_{F} \\
\sin \beta_{F} & -\cos \beta_{F} & 0 \\
\sin \alpha_{F} \cos \beta_{F} & \sin \alpha_{F} \sin \beta_{F} & \cos \alpha_{F}
\end{array}\right]\left[\begin{array}{l}
-\frac{D_{F}}{q_{F}} q_{F} \\
-\frac{Y_{F}}{q_{F}} q_{F} \\
-\frac{L_{F}}{q_{F}} q_{F}
\end{array}\right]
$$




$$
\left[\begin{array}{c}
R_{F} \\
M_{F} \\
N_{F}
\end{array}\right]=\left[\begin{array}{ccc}
\cos \alpha_{F} \cos \beta_{F} & \cos \alpha_{F} \sin \beta_{F} & -\sin \alpha_{F} \\
\sin \beta_{F} & -\cos \beta_{F} & 0 \\
\sin \alpha_{F} \cos \beta_{F} & \sin \alpha_{F} \sin \beta_{F} & \cos \alpha_{F}
\end{array}\right]\left[\begin{array}{c}
\frac{R_{F}}{q_{F}} q_{F} \\
-\frac{M_{F}}{q_{F}} q_{F} \\
\frac{N_{F}}{q_{F}} q_{F}
\end{array}\right]+\left[\begin{array}{c}
-Y_{F} h_{f}+Z_{F} y_{F} \\
-Z_{F} l_{F}+X_{F} h_{F} \\
Y_{F} l_{F}-X_{F} y_{F}
\end{array}\right]
$$

where $\beta_{F}=0$ and $Y_{F} / q_{F}=R_{F} / q_{F}=N_{F} / q_{F}=0$.

\subsubsection{Empennage Calculations for Forward Flight}

The first step in modeling the empennage is determining the appropriate angle of incidence for the horizontal stabilizer $\left(i_{H}\right)$. The angle of incidence is determined using a control system outlined in Appendix A:. Since the pitch rate $(q)$ and lateral acceleration $\left(a_{Y}\right)$ of the helicopter are assumed to be zero at forward flight, the angle of incidence for the horizontal stabilizer becomes a function of forward velocity in the body axes $(u)$ and collective stick input $\left(\delta_{c_{p}}\right)$. Therefore, accurately modeling the main rotor collective is of key importance for modeling the horizontal stabilizer.

The remainder of the modeling process for the empennage is taken directly from Howlett [22]. To prevent redundancy, the equations and look-up tables for the empennage will not be explained in this report.

\subsubsection{Tail Rotor Calculations for Forward Flight}

The tail rotor is probably the most complex subsystem to model at forward flight conditions. As mentioned previously, the tail rotor of the UH-60 helicopter is canted at an angle of $20^{\circ}$, as seen in Figure 3.5. This makes it very difficult to accurately model the tail rotor inflow, particularly at low forward speeds. In the end, a variety of modeling approaches are used from several different technical reports and textbooks, including Prouty [2], Howlett [22], Hilbert [24], and Ballin [25]. The following assumptions are used in the modeling of the tail rotor:

- Tip loss and root cutout are ignored.

- Compressibility losses and tip relief are ignored.

- A constant blade element drag coefficient is used

- Uniform inflow is assumed across the main rotor disk 
First, the tail rotor thrust is calculated using the yaw equilibrium equation, which must now account for lateral forces produced by the vertical tail:

$$
\begin{gathered}
Q_{M}-l_{T} Y_{T}-l_{V} Y_{V}=0 \\
Y_{T}=\frac{Q_{M}}{l_{T}}-Y_{V} \frac{l_{V}}{l_{T}} \\
T_{T}=\frac{Y_{T}}{\cos \Gamma_{\mathrm{T}}}
\end{gathered}
$$

Next, the tail rotor coning angle is calculated as a function of the tail rotor thrust:

$$
a_{0_{T}}=T_{T} \frac{\partial a_{0_{T}}}{\partial T_{T}}
$$

where $\partial a_{0_{T}} / \partial T_{T}$ is the rate of change of coning with respect to thrust.

Next, the main rotor wash factors $\left(E K_{X T R}, E K_{Y T R}, E K_{Z T R},\right)$ are calculated using look-up tables from Howlett [22]. Using the wash factors, the main rotor interference velocities are calculated as follows:

$$
\begin{gathered}
V_{X M R T R}=E K_{X T R} D_{W O}(\Omega R) \\
V_{Y M R T R}=E K_{Y T R} D_{W O}(\Omega R)=0 \\
V_{Z M R T R}=E K_{Z T R} D_{W O}(\Omega R)
\end{gathered}
$$

Next, the dynamic pressure ratio at the tail rotor $\left(q_{T R}\right)$, fuselage sidewash at the tail rotor $\left(S_{I G T R}\right)$, and fuselage downwash at the tail rotor $\left(E_{P S T R}\right)$ are all calculated using look-up table data from Howlett [22]. The associated fuselage interference velocities are calculated using:

$$
\begin{aligned}
& V_{Y W F T R}=-\frac{u}{57.3} S_{I G T R} \sqrt{q_{T R}} \\
& V_{Z W F T R}=-\frac{u}{57.3} E_{P S T R} \sqrt{q_{T R}}
\end{aligned}
$$

The tail rotor interference velocities from the main rotor and fuselage are summed as follows:

$$
\begin{gathered}
V_{X I T R}=V_{X M R T R} \\
V_{Y I T R}=V_{Y M R T R}+V_{Y W F T R} \\
V_{Z I T R}=V_{Z M R T R}+V_{Z W F T R}
\end{gathered}
$$

The tail rotor velocities in the body axis are:

$$
V_{X T R}=\left(u+V_{X G W F}\right) \sqrt{q_{T R Q W F}}-q h_{T}+r y_{T}+V_{X I T R}
$$




$$
\begin{aligned}
& V_{Y T R}=\left(v+V_{Y G W F}\right) \sqrt{q_{T R Q W F}}-r l_{T}+p h_{T}+V_{Y I T R} \\
& V_{Z T R}=\left(w+V_{Z G W F}\right) \sqrt{q_{T R Q W F}}-q l_{T}-p y_{T}+V_{Z I T R}
\end{aligned}
$$

where the lateral velocity component of the aircraft is assumed to be zero $(v \approx 0)$, the aircraft roll, pitch, and yaw rates are assumed to be zero ( $p=q=r=0)$, and the gust components are assumed to be zero $\left(V_{X G W F}=V_{Y G W F}=V_{Z G W F}=0\right)$.

Next, because the tail rotor is canted it is necessary to introduce a new axes system, termed the cant axes system (AKA the shaft axes system):

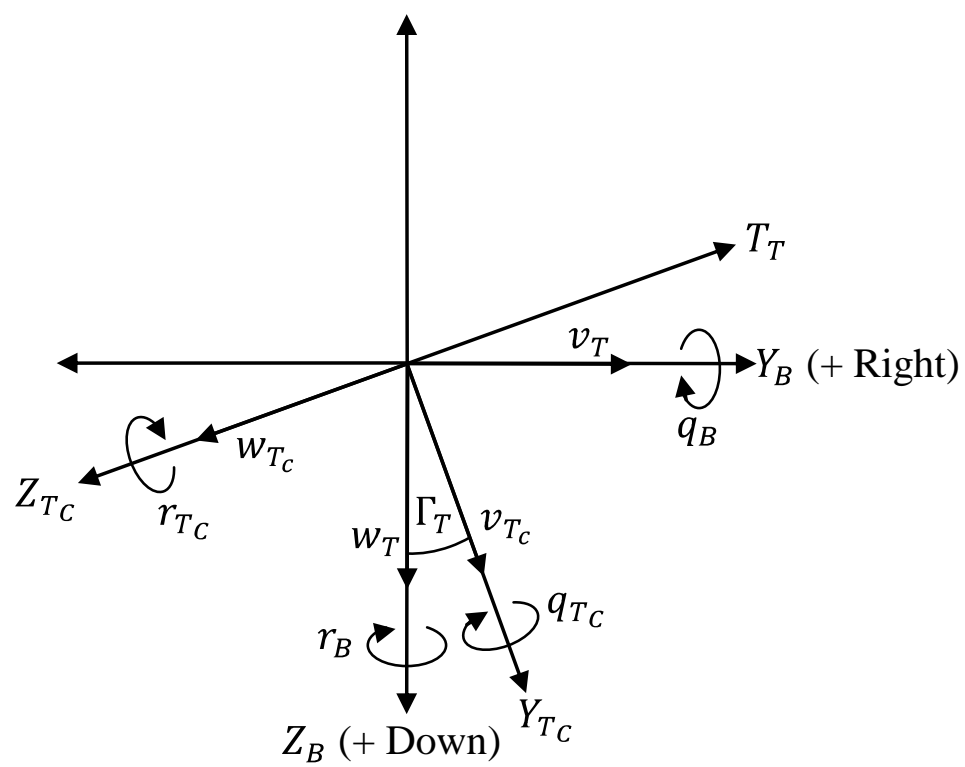

Figure 3.10: Tail Rotor Cant Axes System

In Figure 3.10, the subscript $B$ denotes the body axes system and the subscript $C$ denotes the cant axes system.

The tail rotor velocities are now converted from the body axes system to the cant axes system:

$$
\begin{gathered}
u_{T_{C}}=V_{X T R} \\
v_{T_{C}}=V_{Y T R} \sin \Gamma_{T}+V_{Z T R} \cos \Gamma_{T} \\
w_{T_{C}}=-V_{Y T R} \cos \Gamma_{T}+V_{Z T R} \sin \Gamma_{T}
\end{gathered}
$$

The tip speed ratio for the tail rotor is now calculated in the cant axes system using:

$$
\mu_{T_{C}}=\sqrt{\frac{u_{T_{C}}{ }^{2}+v_{T_{C}}{ }^{2}}{(\Omega R)_{T}}}
$$


A loop is then built to solve for the tail rotor inflow ratio using:

$$
\lambda_{T}=\frac{w_{T_{C}}}{(\Omega R)_{T}}-\frac{C_{T_{T}}}{2 \sqrt{\mu_{T_{C}{ }^{2}+\lambda_{T}{ }^{2}}}}
$$

The tail rotor flapping and collective pitch can now be calculated. It is important to note that the tail rotor is flapping without cyclic pitch. The tail rotor is controlled completely by the collective pitch. Due to this fact, the tail rotor of the UH-60 helicopter is designed with a mechanical coupling between flapping and blade pitch such that a change in flapping produces a change in blade pitch:

$$
\Delta \theta=\Delta \beta \tan \delta_{3}
$$

where $\beta$ represents the overall flapping motion of the rotor and $\delta_{3}$ is the slant angle of the flapping hinge, as shown in Figure 3.11:

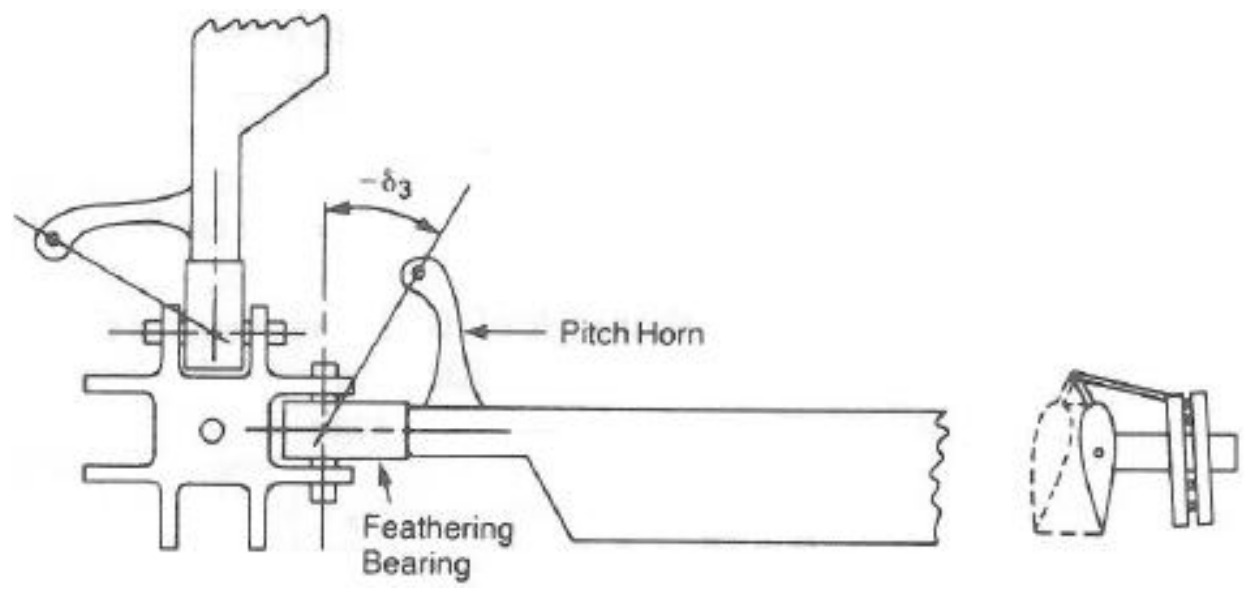

Figure 3.11: Tail Rotor Mechanical Control System [2]

Incorporating the slant angle and using the tail rotor inflow and tip speed ratio in the cant axes system, the flapping equations for the tail rotor become:

$$
\begin{gathered}
N U M a_{1_{s}}=\frac{4 \mu_{T_{C}}}{2+3 \mu_{T_{C}}{ }^{2}}\left\{\frac{4}{2+3 \mu_{T_{C}}{ }^{2}}\left[\left(\frac{4 C_{T_{T}}}{a_{T} \sigma_{T}}-\lambda_{T}\right)-\left(1+\mu_{T_{C}}{ }^{2}\right) \frac{\theta}{2}\right]+\theta_{1}+\lambda_{T}\right\} \\
-2\left[\frac{\frac{4}{3} \mu_{T_{C}} a_{0_{T}}-\lambda_{T}}{2+\mu_{T_{C}}}\right]\left[1-\left(\frac{4 \mu_{T_{C}}}{2+3 \mu_{T_{C}}{ }^{2}}\right)^{2}\right] \tan \delta_{3} \\
D E N a_{1_{s}}=\frac{2-\mu_{T_{C}}{ }^{2}}{2+3 \mu_{T_{C}}{ }^{2}}+\left[1-\left(\frac{4 \mu_{T_{C}}}{2+3 \mu_{T_{C}}{ }^{2}}\right)^{2}\right]\left(\tan \delta_{3}\right)^{2}
\end{gathered}
$$




$$
\begin{gathered}
a_{1_{s}}=\frac{N U M a_{1_{s}}}{D E N a_{1_{s}}} \\
b_{1_{s}}=2\left[\frac{\frac{4}{3} \mu_{T_{C}} a_{0_{T}}-\lambda_{T}}{2+\mu_{T_{C}}}\right]+a_{1_{s}} \tan \delta_{3}
\end{gathered}
$$

It should be noted that due to the length of the lateral flapping equation, the numerator and denominator of the equation were separated.

The tail rotor collective pitch can now be calculated using:

$$
\theta_{0_{\mathrm{T}}}=\frac{\frac{4 C_{T_{T}}}{a_{T} \sigma_{T}}-\left(\frac{1}{2}+\frac{\mu_{T_{C}}{ }^{2}}{2}\right) \theta_{1}+\mu_{T_{C}} b_{1_{s}} \tan \delta_{3}-\lambda_{T}}{\frac{2}{3}+\mu_{T_{C}}{ }^{2}}
$$

The tail rotor torque can now be calculated using the approach outlined by Ballin [25], which was developed using unpublished Sikorsky documentation. This approach uses 20 separate coefficients to accurately model the tail rotor torque coefficient.

Lastly, the tail rotor $\mathrm{H}$-force is calculated as a function of tail rotor hub drag, as documented by Howlett [22] and Ballin [25]:

$$
\mathrm{H}_{\mathrm{T}}=-\mathrm{C}_{\mathrm{D}_{\mathrm{T}}} \frac{1}{2} \rho V_{X T R}^{2}
$$

where $\mathrm{CD}_{\mathrm{T}}$ is the tail rotor hub drag.

\subsubsection{Calculations of Euler Angles for Forward Flight}

The Euler angles can now be calculated using the equilibrium equations. First, the angle of attack of the tip path plane is recalculated as follows:

$$
\alpha_{T P P}=\theta_{e}+a_{1_{s}}+i_{M} \doteq-\left(\frac{H_{a_{1_{s_{M}}=0}}+H_{T}-X_{H}-X_{V}-X_{F}}{G W+Z_{H}+Z_{F}}\right)
$$

The lateral flapping angle for the main rotor is calculated using the following approximation:

$$
\mathrm{a}_{1_{\mathrm{s}}}=\frac{T_{M} l_{M}-H_{a_{1_{M}=0}} h_{M}+Q_{T}-H_{T} h_{T}+L_{H} l_{H}-Z_{H} h_{H}+X_{H} l_{H}+X_{V} h_{V}-Z_{F} l_{F}+X_{F} h_{F}-M_{F}+T_{T} \sin \left(\Gamma_{T}-b_{1_{s_{T}}}\right) l_{T}}{\left(\frac{d M}{d_{a_{1}}}\right)_{M}+T_{M} h_{M}}
$$

The aircraft pitch angle can now be calculated by modifying Eq. (3.114) above:

$$
\theta_{e}=\alpha_{T P P}-a_{1_{s}}-i_{M}
$$

Next, the main rotor thrust is recalculated using a more accurate approach: 


$$
T_{M}=\frac{G W-T_{T} \sin \left(\Gamma_{T}\right)}{(1-0.034) \cos \left(\alpha_{T P P}\right)}
$$

The longitudinal flapping angle for the main rotor is calculated using the following approximation:

$$
b_{1_{s}}=-\frac{Z_{M} y_{M}+Y_{T} h_{T}+Y_{V} h_{V}}{\left(\frac{d R}{d b_{1_{s}}}\right)_{M}+T_{M} h_{M}}
$$

Lastly, the aircraft roll angle can now be calculated using:

$$
\phi_{e}=\frac{T_{M} b_{1_{s}}+Y_{T}+Y_{V}}{-G W}
$$

This process is iterated until convergence is reached for the angle of attack of the tip path plane, the main rotor thrust, and the aircraft Euler angles.

\subsubsection{Control Inputs}

The control inputs are now calculated using an identical approach to the one outlined in Section 3.2.3.

\subsubsection{Stability and Control Derivatives and State-Space Representation}

The stability and control derivatives are calculated for individual subsystems using the formulas developed by Prouty [2]. Additional data for a wide variety of partial derivatives is also required to use this approach. These partial derivatives are found using the look-up charts provided by Prouty [2]. The stability and control derivatives are then combined to form the total derivatives, as described in Section 3.1.3. Lastly, the total derivatives are inserted into the statespace matrices defined by Eq. (3.23) and Eq. (3.24). Now that the helicopter system is defined in state-space format, the matrices can be incorporated into the WVU Flight Simulator for further analysis. 


\subsection{Linear Model Validation}

\subsubsection{Background}

Before exploring the possible benefits of individual blade control, the linear model of the swashplate-based UH-60 Black Hawk helicopter must first be validated. To verify the accuracy of this linear model (also known as the WVU UH-60 linear model) research data were accumulated for a variety of UH-60 Black Hawk models. Unfortunately, simulation models and data for the UH-60 are scarce. Furthermore, the UH-60 helicopter design has undergone numerous changes over the last 30 years. Therefore, the data that is available is difficult to compare. Ultimately, two models were selected for comparison with the WVU linear model from the following reports:

- "A Mathematical Model of the UH-60 Helicopter" [24], (Hilbert Model)

- "Validation of a Real-Time Engineering Simulation of the UH-60A Helicopter" [25], (Gen Hel Model)

\subsubsection{Comparison \#1: Hilbert Model (Ames - 1984)}

The WVU UH-60 linear model is first compared to a UH-60 mathematical model developed by Hilbert [24] at the Ames Research Center in 1984. This model will be identified as the Hilbert model for the remainder of this report. The Hilbert model was developed by linearizing the non-linear UH-60 model originally developed by Howlett [22] around specific trim conditions. Some fundamental differences are present between the WVU UH-60 linear model and the Hilbert model. Specifically, the Hilbert model is simulated with high levels of stability augmentation produced by the UH-60 control system. Many of the features of the UH60 control system are ignored in the WVU UH-60 linear model because they could not be effectively incorporated. However, one exception is the control system for the horizontal stabilizer. The control system for the horizontal stabilizer, which is shown in Appendix A:, is a critical system for accurately modeling the Black Hawk helicopter. The remaining control and augmentation systems are ignored in the WVU UH-60 linear model.

Also, the WVU UH-60 linear model was developed assuming steady, symmetric, straight, and level flight for all flight conditions. In other words, since sideslip is assumed to be zero, velocity is not present in the lateral y-direction $\left(v_{B} \approx 0\right)$. The Hilbert model does not 
adhere to these general assumptions for all forward speeds. The data presented in Table 3.1 describes the level flight trim characteristics derived from the Hilbert math model.

Table 3.1: Level Flight Trim Characteristics (Hilbert UH-60 Math Model)

\begin{tabular}{|c|c|c|c|c|c|c|c|}
\hline \multirow{2}{*}{$\begin{array}{c}\text { Engineering } \\
\text { Symbol }\end{array}$} & \multicolumn{6}{|c|}{ Equivalent Airspeed (knots) } & \multirow{2}{*}{ Units } \\
\hline & 1.0 & 20.0 & 40.0 & 60.0 & 100.0 & 140.0 & \\
\hline$\delta_{e}$ & 0.1266 & -0.3670 & -0.2083 & -0.4238 & -1.063 & -1.800 & in. \\
\hline$\delta_{a}$ & 0.2321 & -0.9956 & -0.7560 & -0.2322 & 0.1812 & 0.3964 & in. \\
\hline$\delta_{c}$ & 5.719 & 5.361 & 4.580 & 4.194 & 4.425 & 5.718 & in. \\
\hline$\delta_{p}$ & -1.279 & -1.066 & -0.5830 & -0.5802 & -0.2606 & -0.005715 & in. \\
\hline$v_{B}$ & -0.006069 & -0.08037 & -0.08960 & 9.989 & 7.996 & 8.813 & $\mathrm{ft} / \mathrm{sec}$ \\
\hline$w_{B}$ & 0.1485 & 3.430 & 5.108 & 6.133 & 7.264 & -1.235 & $\mathrm{ft} / \mathrm{sec}$ \\
\hline$\theta$ & 5.052 & 5.834 & 4.340 & 3.489 & 2.469 & -0.2996 & deg \\
\hline$\phi$ & -2.340 & -1.342 & -1.005 & 0 & 0 & 0 & deg \\
\hline
\end{tabular}

It can be seen in Table 3.1 that the lateral velocities components $\left(v_{B}\right)$ are approximately zero at airspeeds of 40 knots and below. At airspeeds of 60 knots and above, the lateral velocity increases somewhat due to effects of various stability augmentation control systems. It is not entirely clear which stability augmentation system are active in the Hilbert model. However, the effects of these augmentation systems are clearly evident as the roll angle is offset to zero at airspeeds of 60 knots and above. The differences in velocity components will produce some variations in the aircraft Euler angles when comparing the two models.

The Hilbert report also compares the UH-60 math model to a similar model developed by Boeing-Vertol for the Advanced Digital/Optical Control System (ADOCS) program. The data introduced in Table 3.2 presents the level flight trim characteristics derived from the BoeingVertol math model.

Table 3.2: Level Flight Trim Characteristics (Boeing-Vertol UH-60 Math Model)

\begin{tabular}{|c|c|c|c|c|c|c|c|}
\hline \multirow{2}{*}{$\begin{array}{c}\text { Engineering } \\
\text { Symbol }\end{array}$} & \multicolumn{6}{|c|}{ Equivalent Airspeed (knots) } & \multirow{2}{*}{ Units } \\
\hline & 0.5 & 20.0 & 40.0 & 60.0 & 100.0 & 140.0 & \\
\hline$\delta_{e}$ & 1.1947 & 0.5938 & 0.3636 & 0.5149 & -0.5356 & -1.0539 & in. \\
\hline$\delta_{a}$ & 0.4393 & -0.7920 & -0.7106 & -0.3199 & -0.1098 & -0.0917 & in. \\
\hline$\delta_{c}$ & 5.3976 & 5.0054 & 4.2440 & 3.8582 & 4.2054 & 5.6883 & in. \\
\hline$\delta_{p}$ & -0.2598 & -0.2409 & -0.05631 & -0.1254 & 0.0974 & 0.1798 & in. \\
\hline$v_{B}$ & 0 & 0 & 0 & 13.165 & 9.4517 & 11.308 & $\mathrm{ft} / \mathrm{sec}$ \\
\hline$w_{B}$ & 0 & 4.0507 & 6.5824 & 3.8820 & 4.8946 & -13.840 & $\mathrm{ft} / \mathrm{sec}$ \\
\hline$\theta$ & 5.1186 & 6.9262 & 5.5167 & 2.2425 & 1.6799 & -3.3533 & deg \\
\hline$\phi$ & -2.5666 & -1.6093 & -1.2929 & 0 & 0 & 0 & $\operatorname{deg}$ \\
\hline
\end{tabular}

The Boeing-Vertol data displays a good correlation to the Hilbert data. Similar to Table 3.1, the lateral velocities components of the Boeing-Vertol model are zero at airspeeds of 40 
knots and below. At airspeeds of 60 knots and above, the lateral velocity increases somewhat due to stability augmentation control systems. Once again, the lateral velocity components differ from the WVU linear model, and the differences will produce some variations in the aircraft Euler angles.

The WVU UH-60 linear model is now compared to the Hilbert and Boeing-Vertol models using the data presented in Table 3.1 and Table 3.2. Identical aircraft characteristics were used in the comparison of these models:

- Gross Weight: $16400 \mathrm{lb}$.

- CG Stationline: 360.4 in.

- CG Waterline: 247.2 in.

- Altitude Density: 0.002377 slugs $/ \mathrm{ft}^{3}$

The comparative results are shown in Figure 3.12 through Figure 3.14. The lines describing the WVU UH-60 linear model are developed by running the forward flight model at velocity increments of ten knots and plotting the spline interpolation of the data. Data at zero knots was prepared using the hover model.

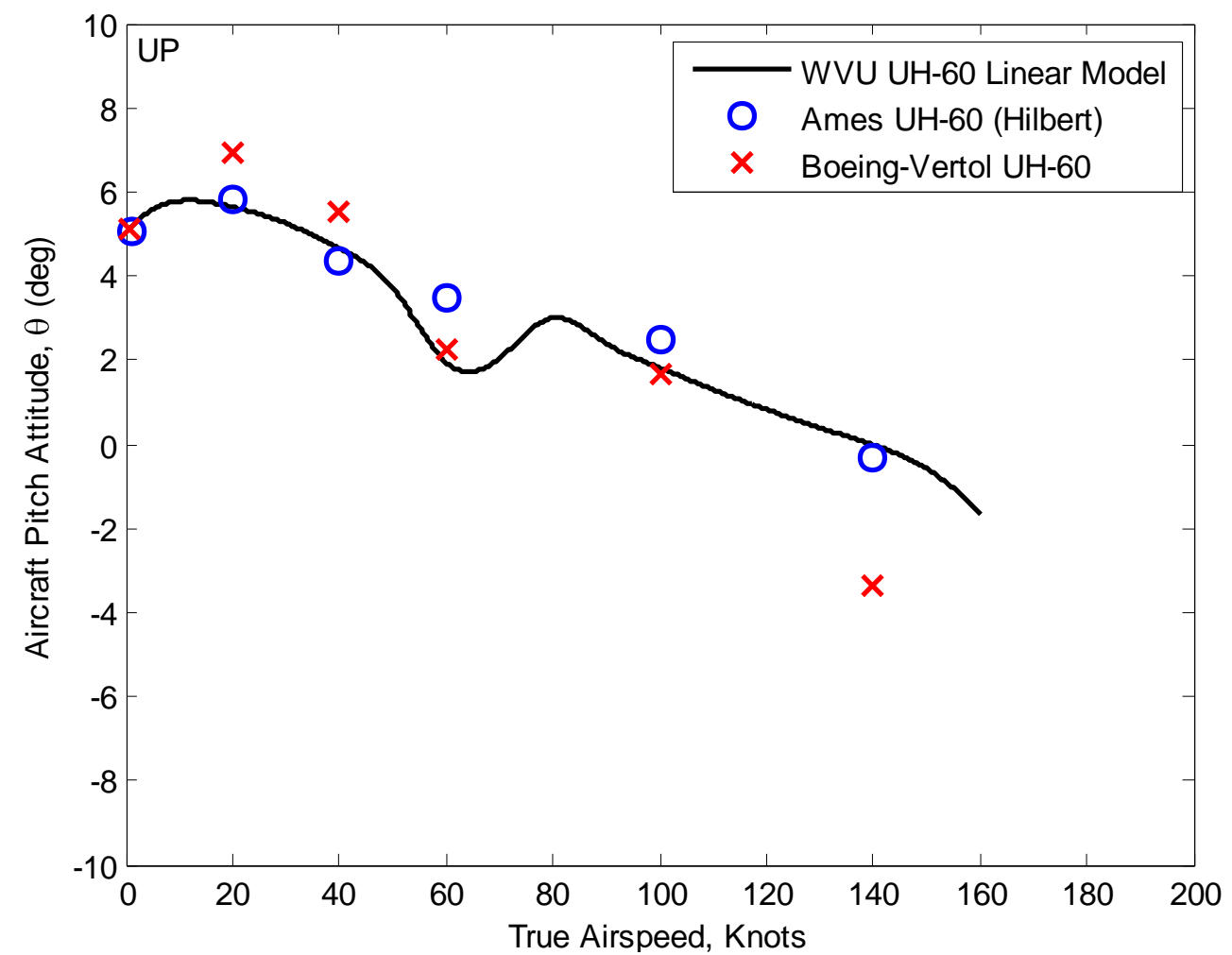

Figure 3.12: Hilbert Model Comparison (Aircraft Pitch Attitude) 


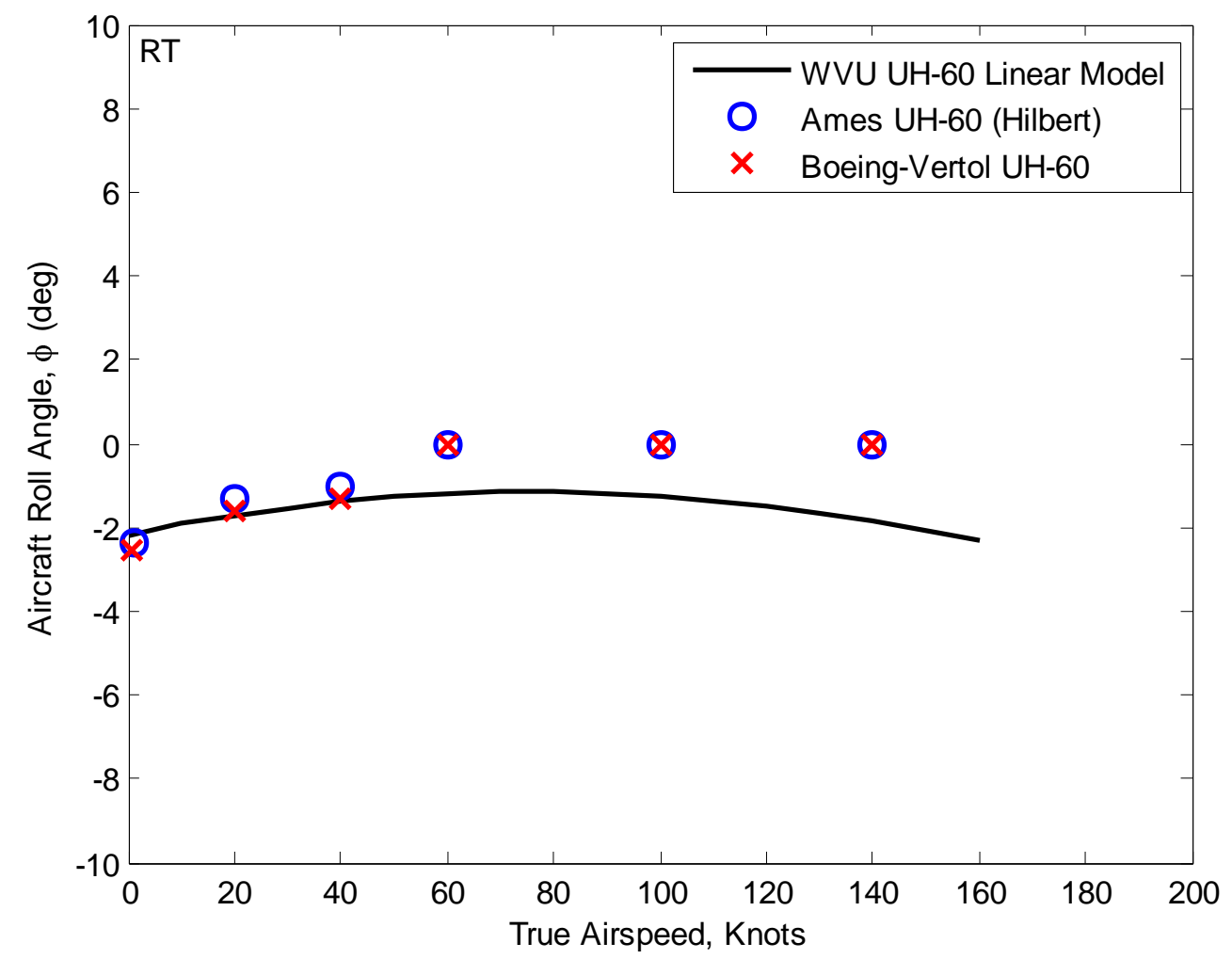

Figure 3.13: Hilbert Model Comparison (Aircraft Roll Angle) 

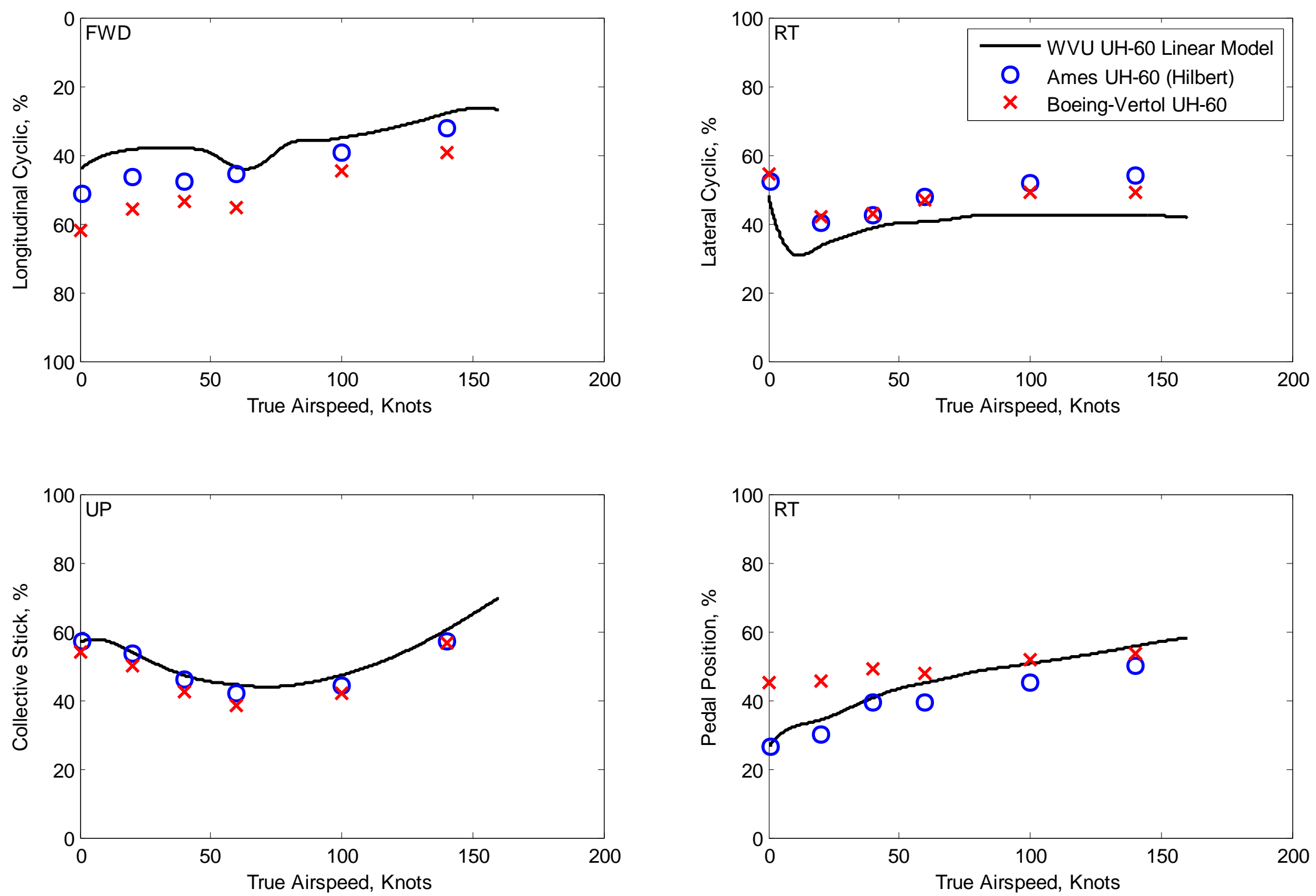

Figure 3.14: Hilbert Model Comparison (Cockpit Controls) 
The WVU UH-60 linear model shows reasonably good correlation with Hilbert model and Boeing-Vertol model for the aircraft Euler angles and the cockpit controls. The hover results are virtually identical when comparing the data for all three models. The forward flight results are also very good, but some variations can be seen due to variations in model assumptions and control schemes.

The aircraft pitch attitude, shown in Figure 3.12, matches up particularly well with the Hilbert model. At both high speeds and low speeds (less than 30 knots) the WVU UH-60 linear model shows very good correlation with the Hilbert data. As mentioned previously, the induced velocity distribution becomes very complex and difficult to model at low speeds. Due to this complex flow, accuracy of the pitch attitude was expected to decrease in this range of the flight envelope. Contrary to the expected results, the pitch attitude shows very good correlation with the Hilbert data at low speeds.

Similarly, the aircraft roll angle of the WVU UH-60 linear model, shown in Figure 3.13, is excellent at low speeds when compared to the other two models. At higher speeds (60 knots and above) the roll angle of the WVU UH-60 model begins to diverge slightly from the other two models. As mentioned before, the Hilbert and Boeing-Vertol models incorporate a control system that fixes the aircraft roll angle to zero at speeds of 60 knots and above, while also incorporating a lateral velocity component. The WVU UH-60 linear model does not incorporate this control system, so the roll angle tends to dwell around $-2^{\circ}$ at all forward speeds.

The cockpit controls of the WVU UH-60 linear model, shown in Figure 3.14, show reasonably good correlation with the other two models. The collective stick of the WVU UH-60 linear model matches up particularly well with the Hilbert model for all forward speeds.

Differences in the longitudinal and lateral cyclic are present mainly due to reasons previously described. Control system disparity that resulted in variations of the roll angle will also result in variations in the lateral cyclic control. Furthermore, the longitudinal cyclic of the Hilbert model is also affected by a pitch bias actuator (PBA). The PBA is a variable length control rod which changes the relationship between longitudinal cyclic control and swashplate tilt as a function of three flight parameters: pitch attitude, pitch rate, and airspeed. The main purpose of the PBA is to improve the apparent static longitudinal stability of the aircraft [24]. The PBA control system is not present in the WVU UH-60 linear model, resulting in some disparity of the longitudinal cyclic data. Furthermore, inherent control coupling between the 
lateral and longitudinal cyclic means that variation in one control input will also produce variation in the other control input.

The differences in the pedal positions are more obvious for all three models. At lower speeds, the pedal positions of the Hilbert and Boeing-Vertol model vary by as much as nineteen percent. The error in pedal position between the two models reduces as forward speed is increased. In comparison, the pedal position of the WVU UH-60 linear model matches up well with the Hilbert model at low speeds. Above 60 knots, minor differences are once again evident due disparity in the control systems.

Another reason for differences in both Euler angles and cockpit controls is that the WVU UH-60 model was developed using a number of modeling assumptions. For example, the WVU UH-60 linear model uses a constant blade drag coefficient for the span of the entire rotor blade. Also, tip loss and root cutout are ignored and a uniform inflow is assumed for the main rotor. Despite the differences in the model assumptions and control system architecture, the WVU UH60 linear model shows reasonably good correlation with both the Hilbert model and the BoeingVertol model.

The Hilbert report also presents a data comparison with Boeing-Vertol for the stability and control derivatives. Comparison of this data, along with the stability and control derivatives for the WVU UH-60 linear model, are presented in Appendix B:. It should be noted that many of the calculated derivatives from the Hilbert report are with respect to joystick deflections in the cockpit. The derivatives of the WVU UH-60 linear model are calculated with respect to the rotor hub deflections, so a direct comparison could not be made for some derivatives.

\subsubsection{Comparison \#2: Gen Hel Model (Ames - 1987)}

The WVU UH-60 linear model is also compared to a UH-60 mathematical model prepared by Ballin [25] at the Ames Research Center in 1987. This model will be identified as the Gen Hel model for the remainder of this report. The Gen Hel model is a nonlinear representation of a single main rotor helicopter that is accurate for a full range of angles of attack, sideslip, and rotor inflow. A general six degree-of-freedom trimming algorithm was used to determine iteratively the steady-state flight conditions by adjusting aircraft attitude and control positions to zero all net forces and moments acting on the aircraft [25]. Furthermore, the Ballin report compares the Ames Gen Hel trim data with trim data produced by Sikorsky's Gen Hel 
model, as well as USAAEFA (United States Army Aviation Engineering Flight Activity) flight test data of the UH-60 helicopter under similar operating conditions.

The Ames Gen Hel and Sikorsky Gen Hel models produce virtually identical results, and both show excellent correlation with the USAAEFA flight test data. As noted by Ballin:

Agreement between the simulation and the flight test is good except for a nearly constant pedal bias of approximately 0.5 in. to the right. There is less agreement at lower speeds, caused in part by the pilot's difficulty in achieving trimmed flight on the back side of the power-required curve and also by the simplified modeling of the impingement of the main rotor downwash on the fuselage and stabilator. This also results in an underestimation of collective stick trim position by both simulations when in hover [25].

Since the results of the two Gen Hel models are virtually identical, they will be considered one data set for comparison with the WVU UH-60 linear model.

Similar to the previous comparison, the Gen Hel models differ somewhat from the WVU UH-60 linear model. First, the WVU UH-60 linear model was developed assuming steady, symmetric, straight and level flight for all aircraft conditions. The sideslip and climb angles are assumed to be zero for the WVU model. The Gen Hel models, on the other hand, do not adhere to these same assumptions. While steady, level flight is assumed, varying degrees of sideslip are incorporated into the model as the helicopter increases forward speed. The variation in sideslip will result in differences between the two models.

The WVU UH-60 linear model is now compared to the Gen Hel models and the USAAEFA flight test using the data presented in the report by Ballin [25]. Level-flight trim data for the Gen Hel models were determined for airspeeds from 0 to 160 knots in 10-knot increments. Identical aircraft characteristics were used in the comparison of these models:

- Gross Weight: 16000 lb.

- CG Stationline: 351.0 in.

- CG Waterline: 231.5 in.

- Altitude Density: $0.0024475 \mathrm{slugs} / \mathrm{ft}^{3}\left(\right.$ alt. $\left.=5250 \mathrm{ft}, \mathrm{T}=17^{\circ} \mathrm{C}\right)$

The comparative results are shown in Figure 3.15 through Figure 3.19. Similar to the Gen Hel data, level-flight data for the WVU UH-60 linear model is developed by running the forward flight model at velocity increments of ten knots and plotting the spline interpolation of the data. Data at zero knots is derived using the hover model. 


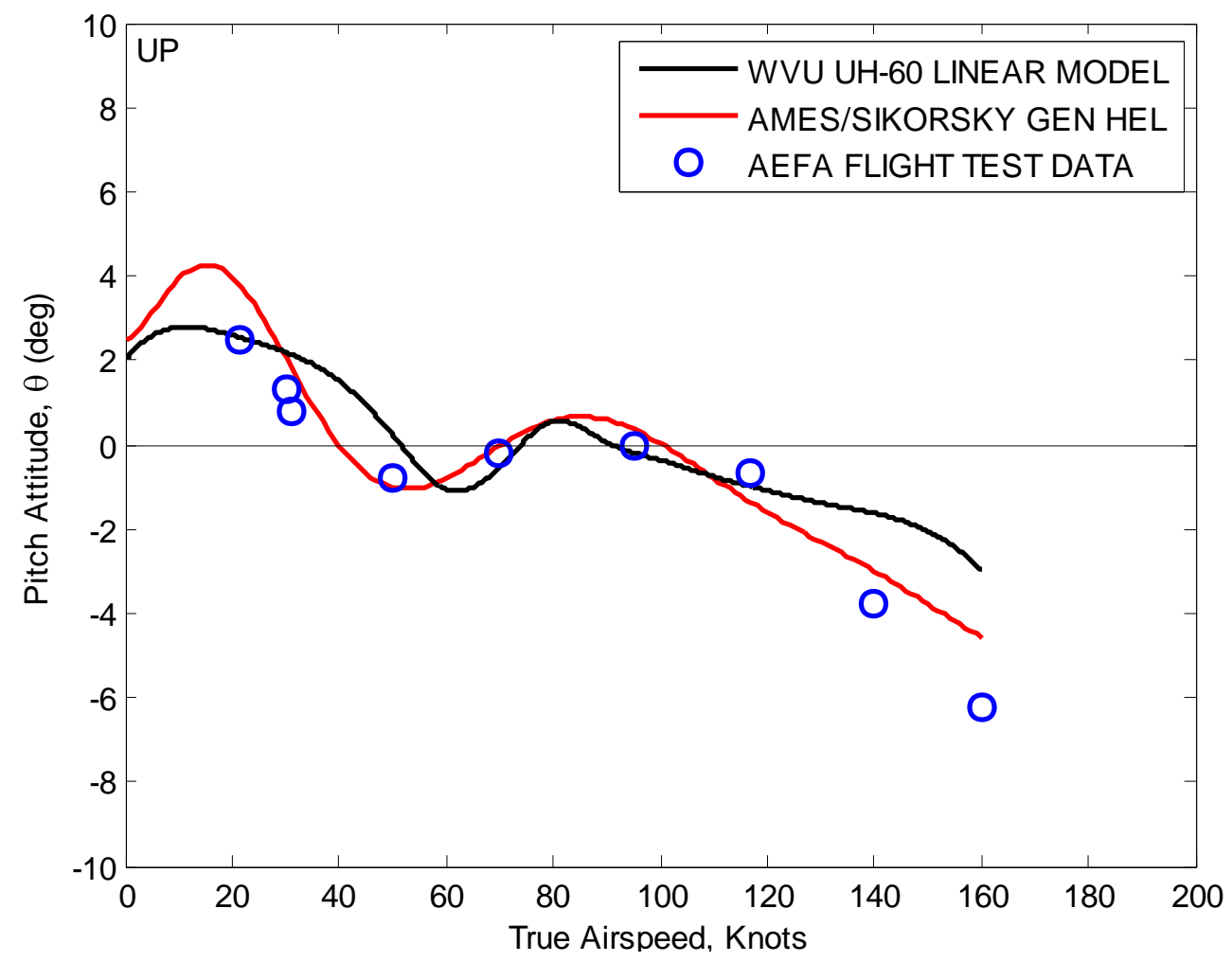

Figure 3.15: Gen Hel Model Comparison (Aircraft Pitch Attitude)

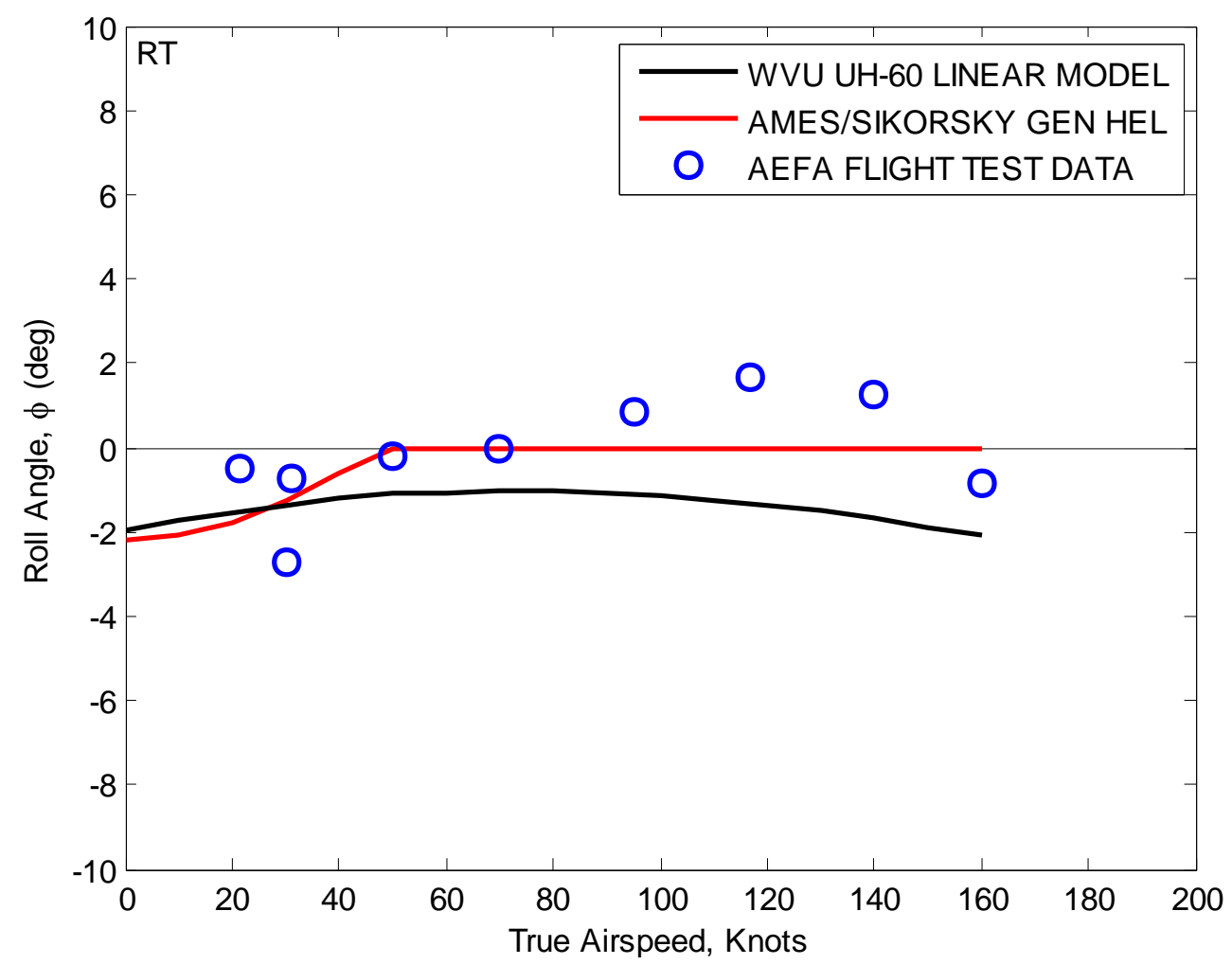

Figure 3.16: Gen Hel Model Comparison (Aircraft Roll Angle) 


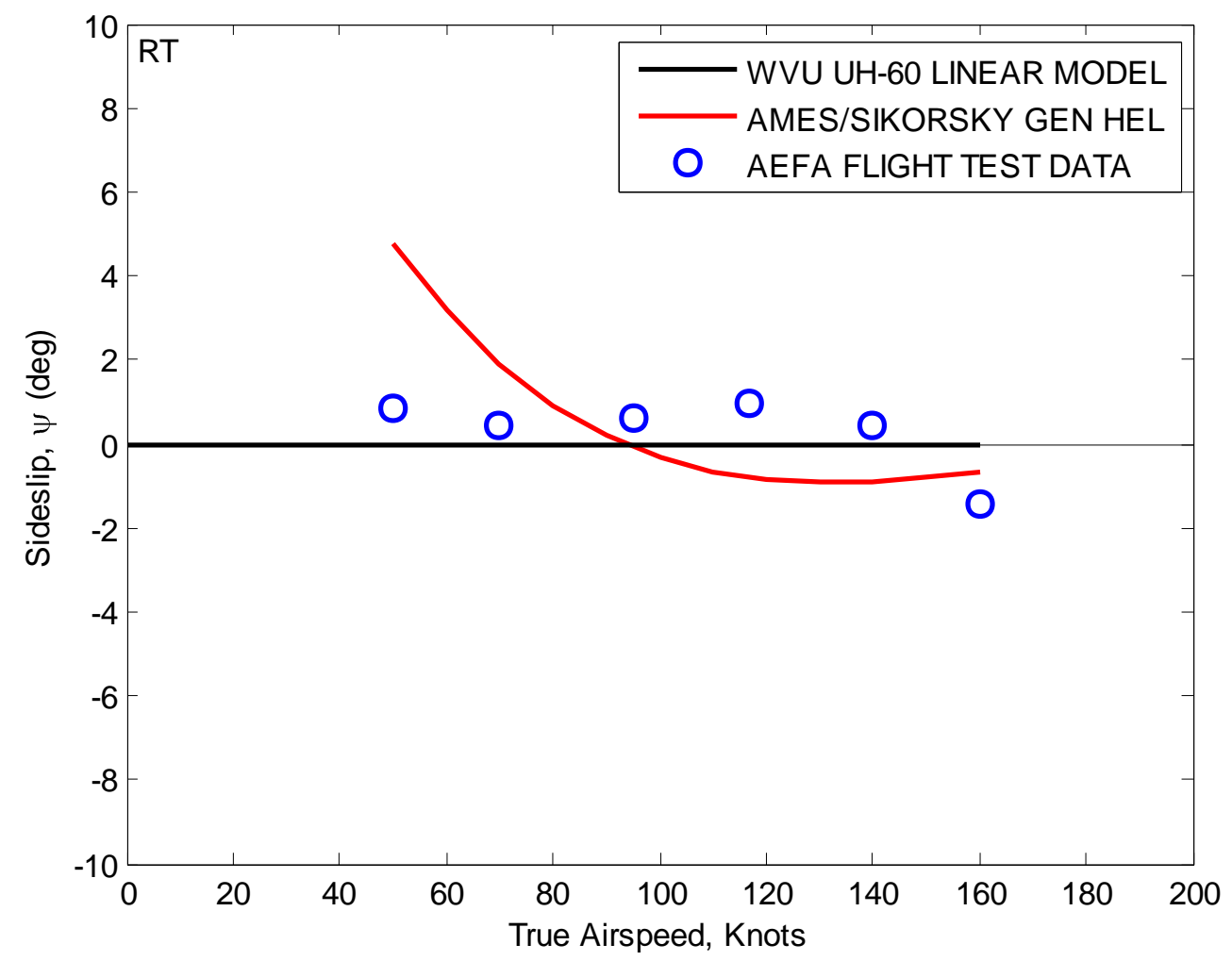

Figure 3.17: Gen Hel Model Comparison (Aircraft Sideslip Angle)

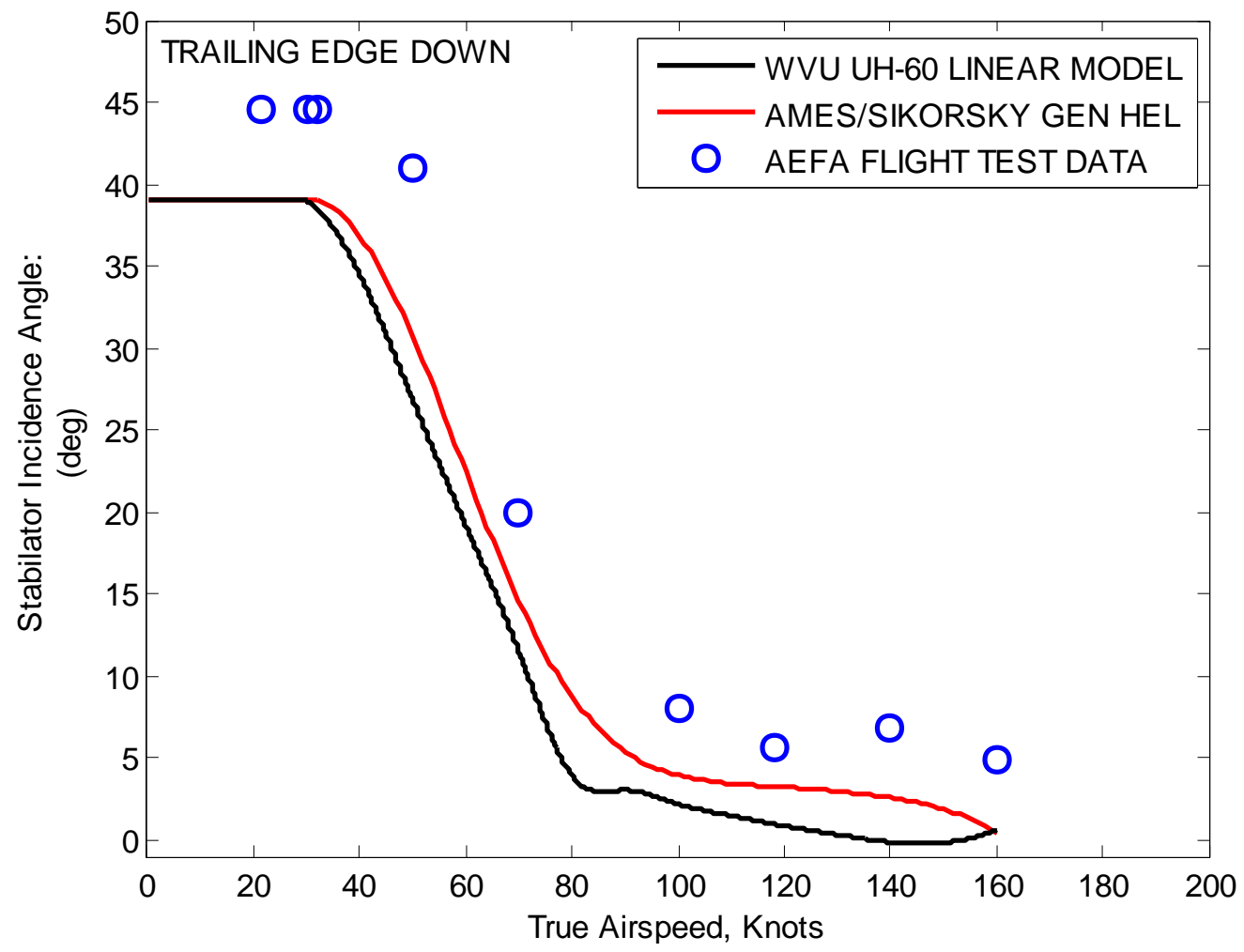

Figure 3.18: Gen Hel Model Comparison (Horizontal Stabilizer Incidence Angle) 

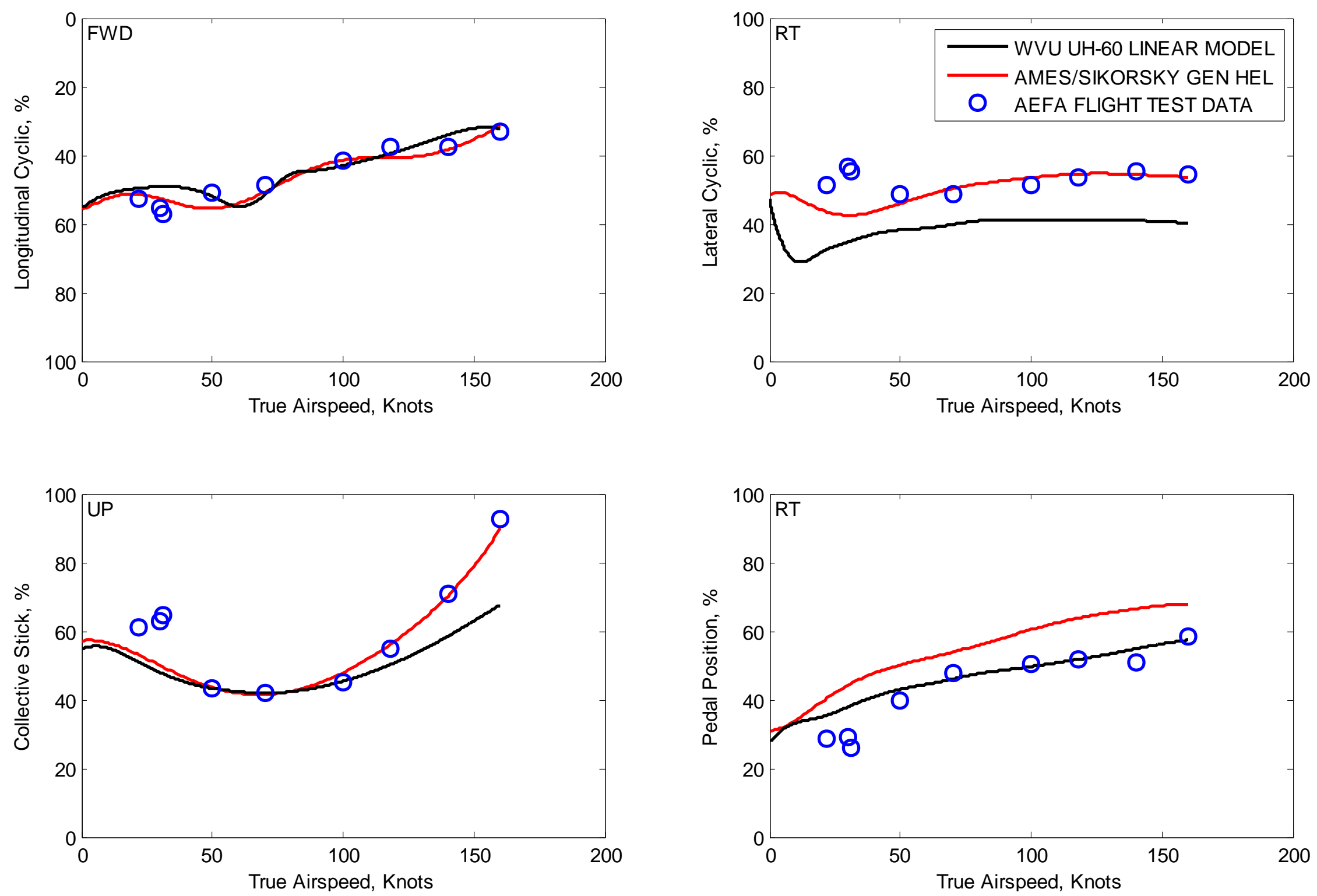

Figure 3.19: Gen Hel Model Comparison (Cockpit Controls) 
Overall, the WVU UH-60 linear model shows reasonably good correlation with Gen Hel model and the USAAEFA flight test data for the aircraft Euler angles, horizontal stabilizer position, and the cockpit controls. The hover results are virtually identical when comparing the data for each case. The forward flight results are also very good, but again, some variations can be seen due to variations in model assumptions.

The aircraft pitch attitude, shown in Figure 3.15, of the WVU UH-60 linear model matches up best with the Gen Hel model and flight test data between approximately 50 knots and 110 knots. Between 30 knots and 50 knots, the WVU model overestimates the aircraft pitch attitude when compared to the Gen Hel model and flight test data. Below 30 knots, the WVU model underestimates the pitch attitude when compared to the Gen Hel model, but matches up well with the flight test data. Above 110 knots, the deficiencies in accuracy for the pitch attitude of the WVU model can be directly attributed to growing inaccuracies in the main rotor calculations described in Section 3.3.2. The assumptions used for the main rotor calculations (ignoring root cutout, tip losses, compressibility losses, tip relief, etc.) reduce the accuracy of the model at higher speeds. Specifically, contributions to main rotor power and H-force are underestimated at higher speeds, which, in turn, affect the accuracy of the pitch attitude. Despite these variations, the WVU UH-60 linear model still correlates reasonably well with the Gen Hel model and flight test data.

Similar effects of the main rotor calculations can also be seen in the collective pitch controls of Figure 3.19. As airspeed increases past 100 knots, the accuracy of the WVU model collective pitch begins to decrease when compared to the Gen Hel model and flight test data.

The aircraft roll angle, shown in Figure 3.16, shows results similar to the Hilbert report (Validation \#1). At approximately 50 knots, the roll angle of the Gen Hel model is offset to zero by incorporating sideslip, as seen in Figure 3.17. The WVU UH-60 model does not incorporate sideslip, and therefore, will not offset to zero at high speeds. Instead, the roll angle of the WVU linear model tends to dwell around $-2^{\circ}$, which is still a very small roll angle and reasonable for aircraft stability.

Unlike the previous validation performed with the Hilbert model, data for the incidence angle of the horizontal stabilizer is available for the Gen Hel model and flight test data. The WVU UH-60 linear model matches up reasonable well with the Gen Hel model, but each of the models varies significantly from the flight test data. According to Ballin, the flight test data are 
in error by a nearly constant $5^{\circ}$ offset. As mentioned previously, at trim the control system of the horizontal stabilizer is strictly a function of the forward airspeed in the body axes $(u)$ and the main rotor collective pitch $\left(\theta_{0}\right)$. Therefore, above $100 \mathrm{knots}$, variations between the incidence angle of the WVU model and Gen Hel model are likely caused by inaccuracies in the collective pitch, which are evident in Figure 3.19. The collective pitch is reasonably accurate below 100 knots, so variations below this speed are caused by two possibilities. The forward velocity component, $(u)$, could be slightly inaccurate, or the $42^{\circ}$ bias present in the horizontal stabilizer control system (Figure A.1 of Appendix A:) has been modified in the Gen Hel model. Based on experience using the control system, the latter case seems to be the most likely cause of variation between the two models.

The cockpit controls of the WVU UH-60 linear model, shown in Figure 3.19, show reasonably good correlation with the Gen Hel Model and flight test data. The longitudinal cyclic data of the WVU UH-60 linear model matches up exceptionally well with the Gen Hel model and the flight test data at all airspeeds. The lateral cyclic data portrays results similar to the previous validation. Once again, this variation is likely caused by the fact that the WVU model does not incorporate sideslip into the trim calculations.

The pedal positions of the WVU UH-60 linear model match up very well with the flight test data for all airspeeds, but some variation are present when compared to the Gen Hel model. Ballin notes that a near constant pedal bias of approximately $0.5 \mathrm{in}$. to the right is present when compared to the flight test data, but does not explain the reasons why. 


\section{Chapter 4: Modeling an IBC Helicopter}

\subsection{Linear Model Conversion of Classical Configuration}

As mentioned previously, individual blade control for the linear model is achieved using the blade pitch control method. This approach replaces the pitch link for each rotor blade with an actuator so that the blade root pitch angles can be changed independently. Unfortunately, this approach has not been widely explored for linear models. In order to simulate this approach, a mathematical model for a swashplate-based rotor system was first developed and then adapted for IBC. The swashplate-based model was developed using the techniques outlined by Prouty [2]. Two types of linear models were developed: one for a hover scenario and one for a forward flight scenario. These models were then modified for IBC based on the following flowchart:

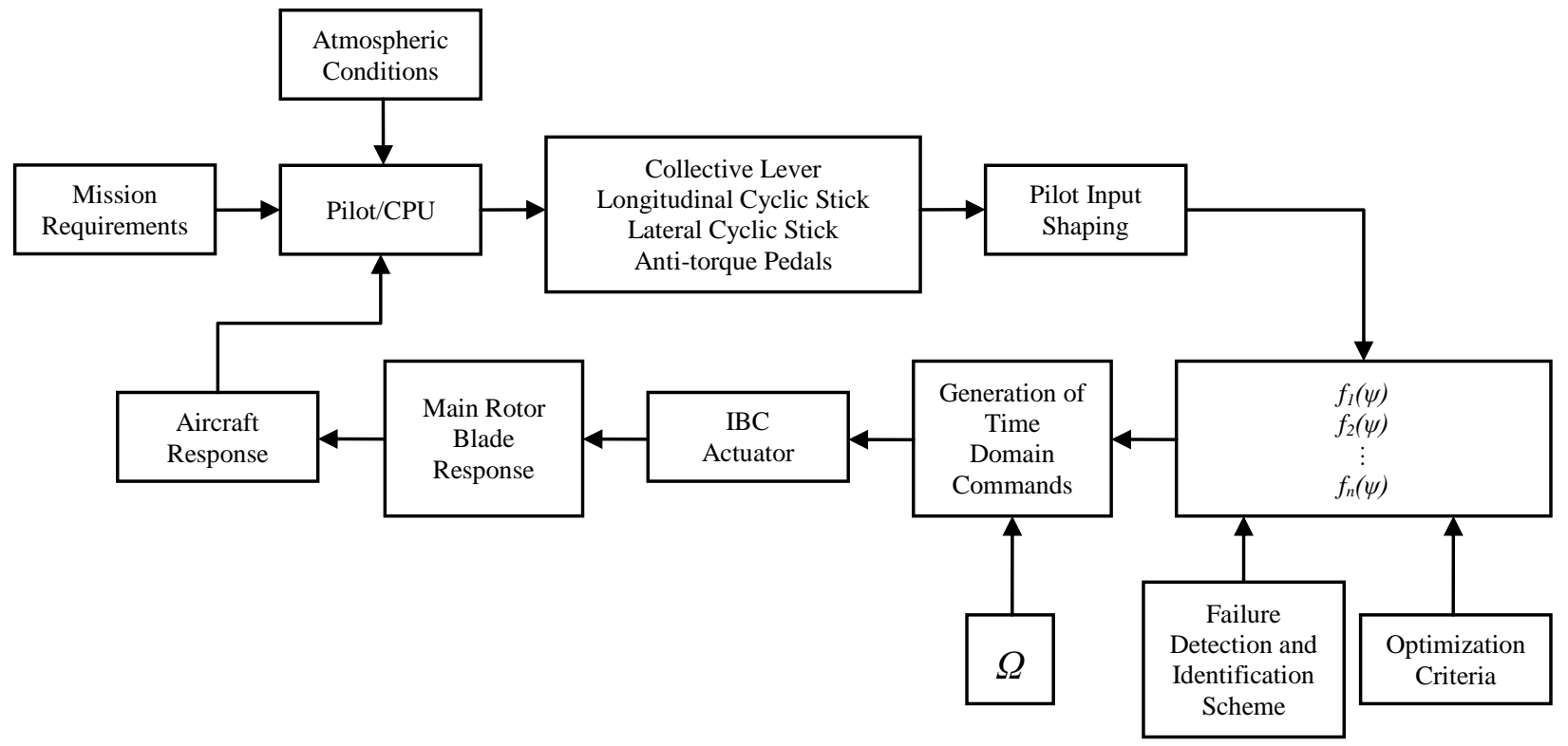

Figure 4.1: Flowchart for IBC Linear Model Conversion [28]

In summary, the linear model structure for individual blade control starts out virtually identical to the structure of a swashplate-based system. The pilot inputs are essentially the same. No changes or modifications are made to the collective lever, longitudinal/lateral cyclic stick, or the anti-torque pedals as they exist in the cockpit for the classic configuration. Next, the control inputs are modified and separated so that they can be applied to each individual blade. Each individual blade input is a function of azimuth position $(\psi)$ throughout the cycle of 1 full blade rotation $(0-2 \pi)$. Additionally, the blade input functions are dependent upon a failure detection 
and identification scheme, as well as an optimization routine. Next, the blade input functions are used to generate a system of time domain commands. In other words, the actuators for each blade need to know when to be activated, at what magnitude, and for what duration of time. The time domain commands are dependent on the rotational speed of the main rotor. Finally, once the actuators are activated the root pitch angles can be controlled for each individual blade and the aircraft response can be gauged by the pilot.

\subsection{IBC Mathematical Model}

The mathematical model for linear IBC can be further broken down to describe the relationship between swashplate control inputs and individual blade control. This relationship is also defined as "Pilot Input Shaping" in Figure 4.1. For the IBC configuration, the individual blade pitch angle can be described as a function of the azimuth position $(\psi)$ :

$$
\theta_{b_{i}}=f(\psi)
$$

$f$ is also blade specific where $i=[1,2, \ldots, n], n=$ number of blades, $\psi=[0,2 \pi]$, and $\theta_{b_{i}}=$ $\left[\theta_{M I N}, \theta_{M A X}\right]$. As mentioned previously, the blade azimuth position $(\psi)$ is assumed to be periodic $(0-2 \pi)$ so that Fourier's Theorem can be applied. Using the first approximation of Fourier's Series we obtain:

$$
f(\psi)=\frac{a_{0}}{2}+a_{1} \cos \psi+b_{1} \sin \psi
$$

where $a_{0}, a_{1}$, and $b_{1}$ are the Fourier coefficients, defined as:

$$
\begin{gathered}
\frac{a_{0}}{2}=\frac{1}{2 \pi} \int_{0}^{2 \pi} f(\psi) d \psi \\
a_{1}=\frac{2}{2 \pi} \int_{0}^{2 \pi} f(\psi) \cos \psi d \psi \\
b_{1}=\frac{2}{2 \pi} \int_{0}^{2 \pi} f(\psi) \sin \psi d \psi
\end{gathered}
$$

For the classical swashplate-based configuration, the blade pitch at any position along the radial axis of the blade is also defined by a Fourier Series:

$$
\theta=\theta_{0}+\frac{r}{R} \theta_{1}-A_{1} \cos \psi-B_{1} \sin \psi
$$

where $\theta_{0}$ is the collective input, $\theta_{1}$ is the linear blade twist, $A_{1}$ is the lateral cyclic input, $B_{1}$ is

the longitudinal cyclic input, and $\frac{r}{R}$ is the radial position along the blade ranging from $[0,1]$. 
Since both configurations are approximations of the Fourier Series, the IBC control inputs can be related to the swashplate-based control inputs using the following equations:

$$
\begin{aligned}
& \bar{\theta}_{0_{i}}=\frac{1}{2 \pi} \int_{0}^{2 \pi} f(\psi) d \psi+\frac{r}{R} \theta_{1} \\
& \bar{A}_{1_{i}}=-\frac{1}{\pi} \int_{0}^{2 \pi} f(\psi) \cos \psi d \psi \\
& \bar{B}_{1_{i}}=-\frac{1}{\pi} \int_{0}^{2 \pi} f(\psi) \sin \psi d \psi
\end{aligned}
$$

where the bar symbol stands for "equivalent". Based on these equivalent inputs and the principle of superposition of effects, the matrices of the linear model developed for the swashplate configuration can be split, as shown later, to model an IBC configuration. This approach allows the pilot to use the same basic control inputs as the swashplate-based configuration. Obviously, the anti-torque pedals have no effect on the main rotor, and therefore, no modifications are necessary for the IBC model. It is also important to note that $f(\psi)$ must be determined based on control objectives. In other words, the control system will determine $f(\psi)$ depending on pilot input, failure detection and identification, and using the optimization routine. Of course, the most common instance of $f(\psi)$ is that the IBC approach is simply attempting to reproduce the blade pitch angle produced by a swashplate control system. For this approach, a direct relationship can be made between swashplate control inputs and the IBC control inputs, as described in Eq. (4.10), Eq. (4.11), and Eq. (4.12). For example, the collective input raises or lowers all of the rotor blades simultaneously, regardless of whether a swashplate control system or IBC system is being used. Therefore, a direct correlation can be made to relate the equivalent IBC control inputs to the swashplate control inputs:

$$
\bar{\theta}_{0_{i}}=\theta_{0}
$$

The same concept is also valid when applied to longitudinal and lateral cyclic:

$$
\begin{aligned}
& \bar{A}_{1_{i}}=A_{1} \\
& \bar{B}_{1_{i}}=B_{1}
\end{aligned}
$$

The underlining assumption being used throughout this process is that each individual rotor blade has an equal component of the total aerodynamic forces acting on the main rotor. Therefore, the equivalent IBC control inputs can be collected for the main rotor, as described in the equations below: 


$$
\begin{aligned}
\bar{\theta}_{0} & =\left[\begin{array}{llll}
\bar{\theta}_{0_{1}} & \bar{\theta}_{0_{2}} & \cdots & \bar{\theta}_{0_{n}}
\end{array}\right] \\
\bar{A}_{1} & =\left[\begin{array}{llll}
\bar{A}_{1_{1}} & \bar{A}_{1_{2}} & \cdots & \bar{A}_{1_{n}}
\end{array}\right] \\
\bar{B}_{1} & =\left[\begin{array}{llll}
\bar{B}_{1_{1}} & \bar{B}_{1_{2}} & \cdots & \bar{B}_{1_{n}}
\end{array}\right]
\end{aligned}
$$

As mentioned previously, the states, inputs, and form of the linear math model are described in Eq. (3.20), Eq. (3.21), and Eq. (3.22). These equations, however, need to be modified to incorporate the equivalent IBC control inputs described by Eq. (4.13), Eq. (4.14), and Eq. (4.15). The state vector, $\mathbf{x}$, remains unchanged, while the state space form and the control vector, $\mathbf{u}$, are modified in the following manner:

$$
\begin{gathered}
\dot{\mathbf{x}}=\mathbf{A x}+\mathbf{B} \overline{\mathbf{u}} \\
\overline{\mathbf{u}}=\left[\begin{array}{llll}
\bar{\theta}_{0} & \bar{A}_{1} & \bar{B}_{1} & \theta_{0_{T}}
\end{array}\right]
\end{gathered}
$$

where $\bar{u}$ is now a matrix of size $(3 n+1) \times 1$.

Similarly, the $A$ and $B$ matrices of Eq. (3.23) and (3.24) must be modified to reflect the changes for IBC. The $A$ matrix is split into 3 main components, consisting of main rotor derivatives, tail rotor derivatives, and all other derivatives. Typically, these components are combined in the classical swashplate model. By separating the components, the main rotor derivatives, and only the main rotor derivatives, can be modified for IBC and fault-tolerant capabilities. Once again using the assumption that each individual rotor blade has an equal component of the total aerodynamic forces acting on the main rotor, each main rotor derivative is simply divided by the number of blades ( 4 , in this case). Similarly, the derivatives of the $B$ matrix are also divided by the number of blades. The B matrix components, however, need to be listed for each control input on each individual blade. The new matrix formats can be seen in Eq. (4.18):

$$
\dot{x}=\left[A_{M R_{1}}+A_{M R_{2}}+\cdots+A_{M R_{n}}+A_{T R}+A_{O T H E R}\right] x+\left[\begin{array}{llll}
B_{M R_{1}} & B_{M R_{2}} & \cdots & B_{M R_{n}}
\end{array}\right] \bar{u}
$$

where $A_{M R_{i}}=A_{M R} / n, B_{M R_{i}}=B_{M R} / n$, and $n=$ the number of blades. The end result is an $A$ matrix of size $8 \times 8$ (same size as Eq. (3.23)) and a $B$ matrix of size $8 \times 13$. These matrices can then be incorporated into the simulation environment, where the linear models can be analyzed and compared. 


\section{Chapter 5: General Architecture of Simulation Environment}

\subsection{Simulation Scenarios and GUI's}

The WVU Helicopter Simulator is a comprehensive system that allows helicopter models to be conveniently added without making major changes to the overall architecture. Additionally, the inputs and outputs have been standardized to easily compare the results of different models. A series of graphical user interfaces (GUI's) allow the user to select a specific helicopter for simulation, as well as define a variety of simulation parameters and failure scenarios. Finally, a virtually reality (VR) interface featuring a 3D representation of the Black Hawk helicopter is included to provide a qualitative assessment of the helicopter during simulation runs. Examples of the GUI's and VR interface are displayed in Figure 5.1 - Figure 5.4:

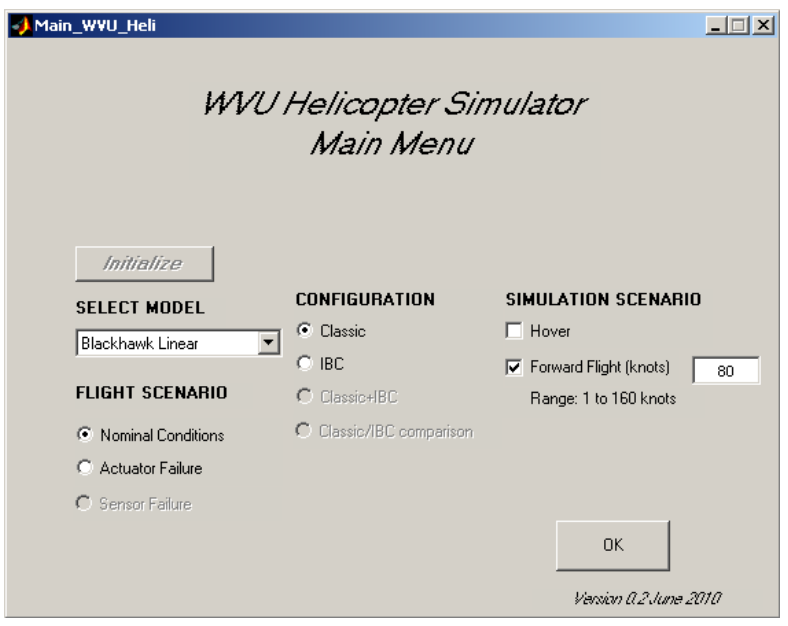

Figure 5.1: WVU Helicopter Simulator - Main Menu

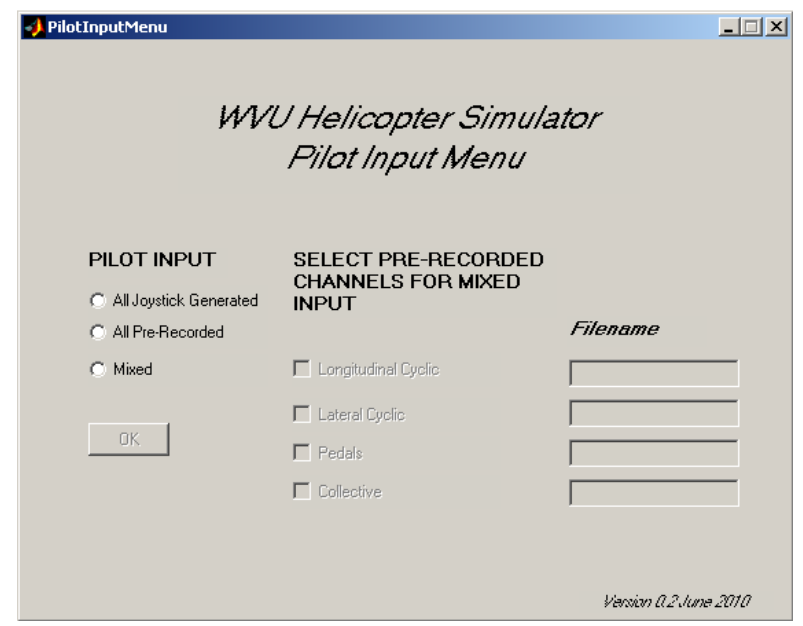

Figure 5.2: WVU Helicopter Simulator - Pilot Input Menu 


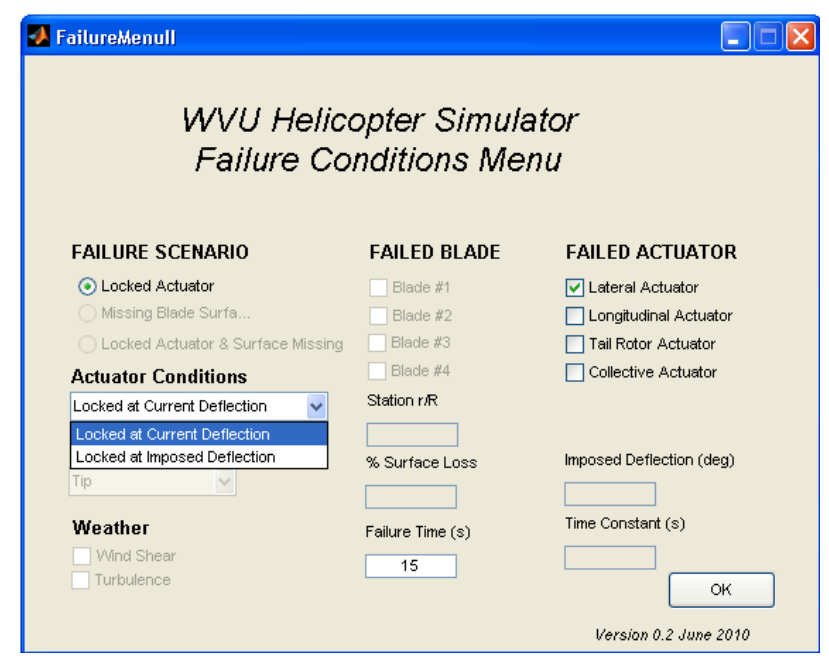

Figure 5.3: WVU Helicopter Simulator - Failure Conditions Menu

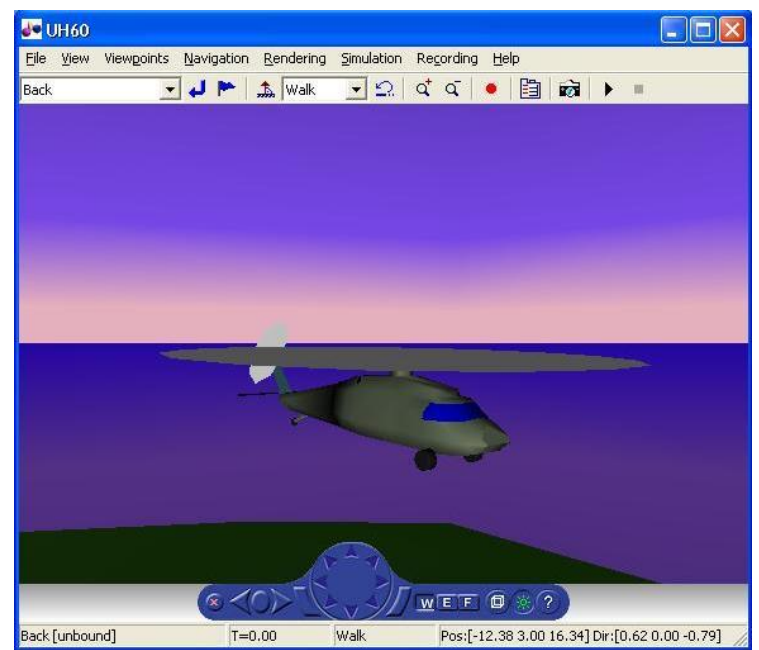

Figure 5.4: UH-60 Virtual Reality Interface

A detailed guide of how to use the WVU Helicopter Simulator for the UH-60 linear model is provided in Appendix C:

A general schematic of the simulation environment for the swashplate-based linear model is shown as follows:

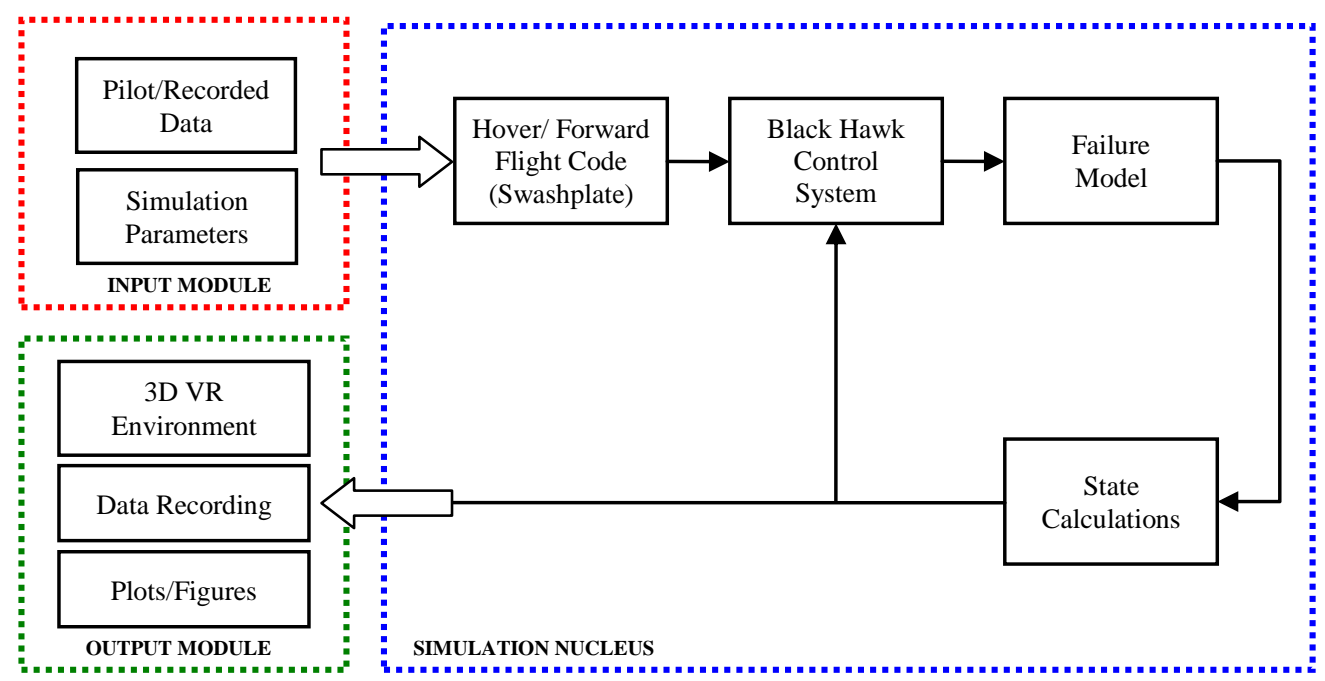

Figure 5.5: General Schematic of Simulation Environment (Swashplate)

It should be noted that the Black Hawk Control System block in Figure 5.5 is based on the control system architecture described in Figure 3.7. The stability augmentation systems (SAS's) described in Reference [22] are not included.

In comparison, a general schematic of the simulation environment for the IBC based linear model is shown as follows: 


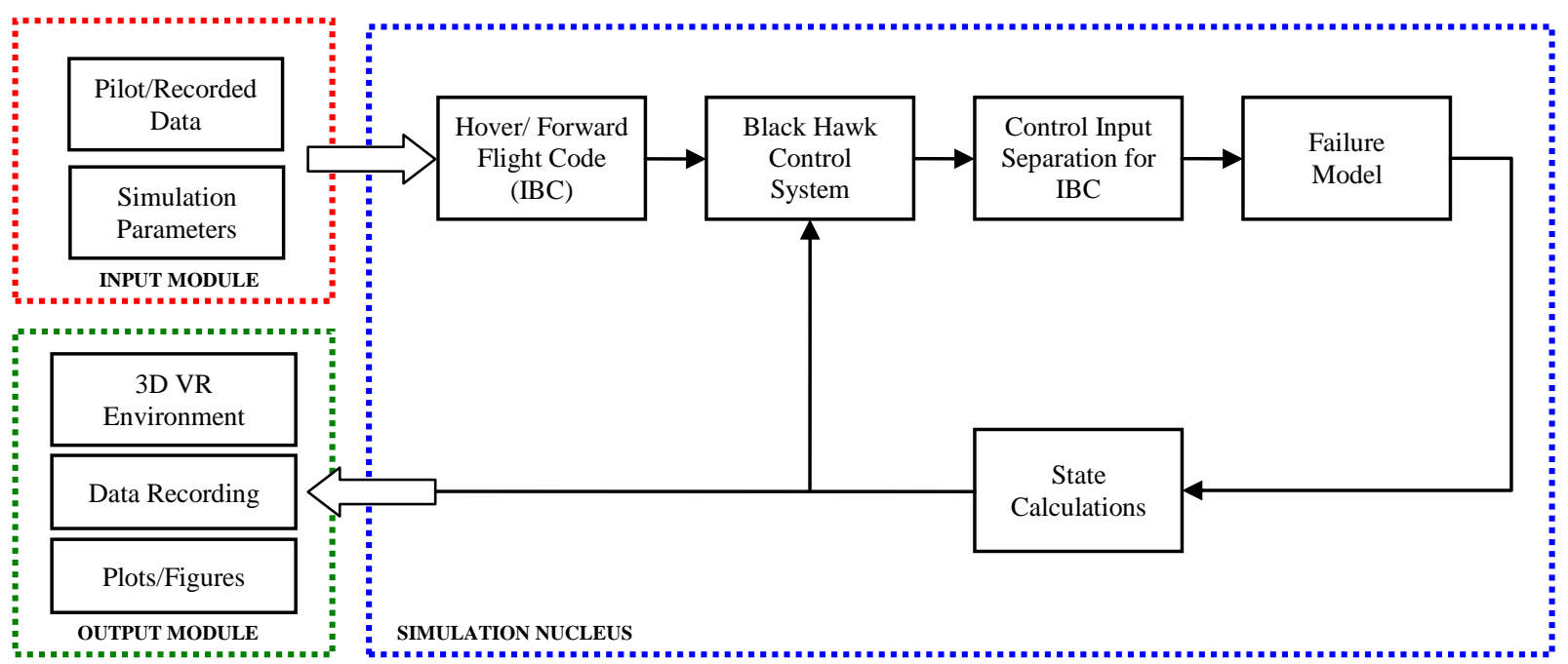

Figure 5.6: General Schematic of Simulation Environment (IBC)

The major difference between the two simulation architectures is the inclusion of block for IBC control inputs. Since the pilot controls are identical to those of the swashplate configuration, the inputs need to be decoupled for the purposes of IBC. Instead of having four control inputs feed to the failure model and state calculations, thirteen inputs are now fed to the subsequent blocks. The control inputs are separated in the following manner:

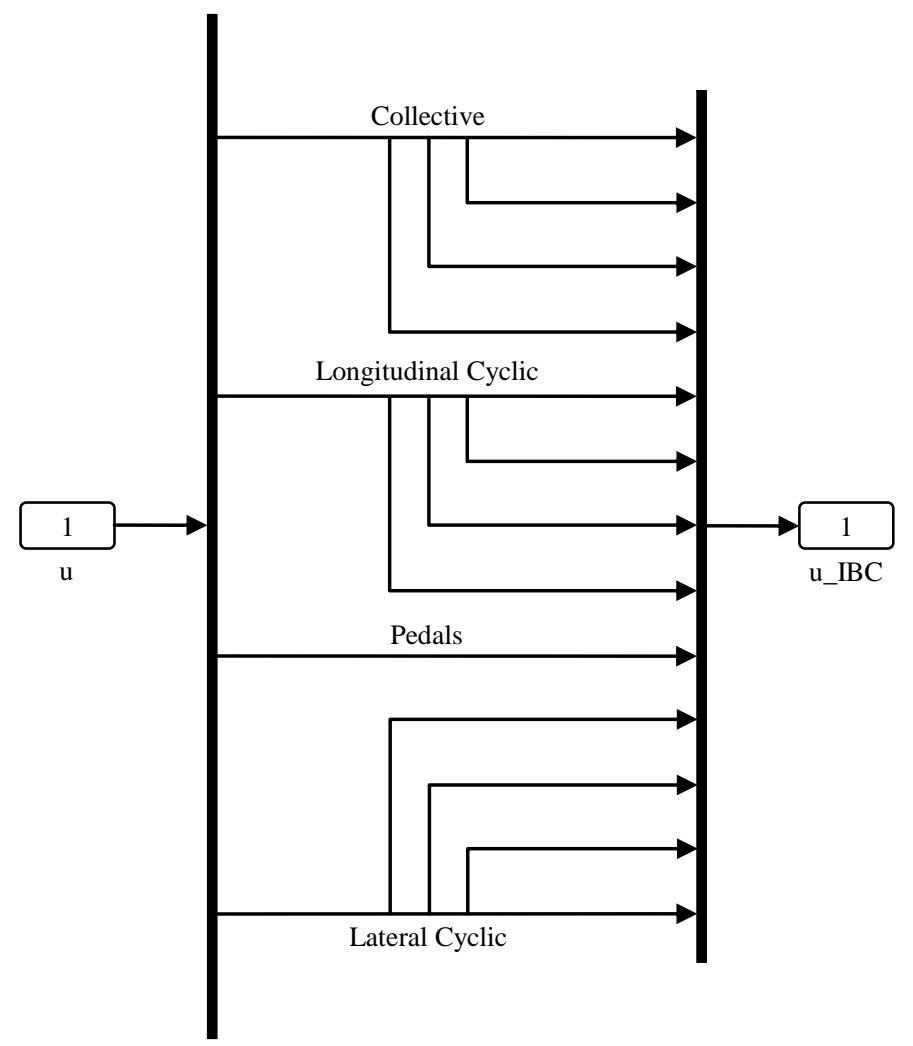

Figure 5.7: Control Input Separation for IBC 
As mentioned in Section 4.2, the collective, longitudinal cyclic, and lateral cyclic control inputs for each blade are assumed to be equivalent to the input parameters for the swashplate configuration. The control inputs for the pedals are not decoupled in any form, so the configuration remains the same for the IBC model. The separated IBC output data for each blade can then be plotted by simply offsetting the data for each blade based on azimuth position.

\subsection{Modeling of Subsystem Failures}

Two types of subsystem failures are incorporated into the simulation environment: timed actuator failures and imposed actuator failures. A timed actuator failure is initiated at a user defined instant during the simulation. The selected actuator is locked at its current value at the time of failure. An imposed actuator failure is also initiated at a user defined instant during the simulation. However, it differs from the timed actuator failure by transitioning the actuator to a set value other than its current setting. The actuator setting will move to a user defined value as a first order system. In other words, the failure doesn't happen instantaneously. For example, if the joystick is deflecting the longitudinal cyclic at a value of one degrees and the imposed deflection failure is set for three degrees (deviation from the current value), then the longitudinal cyclic will gradually move from one degrees to four degrees as a first order system at the time of the failure. The rate that this transition occurs is dependent upon the time constant set by the user, which is defined as the time it takes the first order system to reach $63 \%$ of its steady state value.

The actuator failures differ somewhat when comparing the swashplate and IBC configurations. The swashplate failures are applied to a single actuator. However, due to the somewhat low tolerance of space between the swashplate and main rotor shaft, failing a single actuator will consequently restrict the movement of the actuator on the opposite side of the swashplate. Therefore, failures to the swashplate actuators are categorized as a locked longitudinal cyclic, locked lateral cyclic, or locked collective (all actuators have failed). For example, if the user selects a failure to the lateral cyclic, then the value of the lateral cyclic input is fixed and the pilot no longer has control over that specific input.

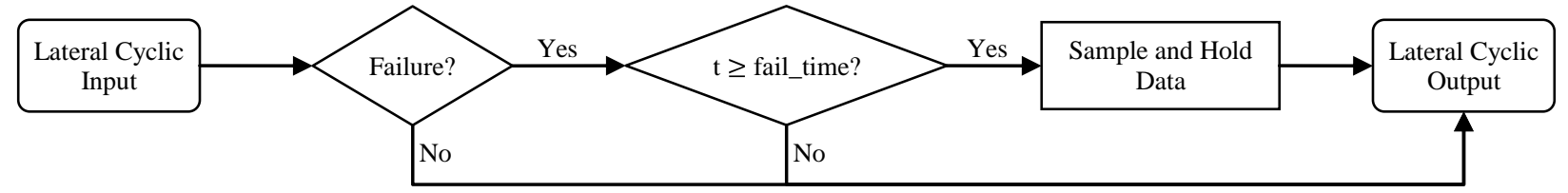

Figure 5.8: Flowchart for Cyclic Actuator Failure (Swashplate) 
In comparison, IBC actuator failures affect a single blade. At the time of an IBC failure, the equivalent collective input becomes locked and the equivalent cyclic inputs are set to zero for the specified blade. Since the cyclic inputs are decoupled, the pilot retains complete control of the inputs for the remaining blades. This allows the pilot to maintain cyclic control of the aircraft during an actuator failure.

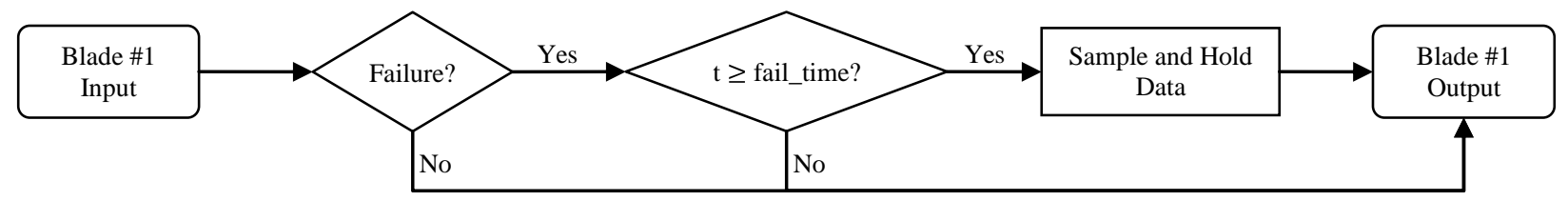

Figure 5.9: Flowchart for Blade Actuator Failure (IBC) 


\section{Chapter 6: Simulation Results and Discussion}

\subsection{Background}

In order to examine the effectiveness of IBC, simulations are performed with incorporated failure scenarios to both the swashplate and IBC configurations. The simulations are performed for hover and forward flight models. To prevent redundancy, only one forward flight speed is examined: 80 knots. The results are compared for each helicopter configuration.

Since the swashplate and IBC systems differ in their general designs, identical failure scenarios cannot be created for the two configurations. In each scenario a single hydraulic actuator is failing (becomes locked). However, a single actuator failure will imply different system functionality for the two configurations. As mentioned previously, failures to the swashplate actuators are categorized as a locked longitudinal cyclic, locked lateral cyclic, or locked collective (all actuators have failed). Conversely, failures to an IBC actuator affect a single blade. Collective failures lock all of the actuators at the same time, and therefore, affect both configurations in the same manner. For this reason, only cyclic failures are examined.

\subsection{Hover Comparison}

\subsubsection{Swashplate Configuration}

The hover model is simulated for a total of fifty seconds and is initially kept at trim for the start of the simulation. At five seconds an imposed lateral cyclic failure is initiated with a magnitude of -4 degrees (deviation from the current trim value) with a time constant of one second. After the failure is initiated the pilot no longer has control over the main rotor lateral cyclic. However, longitudinal cyclic and limited collective control is still available. The control inputs at the rotor hub are presented in Figure 6.1: 

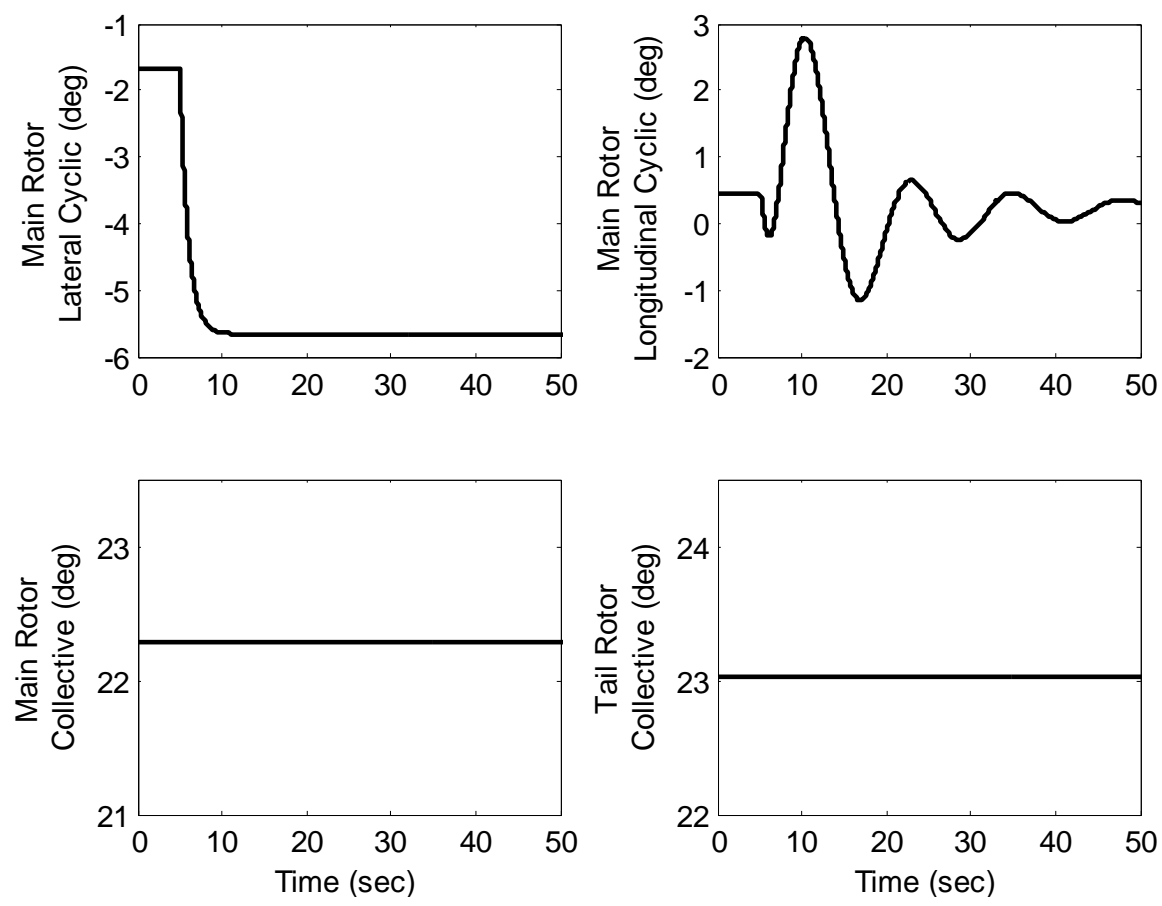

Figure 6.1: Control Inputs at the Rotor Hub (Lateral Cyclic Failure at Hover)

It should be noted that control mixing between the lateral and longitudinal cyclic, as well as feedback of the pitch and roll rates into the control system, causes variation in longitudinal cyclic even though the longitudinal cyclic joystick has not been deflected by the pilot. The corresponding aircraft Euler angles are presented in Figure 6.2:
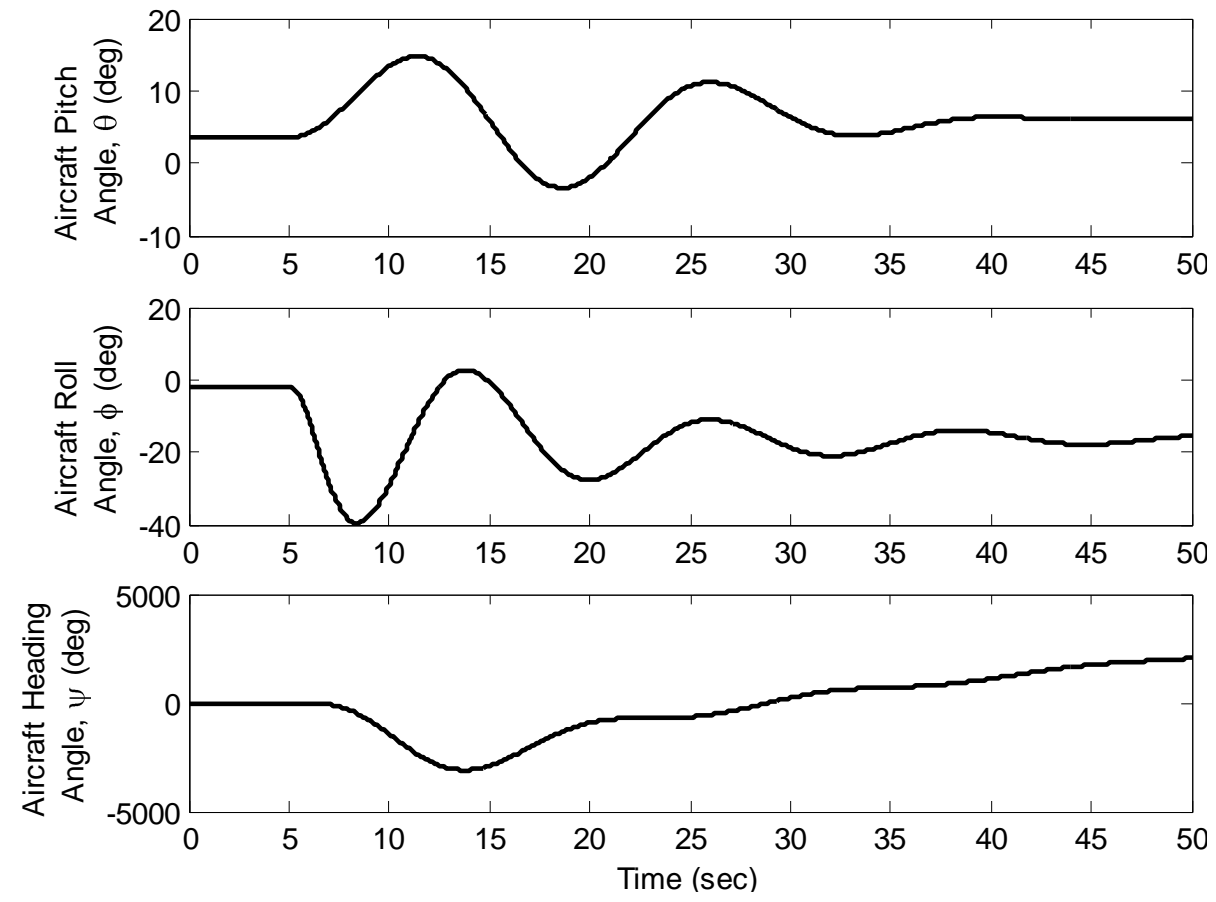

Figure 6.2: Aircraft Euler Angles (Lateral Cyclic Failure at Hover) 
It is apparent from Figure 6.2 that the helicopter has experienced at failure that it cannot recover from. After the failure is initiated at five seconds, the helicopter rapidly begins to spin out of control. In a span of less than ten seconds (5 seconds to 13.5 seconds), the helicopter performs roughly eight and a half rotations. Furthermore, the roll and pitch angles oscillate and eventually dampen to steady state values. Basically, the helicopter is stuck in a series of downward spirals that it cannot recover from, as seen in Figure 6.3.

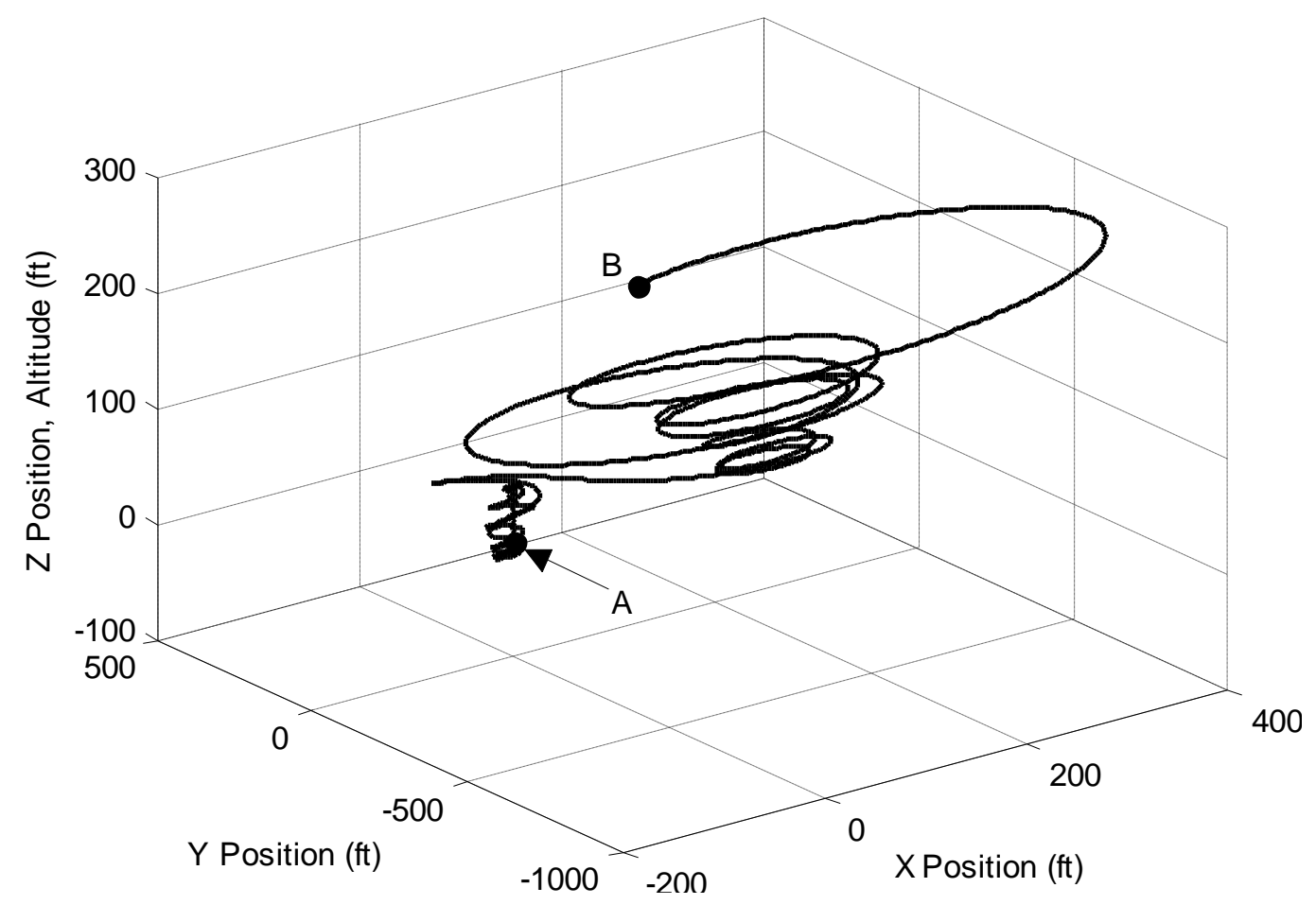

Figure 6.3: Helicopter Flight Path Relative to the Earth (Lateral Cyclic Failure at Hover)

It is important to note that maintaining hovering flight is somewhat difficult without the aid of stability augmentation systems (SAS's). Since the swashplate model is simulated without the aid of any SAS's, small joystick maneuvers are necessary to keep the helicopter at a trimmed hover condition. Joystick maneuvers of large magnitudes for extended periods of time, as in the case illustrated in Figure 6.3, will almost certainly lead to a catastrophic failure from which there is no recovery. Furthermore, since the lateral cyclic is fixed in this case, it is virtually impossible to correct the helicopter roll angle. However, the significantly large yaw angles can be reduced by adjusting the tail rotor collective. The fact remains that, despite the best efforts of the pilot over numerous simulations, the downward spiral motion of the helicopter flight path could not be averted. 


\subsubsection{IBC Configuration}

The hover model is again simulated for a total of fifty seconds for the IBC configuration. The helicopter is initially kept at trim and then a blade failure is initiated at 5 seconds. An imposed failure is initiated with a magnitude of -4 degrees (deviation from the current blade pitch) with a time constant of one second. After the failure is initiated the pilot no longer has control of the pitch for the specified main rotor blade (blade \#1 in this case). However, the pilot does have full control over the remaining three blades. Since the blade inputs are decoupled for IBC, the pilot still has limited longitudinal cyclic, lateral cyclic, and collective control. In theory, a cataclysmic failure can be avoided by simply adjusting the inputs of the remaining three blades.

As mentioned previously, maintaining hovering flight is somewhat difficult without the aid of stability augmentation systems (SAS's). Based on this fact, the pilot was unable to return the helicopter to its original trim conditions by simply offsetting the control inputs for the remaining three blades. The pilot was, however, able to stabilize the helicopter and prevent a crash.

The blade pitch angles at the rotor hub for a blade \#1 failure scenario are presented in Figure 6.4:
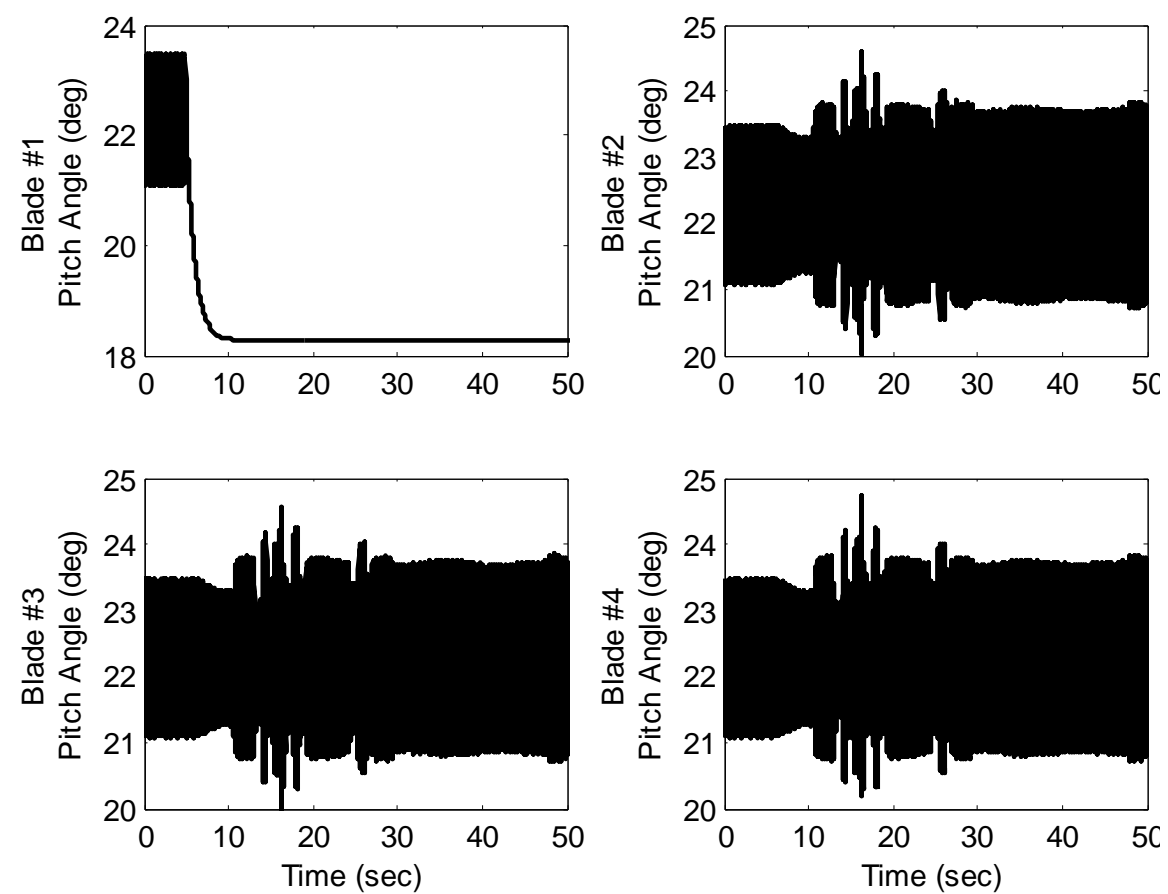

Figure 6.4: Blade Pitch Angles at the Rotor Hub (Blade \#1 Failure Scenario at Hover) 
By zooming in on the response of one of the blades prior to a failure in Figure 6.4, the cyclic input can be examined for a given blade.

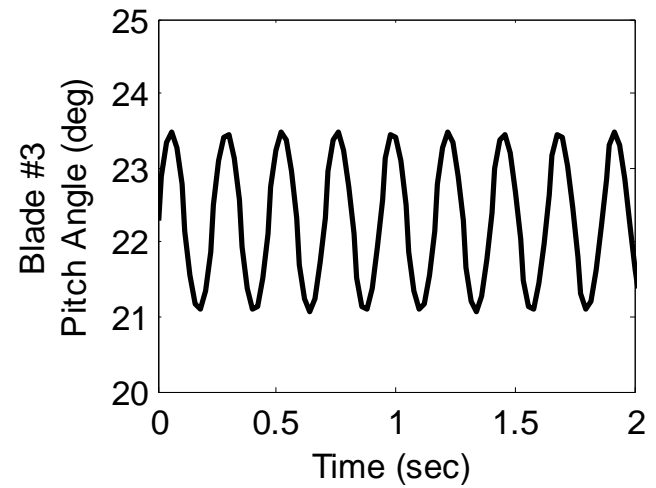

Figure 6.5: Cyclic Response of IBC Blade at Hover Trim Conditions

It is evident that cyclic oscillations occur at an extremely high rate based on the rotational speed of the main rotor. Once the failure occurs the cyclic oscillations are eliminated and the rotor becomes locked at an imposed blade pitch.

The corresponding aircraft Euler angles are presented in Figure 6.6. It should be noted that the failure occurred at five seconds in this scenario and then the pilot (user) began to correct the failure at approximately ten seconds.
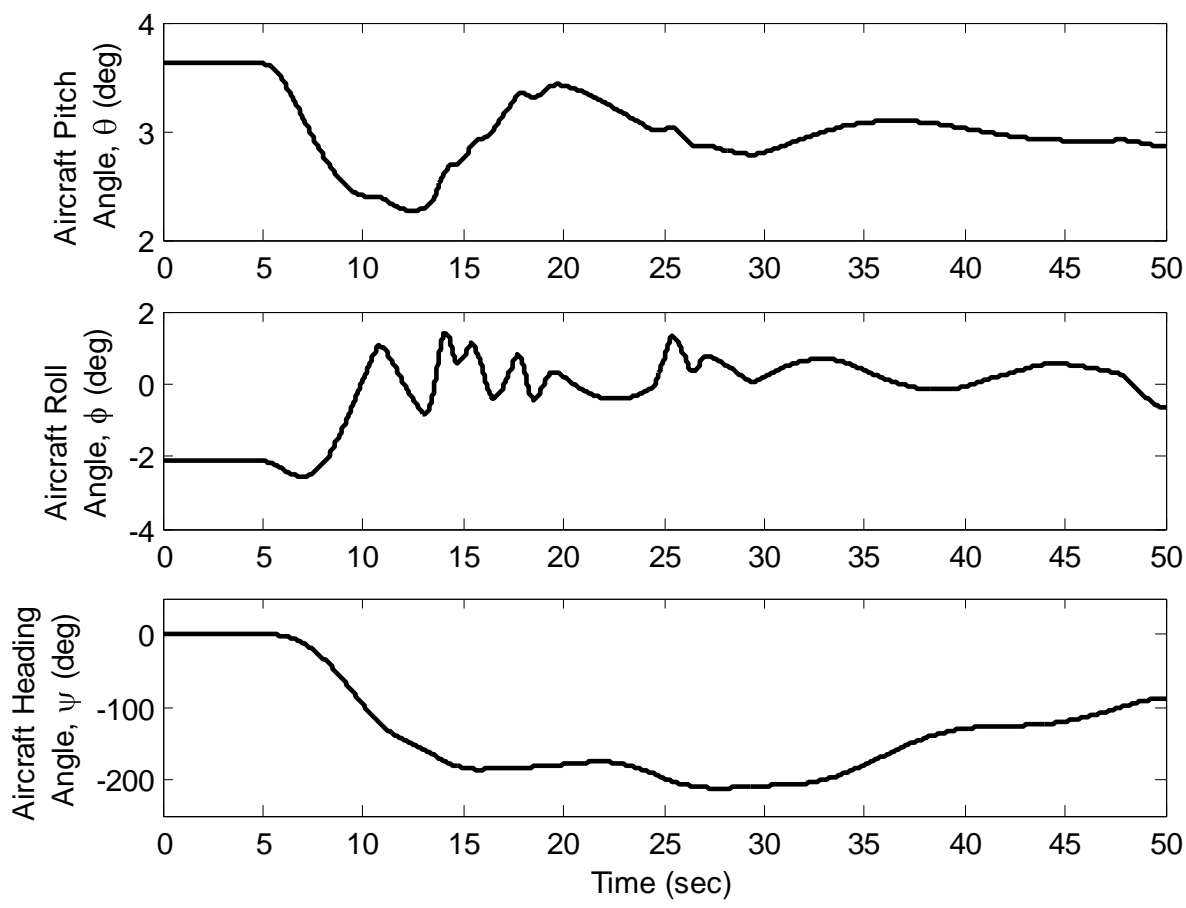

Figure 6.6: Aircraft Euler Angles (Blade \#1 Failure Scenario at Hover) 
As mentioned previously, the pilot was unable to return the helicopter to its original trim conditions for hover. The pilot attempted to correct the failure by simply increasing the lateral cyclic for the remained three blades. The pilot was able to successfully stabilize the aircraft roll angle to an acceptable degree. However, due to the fact that the helicopters yaw angle is controlled using the same joystick as lateral and longitudinal cyclic in this simulation, it was much more difficult to stabilize the helicopter heading angle. Despite this fact, the helicopter is not spinning out of control as observed in the swashplate failure. Additionally, the failure seems to have very little effect on the helicopter pitch angle.

The corresponding helicopter flight path relative to the earth is shown in Figure 6.7:
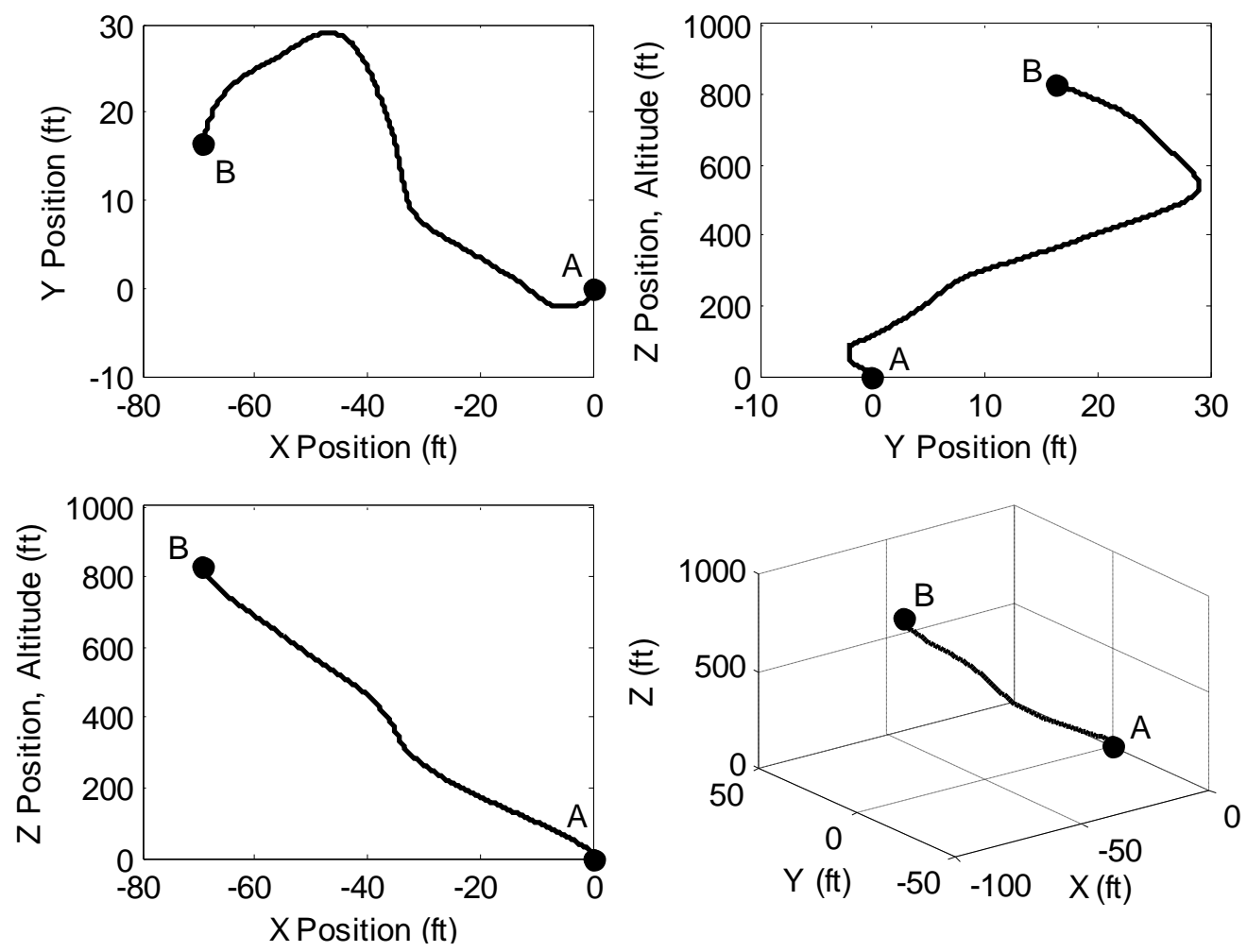

Figure 6.7: Helicopter Flight Path Relative to the Earth (Blade \#1 Failure at Hover)

Though it may be somewhat difficult to visualize, the failure to blade \#1 causes the helicopter to begin an upward spiral motion. This maneuver is corrected by the pilot at approximately ten seconds by offsetting the lateral cyclic of the remaining three blades. The correction to lateral cyclic, however, results in an increase in main rotor thrust, which is evident in the altitude increase illustrated in Figure 6.7. A reduction in collective control is also needed to return the helicopter to its original altitude. So while the pilot was able to stabilize the 
helicopter and avoid a likely crash, it is obvious that additional fault-tolerant control systems are needed to maintain a trimmed hover flight scenario.

\subsection{Forward Flight Comparison}

\subsubsection{Swashplate Configuration}

The forward flight model is simulated at a forward speed of 80 knots for the swashplate configuration. The helicopter is kept at trim and then a lateral cyclic failure is initiated at 5 seconds. An imposed failure is initiated with a magnitude of -4 degrees (deviation from the current trim value) with a time constant of one second. After the failure is initiated the pilot no longer has control over the lateral cyclic of the main rotor. However, longitudinal cyclic and limited collective control is still available. The control inputs at the rotor hub are presented in Figure 6.8:
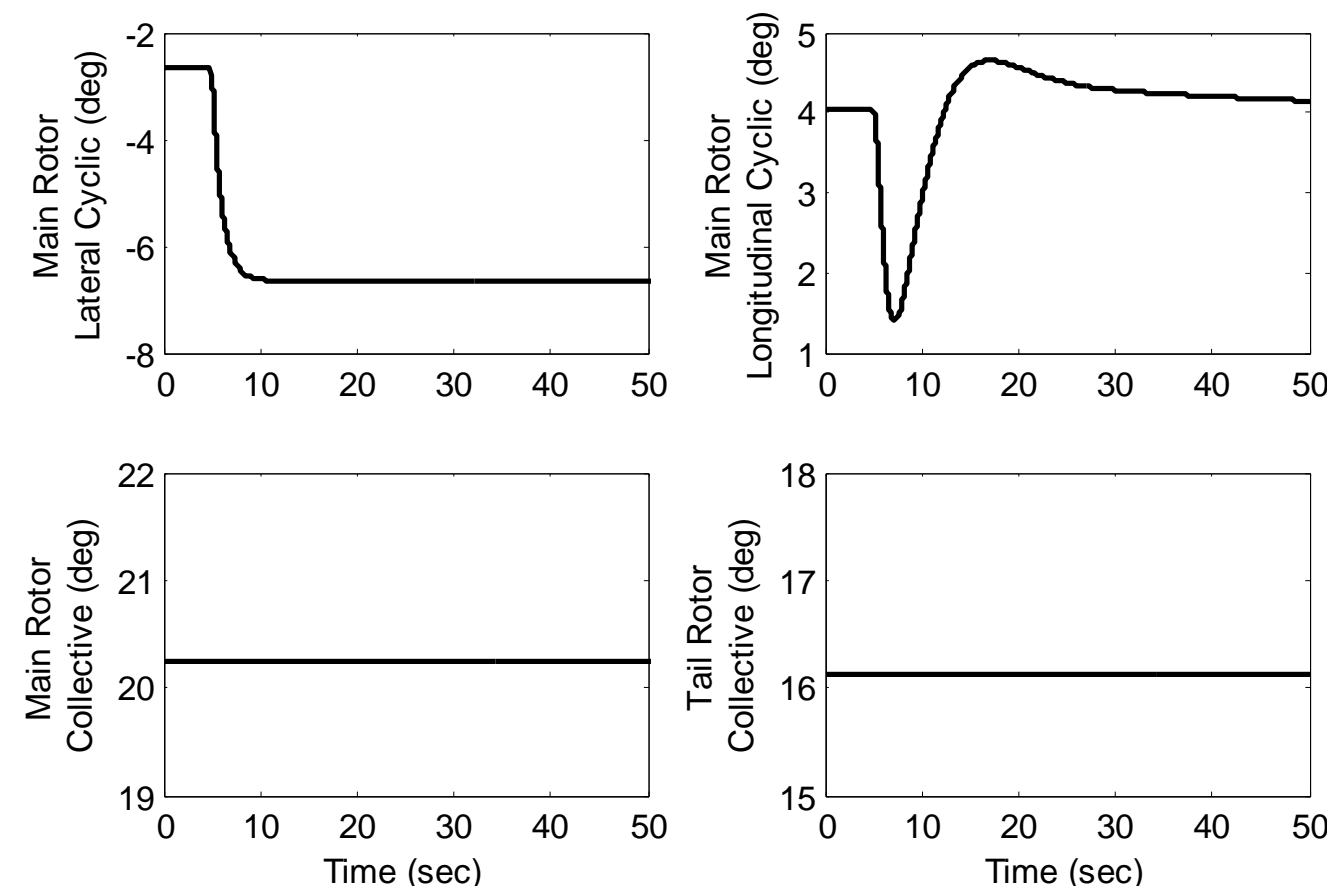

Figure 6.8: Control Inputs at the Rotor Hub (Lateral Cyclic Failure at 80 Knots)

It should be noted that due to the control mixing between the lateral and longitudinal cyclic, as well as feedback of pitch and roll rates into the control system, a slight variation in longitudinal cyclic is present even though the longitudinal cyclic joystick has not been deflected by the pilot. The corresponding aircraft Euler angles are presented in Figure 6.9: 

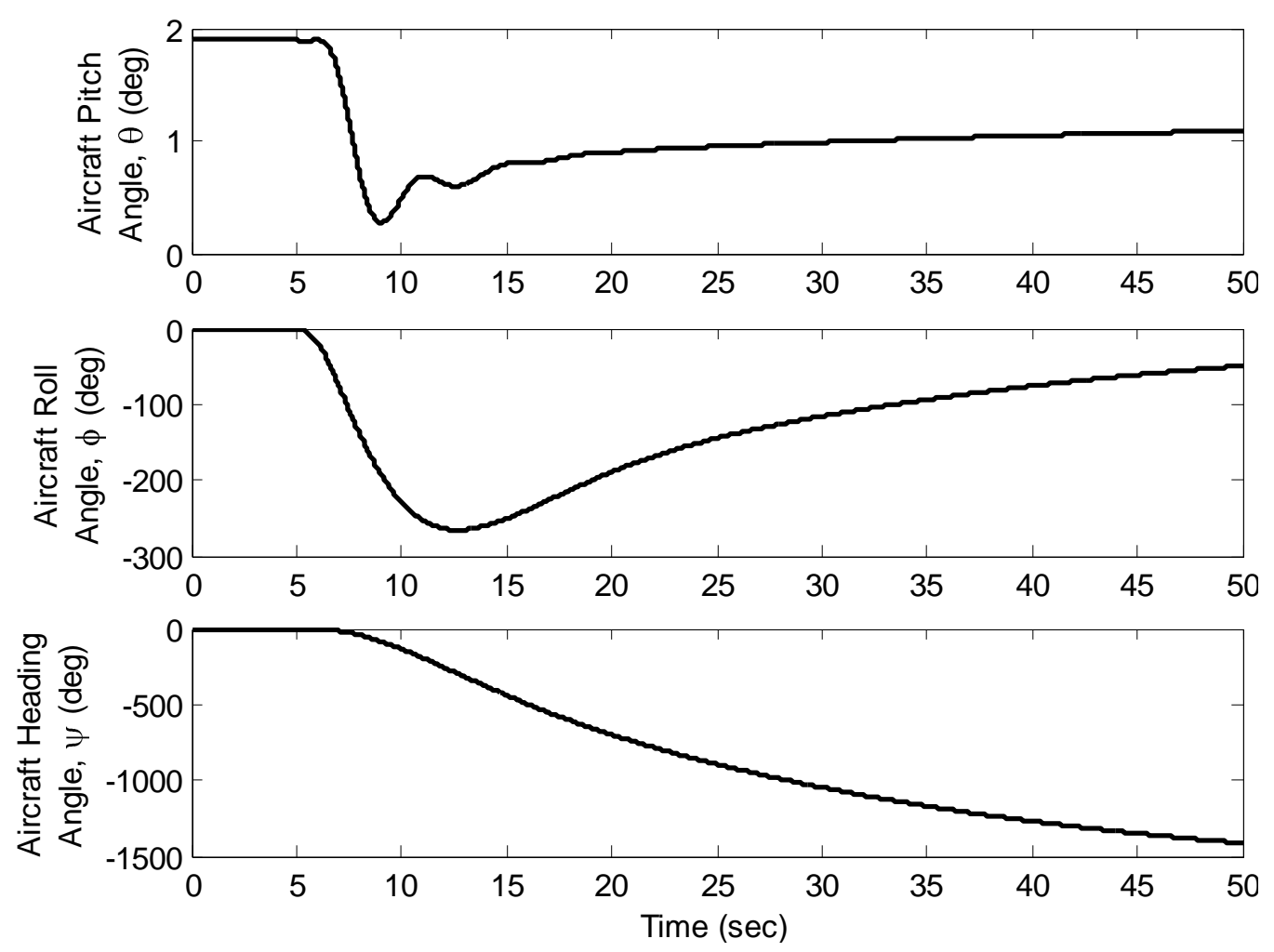

Figure 6.9: Aircraft Euler Angles (Lateral Cyclic Failure at 80 Knots)

It is clear from Figure 6.9 that the helicopter has experienced at failure that it cannot recover from. After the failure is initiated at five seconds, the roll angle quickly increases to greater than $200^{\circ}$. In other words, the helicopter has flipped upside down. Furthermore, based on the aircraft yaw angle, the helicopter is spinning out of control. Essentially, the helicopter is stuck in a type of downward spiral, as seen in Figure 6.10. 


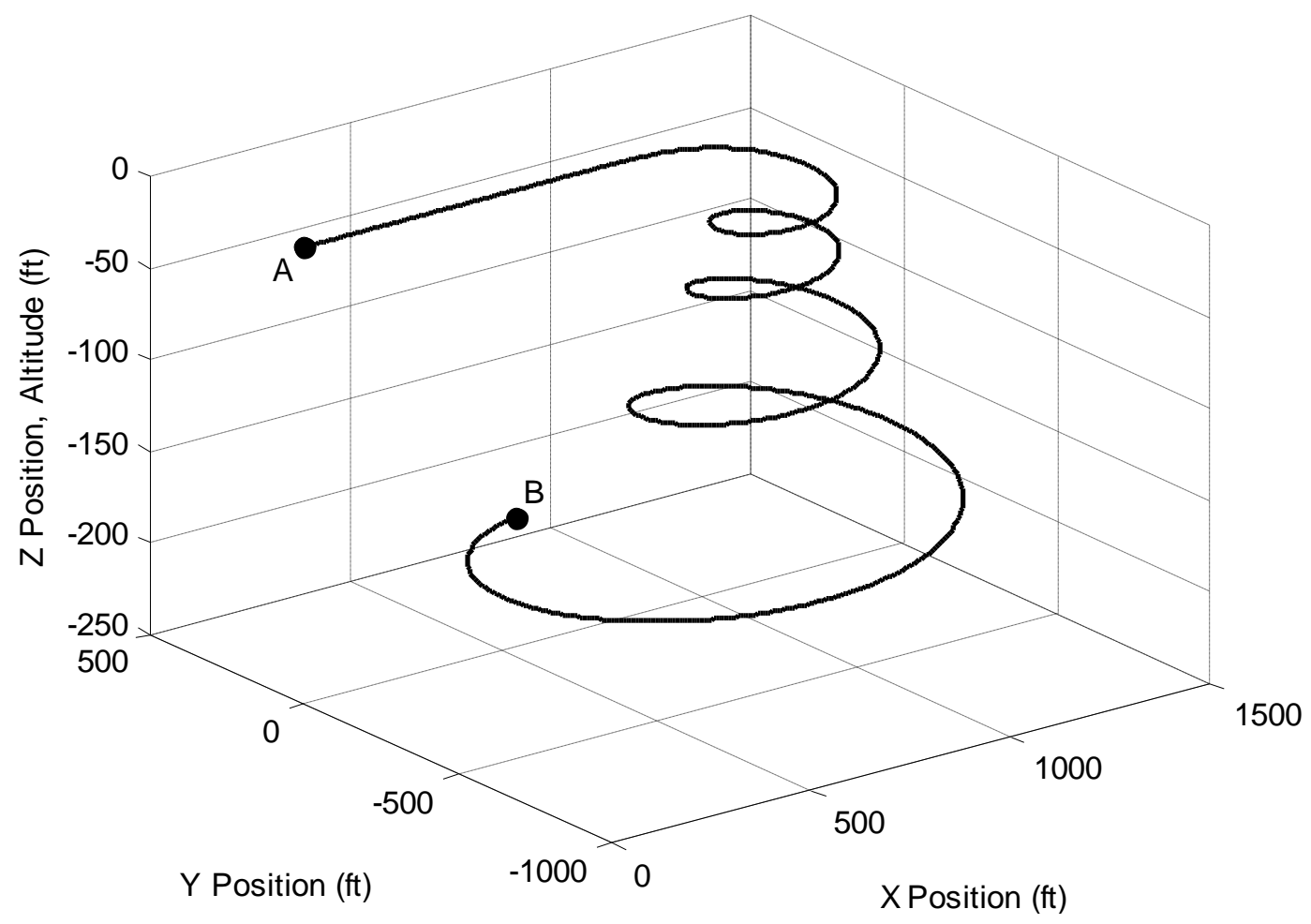

Figure 6.10: Helicopter Flight Path Relative to the Earth (Lateral Cyclic Failure at 80 Knots)

\subsubsection{IBC Configuration}

The forward flight model is once again simulated at a forward speed of 80 knots for the IBC simulation. The helicopter is kept at trim and then a blade failure is initiated at 5 seconds. An imposed failure is initiated with a magnitude of -4 degrees (deviation from the current blade pitch) with a time constant of one second. After the failure is initiated the pilot no longer has control of the pitch for the specified main rotor blade (blade \#4 in this case). However, the pilot does have full control over the remaining three blades. Since the blade inputs are decoupled for IBC, the pilot still has limited longitudinal cyclic, lateral cyclic, and collective control. Using this ability, a catastrophic failure can be diverted for the helicopter by simply adjusting the inputs of the remaining three blades. For this failure scenario, the helicopter was returned to its original trim conditions by simply offsetting the lateral cyclic for the "healthy" three blades. The blade pitch angles at the rotor hub for this failure scenario are presented in Figure 6.11: 

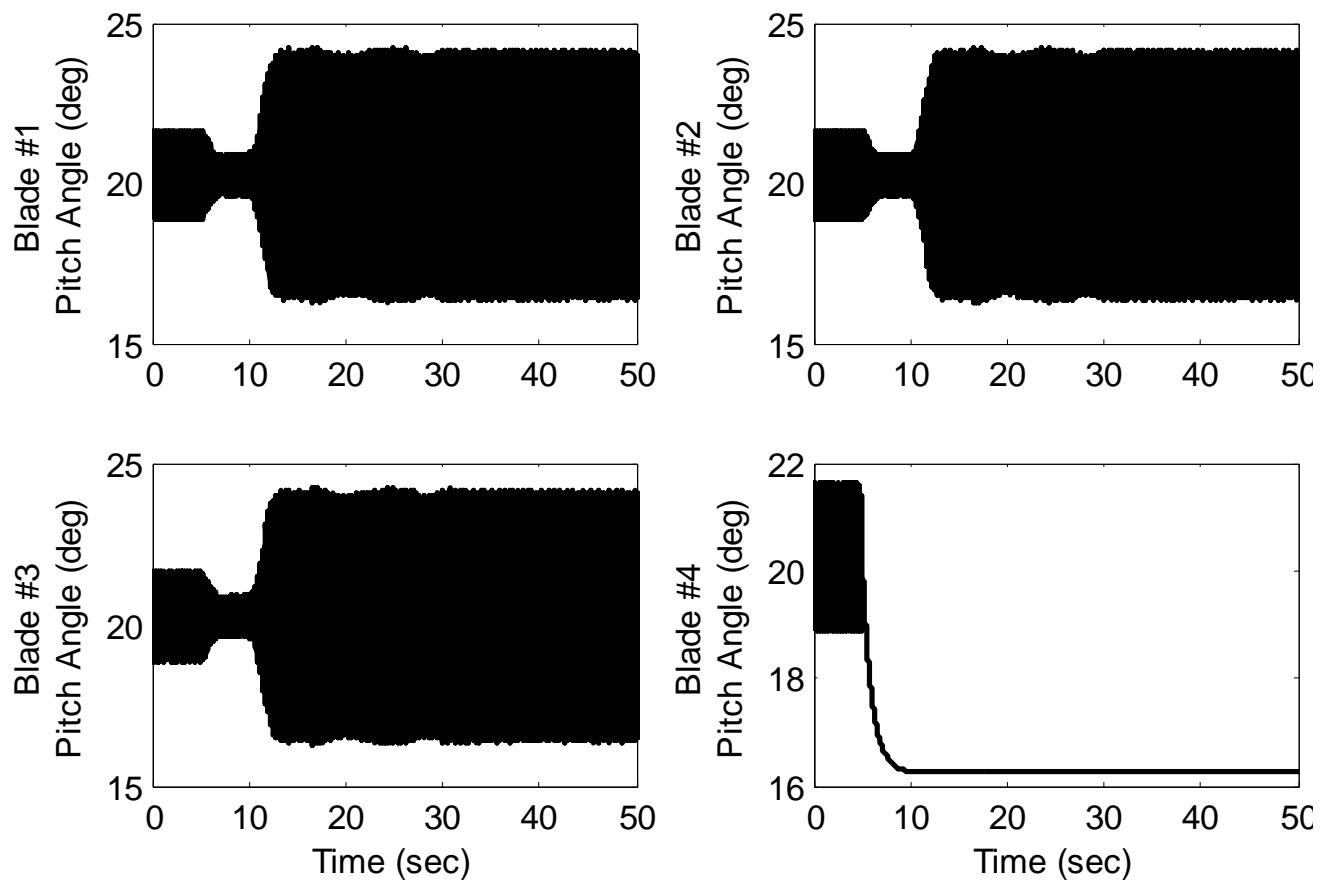

Figure 6.11: Blade Pitch Angles at the Rotor Hub (Blade \#4 Failure at 80 Knots)

It should be noted that as the failure is occurring (Blade \#4 transitioning to imposed value), the cyclic magnitude of the remaining three blades is temporarily reduced because of feedback and control mixing in the control system.

The corresponding aircraft Euler angles are presented in Figure 6.9. It should be noted that the failure occurred at five seconds in this scenario and then the pilot began to correct the failure at approximately ten seconds. 

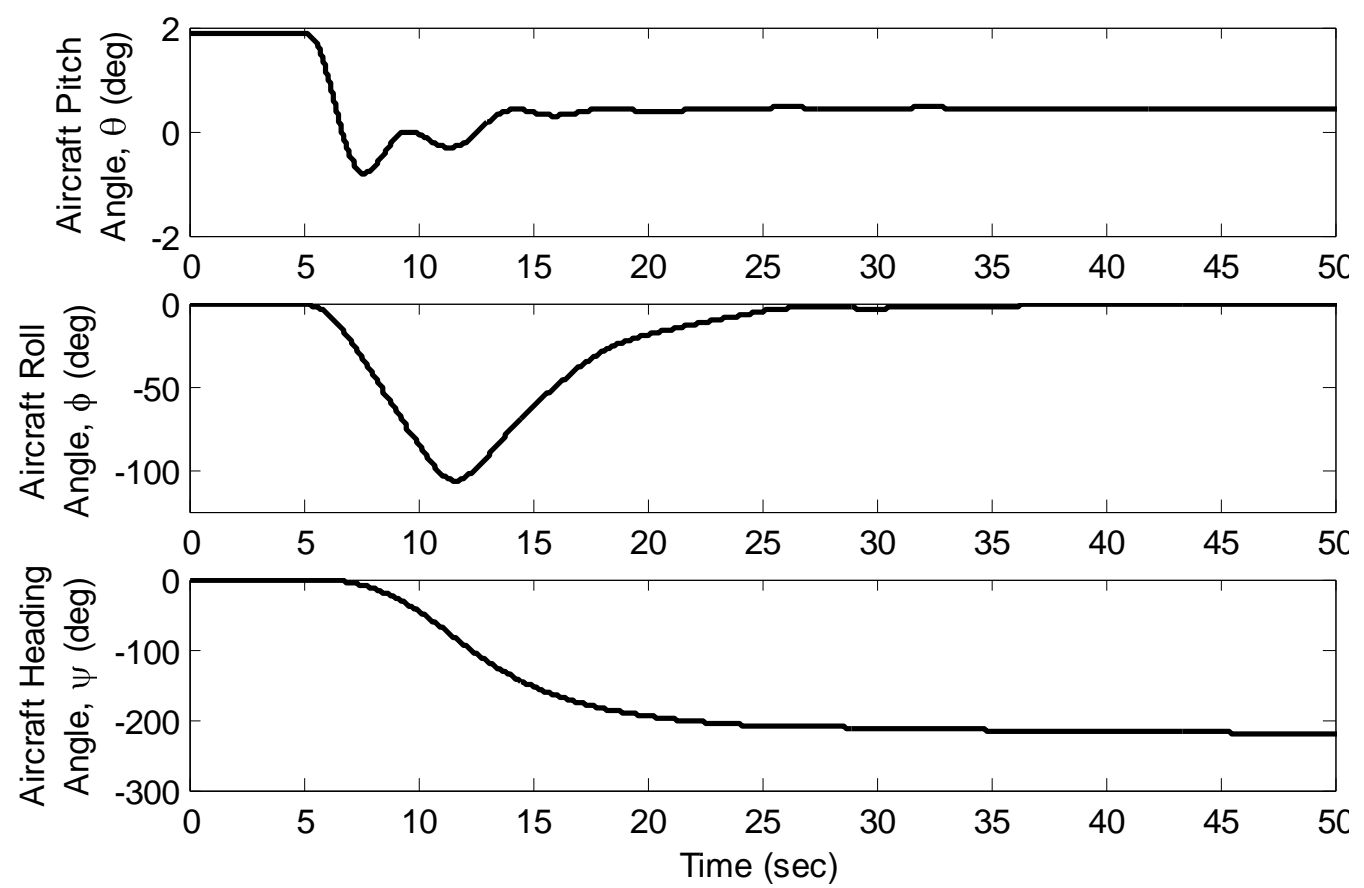

Figure 6.12: Aircraft Euler Angles (Blade \#4 Failure at 80 Knots)

The failure in this scenario causes the helicopter to roll to the left significantly, as well produce a large amount of yaw. It appears that the helicopter is preparing to enter a downward spiral similar to that of the lateral cyclic failure for the swashplate configuration. At approximately ten seconds the pilot begins to correct the roll by increasing the lateral cyclic of the remaining three blades (joystick tilted to the right as shown in Figure 6.13). The yaw is gradually reduced to a constant heading angle and the roll angle returns to a value approximately equal to the original trim condition. It is also important to note that the pilot was able return to the trim conditions without the aid of any fault-tolerant control systems. This manual correction of blade failure is better illustrated by examining the flight path angle shown in 


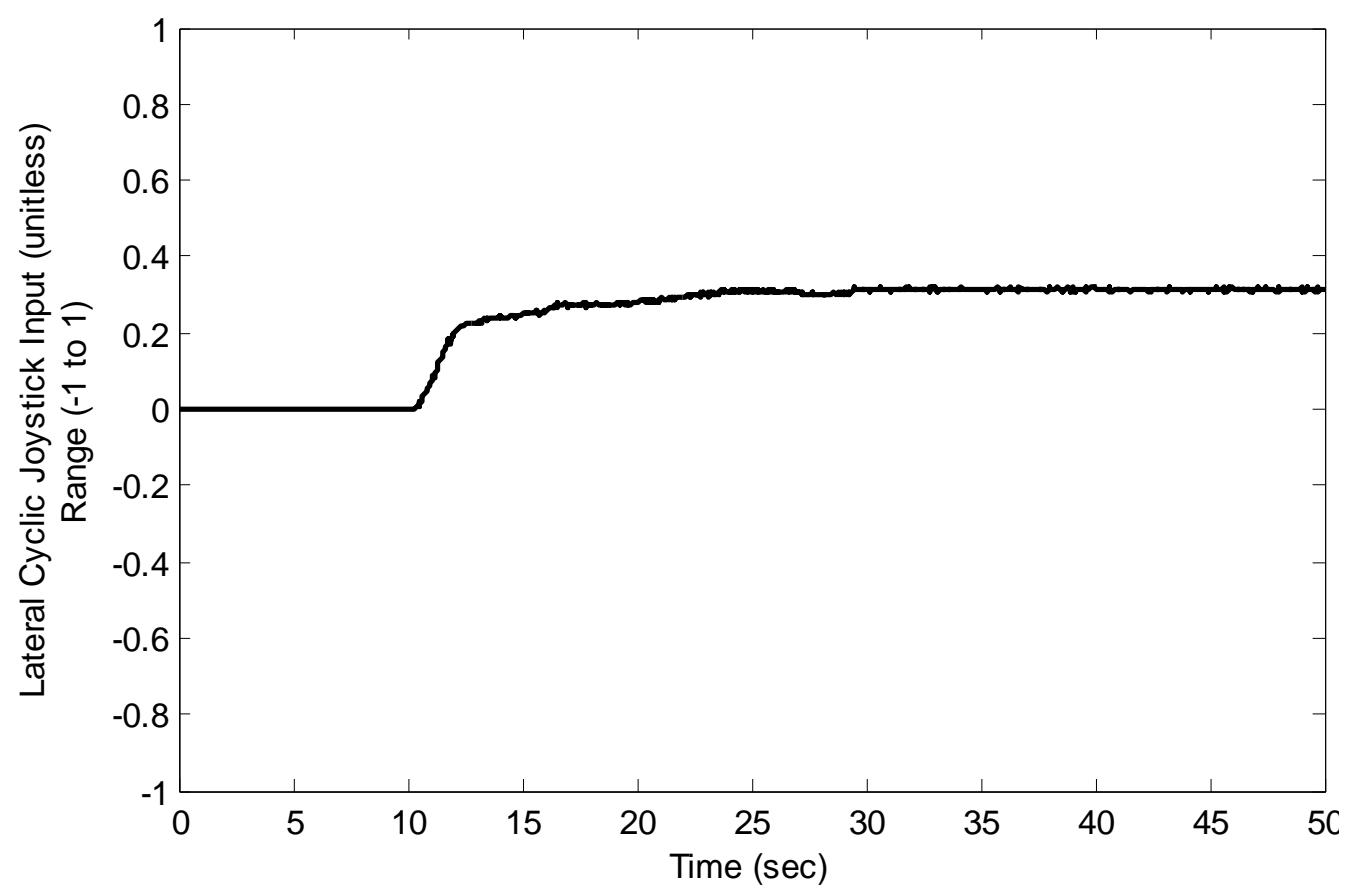

Figure 6.13: Lateral Cyclic Joystick Input (Blade \#4 Failure at 80 Knots)

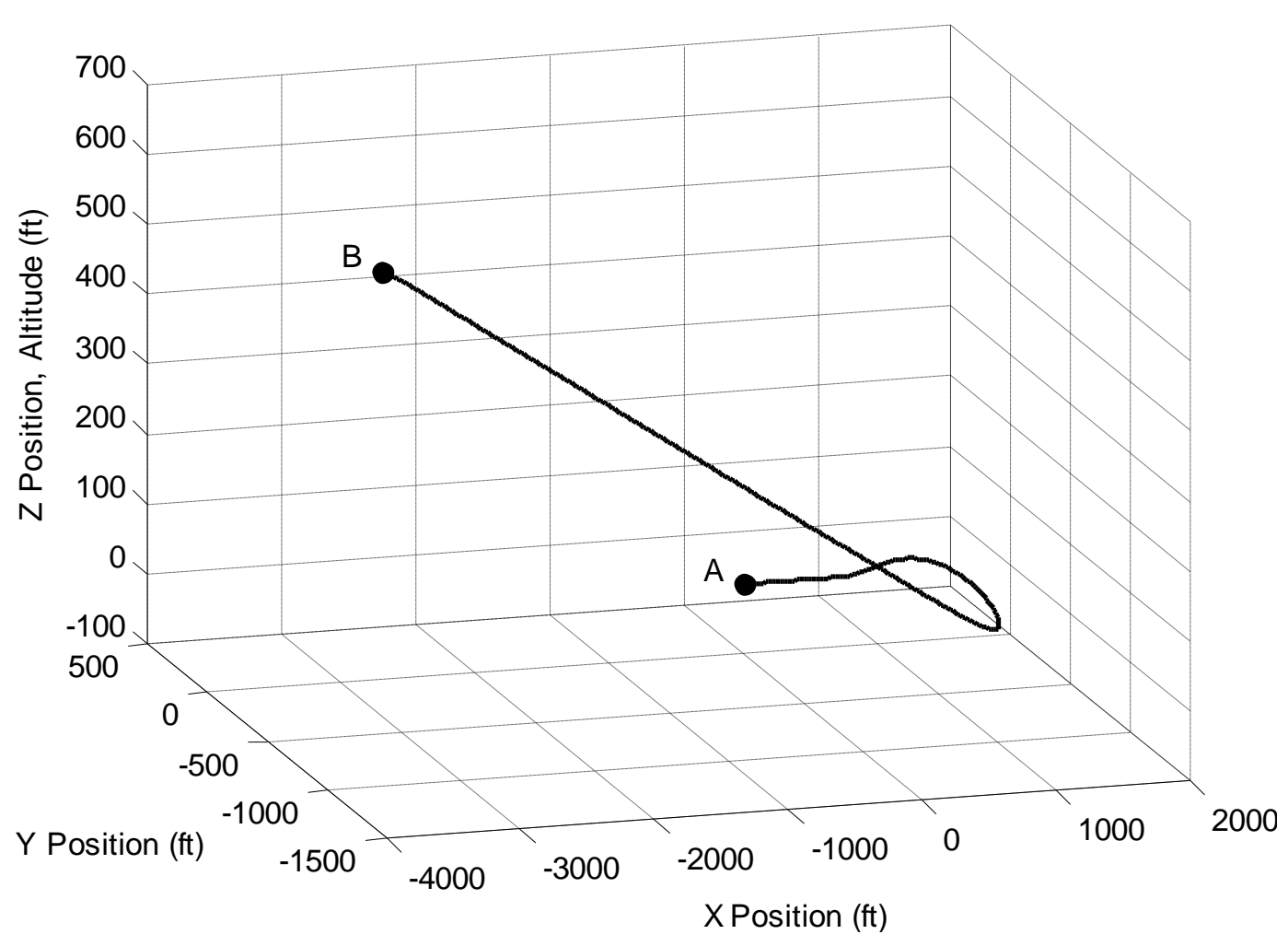

Figure 6.14: Helicopter Flight Path Relative to the Earth (Blade \#4 Failure at 80 Knots)

It is evident from Figure 6.14 that manually increasing the lateral cyclic for the remaining three blades to offset the failure of blade \#4 will consequently increase the overall thrust 
produced by the main rotor. So even though the helicopter Euler angles have been returned to their original trim position and the aircraft is flying straight, a constant climb angle is enforced on the aircraft. The constant climb angle can be limited by reducing the collective blade pitch of the remaining three blades while simultaneously increasing the lateral cyclic inputs. While an experienced pilot is capable of achieving this feat, the addition of fault-tolerant control laws will greatly reduce the complexity of this maneuver. 


\section{Chapter 7: Conclusions and Recommendations}

\subsection{Conclusions}

Virtually all of today's helicopters are designed with a swashplate-based system for control of the main rotor blades. However, the swashplate-based approach for controlling the main rotor does not provide the level of redundancy necessary to cope with abnormal actuator conditions. In this research effort, subsystem failures to the main rotor actuators are overcome with the application of individual blade control. Individual blade control is achieved using the blade pitch control method, which replaces the normally rigid pitch links between the swashplate and the pitch horn of the blade with hydraulic or electronic actuators. This design modification provides complete authority of the aerodynamic characteristics of each rotor blade at any given time.

The results of this research effort prove that IBC can be used to provide the redundancy necessary for subsystem failure accommodation. Without the kinetic restrictions of the swashplate, the IBC model effectively decouples the cyclic control inputs between different blades. Simulations of the IBC model prove that the primary control functions can be manually reconfigured after local actuator failures are initiated, thus preventing a catastrophic failure or crash.

The next step in examining the potential of IBC for subsystem failure accommodation is to design fault-tolerant control laws for the purposes of maintaining trimmed flight after a failure. Since linear models are used in this research effort, the simulator promises to be a useful tool for the design, testing, and analysis of fault-tolerant control laws. Furthermore, the mathematical models can be easily adapted to implement a different aircraft for simulation if geometric, gravimetric, and general aerodynamic data are available.

\subsection{Recommendations}

The accuracy of both the swashplate and IBC simulations can be improved by incorporating several design modifications into each model. First, the main rotor calculations presented in this report are based primarily on momentum theory. As stated previously, momentum theory is a simplified approach that examines the main rotor as a single input/output system. While this approach provides reasonably accurate results for the swashplate model, some accuracy is lost for the IBC model under blade failures. Single, or multiple, blade failures 
affect the main rotor flow field in a manner that cannot be accurately modeled using momentum theory at this time. Ideally, a CFD model needs to be developed to model the main rotor of an IBC helicopter with a high level of precision. In the absence of a complex CFD model, blade element momentum theory could also be used to develop a main rotor model with a reasonably high level of accuracy. BEMT calculates the lift and drag forces produced by each individual rotor blades as a function of angle of attack and rotor wake. Therefore, this approach could be used to account for the flow field discrepancies produced by single or multiple blade failures. Additionally, since BEMT separates the rotor blade into individual blade elements, the approach can be used to model failure scenarios for a damaged or detached blade surfaces.

Next, sideslip should be incorporated into the derivation of the forward flight model. By incorporating sideslip, a better comparison can made with validation data provided by Ballin [25] and Hilbert [24]. Next, the swashplate and IBC simulations can be improved by incorporating the control system developed by Howlett [22] for the UH-60A Black Hawk Engineering Simulation Program. This control system features a variety of stabilty augmentation systems that can imporove the handling qualities of the aircraft. 


\section{References}

[1] Ham, N.D. , "Helicopter Individual-Blade-Control and its Applications," 39th Annual Forum of the American Helicopter Society, St. Louis, MO, May 9-11, 1983, pp. 613-623.

[2] Prouty, R. W. , Helicopter Performance, Stability, and Control. Malabar, FL: Krieger Publishing Company, Inc., 2002.

[3] Federal Aviation Administration. (2000) Rotorcraft Flying Handbook. [Online]. www.faa.gov/library/manuals/aircraft/media/faa-h-8083-21.pdf

[4] Leishman, J. G. , Principles of Helicopter Aerodynamics, 2nd ed. New York, NY: Cambridge University Press, 2006.

[5] Milgram, J. , Chopra, I. , and Straub, F , "Rotors with Trailing Edge Flaps: Analysis and Comparison with Experimental Data," Journal of the American Helicopter Society, Oct. 1998.

[6] Shen, J and Chopra, I. , "Swashplateless Helicopter Rotor with Trailing-Edge Flaps," Journal of Aircraft, vol. 41, no. 2, pp. 208-214, March-April 2004.

[7] Shen, J. , Yang, M. , and Chopra, I. , "Swashplateless Helicopter Rotor with Trailing-Edge Flaps for Flight and Vibration Control," Journal of Aircraft, vol. 43, no. 2, March-April 2006.

[8] Kaman, C.H. , "Aircraft of Rotary Wing Type," Kaman Aircraft Corp., US Patent No. 2,455,866, Dec. 1948.

[9] Straub, F.K. , "A Feasability Study of Using Smart Materials for Rotorcraft," Smart Materials and Structures, vol. 5, no. 1, pp. 1-10, 1995.

[10] Büter, A. , Ehlert, U.C. , Sachau, D. , and Breitbach, E. , "Adaptive Rotor Blade Techniques - Direct Twist and Camber Variation," RTO AVT Symposium on "Active Control Technology for Enhanced Performance Operational Capabilities of Military Aircraft, Land Vehicles and Sea Vehicles", Braunschweig, Germany, May 8-11, 2000.

[11] Wilbur, M.L. , Yeager, W.T. , and Keats, W. , "Hover Testing of the NASA/Army/MIT Active Twist Rotor Prototype Blade," 56th Annual Forum of the American Helicopter Society, Virginia Beach, VA, May 2-4, 2000.

[12] Zimmer, H. , "Helicopter Rotor Blade Control," Dornier GmbH, US Patent No. 4,799,859, Jan. 1989.

[13] Kweder, J. , Panther, C.C. , and Smith, J.E. , "Applications of Circulation Control, Yesterday and Today," International Journal of Engineering, vol. 4, no. 5, pp. 411-429, Dec. 2010.

[14] Lyons, M.J. , "Circulation Control Improvements to Rotor Lift Asymmetry Due to Reverse Flow," West Virginia University, Morgantown, WV, Master's Thesis 2009.

[15] Jacklin, S.A., et al. , "Full-Scale Wind Tunnel Test of an Individual Blade Control System for a UH-60 Helicopter," 58th Annual Forum of the American Helicopter Society, Montreal, CA, June 11-13, 2002.

[16] Arnold, U.T.P , Fuerst, D. , Neuheuser, T. , and Bartels, R. , "Development of an Integrated Electrical Swashplateless Primary and Individual Blade Control System," 63th Annual Forum of the American Helicopter Society, Virginia Beach, VA, May 1-3, 2007. 
[17] U.S. Centennial of Flight Commision. (2011, March) Centennial of Flight. [Online]. http://www.centennialofflight.gov/essay/Theories_of_Flight/Devices/TH17G6.htm

[18] Perhinschi, M. and Tamayo, S. , "A Simulation Environment for Individual Blade Control Helicopters," AIAA Modeling and Simulation Technologies Conference, Chicago, IL, 2009, p. 2.

[19] Ganguli, R. , Jehnert, B. , Wolfram, J. , and Voersmann, P. , "Survivability of Helicopter with Individual Blade Primary Control Failure," The Aeronautical Journal, vol. 111, no. 1124, pp. 645-657, Oct. 2007.

[20] Civil Aviation Authority of New Zealand, "Wake Turbulence," Lower Hutt, New Zealand, GAP Booklet 2008.

[21] Johnson, W. , Helicopter Theory, 1st ed. Princeton, NJ: Princeton University Press, 1980.

[22] Howlett, J.J. , "UH-60A Black Hawk Engineering Simulation Program: Volume 1 Mathematical Model," National Aeronautics and Space Administration, NASA-CR-166309, 1981.

[23] Padfield, G.D. , Helicopter Flight Dynamics: The Theory and Application of Flying Qualities and Simulation Modeling, 2nd ed. Washington DC: American Institute of Aeronautics and Astronautics, Inc., 2007.

[24] Hilbert, K.B. , "A Mathematical Model of the UH-60 Helicopter," National Aeronautics and Space Administration, NASA-TM-85890, 1984.

[25] Ballin, Mark G. , "Validation of a Real-Time Engineering Simulation of the UH-60A Helicopter," National Aeronautics and Space Administration, NASA-TM-88160, 1987.

[26] Lowry, D., et al. , "Structural Concepts and Aerodynamic Analysis for Low Radar Cross Section (LCRS) Fuselage Configurations," United Technologies Corporation, Stratford, CT, 1978.

[27] Talbot, P.D., et al. , "A Mathematical Model of a Single Main Rotor Helicopter for Piloted Simulation," National Aeronautics and Space Administration, NASA-TM-84281, 1982.

[28] Tamayo, S. , Zinchiak, A. , and Perhinschi, M. , "Development of Linear Models for Individual Blade Control Helicopter," AIAA Modeling and Simulation Technologies Conference, Portland, Oregon, August, 2011, (Accepted, not yet published). 


\section{Appendix A: UH-60 Helicopter Constants}

The data for the following tables is derived assuming standard sea-level conditions.

Table A.1: UH-60 Helicopter Constants (Aircraft Mass and Inertias)

\begin{tabular}{|c|c|c|c|c|}
\hline Description & Symbol & $\begin{array}{l}\text { Computer } \\
\text { Mnemonic } \\
\end{array}$ & Units & $\begin{array}{l}\text { UH-60 } \\
\text { Value } \\
\end{array}$ \\
\hline Aircraft Gross Weight & $G W$ & GW & $l b$ & 16,638 \\
\hline Aircraft Roll Inertia & $I_{X X}$ & Ix & $\operatorname{slugs}-f t^{2}$ & 4,659 \\
\hline Aircraft Pitch Inertia & $I_{Y Y}$ & Iy & $\operatorname{slugs-} f t^{2}$ & 38,512 \\
\hline Aircraft Yaw Inertia & $I_{Z Z}$ & Iz & $\operatorname{slugs}-f t^{2}$ & 36,796 \\
\hline Aircraft Cross Coupling Inertia & $I_{X Z}$ & $I x z$ & $\operatorname{slugs}-f t^{2}$ & 1,882 \\
\hline Aircraft CG Stationline & $C G_{X}$ & $\operatorname{cg} x$ & in. & 355.9 \\
\hline Aircraft CG Buttline & $C G_{Y}$ & cgy & in. & 0 \\
\hline Aircraft CG Waterline & $C G_{Z}$ & $\operatorname{cg} z$ & in. & 248.2 \\
\hline
\end{tabular}

Table A.2: UH-60 Helicopter Constants (Main Rotor)

\begin{tabular}{|c|c|c|c|c|}
\hline Description & Symbol & $\begin{array}{l}\text { Computer } \\
\text { Mnemonic }\end{array}$ & Units & $\begin{array}{l}\text { UH-60 } \\
\text { Value } \\
\end{array}$ \\
\hline Number of Blades & $n$ & bn & $N-D$ & 4 \\
\hline MR Blade Weight & $W$ & Wb & $f t$ & 256.9 \\
\hline MR Radius & $R$ & $\mathrm{R}$ & $f t$ & 26.83 \\
\hline MR Chord & $c$ & $\mathrm{C}$ & $f t$ & 1.73 \\
\hline MR Hinge Offset & $e$ & e & $f t$ & 1.25 \\
\hline MR Spare Length Exposed & $e^{\prime}$ & e_prime & $f t$ & 3.83 \\
\hline MR Hinge Offset Ratio & $\varepsilon$ & epsln & percent/100 & 0.0466 \\
\hline MR Tip Loss Factor & $B$ & $\mathrm{~B}$ & $N-D$ & 0.97 \\
\hline MR Rotational Speed & $\Omega$ & $\mathrm{OM}$ & $\mathrm{rad} / \mathrm{sec}$ & 27 \\
\hline MR Lift Curve Slope & $a$ & a & $\mathrm{rad}^{-1}$ & 5.73 \\
\hline MR Linear Twist & $\theta_{1}$ & tet 1 & rad & -0.3142 \\
\hline MR Flapping Spring Constant & $K_{\beta}$ & $\mathrm{Kb}$ & $l b-f t / r a d$ & 0 \\
\hline MR Pitch-Flap Coupling Tangent of $\delta_{3}$ & $K_{1}$ & K1 & $N-D$ & 0 \\
\hline MR Incidence Angle & $i_{M}$ & $\mathrm{im}$ & $\mathrm{rad}$ & -0.0524 \\
\hline MR Blade Area (Combined) & $A_{b}$ & $\mathrm{Ab}$ & $f t^{2}$ & 185.66 \\
\hline MR Individual Blade Area & $S$ & $\mathrm{~S}$ & $f t^{2}$ & 46.416 \\
\hline MR Disk Area & $A$ & A_m & $f t^{2}$ & 2261.5 \\
\hline
\end{tabular}




\begin{tabular}{|l|c||c|c|c||}
\hline \multicolumn{1}{|c|}{ Description } & Symbol & $\begin{array}{c}\text { Computer } \\
\text { Mnemonic }\end{array}$ & Units & $\begin{array}{c}\text { UH-60 } \\
\text { Value }\end{array}$ \\
\hline \hline MR Solidity & $\sigma$ & sigma & $N-D$ & 0.0821 \\
\hline $\begin{array}{l}\text { MR Moment of Inertia of Blade About } \\
\text { the Flapping Hinge }\end{array}$ & $I_{b}$ & Ib & slugs- $f t^{2}$ & 1512.6 \\
\hline $\begin{array}{l}\text { MR Static Moment of Blade About the } \\
\text { Flapping Hinge }\end{array}$ & $M_{b}$ & Mb & $f t$-lb & 2789.5 \\
\hline MR Blade Lock Number & $\gamma$ & Lock & $N-D$ & 8.0721 \\
\hline MR Gain Factor of the Harmonic Inflow & $K_{C T}$ & KCT & $N-D$ & 1.0 \\
\hline MR Time Factor of the Harmonic Inflow & $T_{D W O}$ & TDWO & $N-D$ & 0.01038 \\
\hline MR Stiffness & $d M / d_{a_{1 s}}$ & Mals_m & $f t-l b / r a d$ & 154,120 \\
\hline MR Longitudinal CG Offset & $l_{m}$ & lm & $f t$ & -1.225 \\
\hline MR Lateral CG Offset & $y_{m}$ & ym & $f t$ & 0 \\
\hline MR Vertical CG Offset & $h_{m}$ & $\mathrm{hm}$ & $f t$ & 5.567 \\
\hline \hline
\end{tabular}

Table A.3: UH-60 Helicopter Constants (Tail Rotor)

\begin{tabular}{|c|c|c|c|c|}
\hline Description & Symbol & $\begin{array}{l}\text { Computer } \\
\text { Mnemonic } \\
\end{array}$ & Units & $\begin{array}{l}\text { UH-60 } \\
\text { Value }\end{array}$ \\
\hline Number of Blades & $n_{T}$ & bn_t & $N-D$ & 4 \\
\hline TR Radius & $R_{T}$ & $R_{-} t$ & $f t$ & 5.5 \\
\hline TR Chord & $c_{T}$ & $c_{-} t$ & $f t$ & 0.81 \\
\hline TR Tip Loss Factor & $B_{T}$ & $B_{-} t$ & $N-D$ & 0.92 \\
\hline TR Rotational Speed & $\Omega_{T}$ & $\mathrm{OM} \_t$ & $\mathrm{rad} / \mathrm{sec}$ & 124.62 \\
\hline TR Lift Curve Slope & $a_{T}$ & $a_{-} t$ & $\mathrm{rad}^{-1}$ & 5.73 \\
\hline TR Linear Twist & $\theta_{1_{T}}$ & tet1_t & $\mathrm{rad}$ & -0.3142 \\
\hline TR Blade Area (Combined) & $A_{b_{T}}$ & $A b_{-} t$ & $f t^{2}$ & 17.82 \\
\hline TR Disk Area & $A_{T}$ & A_t & $f t^{2}$ & 95.03 \\
\hline TR Solidity & $\sigma_{T}$ & sigma_t & $N-D$ & 0.1875 \\
\hline TR Cant Angle & $\Gamma$ & cant & $\mathrm{rad}$ & 0.3491 \\
\hline TR Pitch-Flap Coupling Angle & $\delta_{3}$ & delta_3 & $\mathrm{rad}$ & 0.6109 \\
\hline $\begin{array}{l}\text { TR Moment of Inertia of Blade About } \\
\text { the Flapping Hinge }\end{array}$ & $I_{b_{T}}$ & $I b_{-} t$ & $\operatorname{slugs}-f t^{2}$ & 3.1 \\
\hline TR Blade Lock Number & $\gamma_{T}$ & Lock_t & $N-D$ & 3.2566 \\
\hline TR Hub Drag & $C_{D_{T}}$ & CDTR & $N-D$ & 0.4 \\
\hline TR Longitudinal CG Offset & $l_{T}$ & $1 t$ & $f t$ & 34.3417 \\
\hline TR Lateral CG Offset & $y_{T}$ & yt & $f t$ & -1.167 \\
\hline TR Vertical CG Offset & $h_{T}$ & $\mathrm{ht}$ & $f t$ & 6.375 \\
\hline
\end{tabular}


Table A.4: UH-60 Helicopter Constants (Fuselage)

\begin{tabular}{|l|c||c|c|c|}
\hline \multicolumn{1}{|c|}{ Description } & Symbol & $\begin{array}{c}\text { Computer } \\
\text { Mnemonic }\end{array}$ & Units & $\begin{array}{c}\text { UH-60 } \\
\text { Value }\end{array}$ \\
\hline Fus. Sidewash Derivative & $d \eta_{F} / d \beta$ & etabeta_f & $N-D$ & 0.064 \\
\hline Fus. Longitudinal CG Offset & $l_{F}$ & lf & $f t$ & 0.0806 \\
\hline Fus. Lateral CG Offset & $y_{F}$ & yf & $f t$ & 0 \\
\hline Fus. Vertical CG Offset & $h_{F}$ & $\mathrm{hf}$ & $f t$ & -0.3664 \\
\hline
\end{tabular}

Table A.5: UH-60 Helicopter Constants (Horizontal Stabilizer)

\begin{tabular}{|c|c|c|c|c|}
\hline Description & Symbol & $\begin{array}{l}\text { Computer } \\
\text { Mnemonic }\end{array}$ & Units & $\begin{array}{l}\text { UH-60 } \\
\text { Value }\end{array}$ \\
\hline HS Area & $A_{H}$ & A_h & $f t^{2}$ & 45 \\
\hline HS Span & $b_{H}$ & $b_{-}{ }^{H}$ & $f t$ & 14.38 \\
\hline HS Aspect ratio & $A R_{H}$ & ar_h & $N-D$ & 4.6 \\
\hline HS Lift Curve Slope & $a_{H}$ & $a_{-} h$ & $\mathrm{rad}^{-1}$ & 3.934 \\
\hline HS Induced Velocity Ratio & $v_{H} / v_{1}$ & $\mathrm{vh} \_\mathrm{v} 1$ & $N-D$ & 1.8 \\
\hline HS Zero Lift Angle of Attack & $\alpha_{L 0_{\mathrm{H}}}$ & alfao_h & $\mathrm{rad}$ & 0 \\
\hline $\begin{array}{l}\text { HS Downwash Angle from Fus. for } \\
\alpha_{F}=0\end{array}$ & $\varepsilon_{F_{\alpha_{F=0}}}$ & epsF0_h & $\mathrm{rad}$ & 0.0079 \\
\hline HS Span Efficiency factor & $\delta_{i_{H}}$ & deltai_h & $N-D$ & 0.014 \\
\hline HS Zero Lift Drag Coefficient & $C_{D_{0_{H}}}$ & $\mathrm{CdO}$ & $N-D$ & 0.01 \\
\hline HS Longitudinal CG Offset & $l_{H}$ & Ih & $f t$ & 28.6833 \\
\hline HS Lateral CG Offset & $y_{H}$ & yh & $f t$ & 0 \\
\hline HS Vertical CG Offset & $h_{H}$ & $\mathrm{hh}$ & $f t$ & -0.35 \\
\hline
\end{tabular}

Table A.6: UH-60 Helicopter Constants (Vertical Stabilizer)

\begin{tabular}{|l|c||c|c|c||}
\hline \multicolumn{1}{|c|}{ Description } & Symbol & $\begin{array}{c}\text { Computer } \\
\text { Mnemonic }\end{array}$ & Units & $\begin{array}{c}\text { UH-60 } \\
\text { Value }\end{array}$ \\
\hline VS Area & $A_{V}$ & A_v & $f t^{2}$ & 32.3 \\
\hline VS Span & $b_{V}$ & b_v & $f t$ & 8.167 \\
\hline VS Geometric Aspect ratio & $A R_{V}$ & ar_v & $N-D$ & 1.92 \\
\hline VS Effective Aspect ratio & $A R_{E f f_{V}}$ & areff_h & $N-D$ & 4.647 \\
\hline VS Lift Curve Slope & $a_{V}$ & a_v & $\mathrm{rad}^{-1}$ & 2.507 \\
\hline VS Zero Lift Angle of Attack & $\alpha_{L 0_{V}}$ & alfa0_v & $\mathrm{rad}^{-1}$ & 0.0262 \\
\hline VS Span Efficiency factor & $\delta_{i_{V}}$ & deltai_v & $N-D$ & 0.012 \\
\hline VS Avg. MR Sidewash Angle & $\eta_{M_{V}}$ & eta_m_v & $\mathrm{rad}$ & -0.0524 \\
\hline
\end{tabular}




\begin{tabular}{|l|c||c||c|c||}
\hline \multicolumn{1}{|c|}{ Description } & Symbol & $\begin{array}{c}\text { Computer } \\
\text { Mnemonic }\end{array}$ & Units & $\begin{array}{c}\text { UH-60 } \\
\text { Value }\end{array}$ \\
\hline \hline VS Lift Coefficient $(\beta=0)$ & $C_{L_{V}}$ & CLvert & $N-D$ & -0.06 \\
\hline VS Angle of Attack & $\alpha_{V}$ & alfa_v & $r a d$ & -0.0239 \\
\hline VS Longitudinal CG Offset & $l_{V}$ & $l \mathrm{v}$ & $f t$ & 28.2583 \\
\hline VS Lateral CG Offset & $y_{V}$ & $\mathrm{yv}$ & $f t$ & 0 \\
\hline VS Vertical CG Offset & $h_{V}$ & $\mathrm{hv}$ & $f t$ & 2.0667 \\
\hline
\end{tabular}

Table A.7: UH-60 Helicopter Control System Characteristics

\begin{tabular}{|c|c|c|c|c|c|}
\hline \multicolumn{2}{|r|}{ Description } & \multirow{2}{*}{$\begin{array}{c}\text { Symbol } \\
C_{A_{1 s}} \\
\end{array}$} & \multirow{2}{*}{$\begin{array}{c}\text { Computer } \\
\text { Mnemonic } \\
\text { CA1S }\end{array}$} & \multirow{2}{*}{$\begin{array}{r}\text { Units } \\
\text { rad }\end{array}$} & \multirow{2}{*}{$\begin{array}{c}\text { UH-60 } \\
\text { Value } \\
0\end{array}$} \\
\hline \multirow{8}{*}{ Controls } & $\begin{array}{l}\text { Swashplate lateral cyclic pitch for } \\
\text { zero lateral cyclic stick }\end{array}$ & & & & \\
\hline & $\begin{array}{l}\text { Swashplate longitudinal cyclic } \\
\text { pitch for zero longitudinal cyclic } \\
\text { stick }\end{array}$ & $C_{B_{1_{s}}}$ & CB1S & rad & 0 \\
\hline & $\begin{array}{l}\text { Longitudinal cyclic control } \\
\text { sensitivity }\end{array}$ & $C K_{1}$ & CK1 & $\mathrm{rad} / \mathrm{in}$. & 0.04939 \\
\hline & Lateral cyclic control sensitivity & $C K_{2}$ & $\mathrm{CK} 2$ & $\mathrm{rad} / \mathrm{in}$. & 0.02792 \\
\hline & $\begin{array}{l}\text { Main rotor root collective pitch for } \\
\text { zero collective stick }\end{array}$ & $C_{5}$ & C5 & rad & 0.2286 \\
\hline & $\begin{array}{l}\text { Main rotor collective control } \\
\text { sensitivity }\end{array}$ & $C_{6}$ & $\mathrm{C} 6$ & $\mathrm{rad} / \mathrm{in}$. & 0.02792 \\
\hline & $\begin{array}{l}\text { Tail rotor collective pitch for zero } \\
\text { pedal position }\end{array}$ & $C_{7}$ & $\mathrm{C} 7$ & rad & 0.1743 \\
\hline & Pedal sensitivity & $C_{8}$ & $\mathrm{C} 8$ & $\mathrm{rad} / \mathrm{in}$. & -0.07734 \\
\hline \multirow{4}{*}{$\begin{array}{l}\text { Feedforward } \\
\text { Gains }\end{array}$} & $\begin{array}{l}\text { Longitudinal stick to longitudinal } \\
\text { cyclic }\end{array}$ & $\delta_{e} / \delta_{e_{p}}$ & SK1 & in./in. & 1.0 \\
\hline & Lateral stick to lateral cyclic & $\delta_{a} / \delta_{a_{p}}$ & SK5 & in./in. & 1.0 \\
\hline & $\begin{array}{l}\text { Collective stick to collective } \\
\text { control }\end{array}$ & $\delta_{c} / \delta_{c_{p}}$ & SK9 & in./in. & 1.0 \\
\hline & Pedal to directional control & $\delta_{p} / \delta_{p_{p}}$ & SK10 & in./in. & 1.0 \\
\hline \multirow{4}{*}{$\begin{array}{l}\text { Crossfeed } \\
\text { Gains }\end{array}$} & $\begin{array}{l}\text { Collective stick to longitudinal } \\
\text { cyclic }\end{array}$ & $\delta_{e} / \delta_{c_{p}}$ & SK 4 & in./in. & -0.1640 \\
\hline & Pedals to longitudinal cyclic & $\delta_{e} / \delta_{p_{p}}$ & SKM2 & in./in. & -0.5746 \\
\hline & Collective stick to lateral cyclic & $\delta_{a} / \delta_{c_{p}}$ & SK 8 & in./in. & -0.16 \\
\hline & $\begin{array}{l}\text { Collective stick to directional } \\
\text { control }\end{array}$ & $\delta_{p} / \delta_{c_{p}}$ & SK11 & in./in. & -0.2889 \\
\hline \multirow{2}{*}{$\begin{array}{l}\text { Feedback } \\
\text { Gains }\end{array}$} & Pitch rate to lateral cyclic & $\delta_{a} / q_{B}$ & SKV32 & $\mathrm{in} . / \mathrm{rad} / \mathrm{sec}$ & 1.3 \\
\hline & Roll rate to longitudinal cyclic & $\delta_{a} / p_{B}$ & SKV61 & in. $/ \mathrm{rad} / \mathrm{sec}$ & -0.88 \\
\hline
\end{tabular}




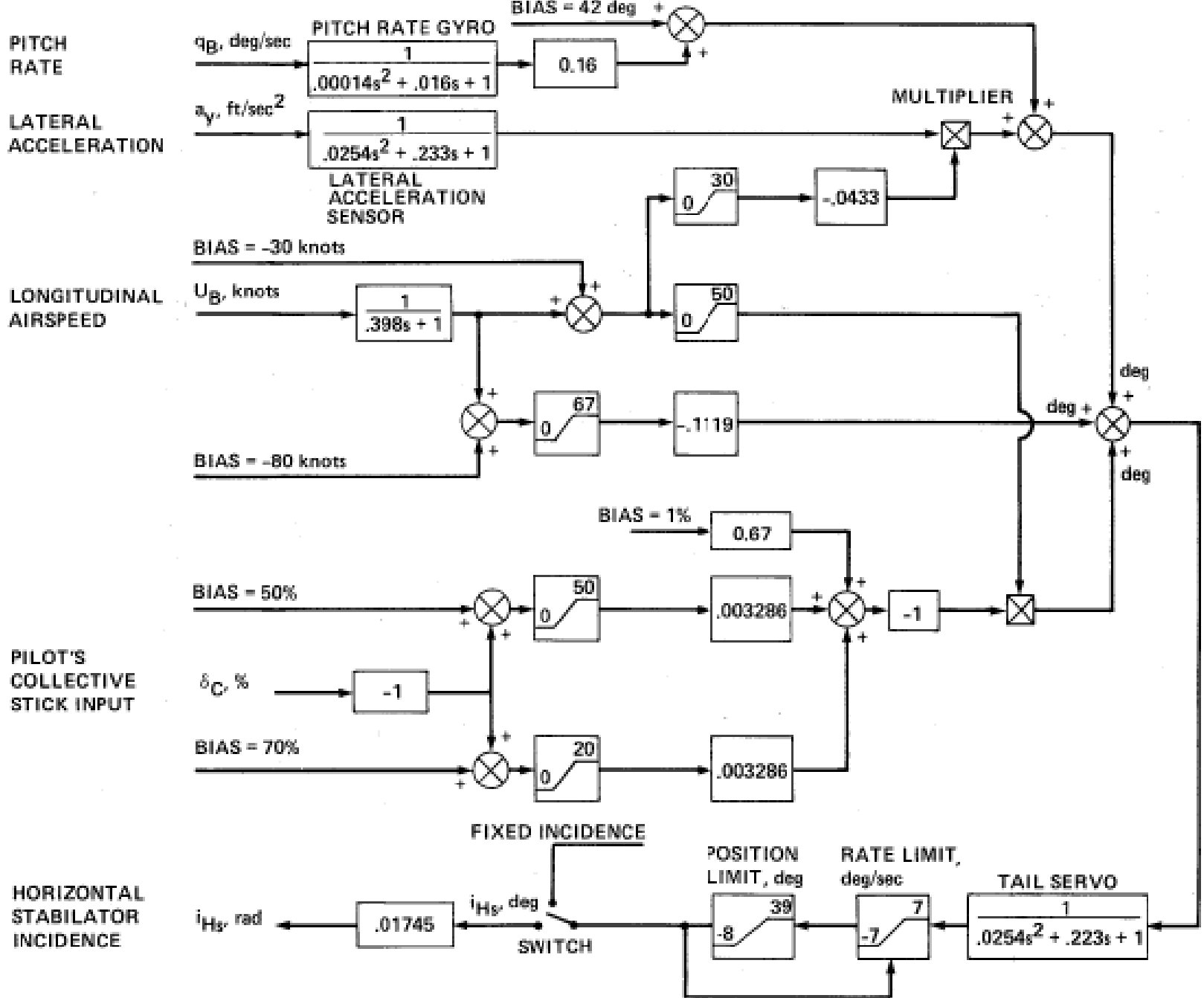

Figure A.1: UH-60 Horizontal Stabilator Control System [24] 


\section{Appendix B: Stability and Control Derivatives}

Table B.1: Stability and Control Derivative Comparison (Hover)

\begin{tabular}{|c|c|c|c|c|c|c|c|c|}
\hline & \multicolumn{4}{|c|}{ WVU Linear Model } & \multicolumn{2}{|c|}{ NASA AMES (HILBERT) } & \multicolumn{2}{|c|}{ BOEING-VERTOL } \\
\hline $\mathrm{Xu}$ & -2.04 & $\mathrm{lb} / \mathrm{ft} / \mathrm{sec}$ & -0.0040 & $1 / \mathrm{sec}$ & -0.0235 & $1 / \mathrm{sec}$ & -0.0150 & $1 / \mathrm{sec}$ \\
\hline$X v$ & -0.59 & $\mathrm{lb} / \mathrm{ft} / \mathrm{sec}$ & -0.0012 & $1 / \mathrm{sec}$ & -0.0340 & $1 / \mathrm{sec}$ & N/A & $1 / \mathrm{sec}$ \\
\hline$X w$ & 0.00 & $\mathrm{lb} / \mathrm{ft} / \mathrm{sec}$ & 0.0000 & $1 / \mathrm{sec}$ & 0.0254 & $1 / \mathrm{sec}$ & N/A & $1 / \mathrm{sec}$ \\
\hline $\mathrm{Xq}$ & 417.96 & $\mathrm{lb} / \mathrm{rad} / \mathrm{sec}$ & 0.8200 & $\mathrm{ft} / \mathrm{rad} / \mathrm{sec}$ & 2.8090 & $\mathrm{ft} / \mathrm{rad} / \mathrm{sec}$ & N/A & $\mathrm{ft} / \mathrm{rad} / \mathrm{sec}$ \\
\hline $\mathrm{Xp}$ & -152.68 & $\mathrm{lb} / \mathrm{rad} / \mathrm{sec}$ & -0.2995 & $\mathrm{ft} / \mathrm{rad} / \mathrm{sec}$ & -0.2585 & $\mathrm{ft} / \mathrm{rad} / \mathrm{sec}$ & N/A & $\mathrm{ft} / \mathrm{rad} / \mathrm{sec}$ \\
\hline $\mathrm{Xr}$ & 0.00 & $\mathrm{lb} / \mathrm{rad} / \mathrm{sec}$ & 0.0000 & $\mathrm{ft} / \mathrm{rad} / \mathrm{sec}$ & -0.2071 & $\mathrm{ft} / \mathrm{rad} / \mathrm{sec}$ & N/A & $\mathrm{ft} / \mathrm{rad} / \mathrm{sec}$ \\
\hline $\mathrm{XB1}$ or $\mathrm{X}_{\delta \mathrm{e}}$ & 4960.53 & $\mathrm{lb} / \mathrm{rad}$ & N/A & $\mathrm{ft} / \mathrm{in} / \mathrm{sec}^{2}$ & -1.6590 & $\mathrm{ft} / \mathrm{in} / \mathrm{sec}^{2}$ & -1.7041 & $\mathrm{ft} / \mathrm{in} / \mathrm{sec}^{2}$ \\
\hline XA1 or $\mathrm{X}_{\delta \mathrm{a}}$ & -398.97 & $\mathrm{Ib} / \mathrm{rad}$ & N/A & $\mathrm{ft} / \mathrm{in} / \mathrm{sec}^{2}$ & 0.0436 & $\mathrm{ft} / \mathrm{in} / \mathrm{sec}^{2}$ & N/A & $\mathrm{ft} / \mathrm{in} / \mathrm{sec}^{2}$ \\
\hline $\mathrm{x} \theta$ or $\mathrm{X}_{\delta c}$ & 12307.63 & $\mathrm{Ib} / \mathrm{rad}$ & N/A & $\mathrm{ft} / \mathrm{in} / \mathrm{sec}^{2}$ & 0.9709 & $\mathrm{ft} / \mathrm{in} / \mathrm{sec}^{2}$ & N/A & $\mathrm{ft} / \mathrm{in} / \mathrm{sec}^{2}$ \\
\hline$x \theta_{T}$ or $X_{\delta p}$ & 0.00 & $\mathrm{lb} / \mathrm{rad}$ & N/A & $\mathrm{ft} / \mathrm{in} / \mathrm{sec}^{2}$ & 0.9544 & $\mathrm{ft} / \mathrm{in} / \mathrm{sec}^{2}$ & N/A & $\mathrm{ft} / \mathrm{in} / \mathrm{sec}^{2}$ \\
\hline $\mathrm{Yu}$ & 0.59 & $\mathrm{lb} / \mathrm{ft} / \mathrm{sec}$ & 0.0012 & $1 / \mathrm{sec}$ & 0.0338 & $1 / \mathrm{sec}$ & N/A & $1 / \mathrm{sec}$ \\
\hline Yv & -12.94 & $\mathrm{lb} / \mathrm{ft} / \mathrm{sec}$ & -0.0254 & $1 / \mathrm{sec}$ & -0.0473 & $1 / \mathrm{sec}$ & -0.0465 & $1 / \mathrm{sec}$ \\
\hline$Y w$ & 0.00 & $\mathrm{lb} / \mathrm{ft} / \mathrm{sec}$ & N/A & $1 / \mathrm{sec}$ & 0.0043 & $1 / \mathrm{sec}$ & N/A & $1 / \mathrm{sec}$ \\
\hline$Y q$ & -152.68 & $\mathrm{lb} / \mathrm{rad} / \mathrm{sec}$ & -0.2995 & $\mathrm{ft} / \mathrm{rad} / \mathrm{sec}$ & -0.3585 & $\mathrm{ft} / \mathrm{rad} / \mathrm{sec}$ & N/A & $\mathrm{ft} / \mathrm{rad} / \mathrm{sec}$ \\
\hline$Y p$ & -488.34 & $\mathrm{lb} / \mathrm{rad} / \mathrm{sec}$ & -0.9580 & $\mathrm{ft} / \mathrm{rad} / \mathrm{sec}$ & -1.7230 & $\mathrm{ft} / \mathrm{rad} / \mathrm{sec}$ & N/A & $\mathrm{ft} / \mathrm{rad} / \mathrm{sec}$ \\
\hline $\mathrm{Yr}$ & 337.49 & $\mathrm{lb} / \mathrm{rad} / \mathrm{sec}$ & 0.6621 & $\mathrm{ft} / \mathrm{rad} / \mathrm{sec}$ & 0.6383 & $\mathrm{ft} / \mathrm{rad} / \mathrm{sec}$ & N/A & $\mathrm{ft} / \mathrm{rad} / \mathrm{sec}$ \\
\hline YB1 or $\mathrm{Y}_{\delta \mathrm{e}}$ & 398.97 & $\mathrm{lb} / \mathrm{rad}$ & N/A & $\mathrm{ft} / \mathrm{in} / \mathrm{sec}^{2}$ & 0.0766 & $\mathrm{ft} / \mathrm{in} / \mathrm{sec}^{2}$ & N/A & $\mathrm{ft} / \mathrm{in} / \mathrm{sec}^{2}$ \\
\hline YA1 or $Y_{\delta a}$ & 4960.53 & $\mathrm{Ib} / \mathrm{rad}$ & N/A & $\mathrm{ft} / \mathrm{in} / \mathrm{sec}^{2}$ & 0.9420 & $\mathrm{ft} / \mathrm{in} / \mathrm{sec}^{2}$ & 0.9664 & $\mathrm{ft} / \mathrm{in} / \mathrm{sec}^{2}$ \\
\hline $\mathrm{Y} \theta$ or $\mathrm{Y}_{\delta c}$ & -4047.15 & $\mathrm{lb} / \mathrm{rad}$ & $N / A$ & $\mathrm{ft} / \mathrm{in} / \mathrm{sec}^{2}$ & 0.1005 & $\mathrm{ft} / \mathrm{in} / \mathrm{sec}^{2}$ & N/A & $\mathrm{ft} / \mathrm{in} / \mathrm{sec}^{2}$ \\
\hline$Y \theta_{\mathrm{T}}$ or $\mathrm{Y}_{\delta \mathrm{p}}$ & 8335.82 & $\mathrm{lb} / \mathrm{rad}$ & N/A & $\mathrm{ft} / \mathrm{in} / \mathrm{sec}^{2}$ & -1.4860 & $\mathrm{ft} / \mathrm{in} / \mathrm{sec}^{2}$ & -1.7151 & $\mathrm{ft} / \mathrm{in} / \mathrm{sec}^{2}$ \\
\hline $\mathrm{Zu}$ & 0.00 & $\mathrm{lb} / \mathrm{ft} / \mathrm{sec}$ & 0 & $1 / \mathrm{sec}$ & 0.0227 & $1 / \mathrm{sec}$ & -0.0050 & $1 / \mathrm{sec}$ \\
\hline Zv & 0.00 & $\mathrm{lb} / \mathrm{ft} / \mathrm{sec}$ & 0 & $1 / \mathrm{sec}$ & -0.0089 & $1 / \mathrm{sec}$ & N/A & $1 / \mathrm{sec}$ \\
\hline Zw & -148.44 & $\mathrm{lb} / \mathrm{ft} / \mathrm{sec}$ & -0.291217 & $1 / \mathrm{sec}$ & -0.2931 & $1 / \mathrm{sec}$ & -0.2748 & $1 / \mathrm{sec}$ \\
\hline $\mathrm{Zq}$ & 0.00 & $\mathrm{lb} / \mathrm{rad} / \mathrm{sec}$ & 0 & $\mathrm{ft} / \mathrm{rad} / \mathrm{sec}$ & 0.3604 & $\mathrm{ft} / \mathrm{rad} / \mathrm{sec}$ & N/A & $\mathrm{ft} / \mathrm{rad} / \mathrm{sec}$ \\
\hline$Z p$ & 0.00 & $\mathrm{lb} / \mathrm{rad} / \mathrm{sec}$ & 0 & $\mathrm{ft} / \mathrm{rad} / \mathrm{sec}$ & -0.0104 & $\mathrm{ft} / \mathrm{rad} / \mathrm{sec}$ & N/A & $\mathrm{ft} / \mathrm{rad} / \mathrm{sec}$ \\
\hline $\mathrm{Zr}$ & 0.00 & $\mathrm{lb} / \mathrm{rad} / \mathrm{sec}$ & 0 & $\mathrm{ft} / \mathrm{rad} / \mathrm{sec}$ & -0.2059 & $\mathrm{ft} / \mathrm{rad} / \mathrm{sec}$ & N/A & $\mathrm{ft} / \mathrm{rad} / \mathrm{sec}$ \\
\hline ZB1 or $Z_{\delta e}$ & 0.00 & $\mathrm{lb} / \mathrm{rad}$ & N/A & $\mathrm{ft} / \mathrm{in} / \mathrm{sec}^{2}$ & -0.1372 & $\mathrm{ft} / \mathrm{in} / \mathrm{sec}^{2}$ & -0.1134 & $\mathrm{ft} / \mathrm{in} / \mathrm{sec}^{2}$ \\
\hline $\mathrm{ZA1}$ or $\mathrm{Z}_{\delta \mathrm{a}}$ & 0.00 & $\mathrm{Ib} / \mathrm{rad}$ & N/A & $\mathrm{ft} / \mathrm{in} / \mathrm{sec}^{2}$ & 0.0041 & $\mathrm{ft} / \mathrm{in} / \mathrm{sec}^{2}$ & N/A & $\mathrm{ft} / \mathrm{in} / \mathrm{sec}^{2}$ \\
\hline$Z \theta$ or $Z_{\delta c}$ & -142313.70 & $\mathrm{lb} / \mathrm{rad}$ & $\mathbf{N} / \mathbf{A}$ & $\mathrm{ft} / \mathrm{in} / \mathrm{sec}^{2}$ & -7.9210 & $\mathrm{ft} / \mathrm{in} / \mathrm{sec}^{2}$ & -8.5829 & $\mathrm{ft} / \mathrm{in} / \mathrm{sec}^{2}$ \\
\hline$Z \theta_{\mathrm{T}}$ or $Z_{\delta p}$ & 0.00 & $\mathrm{lb} / \mathrm{rad}$ & N/A & $\mathrm{ft} / \mathrm{in} / \mathrm{sec}^{2}$ & 0.5791 & $\mathrm{ft} / \mathrm{in} / \mathrm{sec}^{2}$ & 0.6799 & $\mathrm{ft} / \mathrm{in} / \mathrm{sec}^{2}$ \\
\hline
\end{tabular}




\begin{tabular}{|c|c|c|c|c|c|c|c|c|}
\hline & \multicolumn{4}{|c|}{ WVU Linear Model } & \multicolumn{2}{|c|}{ NASA AMES (HILBERT) } & \multicolumn{2}{|c|}{ BOEING-VERTOL } \\
\hline $\mathrm{Mu}$ & 74.43 & $\mathrm{ft}-\mathrm{lb} / \mathrm{ft} / \mathrm{sec}$ & 0.0019 & $\mathrm{rad} / \mathrm{ft} / \mathrm{sec}$ & 0.0036 & $\mathrm{rad} / \mathrm{ft} / \mathrm{sec}$ & 0.0005 & $\mathrm{rad} / \mathrm{ft} / \mathrm{sec}$ \\
\hline $\mathrm{Mv}$ & 31.11 & $\mathrm{ft}-\mathrm{lb} / \mathrm{ft} / \mathrm{sec}$ & 0.0008 & $\mathrm{rad} / \mathrm{ft} / \mathrm{sec}$ & 0.0135 & $\mathrm{rad} / \mathrm{ft} / \mathrm{sec}$ & 0.0085 & $\mathrm{rad} / \mathrm{ft} / \mathrm{sec}$ \\
\hline Mw & 237.51 & $\mathrm{ft}-\mathrm{lb} / \mathrm{ft} / \mathrm{sec}$ & 0.0059 & $\mathrm{rad} / \mathrm{ft} / \mathrm{sec}$ & 0.0020 & $\mathrm{rad} / \mathrm{ft} / \mathrm{sec}$ & 0.0021 & $\mathrm{rad} / \mathrm{ft} / \mathrm{sec}$ \\
\hline $\mathrm{Mq}$ & -15264.81 & $\mathrm{ft}-\mathrm{lb} / \mathrm{rad} / \mathrm{sec}$ & -0.3816 & $1 / \mathrm{sec}$ & -0.8161 & $1 / \mathrm{sec}$ & -0.7674 & $1 / \mathrm{sec}$ \\
\hline $\mathrm{Mp}$ & 5576.06 & $\mathrm{ft}-\mathrm{lb} / \mathrm{rad} / \mathrm{sec}$ & 0.1394 & $1 / \mathrm{sec}$ & 0.3139 & $1 / \mathrm{sec}$ & 0.2983 & $1 / \mathrm{sec}$ \\
\hline $\mathrm{Mr}$ & -290.97 & $\mathrm{ft}-\mathrm{lb} / \mathrm{rad} / \mathrm{sec}$ & -0.0073 & $1 / \mathrm{sec}$ & -0.0034 & $1 / \mathrm{sec}$ & -0.0688 & $1 / \mathrm{sec}$ \\
\hline $\mathrm{MB1}$ or $\mathrm{M}_{\delta \mathrm{e}}$ & -181170.04 & $\mathrm{ft}-\mathrm{lb} / \mathrm{rad}$ & N/A & $\mathrm{ft} / \mathrm{in} / \mathrm{sec}^{2}$ & 0.3346 & $\mathrm{ft} / \mathrm{in} / \mathrm{sec}^{2}$ & 0.3287 & $\mathrm{ft} / \mathrm{in} / \mathrm{sec}^{2}$ \\
\hline MA1 or $\mathrm{M}_{\delta \mathrm{a}}$ & 14571.15 & $\mathrm{ft}-\mathrm{lb} / \mathrm{rad}$ & N/A & $\mathrm{ft} / \mathrm{in} / \mathrm{sec}^{2}$ & -0.0036 & $\mathrm{ft} / \mathrm{in} / \mathrm{sec}^{2}$ & -0.0051 & $\mathrm{ft} / \mathrm{in} / \mathrm{sec}^{2}$ \\
\hline $\mathrm{M} \theta$ or $\mathrm{M}_{\delta \mathrm{c}}$ & 158163.81 & $\mathrm{ft}-\mathrm{lb} / \mathrm{rad}$ & N/A & $\mathrm{ft} / \mathrm{in} / \mathrm{sec}^{2}$ & -0.0056 & $\mathrm{ft} / \mathrm{in} / \mathrm{sec}^{2}$ & -0.0183 & $\mathrm{ft} / \mathrm{in} / \mathrm{sec}^{2}$ \\
\hline $\mathrm{M} \theta_{\mathrm{T}}$ or $\mathrm{M}_{\delta \mathrm{p}}$ & 0.00 & $\mathrm{ft}-\mathrm{lb} / \mathrm{rad}$ & N/A & $\mathrm{ft} / \mathrm{in} / \mathrm{sec}^{2}$ & 0.0154 & $\mathrm{ft} / \mathrm{in} / \mathrm{sec}^{2}$ & 0.0411 & $\mathrm{ft} / \mathrm{in} / \mathrm{sec}^{2}$ \\
\hline $\mathrm{Ru}$ & 21.72 & $\mathrm{ft}-\mathrm{lb} / \mathrm{ft} / \mathrm{sec}$ & 0.0039 & $\mathrm{rad} / \mathrm{ft} / \mathrm{sec}$ & 0.0763 & $\mathrm{rad} / \mathrm{ft} / \mathrm{sec}$ & N/A & $\mathrm{rad} / \mathrm{ft} / \mathrm{sec}$ \\
\hline Rv & -144.82 & $\mathrm{ft}-\mathrm{lb} / \mathrm{ft} / \mathrm{sec}$ & -0.0257 & $\mathrm{rad} / \mathrm{ft} / \mathrm{sec}$ & -0.0412 & $\mathrm{rad} / \mathrm{ft} / \mathrm{sec}$ & -0.0260 & $\mathrm{rad} / \mathrm{ft} / \mathrm{sec}$ \\
\hline Rw & 0.00 & $\mathrm{ft}-\mathrm{lb} / \mathrm{ft} / \mathrm{sec}$ & 0.0000 & $\mathrm{rad} / \mathrm{ft} / \mathrm{sec}$ & 0.0050 & $\mathrm{rad} / \mathrm{ft} / \mathrm{sec}$ & N/A & $\mathrm{rad} / \mathrm{ft} / \mathrm{sec}$ \\
\hline $\mathrm{Rq}$ & -5576.06 & $\mathrm{ft}-\mathrm{lb} / \mathrm{rad} / \mathrm{sec}$ & -0.9906 & $1 / \mathrm{sec}$ & -2.2720 & $1 / \mathrm{sec}$ & -1.7256 & $1 / \mathrm{sec}$ \\
\hline $\mathrm{Rp}$ & -15719.38 & $\mathrm{ft}-\mathrm{lb} / \mathrm{rad} / \mathrm{sec}$ & -2.7926 & $1 / \mathrm{sec}$ & -3.5510 & $1 / \mathrm{sec}$ & -3.3484 & $1 / \mathrm{sec}$ \\
\hline $\mathrm{Rr}$ & 2179.61 & $\mathrm{ft}-\mathrm{lb} / \mathrm{rad} / \mathrm{sec}$ & 0.3872 & $1 / \mathrm{sec}$ & 0.0747 & $1 / \mathrm{sec}$ & 0.2119 & $1 / \mathrm{sec}$ \\
\hline $\mathrm{RB} 1$ or $\mathrm{R}_{\delta \mathrm{e}}$ & 14571.15 & $\mathrm{ft}-\mathrm{lb} / \mathrm{rad}$ & N/A & $\mathrm{ft} / \mathrm{in} / \mathrm{sec}^{2}$ & 0.0436 & $\mathrm{ft} / \mathrm{in} / \mathrm{sec}^{2}$ & N/A & $\mathrm{ft} / \mathrm{in} / \mathrm{sec}^{2}$ \\
\hline RA1 or $R_{\delta a}$ & 181170.04 & $\mathrm{ft}-\mathrm{lb} / \mathrm{rad}$ & N/A & $\mathrm{ft} / \mathrm{in} / \mathrm{sec}^{2}$ & 1.3340 & $\mathrm{ft} / \mathrm{in} / \mathrm{sec}^{2}$ & 1.3118 & $\mathrm{ft} / \mathrm{in} / \mathrm{sec}^{2}$ \\
\hline $\mathrm{R} \theta$ or $\mathrm{R}_{\delta c}$ & -22866.38 & $\mathrm{ft}-\mathrm{lb} / \mathrm{rad}$ & N/A & $\mathrm{ft} / \mathrm{in} / \mathrm{sec}^{2}$ & -0.1471 & $\mathrm{ft} / \mathrm{in} / \mathrm{sec}^{2}$ & N/A & $\mathrm{ft} / \mathrm{in} / \mathrm{sec}^{2}$ \\
\hline$R \theta_{T}$ or $R_{\delta p}$ & 53835.48 & $\mathrm{ft}-\mathrm{lb} / \mathrm{rad}$ & N/A & $\mathrm{ft} / \mathrm{in} / \mathrm{sec}^{2}$ & -0.8406 & $\mathrm{ft} / \mathrm{in} / \mathrm{sec}^{2}$ & -0.9313 & $\mathrm{ft} / \mathrm{in} / \mathrm{sec}^{2}$ \\
\hline $\mathrm{Nu}$ & 0.00 & $\mathrm{ft}-\mathrm{lb} / \mathrm{ft} / \mathrm{sec}$ & 0.0000 & $\mathrm{rad} / \mathrm{ft} / \mathrm{sec}$ & 0.0021 & $\mathrm{rad} / \mathrm{ft} / \mathrm{sec}$ & N/A & $\mathrm{rad} / \mathrm{ft} / \mathrm{sec}$ \\
\hline Nv & 337.49 & $\mathrm{ft}-\mathrm{lb} / \mathrm{ft} / \mathrm{sec}$ & 0.0091 & $\mathrm{rad} / \mathrm{ft} / \mathrm{sec}$ & 0.0098 & $\mathrm{rad} / \mathrm{ft} / \mathrm{sec}$ & 0.0081 & $\mathrm{rad} / \mathrm{ft} / \mathrm{sec}$ \\
\hline $\mathrm{Nw}$ & -874.70 & $\mathrm{ft}-\mathrm{lb} / \mathrm{ft} / \mathrm{sec}$ & -0.0235 & $\mathrm{rad} / \mathrm{ft} / \mathrm{sec}$ & -0.0019 & $\mathrm{rad} / \mathrm{ft} / \mathrm{sec}$ & N/A & $\mathrm{rad} / \mathrm{ft} / \mathrm{sec}$ \\
\hline $\mathrm{Nq}$ & 0.00 & $\mathrm{ft}-\mathrm{lb} / \mathrm{rad} / \mathrm{sec}$ & 0.0000 & $1 / \mathrm{sec}$ & -0.3396 & $1 / \mathrm{sec}$ & N/A & $1 / \mathrm{sec}$ \\
\hline $\mathrm{Np}$ & 2179.61 & $\mathrm{ft}-\mathrm{lb} / \mathrm{rad} / \mathrm{sec}$ & 0.0586 & $1 / \mathrm{sec}$ & -0.1013 & $1 / \mathrm{sec}$ & -0.1856 & $1 / \mathrm{sec}$ \\
\hline $\mathrm{Nr}$ & -7948.79 & $\mathrm{ft}-\mathrm{lb} / \mathrm{rad} / \mathrm{sec}$ & -0.2137 & $1 / \mathrm{sec}$ & -0.3342 & $1 / \mathrm{sec}$ & -0.2879 & $1 / \mathrm{sec}$ \\
\hline NB1 or $N_{\delta e}$ & 0.00 & $\mathrm{ft}-\mathrm{lb} / \mathrm{rad}$ & N/A & $\mathrm{ft} / \mathrm{in} / \mathrm{sec}^{2}$ & 0.0011 & $\mathrm{ft} / \mathrm{in} / \mathrm{sec}^{2}$ & N/A & $\mathrm{ft} / \mathrm{in} / \mathrm{sec}^{2}$ \\
\hline $\mathrm{NA1}$ or $\mathrm{N}_{\delta \mathrm{a}}$ & 0.00 & $\mathrm{ft}-\mathrm{lb} / \mathrm{rad}$ & N/A & $\mathrm{ft} / \mathrm{in} / \mathrm{sec}^{2}$ & 0.0273 & $\mathrm{ft} / \mathrm{in} / \mathrm{sec}^{2}$ & 0.0266 & $\mathrm{ft} / \mathrm{in} / \mathrm{sec}^{2}$ \\
\hline $\mathrm{N} \theta$ or $\mathrm{N}_{\delta c}$ & 516352.78 & $\mathrm{ft}-\mathrm{lb} / \mathrm{rad}$ & N/A & $\mathrm{ft} / \mathrm{in} / \mathrm{sec}^{2}$ & 0.0631 & $\mathrm{ft} / \mathrm{in} / \mathrm{sec}^{2}$ & 0.0665 & $\mathrm{ft} / \mathrm{in} / \mathrm{sec}^{2}$ \\
\hline $\mathrm{N} \theta_{\mathrm{T}}$ or $\mathrm{N}_{\delta \mathrm{p}}$ & -258132.43 & $\mathrm{ft}-\mathrm{lb} / \mathrm{rad}$ & N/A & $\mathrm{ft} / \mathrm{in} / \mathrm{sec}^{2}$ & 0.6040 & $\mathrm{ft} / \mathrm{in} / \mathrm{sec}^{2}$ & 0.7153 & $\mathrm{ft} / \mathrm{in} / \mathrm{sec}^{2}$ \\
\hline
\end{tabular}


Table B.2: Stability and Control Derivative Comparison (20 Knots)

\begin{tabular}{|c|c|c|c|c|c|c|c|c|}
\hline \multirow[b]{2}{*}{$\mathrm{Xu}$} & \multicolumn{4}{|c|}{ WVU Linear Model } & \multicolumn{2}{|c|}{ NASA AMES } & \multicolumn{2}{|c|}{ BOEING-VERTOL } \\
\hline & 0.42 & $\mathrm{lb} / \mathrm{ft} / \mathrm{sec}$ & 0.0008 & $1 / \mathrm{sec}$ & -0.0104 & $1 / \mathrm{sec}$ & 0.0184 & $1 / \mathrm{sec}$ \\
\hline$X v$ & -16.86 & $\mathrm{lb} / \mathrm{ft} / \mathrm{sec}$ & -0.0331 & $1 / \mathrm{sec}$ & -0.02237 & $1 / \mathrm{sec}$ & N/A & $1 / \mathrm{sec}$ \\
\hline $\mathrm{Xw}$ & 15.08 & $\mathrm{lb} / \mathrm{ft} / \mathrm{sec}$ & 0.0296 & $1 / \mathrm{sec}$ & 0.03743 & $1 / \mathrm{sec}$ & N/A & $1 / \mathrm{sec}$ \\
\hline $\mathrm{Xq}$ & 745.73 & $\mathrm{lb} / \mathrm{rad} / \mathrm{sec}$ & 1.4630 & $\mathrm{ft} / \mathrm{rad} / \mathrm{sec}$ & 2.828 & $\mathrm{ft} / \mathrm{rad} / \mathrm{sec}$ & N/A & $\mathrm{ft} / \mathrm{rad} / \mathrm{sec}$ \\
\hline$X p$ & -140.16 & $\mathrm{lb} / \mathrm{rad} / \mathrm{sec}$ & -0.2750 & $\mathrm{ft} / \mathrm{rad} / \mathrm{sec}$ & -0.1883 & $\mathrm{ft} / \mathrm{rad} / \mathrm{sec}$ & N/A & $\mathrm{ft} / \mathrm{rad} / \mathrm{sec}$ \\
\hline $\mathrm{Xr}$ & 0.00 & $\mathrm{lb} / \mathrm{rad} / \mathrm{sec}$ & 0.0000 & $\mathrm{ft} / \mathrm{rad} / \mathrm{sec}$ & -0.1151 & $\mathrm{ft} / \mathrm{rad} / \mathrm{sec}$ & N/A & $\mathrm{ft} / \mathrm{rad} / \mathrm{sec}$ \\
\hline $\mathrm{XB1}$ or $\mathrm{X}_{\delta \mathrm{e}}$ & 9108.45 & $\mathrm{lb} / \mathrm{rad}$ & N/A & $\mathrm{ft} / \mathrm{in} / \mathrm{sec}^{2}$ & -1.582 & $\mathrm{ft} / \mathrm{in} / \mathrm{sec}^{2}$ & -1.5711 & $\mathrm{ft} / \mathrm{in} / \mathrm{sec}^{2}$ \\
\hline XA1 or $X_{\delta a}$ & -725.56 & $\mathrm{lb} / \mathrm{rad}$ & N/A & $\mathrm{ft} / \mathrm{in} / \mathrm{sec}^{2}$ & 0.03288 & $\mathrm{ft} / \mathrm{in} / \mathrm{sec}^{2}$ & N/A & $\mathrm{ft} / \mathrm{in} / \mathrm{sec}^{2}$ \\
\hline $\mathrm{x} \theta$ or $\mathrm{X}_{\delta c}$ & 16664.22 & $\mathrm{lb} / \mathrm{rad}$ & N/A & $\mathrm{ft} / \mathrm{in} / \mathrm{sec}^{2}$ & 0.9707 & $\mathrm{ft} / \mathrm{in} / \mathrm{sec}^{2}$ & N/A & $\mathrm{ft} / \mathrm{in} / \mathrm{sec}^{2}$ \\
\hline$x \theta_{T}$ or $X_{\delta p}$ & 0.00 & $\mathrm{lb} / \mathrm{rad}$ & N/A & $\mathrm{ft} / \mathrm{in} / \mathrm{sec}^{2}$ & 0.9143 & $\mathrm{ft} / \mathrm{in} / \mathrm{sec}^{2}$ & N/A & $\mathrm{ft} / \mathrm{in} / \mathrm{sec}^{2}$ \\
\hline $\mathrm{Yu}$ & 12.51 & $\mathrm{lb} / \mathrm{ft} / \mathrm{sec}$ & 0.0245 & $1 / \mathrm{sec}$ & 0.01808 & $1 / \mathrm{sec}$ & N/A & $1 / \mathrm{sec}$ \\
\hline Yv & -2.49 & $\mathrm{lb} / \mathrm{ft} / \mathrm{sec}$ & -0.0049 & $1 / \mathrm{sec}$ & -0.05825 & $1 / \mathrm{sec}$ & -0.0523 & $1 / \mathrm{sec}$ \\
\hline$Y w$ & 1.99 & $\mathrm{lb} / \mathrm{ft} / \mathrm{sec}$ & 0.0039 & $1 / \mathrm{sec}$ & 0.006895 & $1 / \mathrm{sec}$ & N/A & $1 / \mathrm{sec}$ \\
\hline Yq & -269.40 & $\mathrm{lb} / \mathrm{rad} / \mathrm{sec}$ & -0.5285 & $\mathrm{ft} / \mathrm{rad} / \mathrm{sec}$ & -0.002115 & $\mathrm{ft} / \mathrm{rad} / \mathrm{sec}$ & N/A & $\mathrm{ft} / \mathrm{rad} / \mathrm{sec}$ \\
\hline$Y p$ & -728.20 & $\mathrm{lb} / \mathrm{rad} / \mathrm{sec}$ & -1.4286 & $\mathrm{ft} / \mathrm{rad} / \mathrm{sec}$ & -1.972 & $\mathrm{ft} / \mathrm{rad} / \mathrm{sec}$ & N/A & $\mathrm{ft} / \mathrm{rad} / \mathrm{sec}$ \\
\hline $\mathrm{Yr}$ & -340.48 & $\mathrm{lb} / \mathrm{rad} / \mathrm{sec}$ & -0.6680 & $\mathrm{ft} / \mathrm{rad} / \mathrm{sec}$ & 0.5788 & $\mathrm{ft} / \mathrm{rad} / \mathrm{sec}$ & N/A & $\mathrm{ft} / \mathrm{rad} / \mathrm{sec}$ \\
\hline YB1 or $\mathrm{Y}_{\delta \mathrm{e}}$ & -727.14 & $\mathrm{lb} / \mathrm{rad}$ & N/A & $\mathrm{ft} / \mathrm{in} / \mathrm{sec}^{2}$ & 0.04994 & $\mathrm{ft} / \mathrm{in} / \mathrm{sec}^{2}$ & $\mathbf{N} / \mathbf{A}$ & $\mathrm{ft} / \mathrm{in} / \mathrm{sec}^{2}$ \\
\hline YA1 or $Y_{\delta a}$ & 9069.02 & $\mathrm{lb} / \mathrm{rad}$ & N/A & $\mathrm{ft} / \mathrm{in} / \mathrm{sec}^{2}$ & 0.9542 & $\mathrm{ft} / \mathrm{in} / \mathrm{sec}^{2}$ & 0.9648 & $\mathrm{ft} / \mathrm{in} / \mathrm{sec}^{2}$ \\
\hline $\mathrm{Y} \theta$ or $\mathrm{Y}_{\delta c}$ & -2293.92 & $\mathrm{lb} / \mathrm{rad}$ & $\mathbf{N} / \mathbf{A}$ & $\mathrm{ft} / \mathrm{in} / \mathrm{sec}^{2}$ & 0.06201 & $\mathrm{ft} / \mathrm{in} / \mathrm{sec}^{2}$ & N/A & $\mathrm{ft} / \mathrm{in} / \mathrm{sec}^{2}$ \\
\hline$Y \theta_{T}$ or $Y_{\delta p}$ & 13217.90 & $\mathrm{lb} / \mathrm{rad}$ & N/A & $\mathrm{ft} / \mathrm{in} / \mathrm{sec}^{2}$ & -1.338 & $\mathrm{ft} / \mathrm{in} / \mathrm{sec}^{2}$ & -1.6223 & $\mathrm{ft} / \mathrm{in} / \mathrm{sec}^{2}$ \\
\hline $\mathrm{Zu}$ & -111.53 & $\mathrm{lb} / \mathrm{ft} / \mathrm{sec}$ & -0.218799 & $1 / \mathrm{sec}$ & -0.146 & $1 / \mathrm{sec}$ & -0.1573 & $1 / \mathrm{sec}$ \\
\hline Zv & 0.00 & $\mathrm{lb} / \mathrm{ft} / \mathrm{sec}$ & 0 & $1 / \mathrm{sec}$ & -0.02547 & $1 / \mathrm{sec}$ & N/A & $1 / \mathrm{sec}$ \\
\hline Zw & -163.35 & $\mathrm{lb} / \mathrm{ft} / \mathrm{sec}$ & -0.320474 & $1 / \mathrm{sec}$ & -0.3834 & $1 / \mathrm{sec}$ & -0.3475 & $1 / \mathrm{sec}$ \\
\hline $\mathrm{Zq}$ & -48.25 & $\mathrm{lb} / \mathrm{rad} / \mathrm{sec}$ & -0.094666 & $\mathrm{ft} / \mathrm{rad} / \mathrm{sec}$ & 2.237 & $\mathrm{ft} / \mathrm{rad} / \mathrm{sec}$ & $\mathbf{N} / \mathbf{A}$ & $\mathrm{ft} / \mathrm{rad} / \mathrm{sec}$ \\
\hline $\mathrm{Zp}$ & 0.00 & $\mathrm{lb} / \mathrm{rad} / \mathrm{sec}$ & 0 & $\mathrm{ft} / \mathrm{rad} / \mathrm{sec}$ & 0.3402 & $\mathrm{ft} / \mathrm{rad} / \mathrm{sec}$ & N/A & $\mathrm{ft} / \mathrm{rad} / \mathrm{sec}$ \\
\hline $\mathrm{Zr}$ & 1233.30 & $\mathrm{lb} / \mathrm{rad} / \mathrm{sec}$ & 2.4195299 & $\mathrm{ft} / \mathrm{rad} / \mathrm{sec}$ & -0.3 & $\mathrm{ft} / \mathrm{rad} / \mathrm{sec}$ & N/A & $\mathrm{ft} / \mathrm{rad} / \mathrm{sec}$ \\
\hline ZB1 or $Z_{\delta e}$ & 0.00 & $\mathrm{lb} / \mathrm{rad}$ & N/A & $\mathrm{ft} / \mathrm{in} / \mathrm{sec}^{2}$ & -1.037 & $\mathrm{ft} / \mathrm{in} / \mathrm{sec}^{2}$ & -1.0026 & $\mathrm{ft} / \mathrm{in} / \mathrm{sec}^{2}$ \\
\hline $\mathrm{ZA1}$ or $\mathrm{Z}_{\delta \mathrm{a}}$ & 0.00 & $\mathrm{lb} / \mathrm{rad}$ & N/A & $\mathrm{ft} / \mathrm{in} / \mathrm{sec}^{2}$ & 0.04533 & $\mathrm{ft} / \mathrm{in} / \mathrm{sec}^{2}$ & N/A & $\mathrm{ft} / \mathrm{in} / \mathrm{sec}^{2}$ \\
\hline $\mathrm{Z \theta}$ or $\mathrm{Z}_{\delta c}$ & -170504.38 & $\mathrm{lb} / \mathrm{rad}$ & N/A & $\mathrm{ft} / \mathrm{in} / \mathrm{sec}^{2}$ & -7.377 & $\mathrm{ft} / \mathrm{in} / \mathrm{sec}^{2}$ & -8.1266 & $\mathrm{ft} / \mathrm{in} / \mathrm{sec}^{2}$ \\
\hline$Z \theta_{\mathrm{T}}$ or $Z_{\delta p}$ & 0.00 & $\mathrm{lb} / \mathrm{rad}$ & N/A & $\mathrm{ft} / \mathrm{in} / \mathrm{sec}^{2}$ & 1.074 & $\mathrm{ft} / \mathrm{in} / \mathrm{sec}^{2}$ & 1.183 & $\mathrm{ft} / \mathrm{in} / \mathrm{sec}^{2}$ \\
\hline
\end{tabular}




\begin{tabular}{|c|c|c|c|c|c|c|c|c|}
\hline & \multicolumn{4}{|c|}{ WVU Linear Model } & \multicolumn{2}{|c|}{ NASA AMES } & \multicolumn{2}{|c|}{ BOEING-VERTOL } \\
\hline $\mathrm{Mu}$ & -1028.12 & $\mathrm{ft}-\mathrm{lb} / \mathrm{ft} / \mathrm{sec}$ & -0.025703 & $\mathrm{rad} / \mathrm{ft} / \mathrm{sec}$ & 0.001085 & $\mathrm{rad} / \mathrm{ft} / \mathrm{sec}$ & 0.0091 & $\mathrm{rad} / \mathrm{ft} / \mathrm{sec}$ \\
\hline $\mathrm{Mv}$ & -87.81 & $\mathrm{ft}-\mathrm{lb} / \mathrm{ft} / \mathrm{sec}$ & -0.002195 & $\mathrm{rad} / \mathrm{ft} / \mathrm{sec}$ & 0.01115 & $\mathrm{rad} / \mathrm{ft} / \mathrm{sec}$ & 0.0022 & $\mathrm{rad} / \mathrm{ft} / \mathrm{sec}$ \\
\hline Mw & 153.79 & $\mathrm{ft}-\mathrm{lb} / \mathrm{ft} / \mathrm{sec}$ & 0.0038448 & $\mathrm{rad} / \mathrm{ft} / \mathrm{sec}$ & 0.003433 & $\mathrm{rad} / \mathrm{ft} / \mathrm{sec}$ & 0.0122 & $\mathrm{rad} / \mathrm{ft} / \mathrm{sec}$ \\
\hline $\mathrm{Mq}$ & -18496.26 & $\mathrm{ft}-\mathrm{lb} / \mathrm{rad} / \mathrm{sec}$ & -0.462406 & $1 / \mathrm{sec}$ & -0.891 & $1 / \mathrm{sec}$ & -1.0262 & $1 / \mathrm{sec}$ \\
\hline $\mathrm{Mp}$ & 5511.55 & $\mathrm{ft}-\mathrm{lb} / \mathrm{rad} / \mathrm{sec}$ & 0.1377889 & $1 / \mathrm{sec}$ & 0.2894 & $1 / \mathrm{sec}$ & 0.2859 & $1 / \mathrm{sec}$ \\
\hline $\mathrm{Mr}$ & 0.00 & $\mathrm{ft}-\mathrm{lb} / \mathrm{rad} / \mathrm{sec}$ & 0 & $1 / \mathrm{sec}$ & -0.02974 & $1 / \mathrm{sec}$ & -0.0595 & $1 / \mathrm{sec}$ \\
\hline $\mathrm{MB1}$ or $\mathrm{M}_{\delta \mathrm{e}}$ & -206253.93 & $\mathrm{ft}-\mathrm{lb} / \mathrm{rad}$ & N/A & $\mathrm{ft} / \mathrm{in} / \mathrm{sec}^{2}$ & 0.3516 & $\mathrm{ft} / \mathrm{in} / \mathrm{sec}^{2}$ & 0.3366 & $\mathrm{ft} / \mathrm{in} / \mathrm{sec}^{2}$ \\
\hline MA1 or $\mathrm{M}_{\delta \mathrm{a}}$ & 16429.81 & $\mathrm{ft}-\mathrm{lb} / \mathrm{rad}$ & N/A & $\mathrm{ft} / \mathrm{in} / \mathrm{sec}^{2}$ & -0.003824 & $\mathrm{ft} / \mathrm{in} / \mathrm{sec}^{2}$ & 0.0042 & $\mathrm{ft} / \mathrm{in} / \mathrm{sec}^{2}$ \\
\hline $\mathrm{M} \theta$ or $\mathrm{M}_{\delta \mathrm{c}}$ & 201097.19 & $\mathrm{ft}-\mathrm{lb} / \mathrm{rad}$ & N/A & $\mathrm{ft} / \mathrm{in} / \mathrm{sec}^{2}$ & 0.0273 & $\mathrm{ft} / \mathrm{in} / \mathrm{sec}^{2}$ & -0.0352 & $\mathrm{ft} / \mathrm{in} / \mathrm{sec}^{2}$ \\
\hline $\mathrm{M} \theta_{\mathrm{T}}$ or $\mathrm{M}_{\delta \mathrm{p}}$ & 0.00 & $\mathrm{ft}-\mathrm{lb} / \mathrm{rad}$ & N/A & $\mathrm{ft} / \mathrm{in} / \mathrm{sec}^{2}$ & -0.006399 & $\mathrm{ft} / \mathrm{in} / \mathrm{sec}^{2}$ & -0.001 & $\mathrm{ft} / \mathrm{in} / \mathrm{sec}^{2}$ \\
\hline $\mathrm{Ru}$ & 44.39 & $\mathrm{ft}-\mathrm{lb} / \mathrm{ft} / \mathrm{sec}$ & 0.0078854 & $\mathrm{rad} / \mathrm{ft} / \mathrm{sec}$ & 0.02327 & $\mathrm{rad} / \mathrm{ft} / \mathrm{sec}$ & N/A & $\mathrm{rad} / \mathrm{ft} / \mathrm{sec}$ \\
\hline Rv & -31.86 & $\mathrm{ft}-\mathrm{lb} / \mathrm{ft} / \mathrm{sec}$ & -0.00566 & $\mathrm{rad} / \mathrm{ft} / \mathrm{sec}$ & -0.03956 & $\mathrm{rad} / \mathrm{ft} / \mathrm{sec}$ & -0.025 & $\mathrm{rad} / \mathrm{ft} / \mathrm{sec}$ \\
\hline Rw & 45.17 & $\mathrm{ft}-\mathrm{lb} / \mathrm{ft} / \mathrm{sec}$ & 0.0080251 & $\mathrm{rad} / \mathrm{ft} / \mathrm{sec}$ & 0.01749 & $\mathrm{rad} / \mathrm{ft} / \mathrm{sec}$ & N/A & $\mathrm{rad} / \mathrm{ft} / \mathrm{sec}$ \\
\hline $\mathrm{Rq}$ & -6229.35 & $\mathrm{ft}-\mathrm{lb} / \mathrm{rad} / \mathrm{sec}$ & -1.106653 & $1 / \mathrm{sec}$ & -1.73 & $1 / \mathrm{sec}$ & -1.8067 & $1 / \mathrm{sec}$ \\
\hline $\mathrm{Rp}$ & -16953.91 & $\mathrm{ft}-\mathrm{lb} / \mathrm{rad} / \mathrm{sec}$ & -3.011887 & $1 / \mathrm{sec}$ & -3.604 & $1 / \mathrm{sec}$ & -3.5455 & $1 / \mathrm{sec}$ \\
\hline $\mathrm{Rr}$ & -2128.80 & $\mathrm{ft}-\mathrm{lb} / \mathrm{rad} / \mathrm{sec}$ & -0.378184 & $1 / \mathrm{sec}$ & 0.04429 & $1 / \mathrm{sec}$ & 0.3507 & $1 / \mathrm{sec}$ \\
\hline $\mathrm{RB} 1$ or $\mathrm{R}_{\delta \mathrm{e}}$ & -16465.44 & $\mathrm{ft}-\mathrm{lb} / \mathrm{rad}$ & N/A & $\mathrm{ft} / \mathrm{in} / \mathrm{sec}^{2}$ & 0.04924 & $\mathrm{ft} / \mathrm{in} / \mathrm{sec}^{2}$ & N/A & $\mathrm{ft} / \mathrm{in} / \mathrm{sec}^{2}$ \\
\hline $\mathrm{RA} 1$ or $\mathrm{R}_{\delta \mathrm{a}}$ & 205361.12 & $\mathrm{ft}-\mathrm{lb} / \mathrm{rad}$ & N/A & $\mathrm{ft} / \mathrm{in} / \mathrm{sec}^{2}$ & 1.339 & $\mathrm{ft} / \mathrm{in} / \mathrm{sec}^{2}$ & 1.3297 & $\mathrm{ft} / \mathrm{in} / \mathrm{sec}^{2}$ \\
\hline $\mathrm{R} \theta$ or $\mathrm{R}_{\delta c}$ & 13755.51 & $\mathrm{ft}-\mathrm{lb} / \mathrm{rad}$ & N/A & $\mathrm{ft} / \mathrm{in} / \mathrm{sec}^{2}$ & -0.0308 & $\mathrm{ft} / \mathrm{in} / \mathrm{sec}^{2}$ & N/A & $\mathrm{ft} / \mathrm{in} / \mathrm{sec}^{2}$ \\
\hline$R \theta_{T}$ or $R_{\delta p}$ & 85365.60 & $\mathrm{ft}-\mathrm{lb} / \mathrm{rad}$ & N/A & $\mathrm{ft} / \mathrm{in} / \mathrm{sec}^{2}$ & -0.7759 & $\mathrm{ft} / \mathrm{in} / \mathrm{sec}^{2}$ & -0.8816 & $\mathrm{ft} / \mathrm{in} / \mathrm{sec}^{2}$ \\
\hline $\mathrm{Nu}$ & -524.90 & $\mathrm{ft}-\mathrm{lb} / \mathrm{ft} / \mathrm{sec}$ & -0.01411 & $\mathrm{rad} / \mathrm{ft} / \mathrm{sec}$ & -0.005618 & $\mathrm{rad} / \mathrm{ft} / \mathrm{sec}$ & N/A & $\mathrm{rad} / \mathrm{ft} / \mathrm{sec}$ \\
\hline $\mathrm{Nv}$ & -382.28 & $\mathrm{ft}-\mathrm{lb} / \mathrm{ft} / \mathrm{sec}$ & -0.010276 & $\mathrm{rad} / \mathrm{ft} / \mathrm{sec}$ & 0.008566 & $\mathrm{rad} / \mathrm{ft} / \mathrm{sec}$ & 0.0108 & $\mathrm{rad} / \mathrm{ft} / \mathrm{sec}$ \\
\hline Nw & -316.50 & $\mathrm{ft}-\mathrm{lb} / \mathrm{ft} / \mathrm{sec}$ & -0.008508 & $\mathrm{rad} / \mathrm{ft} / \mathrm{sec}$ & -0.003705 & $\mathrm{rad} / \mathrm{ft} / \mathrm{sec}$ & N/A & $\mathrm{rad} / \mathrm{ft} / \mathrm{sec}$ \\
\hline $\mathrm{Nq}$ & 0.00 & $\mathrm{ft}-\mathrm{lb} / \mathrm{rad} / \mathrm{sec}$ & 0 & $1 / \mathrm{sec}$ & -0.7563 & $1 / \mathrm{sec}$ & N/A & $1 / \mathrm{sec}$ \\
\hline $\mathrm{Np}$ & -2128.80 & $\mathrm{ft}-\mathrm{lb} / \mathrm{rad} / \mathrm{sec}$ & -0.057226 & $1 / \mathrm{sec}$ & -0.2857 & $1 / \mathrm{sec}$ & 0.0322 & $1 / \mathrm{sec}$ \\
\hline $\mathrm{Nr}$ & 8491.70 & $\mathrm{ft}-\mathrm{lb} / \mathrm{rad} / \mathrm{sec}$ & 0.2282715 & $1 / \mathrm{sec}$ & -0.3662 & $1 / \mathrm{sec}$ & -0.3902 & $1 / \mathrm{sec}$ \\
\hline $\mathrm{NB1}$ or $\mathrm{N}_{\delta \mathrm{e}}$ & 0.00 & $\mathrm{ft}-\mathrm{lb} / \mathrm{rad}$ & N/A & $\mathrm{ft} / \mathrm{in} / \mathrm{sec}^{2}$ & -0.009063 & $\mathrm{ft} / \mathrm{in} / \mathrm{sec}^{2}$ & N/A & $\mathrm{ft} / \mathrm{in} / \mathrm{sec}^{2}$ \\
\hline $\mathrm{NA1}$ or $\mathrm{N}_{\delta \mathrm{a}}$ & 0.00 & $\mathrm{ft}-\mathrm{lb} / \mathrm{rad}$ & N/A & $\mathrm{ft} / \mathrm{in} / \mathrm{sec}^{2}$ & 0.02695 & $\mathrm{ft} / \mathrm{in} / \mathrm{sec}^{2}$ & -0.0286 & $\mathrm{ft} / \mathrm{in} / \mathrm{sec}^{2}$ \\
\hline $\mathrm{N} \theta$ or $\mathrm{N}_{\delta c}$ & 323508.46 & $\mathrm{ft}-\mathrm{lb} / \mathrm{rad}$ & N/A & $\mathrm{ft} / \mathrm{in} / \mathrm{sec}^{2}$ & 0.06005 & $\mathrm{ft} / \mathrm{in} / \mathrm{sec}^{2}$ & 0.0576 & $\mathrm{ft} / \mathrm{in} / \mathrm{sec}^{2}$ \\
\hline$N \theta_{T}$ or $N_{\delta p}$ & -409314.30 & $\mathrm{ft}-\mathrm{lb} / \mathrm{rad}$ & N/A & $\mathrm{ft} / \mathrm{in} / \mathrm{sec}^{2}$ & 0.555 & $\mathrm{ft} / \mathrm{in} / \mathrm{sec}^{2}$ & 0.6731 & $\mathrm{ft} / \mathrm{in} / \mathrm{sec}^{2}$ \\
\hline
\end{tabular}


Table B.3: Stability and Control Derivative Comparison (40 Knots)

\begin{tabular}{|c|c|c|c|c|c|c|c|c|}
\hline & \multicolumn{4}{|c|}{ WVU Linear Model } & \multicolumn{2}{|c|}{ NASA AMES } & \multicolumn{2}{|c|}{ BOEING-VERTOL } \\
\hline $\mathrm{Xu}$ & -0.50 & $\mathrm{lb} / \mathrm{ft} / \mathrm{sec}$ & -0.0010 & $1 / \mathrm{sec}$ & -0.0112 & $1 / \mathrm{sec}$ & -0.0274 & $1 / \mathrm{sec}$ \\
\hline$X v$ & -4.38 & $\mathrm{lb} / \mathrm{ft} / \mathrm{sec}$ & -0.0086 & $1 / \mathrm{sec}$ & -0.0098 & $1 / \mathrm{sec}$ & N/A & $1 / \mathrm{sec}$ \\
\hline Xw & 24.73 & $\mathrm{lb} / \mathrm{ft} / \mathrm{sec}$ & 0.0485 & $1 / \mathrm{sec}$ & 0.0430 & $1 / \mathrm{sec}$ & N/A & $1 / \mathrm{sec}$ \\
\hline $\mathrm{Xq}$ & 937.44 & $\mathrm{lb} / \mathrm{rad} / \mathrm{sec}$ & 1.8391 & $\mathrm{ft} / \mathrm{rad} / \mathrm{sec}$ & 3.2210 & $\mathrm{ft} / \mathrm{rad} / \mathrm{sec}$ & N/A & $\mathrm{ft} / \mathrm{rad} / \mathrm{sec}$ \\
\hline $\mathrm{Xp}$ & -296.79 & $\mathrm{lb} / \mathrm{rad} / \mathrm{sec}$ & -0.5822 & $\mathrm{ft} / \mathrm{rad} / \mathrm{sec}$ & -0.0580 & $\mathrm{ft} / \mathrm{rad} / \mathrm{sec}$ & N/A & $\mathrm{ft} / \mathrm{rad} / \mathrm{sec}$ \\
\hline $\mathrm{Xr}$ & 0.00 & $\mathrm{lb} / \mathrm{rad} / \mathrm{sec}$ & 0.0000 & $\mathrm{ft} / \mathrm{rad} / \mathrm{sec}$ & -0.0171 & $\mathrm{ft} / \mathrm{rad} / \mathrm{sec}$ & N/A & $\mathrm{ft} / \mathrm{rad} / \mathrm{sec}$ \\
\hline $\mathrm{XB1}$ or $\mathrm{X}_{\delta \mathrm{e}}$ & 11592.31 & $\mathrm{lb} / \mathrm{rad}$ & N/A & $\mathrm{ft} / \mathrm{in} / \mathrm{sec}^{2}$ & -1.4980 & $\mathrm{ft} / \mathrm{in} / \mathrm{sec}^{2}$ & -1.3039 & $\mathrm{ft} / \mathrm{in} / \mathrm{sec}^{2}$ \\
\hline XA1 or $X_{\delta a}$ & -914.51 & $\mathrm{lb} / \mathrm{rad}$ & N/A & $\mathrm{ft} / \mathrm{in} / \mathrm{sec}^{2}$ & 0.0180 & $\mathrm{ft} / \mathrm{in} / \mathrm{sec}^{2}$ & N/A & $\mathrm{ft} / \mathrm{in} / \mathrm{sec}^{2}$ \\
\hline $\mathrm{x} \theta$ or $\mathrm{X}_{\delta c}$ & 17154.57 & $\mathrm{lb} / \mathrm{rad}$ & N/A & $\mathrm{ft} / \mathrm{in} / \mathrm{sec}^{2}$ & 0.7004 & $\mathrm{ft} / \mathrm{in} / \mathrm{sec}^{2}$ & N/A & $\mathrm{ft} / \mathrm{in} / \mathrm{sec}^{2}$ \\
\hline$x \theta_{\mathrm{T}}$ or $\mathrm{X}_{\delta p}$ & 0.00 & $\mathrm{lb} / \mathrm{rad}$ & $N / A$ & $\mathrm{ft} / \mathrm{in} / \mathrm{sec}^{2}$ & 0.8656 & $\mathrm{ft} / \mathrm{in} / \mathrm{sec}^{2}$ & N/A & $\mathrm{ft} / \mathrm{in} / \mathrm{sec}^{2}$ \\
\hline Yu & 5.07 & $\mathrm{lb} / \mathrm{ft} / \mathrm{sec}$ & 0.0100 & $1 / \mathrm{sec}$ & 0.0026 & $1 / \mathrm{sec}$ & N/A & $1 / \mathrm{sec}$ \\
\hline$Y v$ & -32.03 & $\mathrm{lb} / \mathrm{ft} / \mathrm{sec}$ & -0.0628 & $1 / \mathrm{sec}$ & -0.0818 & $1 / \mathrm{sec}$ & -0.0693 & $1 / \mathrm{sec}$ \\
\hline$Y w$ & 5.67 & $\mathrm{lb} / \mathrm{ft} / \mathrm{sec}$ & 0.0111 & $1 / \mathrm{sec}$ & 0.0081 & $1 / \mathrm{sec}$ & N/A & $1 / \mathrm{sec}$ \\
\hline$Y q$ & -337.35 & $\mathrm{lb} / \mathrm{rad} / \mathrm{sec}$ & -0.6618 & $\mathrm{ft} / \mathrm{rad} / \mathrm{sec}$ & 0.2133 & $\mathrm{ft} / \mathrm{rad} / \mathrm{sec}$ & N/A & $\mathrm{ft} / \mathrm{rad} / \mathrm{sec}$ \\
\hline$Y p$ & -1075.38 & $\mathrm{lb} / \mathrm{rad} / \mathrm{sec}$ & -2.1097 & $\mathrm{ft} / \mathrm{rad} / \mathrm{sec}$ & -2.3810 & $\mathrm{ft} / \mathrm{rad} / \mathrm{sec}$ & N/A & $\mathrm{ft} / \mathrm{rad} / \mathrm{sec}$ \\
\hline $\mathrm{Yr}$ & 391.51 & $\mathrm{lb} / \mathrm{rad} / \mathrm{sec}$ & 0.7681 & $\mathrm{ft} / \mathrm{rad} / \mathrm{sec}$ & 0.9683 & $\mathrm{ft} / \mathrm{rad} / \mathrm{sec}$ & N/A & $\mathrm{ft} / \mathrm{rad} / \mathrm{sec}$ \\
\hline YB1 or $Y_{\delta e}$ & -922.42 & $\mathrm{lb} / \mathrm{rad}$ & N/A & $\mathrm{ft} / \mathrm{in} / \mathrm{sec}^{2}$ & 0.0396 & $\mathrm{ft} / \mathrm{in} / \mathrm{sec}^{2}$ & N/A & $\mathrm{ft} / \mathrm{in} / \mathrm{sec}^{2}$ \\
\hline YA1 or $\mathrm{Y}_{\delta \mathrm{a}}$ & 11393.52 & $\mathrm{lb} / \mathrm{rad}$ & N/A & $\mathrm{ft} / \mathrm{in} / \mathrm{sec}^{2}$ & 0.9389 & $\mathrm{ft} / \mathrm{in} / \mathrm{sec}^{2}$ & 0.9417 & $\mathrm{ft} / \mathrm{in} / \mathrm{sec}^{2}$ \\
\hline $\mathrm{Y} \theta$ or $\mathrm{Y}_{\delta c}$ & 422.01 & $\mathrm{lb} / \mathrm{rad}$ & N/A & $\mathrm{ft} / \mathrm{in} / \mathrm{sec}^{2}$ & 0.1970 & $\mathrm{ft} / \mathrm{in} / \mathrm{sec}^{2}$ & N/A & $\mathrm{ft} / \mathrm{in} / \mathrm{sec}^{2}$ \\
\hline$Y \theta_{\mathrm{T}}$ or $Y_{\delta p}$ & 18099.98 & $\mathrm{lb} / \mathrm{rad}$ & N/A & $\mathrm{ft} / \mathrm{in} / \mathrm{sec}^{2}$ & -1.3590 & $\mathrm{ft} / \mathrm{in} / \mathrm{sec}^{2}$ & -1.6140 & $\mathrm{ft} / \mathrm{in} / \mathrm{sec}^{2}$ \\
\hline $\mathrm{Zu}$ & -134.16 & $\mathrm{lb} / \mathrm{ft} / \mathrm{sec}$ & -0.2632 & $1 / \mathrm{sec}$ & -0.1252 & $1 / \mathrm{sec}$ & -0.1332 & $1 / \mathrm{sec}$ \\
\hline Zv & 0.00 & $\mathrm{lb} / \mathrm{ft} / \mathrm{sec}$ & 0.0000 & $1 / \mathrm{sec}$ & -0.0153 & $1 / \mathrm{sec}$ & N/A & $1 / \mathrm{sec}$ \\
\hline$Z w$ & -272.75 & $\mathrm{lb} / \mathrm{ft} / \mathrm{sec}$ & -0.5351 & $1 / \mathrm{sec}$ & -0.5617 & $1 / \mathrm{sec}$ & -0.5395 & $1 / \mathrm{sec}$ \\
\hline $\mathrm{Zq}$ & -123.23 & $\mathrm{lb} / \mathrm{rad} / \mathrm{sec}$ & -0.2417 & $\mathrm{ft} / \mathrm{rad} / \mathrm{sec}$ & 2.8650 & $\mathrm{ft} / \mathrm{rad} / \mathrm{sec}$ & N/A & $\mathrm{ft} / \mathrm{rad} / \mathrm{sec}$ \\
\hline$Z p$ & 0.00 & $\mathrm{lb} / \mathrm{rad} / \mathrm{sec}$ & 0.0000 & $\mathrm{ft} / \mathrm{rad} / \mathrm{sec}$ & 0.8862 & $\mathrm{ft} / \mathrm{rad} / \mathrm{sec}$ & N/A & $\mathrm{ft} / \mathrm{rad} / \mathrm{sec}$ \\
\hline $\mathrm{Zr}$ & 1239.06 & $\mathrm{lb} / \mathrm{rad} / \mathrm{sec}$ & 2.4308 & $\mathrm{ft} / \mathrm{rad} / \mathrm{sec}$ & -0.4176 & $\mathrm{ft} / \mathrm{rad} / \mathrm{sec}$ & N/A & $\mathrm{ft} / \mathrm{rad} / \mathrm{sec}$ \\
\hline $\mathrm{ZB1}$ or $\mathrm{Z}_{\delta \mathrm{e}}$ & 0.00 & $\mathrm{lb} / \mathrm{rad}$ & N/A & $\mathrm{ft} / \mathrm{in} / \mathrm{sec}^{2}$ & -2.0300 & $\mathrm{ft} / \mathrm{in} / \mathrm{sec}^{2}$ & -1.8678 & $\mathrm{ft} / \mathrm{in} / \mathrm{sec}^{2}$ \\
\hline ZA1 or $Z_{\delta a}$ & 0.00 & $\mathrm{lb} / \mathrm{rad}$ & N/A & $\mathrm{ft} / \mathrm{in} / \mathrm{sec}^{2}$ & 0.0096 & $\mathrm{ft} / \mathrm{in} / \mathrm{sec}^{2}$ & N/A & $\mathrm{ft} / \mathrm{in} / \mathrm{sec}^{2}$ \\
\hline$Z \theta$ or $Z_{\delta c}$ & -201196.26 & $\mathrm{lb} / \mathrm{rad}$ & $N / A$ & $\mathrm{ft} / \mathrm{in} / \mathrm{sec}^{2}$ & -7.4780 & $\mathrm{ft} / \mathrm{in} / \mathrm{sec}^{2}$ & -7.8250 & $\mathrm{ft} / \mathrm{in} / \mathrm{sec}^{2}$ \\
\hline$Z \theta_{T}$ or $Z_{\delta p}$ & 0.00 & $\mathrm{lb} / \mathrm{rad}$ & N/A & $\mathrm{ft} / \mathrm{in} / \mathrm{sec}^{2}$ & 1.6260 & $\mathrm{ft} / \mathrm{in} / \mathrm{sec}^{2}$ & 1.7228 & $\mathrm{ft} / \mathrm{in} / \mathrm{sec}^{2}$ \\
\hline
\end{tabular}




\begin{tabular}{|c|c|c|c|c|c|c|c|c|}
\hline \multirow[b]{2}{*}{$\mathrm{Mu}$} & \multicolumn{4}{|c|}{ WVU Linear Model } & \multicolumn{2}{|c|}{ NASA AMES } & \multicolumn{2}{|c|}{ BOEING-VERTOL } \\
\hline & -536.19 & $\mathrm{ft}-\mathrm{lb} / \mathrm{ft} / \mathrm{sec}$ & -0.0134 & $\mathrm{rad} / \mathrm{ft} / \mathrm{sec}$ & -0.0002 & $\mathrm{rad} / \mathrm{ft} / \mathrm{sec}$ & -0.0043 & $\mathrm{rad} / \mathrm{ft} / \mathrm{sec}$ \\
\hline $\mathrm{Mv}$ & -33.74 & $\mathrm{ft}-\mathrm{lb} / \mathrm{ft} / \mathrm{sec}$ & -0.0008 & $\mathrm{rad} / \mathrm{ft} / \mathrm{sec}$ & 0.0078 & $\mathrm{rad} / \mathrm{ft} / \mathrm{sec}$ & -0.0006 & $\mathrm{rad} / \mathrm{ft} / \mathrm{sec}$ \\
\hline $\mathrm{Mw}$ & 226.59 & $\mathrm{ft}-\mathrm{lb} / \mathrm{ft} / \mathrm{sec}$ & 0.0057 & $\mathrm{rad} / \mathrm{ft} / \mathrm{sec}$ & 0.0067 & $\mathrm{rad} / \mathrm{ft} / \mathrm{sec}$ & 0.0050 & $\mathrm{rad} / \mathrm{ft} / \mathrm{sec}$ \\
\hline $\mathrm{Mq}$ & -21742.50 & $\mathrm{ft}-\mathrm{lb} / \mathrm{rad} / \mathrm{sec}$ & -0.5436 & $1 / \mathrm{sec}$ & -1.0670 & $1 / \mathrm{sec}$ & -1.2832 & $1 / \mathrm{sec}$ \\
\hline $\mathrm{Mp}$ & 6415.17 & $\mathrm{ft}-\mathrm{lb} / \mathrm{rad} / \mathrm{sec}$ & 0.1604 & $1 / \mathrm{sec}$ & 0.2468 & $1 / \mathrm{sec}$ & 0.2567 & $1 / \mathrm{sec}$ \\
\hline $\mathrm{Mr}$ & 0.00 & $\mathrm{ft}-\mathrm{lb} / \mathrm{rad} / \mathrm{sec}$ & 0.0000 & $1 / \mathrm{sec}$ & -0.0896 & $1 / \mathrm{sec}$ & -0.1181 & $1 / \mathrm{sec}$ \\
\hline $\mathrm{MB1}$ or $\mathrm{M}_{\delta \mathrm{e}}$ & -222306.60 & $\mathrm{ft}-\mathrm{lb} / \mathrm{rad}$ & N/A & $\mathrm{ft} / \mathrm{in} / \mathrm{sec}^{2}$ & 0.3721 & $\mathrm{ft} / \mathrm{in} / \mathrm{sec}^{2}$ & 0.3850 & $\mathrm{ft} / \mathrm{in} / \mathrm{sec}^{2}$ \\
\hline MA1 or $M_{\delta a}$ & 17537.72 & $\mathrm{ft}-\mathrm{lb} / \mathrm{rad}$ & N/A & $\mathrm{ft} / \mathrm{in} / \mathrm{sec}^{2}$ & -0.0015 & $\mathrm{ft} / \mathrm{in} / \mathrm{sec}^{2}$ & 0.0134 & $\mathrm{ft} / \mathrm{in} / \mathrm{sec}^{2}$ \\
\hline $\mathrm{M} \theta$ or $\mathrm{M}_{\delta \mathrm{c}}$ & 269876.76 & $\mathrm{ft}-\mathrm{lb} / \mathrm{rad}$ & N/A & $\mathrm{ft} / \mathrm{in} / \mathrm{sec}^{2}$ & 0.0635 & $\mathrm{ft} / \mathrm{in} / \mathrm{sec}^{2}$ & 0.1574 & $\mathrm{ft} / \mathrm{in} / \mathrm{sec}^{2}$ \\
\hline$M \theta_{T}$ or $M_{\delta p}$ & 0.00 & $\mathrm{ft}-\mathrm{lb} / \mathrm{rad}$ & N/A & $\mathrm{ft} / \mathrm{in} / \mathrm{sec}^{2}$ & -0.0297 & $\mathrm{ft} / \mathrm{in} / \mathrm{sec}^{2}$ & -0.0499 & $\mathrm{ft} / \mathrm{in} / \mathrm{sec}^{2}$ \\
\hline $\mathrm{Ru}$ & 23.71 & $\mathrm{ft}-\mathrm{lb} / \mathrm{ft} / \mathrm{sec}$ & 0.0042 & $\mathrm{rad} / \mathrm{ft} / \mathrm{sec}$ & -0.0078 & $\mathrm{rad} / \mathrm{ft} / \mathrm{sec}$ & N/A & $\mathrm{rad} / \mathrm{ft} / \mathrm{sec}$ \\
\hline $\mathrm{Rv}$ & -182.02 & $\mathrm{ft}-\mathrm{lb} / \mathrm{ft} / \mathrm{sec}$ & -0.0323 & $\mathrm{rad} / \mathrm{ft} / \mathrm{sec}$ & -0.0345 & $\mathrm{rad} / \mathrm{ft} / \mathrm{sec}$ & -0.0267 & $\mathrm{rad} / \mathrm{ft} / \mathrm{sec}$ \\
\hline $\mathrm{Rw}$ & 108.70 & $\mathrm{ft}-\mathrm{lb} / \mathrm{ft} / \mathrm{sec}$ & 0.0193 & $\mathrm{rad} / \mathrm{ft} / \mathrm{sec}$ & 0.0284 & $\mathrm{rad} / \mathrm{ft} / \mathrm{sec}$ & N/A & $\mathrm{rad} / \mathrm{ft} / \mathrm{sec}$ \\
\hline $\mathrm{Rq}$ & -6594.74 & $\mathrm{ft}-\mathrm{lb} / \mathrm{rad} / \mathrm{sec}$ & -1.1716 & $1 / \mathrm{sec}$ & -1.5660 & $1 / \mathrm{sec}$ & -1.5485 & $1 / \mathrm{sec}$ \\
\hline $\mathrm{Rp}$ & -19020.04 & $\mathrm{ft}-\mathrm{lb} / \mathrm{rad} / \mathrm{sec}$ & -3.3789 & $1 / \mathrm{sec}$ & -3.8190 & $1 / \mathrm{sec}$ & -3.7116 & $1 / \mathrm{sec}$ \\
\hline $\mathrm{Rr}$ & 2809.52 & $\mathrm{ft}-\mathrm{lb} / \mathrm{rad} / \mathrm{sec}$ & 0.4991 & $1 / \mathrm{sec}$ & 0.2726 & $1 / \mathrm{sec}$ & 0.4149 & $1 / \mathrm{sec}$ \\
\hline $\mathrm{RB} 1$ or $\mathrm{R}_{\delta \mathrm{e}}$ & -17689.39 & $\mathrm{ft}-\mathrm{lb} / \mathrm{rad}$ & N/A & $\mathrm{ft} / \mathrm{in} / \mathrm{sec}^{2}$ & 0.1010 & $\mathrm{ft} / \mathrm{in} / \mathrm{sec}^{2}$ & N/A & $\mathrm{ft} / \mathrm{in} / \mathrm{sec}^{2}$ \\
\hline $\mathrm{RA1}$ or $\mathrm{R}_{\delta \mathrm{a}}$ & 218494.55 & $\mathrm{ft}-\mathrm{lb} / \mathrm{rad}$ & N/A & $\mathrm{ft} / \mathrm{in} / \mathrm{sec}^{2}$ & 1.3290 & $\mathrm{ft} / \mathrm{in} / \mathrm{sec}^{2}$ & 1.3147 & $\mathrm{ft} / \mathrm{in} / \mathrm{sec}^{2}$ \\
\hline$R \theta$ or $R_{\delta c}$ & 55816.69 & $\mathrm{ft}-\mathrm{lb} / \mathrm{rad}$ & N/A & $\mathrm{ft} / \mathrm{in} / \mathrm{sec}^{2}$ & 0.1981 & $\mathrm{ft} / \mathrm{in} / \mathrm{sec}^{2}$ & N/A & $\mathrm{ft} / \mathrm{in} / \mathrm{sec}^{2}$ \\
\hline$R \theta_{T}$ or $R_{\delta p}$ & 116895.73 & $\mathrm{ft}-\mathrm{lb} / \mathrm{rad}$ & N/A & $\mathrm{ft} / \mathrm{in} / \mathrm{sec}^{2}$ & -0.7967 & $\mathrm{ft} / \mathrm{in} / \mathrm{sec}^{2}$ & -0.8968 & $\mathrm{ft} / \mathrm{in} / \mathrm{sec}^{2}$ \\
\hline $\mathrm{Nu}$ & -230.06 & $\mathrm{ft}-\mathrm{lb} / \mathrm{ft} / \mathrm{sec}$ & -0.0062 & $\mathrm{rad} / \mathrm{ft} / \mathrm{sec}$ & -0.0058 & $\mathrm{rad} / \mathrm{ft} / \mathrm{sec}$ & N/A & $\mathrm{rad} / \mathrm{ft} / \mathrm{sec}$ \\
\hline $\mathrm{Nv}$ & 307.90 & $\mathrm{ft}-\mathrm{lb} / \mathrm{ft} / \mathrm{sec}$ & 0.0083 & $\mathrm{rad} / \mathrm{ft} / \mathrm{sec}$ & 0.0125 & $\mathrm{rad} / \mathrm{ft} / \mathrm{sec}$ & 0.0119 & $\mathrm{rad} / \mathrm{ft} / \mathrm{sec}$ \\
\hline $\mathrm{Nw}$ & -131.74 & $\mathrm{ft}-\mathrm{lb} / \mathrm{ft} / \mathrm{sec}$ & -0.0035 & $\mathrm{rad} / \mathrm{ft} / \mathrm{sec}$ & -0.0064 & $\mathrm{rad} / \mathrm{ft} / \mathrm{sec}$ & N/A & $\mathrm{rad} / \mathrm{ft} / \mathrm{sec}$ \\
\hline $\mathrm{Nq}$ & 0.00 & $\mathrm{ft}-\mathrm{lb} / \mathrm{rad} / \mathrm{sec}$ & 0.0000 & $1 / \mathrm{sec}$ & -0.5837 & $1 / \mathrm{sec}$ & N/A & $1 / \mathrm{sec}$ \\
\hline $\mathrm{Np}$ & 2809.52 & $\mathrm{ft}-\mathrm{lb} / \mathrm{rad} / \mathrm{sec}$ & 0.0755 & $1 / \mathrm{sec}$ & -0.2310 & $1 / \mathrm{sec}$ & 0.0251 & $1 / \mathrm{sec}$ \\
\hline $\mathrm{Nr}$ & -13883.70 & $\mathrm{ft}-\mathrm{lb} / \mathrm{rad} / \mathrm{sec}$ & -0.3732 & $1 / \mathrm{sec}$ & -0.5336 & $1 / \mathrm{sec}$ & -0.5142 & $1 / \mathrm{sec}$ \\
\hline NB1 or $N_{\delta e}$ & 0.00 & $\mathrm{ft}-\mathrm{lb} / \mathrm{rad}$ & N/A & $\mathrm{ft} / \mathrm{in} / \mathrm{sec}^{2}$ & -0.0176 & $\mathrm{ft} / \mathrm{in} / \mathrm{sec}^{2}$ & N/A & $\mathrm{ft} / \mathrm{in} / \mathrm{sec}^{2}$ \\
\hline $\mathrm{NA1}$ or $\mathrm{N}_{\delta \mathrm{a}}$ & 0.00 & $\mathrm{ft}-\mathrm{lb} / \mathrm{rad}$ & N/A & $\mathrm{ft} / \mathrm{in} / \mathrm{sec}^{2}$ & 0.0260 & $\mathrm{ft} / \mathrm{in} / \mathrm{sec}^{2}$ & -0.0268 & $\mathrm{ft} / \mathrm{in} / \mathrm{sec}^{2}$ \\
\hline $\mathrm{N} \theta$ or $\mathrm{N}_{\delta c}$ & 305267.19 & $\mathrm{ft}-\mathrm{lb} / \mathrm{rad}$ & N/A & $\mathrm{ft} / \mathrm{in} / \mathrm{sec}^{2}$ & 0.0161 & $\mathrm{ft} / \mathrm{in} / \mathrm{sec}^{2}$ & 0.0222 & $\mathrm{ft} / \mathrm{in} / \mathrm{sec}^{2}$ \\
\hline $\mathrm{N} \theta_{\mathrm{T}}$ or $\mathrm{N}_{\delta p}$ & -560496.17 & $\mathrm{ft}-\mathrm{lb} / \mathrm{rad}$ & N/A & $\mathrm{ft} / \mathrm{in} / \mathrm{sec}^{2}$ & 0.5701 & $\mathrm{ft} / \mathrm{in} / \mathrm{sec}^{2}$ & 0.6720 & $\mathrm{ft} / \mathrm{in} / \mathrm{sec}^{2}$ \\
\hline
\end{tabular}


Table B.4: Stability and Control Derivative Comparison (60 Knots)

\begin{tabular}{|c|c|c|c|c|c|c|c|c|}
\hline & \multicolumn{4}{|c|}{ WVU Linear Model } & \multicolumn{2}{|c|}{ NASA AMES } & \multicolumn{2}{|c|}{ BOEING-VERTOL } \\
\hline $\mathrm{Xu}$ & -12.14 & $\mathrm{lb} / \mathrm{ft} / \mathrm{sec}$ & -0.0238 & $1 / \mathrm{sec}$ & -0.019 & $1 / \mathrm{sec}$ & -0.0201 & $1 / \mathrm{sec}$ \\
\hline$X v$ & -32.01 & $\mathrm{lb} / \mathrm{ft} / \mathrm{sec}$ & -0.0628 & $1 / \mathrm{sec}$ & -0.002259 & $1 / \mathrm{sec}$ & N/A & $1 / \mathrm{sec}$ \\
\hline Xw & 13.58 & $\mathrm{lb} / \mathrm{ft} / \mathrm{sec}$ & 0.0266 & $1 / \mathrm{sec}$ & 0.04814 & $1 / \mathrm{sec}$ & N/A & $1 / \mathrm{sec}$ \\
\hline $\mathrm{Xq}$ & 1088.28 & $\mathrm{lb} / \mathrm{rad} / \mathrm{sec}$ & 2.1350 & $\mathrm{ft} / \mathrm{rad} / \mathrm{sec}$ & 3.352 & $\mathrm{ft} / \mathrm{rad} / \mathrm{sec}$ & N/A & $\mathrm{ft} / \mathrm{rad} / \mathrm{sec}$ \\
\hline $\mathrm{Xp}$ & -354.96 & $\mathrm{lb} / \mathrm{rad} / \mathrm{sec}$ & -0.6964 & $\mathrm{ft} / \mathrm{rad} / \mathrm{sec}$ & 0.01583 & $\mathrm{ft} / \mathrm{rad} / \mathrm{sec}$ & N/A & $\mathrm{ft} / \mathrm{rad} / \mathrm{sec}$ \\
\hline $\mathrm{Xr}$ & 0.00 & $\mathrm{lb} / \mathrm{rad} / \mathrm{sec}$ & 0.0000 & $\mathrm{ft} / \mathrm{rad} / \mathrm{sec}$ & -0.08981 & $\mathrm{ft} / \mathrm{rad} / \mathrm{sec}$ & N/A & $\mathrm{ft} / \mathrm{rad} / \mathrm{sec}$ \\
\hline $\mathrm{XB1}$ or $\mathrm{X}_{\delta \mathrm{e}}$ & 12957.25 & $\mathrm{lb} / \mathrm{rad}$ & N/A & $\mathrm{ft} / \mathrm{in} / \mathrm{sec}^{2}$ & -1.402 & $\mathrm{ft} / \mathrm{in} / \mathrm{sec}^{2}$ & -1.2532 & $\mathrm{ft} / \mathrm{in} / \mathrm{sec}^{2}$ \\
\hline XA1 or $\mathrm{X}_{\delta \mathrm{a}}$ & -1006.02 & $\mathrm{lb} / \mathrm{rad}$ & N/A & $\mathrm{ft} / \mathrm{in} / \mathrm{sec}^{2}$ & 0.01082 & $\mathrm{ft} / \mathrm{in} / \mathrm{sec}^{2}$ & N/A & $\mathrm{ft} / \mathrm{in} / \mathrm{sec}^{2}$ \\
\hline $\mathrm{X} \theta$ or $\mathrm{X}_{\delta c}$ & 6208.05 & $\mathrm{lb} / \mathrm{rad}$ & N/A & $\mathrm{ft} / \mathrm{in} / \mathrm{sec}^{2}$ & 0.5939 & $\mathrm{ft} / \mathrm{in} / \mathrm{sec}^{2}$ & N/A & $\mathrm{ft} / \mathrm{in} / \mathrm{sec}^{2}$ \\
\hline$x \theta_{T}$ or $X_{\delta p}$ & 0.00 & $\mathrm{lb} / \mathrm{rad}$ & $N / A$ & $\mathrm{ft} / \mathrm{in} / \mathrm{sec}^{2}$ & 0.8695 & $\mathrm{ft} / \mathrm{in} / \mathrm{sec}^{2}$ & N/A & $\mathrm{ft} / \mathrm{in} / \mathrm{sec}^{2}$ \\
\hline Yu & 2.84 & $\mathrm{lb} / \mathrm{ft} / \mathrm{sec}$ & 0.0056 & $1 / \mathrm{sec}$ & -0.003401 & $1 / \mathrm{sec}$ & N/A & $1 / \mathrm{sec}$ \\
\hline$Y v$ & -75.03 & $\mathrm{lb} / \mathrm{ft} / \mathrm{sec}$ & -0.1472 & $1 / \mathrm{sec}$ & -0.1044 & $1 / \mathrm{sec}$ & -0.095 & $1 / \mathrm{sec}$ \\
\hline$Y w$ & 7.45 & $\mathrm{lb} / \mathrm{ft} / \mathrm{sec}$ & 0.0146 & $1 / \mathrm{sec}$ & 0.0129 & $1 / \mathrm{sec}$ & N/A & $1 / \mathrm{sec}$ \\
\hline$Y q$ & -369.30 & $\mathrm{lb} / \mathrm{rad} / \mathrm{sec}$ & -0.7245 & $\mathrm{ft} / \mathrm{rad} / \mathrm{sec}$ & 0.4611 & $\mathrm{ft} / \mathrm{rad} / \mathrm{sec}$ & N/A & $\mathrm{ft} / \mathrm{rad} / \mathrm{sec}$ \\
\hline$Y p$ & -1254.58 & $\mathrm{lb} / \mathrm{rad} / \mathrm{sec}$ & -2.4613 & $\mathrm{ft} / \mathrm{rad} / \mathrm{sec}$ & -2.608 & $\mathrm{ft} / \mathrm{rad} / \mathrm{sec}$ & N/A & $\mathrm{ft} / \mathrm{rad} / \mathrm{sec}$ \\
\hline $\mathrm{Yr}$ & 1427.66 & $\mathrm{lb} / \mathrm{rad} / \mathrm{sec}$ & 2.8008 & $\mathrm{ft} / \mathrm{rad} / \mathrm{sec}$ & 1.249 & $\mathrm{ft} / \mathrm{rad} / \mathrm{sec}$ & N/A & $\mathrm{ft} / \mathrm{rad} / \mathrm{sec}$ \\
\hline YB1 or $Y_{\delta e}$ & -1025.49 & $\mathrm{lb} / \mathrm{rad}$ & N/A & $\mathrm{ft} / \mathrm{in} / \mathrm{sec}^{2}$ & 0.02118 & $\mathrm{ft} / \mathrm{in} / \mathrm{sec}^{2}$ & N/A & $\mathrm{ft} / \mathrm{in} / \mathrm{sec}^{2}$ \\
\hline YA1 or $\mathrm{Y}_{\delta \mathrm{a}}$ & 12465.25 & $\mathrm{lb} / \mathrm{rad}$ & N/A & $\mathrm{ft} / \mathrm{in} / \mathrm{sec}^{2}$ & 0.9284 & $\mathrm{ft} / \mathrm{in} / \mathrm{sec}^{2}$ & 0.9148 & $\mathrm{ft} / \mathrm{in} / \mathrm{sec}^{2}$ \\
\hline$Y \theta$ or $Y_{\delta c}$ & 2381.54 & $\mathrm{lb} / \mathrm{rad}$ & N/A & $\mathrm{ft} / \mathrm{in} / \mathrm{sec}^{2}$ & 0.247 & $\mathrm{ft} / \mathrm{in} / \mathrm{sec}^{2}$ & N/A & $\mathrm{ft} / \mathrm{in} / \mathrm{sec}^{2}$ \\
\hline $\mathrm{Y} \theta_{\mathrm{T}}$ or $\mathrm{Y}_{\delta \mathrm{p}}$ & 17903.73 & $\mathrm{lb} / \mathrm{rad}$ & N/A & $\mathrm{ft} / \mathrm{in} / \mathrm{sec}^{2}$ & -1.587 & $\mathrm{ft} / \mathrm{in} / \mathrm{sec}^{2}$ & -1.7968 & $\mathrm{ft} / \mathrm{in} / \mathrm{sec}^{2}$ \\
\hline $\mathrm{Zu}$ & -46.83 & $\mathrm{lb} / \mathrm{ft} / \mathrm{sec}$ & -0.0919 & $1 / \mathrm{sec}$ & -0.04741 & $1 / \mathrm{sec}$ & -0.0546 & $1 / \mathrm{sec}$ \\
\hline Zv & 0.00 & $\mathrm{Ib} / \mathrm{ft} / \mathrm{sec}$ & 0.0000 & $1 / \mathrm{sec}$ & -0.02032 & $1 / \mathrm{sec}$ & N/A & $1 / \mathrm{sec}$ \\
\hline Zw & -319.84 & $\mathrm{lb} / \mathrm{ft} / \mathrm{sec}$ & -0.6275 & $1 / \mathrm{sec}$ & 0.6696 & $1 / \mathrm{sec}$ & -0.6523 & $1 / \mathrm{sec}$ \\
\hline $\mathrm{Zq}$ & -258.17 & $\mathrm{lb} / \mathrm{rad} / \mathrm{sec}$ & -0.5065 & $\mathrm{ft} / \mathrm{rad} / \mathrm{sec}$ & 3.502 & $\mathrm{ft} / \mathrm{rad} / \mathrm{sec}$ & N/A & $\mathrm{ft} / \mathrm{rad} / \mathrm{sec}$ \\
\hline$Z p$ & 0.00 & $\mathrm{lb} / \mathrm{rad} / \mathrm{sec}$ & 0.0000 & $\mathrm{ft} / \mathrm{rad} / \mathrm{sec}$ & 1.358 & $\mathrm{ft} / \mathrm{rad} / \mathrm{sec}$ & N/A & $\mathrm{ft} / \mathrm{rad} / \mathrm{sec}$ \\
\hline $\mathrm{Zr}$ & 1242.25 & $\mathrm{lb} / \mathrm{rad} / \mathrm{sec}$ & 2.4371 & $\mathrm{ft} / \mathrm{rad} / \mathrm{sec}$ & -0.4981 & $\mathrm{ft} / \mathrm{rad} / \mathrm{sec}$ & N/A & $\mathrm{ft} / \mathrm{rad} / \mathrm{sec}$ \\
\hline $\mathrm{ZB1}$ or $\mathrm{Z}_{\delta \mathrm{e}}$ & 0.00 & $\mathrm{lb} / \mathrm{rad}$ & $N / A$ & $\mathrm{ft} / \mathrm{in} / \mathrm{sec}^{2}$ & -3.271 & $\mathrm{ft} / \mathrm{in} / \mathrm{sec}^{2}$ & -3.0911 & $\mathrm{ft} / \mathrm{in} / \mathrm{sec}^{2}$ \\
\hline ZA1 or $Z_{\delta a}$ & 0.00 & $\mathrm{lb} / \mathrm{rad}$ & N/A & $\mathrm{ft} / \mathrm{in} / \mathrm{sec}^{2}$ & 0.3733 & $\mathrm{ft} / \mathrm{in} / \mathrm{sec}^{2}$ & N/A & $\mathrm{ft} / \mathrm{in} / \mathrm{sec}^{2}$ \\
\hline$Z \theta$ or $Z_{\delta c}$ & -189807.60 & $\mathrm{lb} / \mathrm{rad}$ & $N / A$ & $\mathrm{ft} / \mathrm{in} / \mathrm{sec}^{2}$ & -8.324 & $\mathrm{ft} / \mathrm{in} / \mathrm{sec}^{2}$ & -9.0061 & $\mathrm{ft} / \mathrm{in} / \mathrm{sec}^{2}$ \\
\hline$z \theta_{\mathrm{T}}$ or $\mathrm{Z}_{\delta p}$ & 0.00 & $\mathrm{lb} / \mathrm{rad}$ & N/A & $\mathrm{ft} / \mathrm{in} / \mathrm{sec}^{2}$ & 2.372 & $\mathrm{ft} / \mathrm{in} / \mathrm{sec}^{2}$ & 2.5612 & $\mathrm{ft} / \mathrm{in} / \mathrm{sec}^{2}$ \\
\hline
\end{tabular}




\begin{tabular}{|c|c|c|c|c|c|c|c|c|}
\hline & \multicolumn{4}{|c|}{ WVU Linear Model } & \multicolumn{2}{|c|}{ NASA AMES } & \multicolumn{2}{|c|}{ BOEING-VERTOL } \\
\hline $\mathrm{Mu}$ & -417.73 & $\mathrm{ft}-\mathrm{lb} / \mathrm{ft} / \mathrm{sec}$ & -0.0104 & $\mathrm{rad} / \mathrm{ft} / \mathrm{sec}$ & 0.001929 & $\mathrm{rad} / \mathrm{ft} / \mathrm{sec}$ & 0.004 & $\mathrm{rad} / \mathrm{ft} / \mathrm{sec}$ \\
\hline $\mathrm{Mv}$ & -19.30 & $\mathrm{ft}-\mathrm{lb} / \mathrm{ft} / \mathrm{sec}$ & -0.0005 & $\mathrm{rad} / \mathrm{ft} / \mathrm{sec}$ & 0.006016 & $\mathrm{rad} / \mathrm{ft} / \mathrm{sec}$ & 0.0011 & $\mathrm{rad} / \mathrm{ft} / \mathrm{sec}$ \\
\hline $\mathrm{Mw}$ & 315.80 & $\mathrm{ft}-\mathrm{lb} / \mathrm{ft} / \mathrm{sec}$ & 0.0079 & $\mathrm{rad} / \mathrm{ft} / \mathrm{sec}$ & 0.008916 & $\mathrm{rad} / \mathrm{ft} / \mathrm{sec}$ & 0.0072 & $\mathrm{rad} / \mathrm{ft} / \mathrm{sec}$ \\
\hline $\mathrm{Mq}$ & -26483.52 & $\mathrm{ft}-\mathrm{lb} / \mathrm{rad} / \mathrm{sec}$ & -0.6621 & $1 / \mathrm{sec}$ & -1.23 & $1 / \mathrm{sec}$ & -1.5541 & $1 / \mathrm{sec}$ \\
\hline $\mathrm{Mp}$ & 6775.21 & $\mathrm{ft}-\mathrm{lb} / \mathrm{rad} / \mathrm{sec}$ & 0.1694 & $1 / \mathrm{sec}$ & 0.2008 & $1 / \mathrm{sec}$ & 0.2379 & $1 / \mathrm{sec}$ \\
\hline $\mathrm{Mr}$ & 0.00 & $\mathrm{ft}-\mathrm{lb} / \mathrm{rad} / \mathrm{sec}$ & 0.0000 & $1 / \mathrm{sec}$ & -0.113 & $1 / \mathrm{sec}$ & -0.1149 & $1 / \mathrm{sec}$ \\
\hline $\mathrm{MB1}$ or $\mathrm{M}_{\delta \mathrm{e}}$ & -233412.82 & $\mathrm{ft}-\mathrm{lb} / \mathrm{rad}$ & N/A & $\mathrm{ft} / \mathrm{in} / \mathrm{sec}^{2}$ & 0.3997 & $\mathrm{ft} / \mathrm{in} / \mathrm{sec}^{2}$ & 0.4133 & $\mathrm{ft} / \mathrm{in} / \mathrm{sec}^{2}$ \\
\hline MA1 or $\mathrm{M}_{\delta \mathrm{a}}$ & 18122.56 & $\mathrm{ft}-\mathrm{lb} / \mathrm{rad}$ & N/A & $\mathrm{ft} / \mathrm{in} / \mathrm{sec}^{2}$ & 0.005281 & $\mathrm{ft} / \mathrm{in} / \mathrm{sec}^{2}$ & 0.0128 & $\mathrm{ft} / \mathrm{in} / \mathrm{sec}^{2}$ \\
\hline $\mathrm{M} \theta$ or $\mathrm{M}_{\delta c}$ & 355111.17 & $\mathrm{ft}-\mathrm{lb} / \mathrm{rad}$ & N/A & $\mathrm{ft} / \mathrm{in} / \mathrm{sec}^{2}$ & 0.08925 & $\mathrm{ft} / \mathrm{in} / \mathrm{sec}^{2}$ & 0.1362 & $\mathrm{ft} / \mathrm{in} / \mathrm{sec}^{2}$ \\
\hline $\mathrm{M} \theta_{\mathrm{T}}$ or $\mathrm{M}_{\delta \mathrm{p}}$ & 0.00 & $\mathrm{ft}-\mathrm{lb} / \mathrm{rad}$ & N/A & $\mathrm{ft} / \mathrm{in} / \mathrm{sec}^{2}$ & -0.03336 & $\mathrm{ft} / \mathrm{in} / \mathrm{sec}^{2}$ & -0.0562 & $\mathrm{ft} / \mathrm{in} / \mathrm{sec}^{2}$ \\
\hline $\mathrm{Ru}$ & 13.33 & $\mathrm{ft}-\mathrm{lb} / \mathrm{ft} / \mathrm{sec}$ & 0.0024 & $\mathrm{rad} / \mathrm{ft} / \mathrm{sec}$ & -0.006377 & $\mathrm{rad} / \mathrm{ft} / \mathrm{sec}$ & N/A & $\mathrm{rad} / \mathrm{ft} / \mathrm{sec}$ \\
\hline Rv & -274.71 & $\mathrm{ft}-\mathrm{lb} / \mathrm{ft} / \mathrm{sec}$ & -0.0488 & $\mathrm{rad} / \mathrm{ft} / \mathrm{sec}$ & -0.0369 & $\mathrm{rad} / \mathrm{ft} / \mathrm{sec}$ & -0.0258 & $\mathrm{rad} / \mathrm{ft} / \mathrm{sec}$ \\
\hline Rw & 134.17 & $\mathrm{ft}-\mathrm{lb} / \mathrm{ft} / \mathrm{sec}$ & 0.0238 & $\mathrm{rad} / \mathrm{ft} / \mathrm{sec}$ & 0.02586 & $\mathrm{rad} / \mathrm{ft} / \mathrm{sec}$ & N/A & $\mathrm{rad} / \mathrm{ft} / \mathrm{sec}$ \\
\hline $\mathrm{Rq}$ & -6744.68 & $\mathrm{ft}-\mathrm{lb} / \mathrm{rad} / \mathrm{sec}$ & -1.1982 & $1 / \mathrm{sec}$ & -1.522 & $1 / \mathrm{sec}$ & -1.4919 & $1 / \mathrm{sec}$ \\
\hline $\mathrm{Rp}$ & -19742.52 & $\mathrm{ft}-\mathrm{lb} / \mathrm{rad} / \mathrm{sec}$ & -3.5073 & $1 / \mathrm{sec}$ & -3.954 & $1 / \mathrm{sec}$ & -3.7659 & $1 / \mathrm{sec}$ \\
\hline $\mathrm{Rr}$ & 5589.95 & $\mathrm{ft}-\mathrm{lb} / \mathrm{rad} / \mathrm{sec}$ & 0.9931 & $1 / \mathrm{sec}$ & 0.4375 & $1 / \mathrm{sec}$ & 0.4878 & $1 / \mathrm{sec}$ \\
\hline $\mathrm{RB} 1$ or $\mathrm{R}_{\delta \mathrm{e}}$ & -18473.29 & $\mathrm{ft}-\mathrm{lb} / \mathrm{rad}$ & N/A & $\mathrm{ft} / \mathrm{in} / \mathrm{sec}^{2}$ & 0.121 & $\mathrm{ft} / \mathrm{in} / \mathrm{sec}^{2}$ & N/A & $\mathrm{ft} / \mathrm{in} / \mathrm{sec}^{2}$ \\
\hline RA1 or $R_{\delta a}$ & 224549.78 & $\mathrm{ft}-\mathrm{lb} / \mathrm{rad}$ & N/A & $\mathrm{ft} / \mathrm{in} / \mathrm{sec}^{2}$ & 1.316 & $\mathrm{ft} / \mathrm{in} / \mathrm{sec}^{2}$ & 1.2866 & $\mathrm{ft} / \mathrm{in} / \mathrm{sec}^{2}$ \\
\hline $\mathrm{R} \theta$ or $\mathrm{R}_{\delta c}$ & 78344.72 & $\mathrm{ft}-\mathrm{lb} / \mathrm{rad}$ & N/A & $\mathrm{ft} / \mathrm{in} / \mathrm{sec}^{2}$ & 0.2095 & $\mathrm{ft} / \mathrm{in} / \mathrm{sec}^{2}$ & N/A & $\mathrm{ft} / \mathrm{in} / \mathrm{sec}^{2}$ \\
\hline$R \theta_{T}$ or $R_{\delta p}$ & 115628.27 & $\mathrm{ft}-\mathrm{lb} / \mathrm{rad}$ & N/A & $\mathrm{ft} / \mathrm{in} / \mathrm{sec}^{2}$ & -0.9414 & $\mathrm{ft} / \mathrm{in} / \mathrm{sec}^{2}$ & -1.0035 & $\mathrm{ft} / \mathrm{in} / \mathrm{sec}^{2}$ \\
\hline $\mathrm{Nu}$ & -95.12 & $\mathrm{ft}-\mathrm{lb} / \mathrm{ft} / \mathrm{sec}$ & -0.0026 & $\mathrm{rad} / \mathrm{ft} / \mathrm{sec}$ & -0.003739 & $\mathrm{rad} / \mathrm{ft} / \mathrm{sec}$ & N/A & $\mathrm{rad} / \mathrm{ft} / \mathrm{sec}$ \\
\hline Nv & 1302.25 & $\mathrm{ft}-\mathrm{lb} / \mathrm{ft} / \mathrm{sec}$ & 0.0350 & $\mathrm{rad} / \mathrm{ft} / \mathrm{sec}$ & 0.01529 & $\mathrm{rad} / \mathrm{ft} / \mathrm{sec}$ & 0.0141 & $\mathrm{rad} / \mathrm{ft} / \mathrm{sec}$ \\
\hline Nw & -82.23 & $\mathrm{ft}-\mathrm{lb} / \mathrm{ft} / \mathrm{sec}$ & -0.0022 & $\mathrm{rad} / \mathrm{ft} / \mathrm{sec}$ & -0.01079 & $\mathrm{rad} / \mathrm{ft} / \mathrm{sec}$ & N/A & $\mathrm{rad} / \mathrm{ft} / \mathrm{sec}$ \\
\hline $\mathrm{Nq}$ & 0.00 & $\mathrm{ft}-\mathrm{lb} / \mathrm{rad} / \mathrm{sec}$ & 0.0000 & $1 / \mathrm{sec}$ & -0.4874 & $1 / \mathrm{sec}$ & N/A & $1 / \mathrm{sec}$ \\
\hline $\mathrm{Np}$ & 5589.95 & $\mathrm{ft}-\mathrm{lb} / \mathrm{rad} / \mathrm{sec}$ & 0.1503 & $1 / \mathrm{sec}$ & -0.1499 & $1 / \mathrm{sec}$ & -0.0446 & $1 / \mathrm{sec}$ \\
\hline $\mathrm{Nr}$ & -42968.09 & $\mathrm{ft}-\mathrm{lb} / \mathrm{rad} / \mathrm{sec}$ & -1.1551 & $1 / \mathrm{sec}$ & 0.6547 & $1 / \mathrm{sec}$ & -0.6283 & $1 / \mathrm{sec}$ \\
\hline $\mathrm{NB1}$ or $\mathrm{N}_{\delta \mathrm{e}}$ & 0.00 & $\mathrm{ft}-\mathrm{lb} / \mathrm{rad}$ & N/A & $\mathrm{ft} / \mathrm{in} / \mathrm{sec}^{2}$ & 0.03105 & $\mathrm{ft} / \mathrm{in} / \mathrm{sec}^{2}$ & N/A & $\mathrm{ft} / \mathrm{in} / \mathrm{sec}^{2}$ \\
\hline $\mathrm{NA1}$ or $\mathrm{N}_{\delta \mathrm{a}}$ & 0.00 & $\mathrm{ft}-\mathrm{lb} / \mathrm{rad}$ & N/A & $\mathrm{ft} / \mathrm{in} / \mathrm{sec}^{2}$ & 0.02691 & $\mathrm{ft} / \mathrm{in} / \mathrm{sec}^{2}$ & -0.011 & $\mathrm{ft} / \mathrm{in} / \mathrm{sec}^{2}$ \\
\hline $\mathrm{N} \theta$ or $\mathrm{N}_{\delta c}$ & 316945.15 & $\mathrm{ft}-\mathrm{lb} / \mathrm{rad}$ & N/A & $\mathrm{ft} / \mathrm{in} / \mathrm{sec}^{2}$ & -0.04757 & $\mathrm{ft} / \mathrm{in} / \mathrm{sec}^{2}$ & -0.0191 & $\mathrm{ft} / \mathrm{in} / \mathrm{sec}^{2}$ \\
\hline $\mathrm{N} \theta_{T}$ or $\mathrm{N}_{\delta p}$ & -554418.90 & $\mathrm{ft}-\mathrm{lb} / \mathrm{rad}$ & N/A & $\mathrm{ft} / \mathrm{in} / \mathrm{sec}^{2}$ & 0.6785 & $\mathrm{ft} / \mathrm{in} / \mathrm{sec}^{2}$ & 0.7668 & $\mathrm{ft} / \mathrm{in} / \mathrm{sec}^{2}$ \\
\hline
\end{tabular}


Table B.5: Stability and Control Derivative Comparison (100 Knots)

\begin{tabular}{|c|c|c|c|c|c|c|c|c|}
\hline \multirow[b]{2}{*}{$\mathrm{Xu}$} & \multicolumn{4}{|c|}{ WVU Linear Model } & \multicolumn{2}{|c|}{ NASA AMES } & \multicolumn{2}{|c|}{ BOEING-VERTOL } \\
\hline & -19.16 & $\mathrm{lb} / \mathrm{ft} / \mathrm{sec}$ & -0.0376 & $1 / \mathrm{sec}$ & -0.0324 & $1 / \mathrm{sec}$ & -0.0422 & $1 / \mathrm{sec}$ \\
\hline$X v$ & -6.56 & $\mathrm{lb} / \mathrm{ft} / \mathrm{sec}$ & -0.0129 & $1 / \mathrm{sec}$ & -0.0006 & $1 / \mathrm{sec}$ & N/A & $1 / \mathrm{sec}$ \\
\hline$X w$ & 20.29 & $\mathrm{lb} / \mathrm{ft} / \mathrm{sec}$ & 0.0398 & $1 / \mathrm{sec}$ & 0.0643 & $1 / \mathrm{sec}$ & N/A & $1 / \mathrm{sec}$ \\
\hline $\mathrm{Xq}$ & 1105.48 & $\mathrm{lb} / \mathrm{rad} / \mathrm{sec}$ & 2.1688 & $\mathrm{ft} / \mathrm{rad} / \mathrm{sec}$ & 2.7880 & $\mathrm{ft} / \mathrm{rad} / \mathrm{sec}$ & N/A & $\mathrm{ft} / \mathrm{rad} / \mathrm{sec}$ \\
\hline $\mathrm{Xp}$ & -368.55 & $\mathrm{lb} / \mathrm{rad} / \mathrm{sec}$ & -0.7230 & $\mathrm{ft} / \mathrm{rad} / \mathrm{sec}$ & -0.1132 & $\mathrm{ft} / \mathrm{rad} / \mathrm{sec}$ & N/A & $\mathrm{ft} / \mathrm{rad} / \mathrm{sec}$ \\
\hline $\mathrm{Xr}$ & 0.00 & $\mathrm{lb} / \mathrm{rad} / \mathrm{sec}$ & 0.0000 & $\mathrm{ft} / \mathrm{rad} / \mathrm{sec}$ & -0.0686 & $\mathrm{ft} / \mathrm{rad} / \mathrm{sec}$ & N/A & $\mathrm{ft} / \mathrm{rad} / \mathrm{sec}$ \\
\hline $\mathrm{XB1}$ or $\mathrm{X}_{\delta \mathrm{e}}$ & 13598.42 & $\mathrm{lb} / \mathrm{rad}$ & N/A & $\mathrm{ft} / \mathrm{in} / \mathrm{sec}^{2}$ & -1.0830 & $\mathrm{ft} / \mathrm{in} / \mathrm{sec}^{2}$ & -0.7256 & $\mathrm{ft} / \mathrm{in} / \mathrm{sec}^{2}$ \\
\hline XA1 or $\mathrm{X}_{\delta \mathrm{a}}$ & -1004.93 & $\mathrm{lb} / \mathrm{rad}$ & N/A & $\mathrm{ft} / \mathrm{in} / \mathrm{sec}^{2}$ & -0.0166 & $\mathrm{ft} / \mathrm{in} / \mathrm{sec}^{2}$ & N/A & $\mathrm{ft} / \mathrm{in} / \mathrm{sec}^{2}$ \\
\hline $\mathrm{x} \theta$ or $\mathrm{X}_{\delta c}$ & 10523.36 & $\mathrm{lb} / \mathrm{rad}$ & N/A & $\mathrm{ft} / \mathrm{in} / \mathrm{sec}^{2}$ & 0.6461 & $\mathrm{ft} / \mathrm{in} / \mathrm{sec}^{2}$ & N/A & $\mathrm{ft} / \mathrm{in} / \mathrm{sec}^{2}$ \\
\hline$x \theta_{\mathrm{T}}$ or $\mathrm{X}_{\delta p}$ & 0.00 & $\mathrm{lb} / \mathrm{rad}$ & N/A & $\mathrm{ft} / \mathrm{in} / \mathrm{sec}^{2}$ & 0.6988 & $\mathrm{ft} / \mathrm{in} / \mathrm{sec}^{2}$ & N/A & $\mathrm{ft} / \mathrm{in} / \mathrm{sec}^{2}$ \\
\hline Yu & 3.98 & $\mathrm{lb} / \mathrm{ft} / \mathrm{sec}$ & 0.0078 & $1 / \mathrm{sec}$ & -0.0007 & $1 / \mathrm{sec}$ & N/A & $1 / \mathrm{sec}$ \\
\hline Yv & -72.47 & $\mathrm{lb} / \mathrm{ft} / \mathrm{sec}$ & -0.1422 & $1 / \mathrm{sec}$ & -0.1430 & $1 / \mathrm{sec}$ & -0.1336 & $1 / \mathrm{sec}$ \\
\hline$Y w$ & 9.06 & $\mathrm{lb} / \mathrm{ft} / \mathrm{sec}$ & 0.0178 & $1 / \mathrm{sec}$ & 0.0103 & $1 / \mathrm{sec}$ & N/A & $1 / \mathrm{sec}$ \\
\hline Yq & -347.80 & $\mathrm{lb} / \mathrm{rad} / \mathrm{sec}$ & -0.6823 & $\mathrm{ft} / \mathrm{rad} / \mathrm{sec}$ & 0.7513 & $\mathrm{ft} / \mathrm{rad} / \mathrm{sec}$ & N/A & $\mathrm{ft} / \mathrm{rad} / \mathrm{sec}$ \\
\hline Yp & -1203.68 & $\mathrm{lb} / \mathrm{rad} / \mathrm{sec}$ & -2.3614 & $\mathrm{ft} / \mathrm{rad} / \mathrm{sec}$ & -2.6100 & $\mathrm{ft} / \mathrm{rad} / \mathrm{sec}$ & N/A & $\mathrm{ft} / \mathrm{rad} / \mathrm{sec}$ \\
\hline $\mathrm{Yr}$ & 999.34 & $\mathrm{lb} / \mathrm{rad} / \mathrm{sec}$ & 1.9605 & $\mathrm{ft} / \mathrm{rad} / \mathrm{sec}$ & 1.6580 & $\mathrm{ft} / \mathrm{rad} / \mathrm{sec}$ & N/A & $\mathrm{ft} / \mathrm{rad} / \mathrm{sec}$ \\
\hline YB1 or $Y_{\delta e}$ & -1058.04 & $\mathrm{lb} / \mathrm{rad}$ & N/A & $\mathrm{ft} / \mathrm{in} / \mathrm{sec}^{2}$ & -0.0162 & $\mathrm{ft} / \mathrm{in} / \mathrm{sec}^{2}$ & N/A & $\mathrm{ft} / \mathrm{in} / \mathrm{sec}^{2}$ \\
\hline YA1 or $Y_{\delta a}$ & 12233.21 & $\mathrm{lb} / \mathrm{rad}$ & N/A & $\mathrm{ft} / \mathrm{in} / \mathrm{sec}^{2}$ & 0.9305 & $\mathrm{ft} / \mathrm{in} / \mathrm{sec}^{2}$ & 0.9364 & $\mathrm{ft} / \mathrm{in} / \mathrm{sec}^{2}$ \\
\hline $\mathrm{Y} \theta$ or $\mathrm{Y}_{\delta c}$ & 3053.24 & $\mathrm{lb} / \mathrm{rad}$ & N/A & $\mathrm{ft} / \mathrm{in} / \mathrm{sec}^{2}$ & 0.3408 & $\mathrm{ft} / \mathrm{in} / \mathrm{sec}^{2}$ & N/A & $\mathrm{ft} / \mathrm{in} / \mathrm{sec}^{2}$ \\
\hline $\mathrm{Y} \theta_{\mathrm{T}}$ or $\mathrm{Y}_{\delta p}$ & 14832.69 & $\mathrm{lb} / \mathrm{rad}$ & N/A & $\mathrm{ft} / \mathrm{in} / \mathrm{sec}^{2}$ & -1.9410 & $\mathrm{ft} / \mathrm{in} / \mathrm{sec}^{2}$ & -2.1322 & $\mathrm{ft} / \mathrm{in} / \mathrm{sec}^{2}$ \\
\hline $\mathrm{Zu}$ & 24.78 & $\mathrm{lb} / \mathrm{ft} / \mathrm{sec}$ & 0.0486 & $1 / \mathrm{sec}$ & -0.0089 & $1 / \mathrm{sec}$ & -0.0158 & $1 / \mathrm{sec}$ \\
\hline $\mathrm{Zv}$ & 0.00 & $\mathrm{lb} / \mathrm{ft} / \mathrm{sec}$ & 0.0000 & $1 / \mathrm{sec}$ & -0.0172 & $1 / \mathrm{sec}$ & N/A & $1 / \mathrm{sec}$ \\
\hline Zw & -363.37 & $\mathrm{lb} / \mathrm{ft} / \mathrm{sec}$ & -0.7129 & $1 / \mathrm{sec}$ & -0.7897 & $1 / \mathrm{sec}$ & -0.7658 & $1 / \mathrm{sec}$ \\
\hline $\mathrm{Zq}$ & -550.95 & $\mathrm{lb} / \mathrm{rad} / \mathrm{sec}$ & -1.0809 & $\mathrm{ft} / \mathrm{rad} / \mathrm{sec}$ & 4.9810 & $\mathrm{ft} / \mathrm{rad} / \mathrm{sec}$ & N/A & $\mathrm{ft} / \mathrm{rad} / \mathrm{sec}$ \\
\hline $\mathrm{Zp}$ & 0.00 & $\mathrm{lb} / \mathrm{rad} / \mathrm{sec}$ & 0.0000 & $\mathrm{ft} / \mathrm{rad} / \mathrm{sec}$ & 2.6760 & $\mathrm{ft} / \mathrm{rad} / \mathrm{sec}$ & N/A & $\mathrm{ft} / \mathrm{rad} / \mathrm{sec}$ \\
\hline $\mathrm{Zr}$ & 1243.86 & $\mathrm{lb} / \mathrm{rad} / \mathrm{sec}$ & 2.4402 & $\mathrm{ft} / \mathrm{rad} / \mathrm{sec}$ & -0.5056 & $\mathrm{ft} / \mathrm{rad} / \mathrm{sec}$ & N/A & $\mathrm{ft} / \mathrm{rad} / \mathrm{sec}$ \\
\hline ZB1 or $Z_{\delta e}$ & 0.00 & $\mathrm{lb} / \mathrm{rad}$ & N/A & $\mathrm{ft} / \mathrm{in} / \mathrm{sec}^{2}$ & -6.1380 & $\mathrm{ft} / \mathrm{in} / \mathrm{sec}^{2}$ & -5.8800 & $\mathrm{ft} / \mathrm{in} / \mathrm{sec}^{2}$ \\
\hline ZA1 or $Z_{\delta a}$ & 0.00 & $\mathrm{lb} / \mathrm{rad}$ & N/A & $\mathrm{ft} / \mathrm{in} / \mathrm{sec}^{2}$ & 0.5627 & $\mathrm{ft} / \mathrm{in} / \mathrm{sec}^{2}$ & $\mathrm{~N} / \mathrm{A}$ & $\mathrm{ft} / \mathrm{in} / \mathrm{sec}^{2}$ \\
\hline$Z \theta$ or $Z_{\delta c}$ & -177148.53 & $\mathrm{lb} / \mathrm{rad}$ & N/A & $\mathrm{ft} / \mathrm{in} / \mathrm{sec}^{2}$ & -9.6300 & $\mathrm{ft} / \mathrm{in} / \mathrm{sec}^{2}$ & -10.4761 & $\mathrm{ft} / \mathrm{in} / \mathrm{sec}^{2}$ \\
\hline $\mathrm{Z} \theta_{\mathrm{T}}$ or $\mathrm{Z}_{\delta p}$ & 0.00 & $\mathrm{lb} / \mathrm{rad}$ & N/A & $\mathrm{ft} / \mathrm{in} / \mathrm{sec}^{2}$ & 3.9950 & $\mathrm{ft} / \mathrm{in} / \mathrm{sec}^{2}$ & 4.3935 & $\mathrm{ft} / \mathrm{in} / \mathrm{sec}^{2}$ \\
\hline
\end{tabular}




\begin{tabular}{|c|c|c|c|c|c|c|c|c|}
\hline \multirow[b]{2}{*}{$\mathrm{Mu}$} & \multicolumn{4}{|c|}{ WVU Linear Model } & \multicolumn{2}{|c|}{ NASA AMES } & \multicolumn{2}{|c|}{ BOEING-VERTOL } \\
\hline & -78.18 & $\mathrm{ft}-\mathrm{lb} / \mathrm{ft} / \mathrm{sec}$ & -0.0020 & $\mathrm{rad} / \mathrm{ft} / \mathrm{sec}$ & 0.0025 & $\mathrm{rad} / \mathrm{ft} / \mathrm{sec}$ & 0.0022 & $\mathrm{rad} / \mathrm{ft} / \mathrm{sec}$ \\
\hline $\mathrm{Mv}$ & -11.34 & $\mathrm{ft}-\mathrm{lb} / \mathrm{ft} / \mathrm{sec}$ & -0.0003 & $\mathrm{rad} / \mathrm{ft} / \mathrm{sec}$ & 0.0016 & $\mathrm{rad} / \mathrm{ft} / \mathrm{sec}$ & -0.0019 & $\mathrm{rad} / \mathrm{ft} / \mathrm{sec}$ \\
\hline $\mathrm{Mw}$ & 204.07 & $\mathrm{ft}-\mathrm{lb} / \mathrm{ft} / \mathrm{sec}$ & 0.0051 & $\mathrm{rad} / \mathrm{ft} / \mathrm{sec}$ & 0.0092 & $\mathrm{rad} / \mathrm{ft} / \mathrm{sec}$ & 0.0082 & $\mathrm{rad} / \mathrm{ft} / \mathrm{sec}$ \\
\hline $\mathrm{Mq}$ & -35093.29 & $\mathrm{ft}-\mathrm{lb} / \mathrm{rad} / \mathrm{sec}$ & -0.8773 & $1 / \mathrm{sec}$ & -1.6060 & $1 / \mathrm{sec}$ & -1.9808 & $1 / \mathrm{sec}$ \\
\hline $\mathrm{Mp}$ & 6954.30 & $\mathrm{ft}-\mathrm{lb} / \mathrm{rad} / \mathrm{sec}$ & 0.1739 & $1 / \mathrm{sec}$ & 0.1031 & $1 / \mathrm{sec}$ & 0.1797 & $1 / \mathrm{sec}$ \\
\hline $\mathrm{Mr}$ & 0.00 & $\mathrm{ft}-\mathrm{lb} / \mathrm{rad} / \mathrm{sec}$ & 0.0000 & $1 / \mathrm{sec}$ & -0.1039 & $1 / \mathrm{sec}$ & -0.0860 & $1 / \mathrm{sec}$ \\
\hline $\mathrm{MB1}$ or $\mathrm{M}_{\delta \mathrm{e}}$ & $\mid-248151.92$ & $\mathrm{ft}-\mathrm{lb} / \mathrm{rad}$ & N/A & $\mathrm{ft} / \mathrm{in} / \mathrm{sec}^{2}$ & 0.4594 & $\mathrm{ft} / \mathrm{in} / \mathrm{sec}^{2}$ & 0.4543 & $\mathrm{ft} / \mathrm{in} / \mathrm{sec}^{2}$ \\
\hline $\mathrm{MA} 1$ or $\mathrm{M}_{\delta \mathrm{a}}$ & 18338.46 & $\mathrm{ft}-\mathrm{lb} / \mathrm{rad}$ & N/A & $\mathrm{ft} / \mathrm{in} / \mathrm{sec}^{2}$ & 0.0283 & $\mathrm{ft} / \mathrm{in} / \mathrm{sec}^{2}$ & 0.0397 & $\mathrm{ft} / \mathrm{in} / \mathrm{sec}^{2}$ \\
\hline $\mathrm{M} \theta$ or $\mathrm{M}_{\delta \mathrm{c}}$ & 320306.38 & $\mathrm{ft}-\mathrm{lb} / \mathrm{rad}$ & N/A & $\mathrm{ft} / \mathrm{in} / \mathrm{sec}^{2}$ & 0.0951 & $\mathrm{ft} / \mathrm{in} / \mathrm{sec}^{2}$ & 0.1294 & $\mathrm{ft} / \mathrm{in} / \mathrm{sec}^{2}$ \\
\hline $\mathrm{M} \theta_{\mathrm{T}}$ or $\mathrm{M}_{\delta p}$ & 0.00 & $\mathrm{ft}-\mathrm{lb} / \mathrm{rad}$ & N/A & $\mathrm{ft} / \mathrm{in} / \mathrm{sec}^{2}$ & -0.0752 & $\mathrm{ft} / \mathrm{in} / \mathrm{sec}^{2}$ & -0.0881 & $\mathrm{ft} / \mathrm{in} / \mathrm{sec}^{2}$ \\
\hline $\mathrm{Ru}$ & 37.86 & $\mathrm{ft}-\mathrm{lb} / \mathrm{ft} / \mathrm{sec}$ & 0.0067 & $\mathrm{rad} / \mathrm{ft} / \mathrm{sec}$ & -0.0021 & $\mathrm{rad} / \mathrm{ft} / \mathrm{sec}$ & N/A & $\mathrm{rad} / \mathrm{ft} / \mathrm{sec}$ \\
\hline Rv & -260.66 & $\mathrm{ft}-\mathrm{lb} / \mathrm{ft} / \mathrm{sec}$ & -0.0463 & $\mathrm{rad} / \mathrm{ft} / \mathrm{sec}$ & -0.0374 & $\mathrm{rad} / \mathrm{ft} / \mathrm{sec}$ & -0.0304 & $\mathrm{rad} / \mathrm{ft} / \mathrm{sec}$ \\
\hline Rw & 165.39 & $\mathrm{ft}-\mathrm{lb} / \mathrm{ft} / \mathrm{sec}$ & 0.0294 & $\mathrm{rad} / \mathrm{ft} / \mathrm{sec}$ & 0.0226 & $\mathrm{rad} / \mathrm{ft} / \mathrm{sec}$ & N/A & $\mathrm{rad} / \mathrm{ft} / \mathrm{sec}$ \\
\hline $\mathrm{Rq}$ & -6526.94 & $\mathrm{ft}-\mathrm{lb} / \mathrm{rad} / \mathrm{sec}$ & -1.1595 & $1 / \mathrm{sec}$ & -1.4240 & $1 / \mathrm{sec}$ & -1.3987 & $1 / \mathrm{sec}$ \\
\hline $\mathrm{Rp}$ & -19419.97 & $\mathrm{ft}-\mathrm{lb} / \mathrm{rad} / \mathrm{sec}$ & -3.4500 & $1 / \mathrm{sec}$ & -3.9110 & $1 / \mathrm{sec}$ & -3.6853 & $1 / \mathrm{sec}$ \\
\hline $\mathrm{Rr}$ & 5235.08 & $\mathrm{ft}-\mathrm{lb} / \mathrm{rad} / \mathrm{sec}$ & 0.9300 & $1 / \mathrm{sec}$ & 0.6039 & $1 / \mathrm{sec}$ & 0.6814 & $1 / \mathrm{sec}$ \\
\hline $\mathrm{RB1}$ or $\mathrm{R}_{\delta \mathrm{e}}$ & -19307.65 & $\mathrm{ft}-\mathrm{lb} / \mathrm{rad}$ & N/A & $\mathrm{ft} / \mathrm{in} / \mathrm{sec}^{2}$ & 0.1502 & $\mathrm{ft} / \mathrm{in} / \mathrm{sec}^{2}$ & N/A & $\mathrm{ft} / \mathrm{in} / \mathrm{sec}^{2}$ \\
\hline $\mathrm{RA1}$ or $\mathrm{R}_{\delta \mathrm{a}}$ & 223238.80 & $\mathrm{ft}-\mathrm{lb} / \mathrm{rad}$ & N/A & $\mathrm{ft} / \mathrm{in} / \mathrm{sec}^{2}$ & 1.3160 & $\mathrm{ft} / \mathrm{in} / \mathrm{sec}^{2}$ & 1.2907 & $\mathrm{ft} / \mathrm{in} / \mathrm{sec}^{2}$ \\
\hline $\mathrm{R} \theta$ or $\mathrm{R}_{\delta c}$ & 90130.48 & $\mathrm{ft}-\mathrm{lb} / \mathrm{rad}$ & N/A & $\mathrm{ft} / \mathrm{in} / \mathrm{sec}^{2}$ & 0.2580 & $\mathrm{ft} / \mathrm{in} / \mathrm{sec}^{2}$ & N/A & $\mathrm{ft} / \mathrm{in} / \mathrm{sec}^{2}$ \\
\hline $\mathrm{R} \theta_{\mathrm{T}}$ or $\mathrm{R}_{\delta \mathrm{p}}$ & 95794.47 & $\mathrm{ft}-\mathrm{lb} / \mathrm{rad}$ & N/A & $\mathrm{ft} / \mathrm{in} / \mathrm{sec}^{2}$ & -1.1630 & $\mathrm{ft} / \mathrm{in} / \mathrm{sec}^{2}$ & -1.1990 & $\mathrm{ft} / \mathrm{in} / \mathrm{sec}^{2}$ \\
\hline $\mathrm{Nu}$ & -98.07 & $\mathrm{ft}-\mathrm{lb} / \mathrm{ft} / \mathrm{sec}$ & -0.0026 & $\mathrm{rad} / \mathrm{ft} / \mathrm{sec}$ & -0.0029 & $\mathrm{rad} / \mathrm{ft} / \mathrm{sec}$ & N/A & $\mathrm{rad} / \mathrm{ft} / \mathrm{sec}$ \\
\hline Nv & 790.32 & $\mathrm{ft}-\mathrm{lb} / \mathrm{ft} / \mathrm{sec}$ & 0.0212 & $\mathrm{rad} / \mathrm{ft} / \mathrm{sec}$ & 0.0182 & $\mathrm{rad} / \mathrm{ft} / \mathrm{sec}$ & 0.0176 & $\mathrm{rad} / \mathrm{ft} / \mathrm{sec}$ \\
\hline $\mathrm{Nw}$ & -173.77 & $\mathrm{ft}-\mathrm{lb} / \mathrm{ft} / \mathrm{sec}$ & -0.0047 & $\mathrm{rad} / \mathrm{ft} / \mathrm{sec}$ & -0.0125 & $\mathrm{rad} / \mathrm{ft} / \mathrm{sec}$ & N/A & $\mathrm{rad} / \mathrm{ft} / \mathrm{sec}$ \\
\hline $\mathrm{Nq}$ & 0.00 & $\mathrm{ft}-\mathrm{lb} / \mathrm{rad} / \mathrm{sec}$ & 0.0000 & $1 / \mathrm{sec}$ & -0.4424 & $1 / \mathrm{sec}$ & N/A & $1 / \mathrm{sec}$ \\
\hline $\mathrm{Np}$ & 5235.08 & $\mathrm{ft}-\mathrm{lb} / \mathrm{rad} / \mathrm{sec}$ & 0.1407 & $1 / \mathrm{sec}$ & -0.1136 & $1 / \mathrm{sec}$ & -0.0706 & $1 / \mathrm{sec}$ \\
\hline $\mathrm{Nr}$ & -31492.93 & $\mathrm{ft}-\mathrm{lb} / \mathrm{rad} / \mathrm{sec}$ & -0.8466 & $1 / \mathrm{sec}$ & -0.8515 & $1 / \mathrm{sec}$ & -0.8389 & $1 / \mathrm{sec}$ \\
\hline $\mathrm{NB1}$ or $\mathrm{N}_{\delta \mathrm{e}}$ & 0.00 & $\mathrm{ft}-\mathrm{lb} / \mathrm{rad}$ & N/A & $\mathrm{ft} / \mathrm{in} / \mathrm{sec}^{2}$ & -0.0472 & $\mathrm{ft} / \mathrm{in} / \mathrm{sec}^{2}$ & N/A & $\mathrm{ft} / \mathrm{in} / \mathrm{sec}^{2}$ \\
\hline $\mathrm{NA1}$ or $\mathrm{N}_{\delta \mathrm{a}}$ & 0.00 & $\mathrm{ft}-\mathrm{lb} / \mathrm{rad}$ & N/A & $\mathrm{ft} / \mathrm{in} / \mathrm{sec}^{2}$ & 0.0258 & $\mathrm{ft} / \mathrm{in} / \mathrm{sec}^{2}$ & 0.0014 & $\mathrm{ft} / \mathrm{in} / \mathrm{sec}^{2}$ \\
\hline $\mathrm{N} \theta$ or $\mathrm{N}_{\delta c}$ & 296864.05 & $\mathrm{ft}-\mathrm{lb} / \mathrm{rad}$ & N/A & $\mathrm{ft} / \mathrm{in} / \mathrm{sec}^{2}$ & -0.1096 & $\mathrm{ft} / \mathrm{in} / \mathrm{sec}^{2}$ & -0.0544 & $\mathrm{ft} / \mathrm{in} / \mathrm{sec}^{2}$ \\
\hline $\mathrm{N} \theta_{T}$ or $\mathrm{N}_{\delta p}$ & -459319.03 & $\mathrm{ft}-\mathrm{lb} / \mathrm{rad}$ & N/A & $\mathrm{ft} / \mathrm{in} / \mathrm{sec}^{2}$ & 0.8460 & $\mathrm{ft} / \mathrm{in} / \mathrm{sec}^{2}$ & 0.9319 & $\mathrm{ft} / \mathrm{in} / \mathrm{sec}^{2}$ \\
\hline
\end{tabular}


Table B.6: Stability and Control Derivative Comparison (140 Knots)

\begin{tabular}{|c|c|c|c|c|c|c|c|c|}
\hline \multirow[b]{2}{*}{$\mathrm{Xu}$} & \multicolumn{4}{|c|}{ WVU Linear Model } & \multicolumn{2}{|c|}{ NASA AMES } & \multicolumn{2}{|c|}{ BOEING-VERTOL } \\
\hline & -23.29 & $\mathrm{lb} / \mathrm{ft} / \mathrm{sec}$ & -0.0457 & $1 / \mathrm{sec}$ & -0.04063 & $1 / \mathrm{sec}$ & -0.0517 & $1 / \mathrm{sec}$ \\
\hline$X v$ & -5.68 & $\mathrm{lb} / \mathrm{ft} / \mathrm{sec}$ & -0.0111 & $1 / \mathrm{sec}$ & -0.002359 & $1 / \mathrm{sec}$ & N/A & $1 / \mathrm{sec}$ \\
\hline Xw & 9.96 & $\mathrm{lb} / \mathrm{ft} / \mathrm{sec}$ & 0.0195 & $1 / \mathrm{sec}$ & 0.07982 & $1 / \mathrm{sec}$ & N/A & $1 / \mathrm{sec}$ \\
\hline $\mathrm{Xq}$ & 891.49 & $\mathrm{lb} / \mathrm{rad} / \mathrm{sec}$ & 1.7490 & $\mathrm{ft} / \mathrm{rad} / \mathrm{sec}$ & 1.626 & $\mathrm{ft} / \mathrm{rad} / \mathrm{sec}$ & N/A & $\mathrm{ft} / \mathrm{rad} / \mathrm{sec}$ \\
\hline $\mathrm{Xp}$ & -294.62 & $\mathrm{lb} / \mathrm{rad} / \mathrm{sec}$ & -0.5780 & $\mathrm{ft} / \mathrm{rad} / \mathrm{sec}$ & -0.3844 & $\mathrm{ft} / \mathrm{rad} / \mathrm{sec}$ & N/A & $\mathrm{ft} / \mathrm{rad} / \mathrm{sec}$ \\
\hline $\mathrm{Xr}$ & 0.00 & $\mathrm{lb} / \mathrm{rad} / \mathrm{sec}$ & 0.0000 & $\mathrm{ft} / \mathrm{rad} / \mathrm{sec}$ & -0.05904 & $\mathrm{ft} / \mathrm{rad} / \mathrm{sec}$ & N/A & $\mathrm{ft} / \mathrm{rad} / \mathrm{sec}$ \\
\hline $\mathrm{XB1}$ or $\mathrm{X}_{\delta \mathrm{e}}$ & 11591.48 & $\mathrm{lb} / \mathrm{rad}$ & 1.1232 & $\mathrm{ft} / \mathrm{in} / \mathrm{sec}^{2}$ & -0.7098 & $\mathrm{ft} / \mathrm{in} / \mathrm{sec}^{2}$ & -0.2927 & $\mathrm{ft} / \mathrm{in} / \mathrm{sec}^{2}$ \\
\hline XA1 or $X_{\delta a}$ & -798.87 & $\mathrm{lb} / \mathrm{rad}$ & -0.0438 & $\mathrm{ft} / \mathrm{in} / \mathrm{sec}^{2}$ & -0.009678 & $\mathrm{ft} / \mathrm{in} / \mathrm{sec}^{2}$ & N/A & $\mathrm{ft} / \mathrm{in} / \mathrm{sec}^{2}$ \\
\hline $\mathrm{X} \theta$ or $\mathrm{X}_{\delta c}$ & 9466.42 & $\mathrm{lb} / \mathrm{rad}$ & 0.5185 & $\mathrm{ft} / \mathrm{in} / \mathrm{sec}^{2}$ & 0.6144 & $\mathrm{ft} / \mathrm{in} / \mathrm{sec}^{2}$ & N/A & $\mathrm{ft} / \mathrm{in} / \mathrm{sec}^{2}$ \\
\hline$x \theta_{\mathrm{T}}$ or $\mathrm{X}_{\delta p}$ & 0.00 & $\mathrm{lb} / \mathrm{rad}$ & 0.0000 & $\mathrm{ft} / \mathrm{in} / \mathrm{sec}^{2}$ & 0.502 & $\mathrm{ft} / \mathrm{in} / \mathrm{sec}^{2}$ & N/A & $\mathrm{ft} / \mathrm{in} / \mathrm{sec}^{2}$ \\
\hline Yu & 0.78 & $\mathrm{lb} / \mathrm{ft} / \mathrm{sec}$ & 0.0015 & $1 / \mathrm{sec}$ & 0.001946 & $1 / \mathrm{sec}$ & N/A & $1 / \mathrm{sec}$ \\
\hline Yv & -91.17 & $\mathrm{lb} / \mathrm{ft} / \mathrm{sec}$ & -0.1789 & $1 / \mathrm{sec}$ & -0.1838 & $1 / \mathrm{sec}$ & -0.1749 & $1 / \mathrm{sec}$ \\
\hline$Y w$ & 7.36 & $\mathrm{lb} / \mathrm{ft} / \mathrm{sec}$ & 0.0144 & $1 / \mathrm{sec}$ & 0.007387 & $1 / \mathrm{sec}$ & N/A & $1 / \mathrm{sec}$ \\
\hline $\mathrm{Yq}$ & -273.98 & $\mathrm{lb} / \mathrm{rad} / \mathrm{sec}$ & -0.5375 & $\mathrm{ft} / \mathrm{rad} / \mathrm{sec}$ & 0.9988 & $\mathrm{ft} / \mathrm{rad} / \mathrm{sec}$ & N/A & $\mathrm{ft} / \mathrm{rad} / \mathrm{sec}$ \\
\hline Yp & -977.15 & $\mathrm{lb} / \mathrm{rad} / \mathrm{sec}$ & -1.9170 & $\mathrm{ft} / \mathrm{rad} / \mathrm{sec}$ & -2.228 & $\mathrm{ft} / \mathrm{rad} / \mathrm{sec}$ & N/A & $\mathrm{ft} / \mathrm{rad} / \mathrm{sec}$ \\
\hline $\mathrm{Yr}$ & 1130.37 & $\mathrm{lb} / \mathrm{rad} / \mathrm{sec}$ & 2.2176 & $\mathrm{ft} / \mathrm{rad} / \mathrm{sec}$ & 2.051 & $\mathrm{ft} / \mathrm{rad} / \mathrm{sec}$ & N/A & $\mathrm{ft} / \mathrm{rad} / \mathrm{sec}$ \\
\hline YB1 or $Y_{\delta e}$ & -879.57 & $\mathrm{lb} / \mathrm{rad}$ & N/A & $\mathrm{ft} / \mathrm{in} / \mathrm{sec}^{2}$ & -0.07161 & $\mathrm{ft} / \mathrm{in} / \mathrm{sec}^{2}$ & N/A & $\mathrm{ft} /$ in $/ \mathrm{sec}^{2}$ \\
\hline YA1 or $Y_{\delta a}$ & 9464.34 & $\mathrm{lb} / \mathrm{rad}$ & N/A & $\mathrm{ft} / \mathrm{in} / \mathrm{sec}^{2}$ & 0.9674 & $\mathrm{ft} / \mathrm{in} / \mathrm{sec}^{2}$ & 0.9924 & $\mathrm{ft} / \mathrm{in} / \mathrm{sec}^{2}$ \\
\hline $\mathrm{Y} \theta$ or $\mathrm{Y}_{\delta c}$ & -117.72 & $\mathrm{lb} / \mathrm{rad}$ & N/A & $\mathrm{ft} / \mathrm{in} / \mathrm{sec}^{2}$ & 0.3814 & $\mathrm{ft} / \mathrm{in} / \mathrm{sec}^{2}$ & N/A & $\mathrm{ft} / \mathrm{in} / \mathrm{sec}^{2}$ \\
\hline$Y \theta_{T}$ or $Y_{\delta p}$ & 15038.93 & $\mathrm{lb} / \mathrm{rad}$ & N/A & $\mathrm{ft} / \mathrm{in} / \mathrm{sec}^{2}$ & -2.176 & $\mathrm{ft} / \mathrm{in} / \mathrm{sec}^{2}$ & -2.3677 & $\mathrm{ft} / \mathrm{in} / \mathrm{sec}^{2}$ \\
\hline $\mathrm{Zu}$ & 37.98 & $\mathrm{lb} / \mathrm{ft} / \mathrm{sec}$ & 0.0745 & $1 / \mathrm{sec}$ & 0.0003375 & $1 / \mathrm{sec}$ & -0.0324 & $1 / \mathrm{sec}$ \\
\hline $\mathrm{Zv}$ & 0.00 & $\mathrm{lb} / \mathrm{ft} / \mathrm{sec}$ & 0.0000 & $1 / \mathrm{sec}$ & -0.04257 & $1 / \mathrm{sec}$ & N/A & $1 / \mathrm{sec}$ \\
\hline Zw & -360.67 & $\mathrm{lb} / \mathrm{ft} / \mathrm{sec}$ & -0.7076 & $1 / \mathrm{sec}$ & 0.8696 & $1 / \mathrm{sec}$ & -0.8418 & $1 / \mathrm{sec}$ \\
\hline $\mathrm{Zq}$ & -884.62 & $\mathrm{lb} / \mathrm{rad} / \mathrm{sec}$ & -1.7355 & $\mathrm{ft} / \mathrm{rad} / \mathrm{sec}$ & 6.638 & $\mathrm{ft} / \mathrm{rad} / \mathrm{sec}$ & N/A & $\mathrm{ft} / \mathrm{rad} / \mathrm{sec}$ \\
\hline $\mathrm{Zp}$ & 0.00 & $\mathrm{lb} / \mathrm{rad} / \mathrm{sec}$ & 0.0000 & $\mathrm{ft} / \mathrm{rad} / \mathrm{sec}$ & 3.935 & $\mathrm{ft} / \mathrm{rad} / \mathrm{sec}$ & N/A & $\mathrm{ft} / \mathrm{rad} / \mathrm{sec}$ \\
\hline $\mathrm{Zr}$ & 1241.85 & $\mathrm{lb} / \mathrm{rad} / \mathrm{sec}$ & 2.4363 & $\mathrm{ft} / \mathrm{rad} / \mathrm{sec}$ & -0.3598 & $\mathrm{ft} / \mathrm{rad} / \mathrm{sec}$ & N/A & $\mathrm{ft} / \mathrm{rad} / \mathrm{sec}$ \\
\hline ZB1 or $Z_{\delta e}$ & 0.00 & $\mathrm{lb} / \mathrm{rad}$ & N/A & $\mathrm{ft} / \mathrm{in} / \mathrm{sec}^{2}$ & -9.118 & $\mathrm{ft} / \mathrm{in} / \mathrm{sec}^{2}$ & -8.8178 & $\mathrm{ft} / \mathrm{in} / \mathrm{sec}^{2}$ \\
\hline ZA1 or $Z_{\delta a}$ & 0.00 & $\mathrm{lb} / \mathrm{rad}$ & N/A & $\mathrm{ft} / \mathrm{in} / \mathrm{sec}^{2}$ & 0.8477 & $\mathrm{ft} / \mathrm{in} / \mathrm{sec}^{2}$ & N/A & $\mathrm{ft} / \mathrm{in} / \mathrm{sec}^{2}$ \\
\hline $\mathrm{Z} \theta$ or $\mathrm{Z}_{\delta c}$ & -107194.45 & $\mathrm{lb} / \mathrm{rad}$ & N/A & $\mathrm{ft} / \mathrm{in} / \mathrm{sec}^{2}$ & -10.76 & $\mathrm{ft} / \mathrm{in} / \mathrm{sec}^{2}$ & -11.8225 & $\mathrm{ft} / \mathrm{in} / \mathrm{sec}^{2}$ \\
\hline$z \theta_{\mathrm{T}}$ or $\mathrm{Z}_{\delta \mathrm{p}}$ & 0.00 & $\mathrm{lb} / \mathrm{rad}$ & N/A & $\mathrm{ft} / \mathrm{in} / \mathrm{sec}^{2}$ & 5.543 & $\mathrm{ft} / \mathrm{in} / \mathrm{sec}^{2}$ & 6.3606 & $\mathrm{ft} / \mathrm{in} / \mathrm{sec}^{2}$ \\
\hline
\end{tabular}




\begin{tabular}{|c|c|c|c|c|c|c|c|c|}
\hline & \multicolumn{4}{|c|}{ WVU Linear Model } & \multicolumn{2}{|c|}{ NASA AMES } & \multicolumn{2}{|c|}{ BOEING-VERTOL } \\
\hline $\mathrm{Mu}$ & 32.60 & $\mathrm{ft}-\mathrm{lb} / \mathrm{ft} / \mathrm{sec}$ & 0.0008 & $\mathrm{rad} / \mathrm{ft} / \mathrm{sec}$ & 0.005558 & $\mathrm{rad} / \mathrm{ft} / \mathrm{sec}$ & 0.0019 & $\mathrm{rad} / \mathrm{ft} / \mathrm{sec}$ \\
\hline $\mathrm{Mv}$ & -9.00 & $\mathrm{ft}-\mathrm{lb} / \mathrm{ft} / \mathrm{sec}$ & -0.0002 & $\mathrm{rad} / \mathrm{ft} / \mathrm{sec}$ & -0.007029 & $\mathrm{rad} / \mathrm{ft} / \mathrm{sec}$ & -0.0068 & $\mathrm{rad} / \mathrm{ft} / \mathrm{sec}$ \\
\hline $\mathrm{Mw}$ & 163.17 & $\mathrm{ft}-\mathrm{lb} / \mathrm{ft} / \mathrm{sec}$ & 0.0041 & $\mathrm{rad} / \mathrm{ft} / \mathrm{sec}$ & 0.008923 & $\mathrm{rad} / \mathrm{ft} / \mathrm{sec}$ & 0.0113 & $\mathrm{rad} / \mathrm{ft} / \mathrm{sec}$ \\
\hline $\mathrm{Mq}$ & -43683.11 & $\mathrm{ft}-\mathrm{lb} / \mathrm{rad} / \mathrm{sec}$ & -1.0921 & $1 / \mathrm{sec}$ & -2.015 & $1 / \mathrm{sec}$ & -2.1616 & $1 / \mathrm{sec}$ \\
\hline $\mathrm{Mp}$ & 6695.93 & $\mathrm{ft}-\mathrm{lb} / \mathrm{rad} / \mathrm{sec}$ & 0.1674 & $1 / \mathrm{sec}$ & 0.007006 & $1 / \mathrm{sec}$ & 0.1937 & $1 / \mathrm{sec}$ \\
\hline $\mathrm{Mr}$ & 0.00 & $\mathrm{ft}-\mathrm{lb} / \mathrm{rad} / \mathrm{sec}$ & 0.0000 & $1 / \mathrm{sec}$ & -0.02461 & $1 / \mathrm{sec}$ & -0.075 & $1 / \mathrm{sec}$ \\
\hline $\mathrm{MB1}$ or $\mathrm{M}_{\delta \mathrm{e}}$ & -254252.17 & $\mathrm{ft}-\mathrm{lb} / \mathrm{rad}$ & N/A & $\mathrm{ft} / \mathrm{in} / \mathrm{sec}^{2}$ & 0.523 & $\mathrm{ft} / \mathrm{in} / \mathrm{sec}^{2}$ & 0.4997 & $\mathrm{ft} / \mathrm{in} / \mathrm{sec}^{2}$ \\
\hline MA1 or $M_{\delta a}$ & 17522.66 & $\mathrm{ft}-\mathrm{lb} / \mathrm{rad}$ & N/A & $\mathrm{ft} / \mathrm{in} / \mathrm{sec}^{2}$ & 0.06496 & $\mathrm{ft} / \mathrm{in} / \mathrm{sec}^{2}$ & 0.0585 & $\mathrm{ft} / \mathrm{in} / \mathrm{sec}^{2}$ \\
\hline $\mathrm{M} \theta$ or $\mathrm{M}_{\delta \mathrm{c}}$ & 227460.32 & $\mathrm{ft}-\mathrm{lb} / \mathrm{rad}$ & N/A & $\mathrm{ft} / \mathrm{in} / \mathrm{sec}^{2}$ & 0.1029 & $\mathrm{ft} / \mathrm{in} / \mathrm{sec}^{2}$ & 0.1418 & $\mathrm{ft} / \mathrm{in} / \mathrm{sec}^{2}$ \\
\hline$M \theta_{T}$ or $M_{\delta p}$ & 0.00 & $\mathrm{ft}-\mathrm{lb} / \mathrm{rad}$ & N/A & $\mathrm{ft} / \mathrm{in} / \mathrm{sec}^{2}$ & -0.1707 & $\mathrm{ft} / \mathrm{in} / \mathrm{sec}^{2}$ & -0.1113 & $\mathrm{ft} / \mathrm{in} / \mathrm{sec}^{2}$ \\
\hline $\mathrm{Ru}$ & -19.22 & $\mathrm{ft}-\mathrm{lb} / \mathrm{ft} / \mathrm{sec}$ & -0.0034 & $\mathrm{rad} / \mathrm{ft} / \mathrm{sec}$ & 0.00161 & $\mathrm{rad} / \mathrm{ft} / \mathrm{sec}$ & N/A & $\mathrm{rad} / \mathrm{ft} / \mathrm{sec}$ \\
\hline Rv & -287.43 & $\mathrm{ft}-\mathrm{lb} / \mathrm{ft} / \mathrm{sec}$ & -0.0511 & $\mathrm{rad} / \mathrm{ft} / \mathrm{sec}$ & -0.03928 & $\mathrm{rad} / \mathrm{ft} / \mathrm{sec}$ & -0.0343 & $\mathrm{rad} / \mathrm{ft} / \mathrm{sec}$ \\
\hline $\mathrm{Rw}$ & 161.55 & $\mathrm{ft}-\mathrm{lb} / \mathrm{ft} / \mathrm{sec}$ & 0.0287 & $\mathrm{rad} / \mathrm{ft} / \mathrm{sec}$ & 0.0174 & $\mathrm{rad} / \mathrm{ft} / \mathrm{sec}$ & N/A & $\mathrm{rad} / \mathrm{ft} / \mathrm{sec}$ \\
\hline $\mathrm{Rq}$ & -5970.28 & $\mathrm{ft}-\mathrm{lb} / \mathrm{rad} / \mathrm{sec}$ & -1.0606 & $1 / \mathrm{sec}$ & -1.269 & $1 / \mathrm{sec}$ & -1.4051 & $1 / \mathrm{sec}$ \\
\hline $\mathrm{Rp}$ & -17813.71 & $\mathrm{ft}-\mathrm{lb} / \mathrm{rad} / \mathrm{sec}$ & -3.1646 & $1 / \mathrm{sec}$ & -3.626 & $1 / \mathrm{sec}$ & -3.3574 & $1 / \mathrm{sec}$ \\
\hline $\mathrm{Rr}$ & 5593.65 & $\mathrm{ft}-\mathrm{lb} / \mathrm{rad} / \mathrm{sec}$ & 0.9937 & $1 / \mathrm{sec}$ & 0.7766 & $1 / \mathrm{sec}$ & 0.8556 & $1 / \mathrm{sec}$ \\
\hline $\mathrm{RB} 1$ or $\mathrm{R}_{\delta \mathrm{e}}$ & -19292.86 & $\mathrm{ft}-\mathrm{lb} / \mathrm{rad}$ & N/A & $\mathrm{ft} / \mathrm{in} / \mathrm{sec}^{2}$ & 0.1426 & $\mathrm{ft} / \mathrm{in} / \mathrm{sec}^{2}$ & N/A & $\mathrm{ft} / \mathrm{in} / \mathrm{sec}^{2}$ \\
\hline $\mathrm{RA1}$ or $\mathrm{R}_{\delta \mathrm{a}}$ & 207594.67 & $\mathrm{ft}-\mathrm{lb} / \mathrm{rad}$ & N/A & $\mathrm{ft} / \mathrm{in} / \mathrm{sec}^{2}$ & 1.332 & $\mathrm{ft} / \mathrm{in} / \mathrm{sec}^{2}$ & 1.3128 & $\mathrm{ft} / \mathrm{in} / \mathrm{sec}^{2}$ \\
\hline $\mathrm{R} \theta$ or $\mathrm{R}_{\delta c}$ & 35705.05 & $\mathrm{ft}-\mathrm{lb} / \mathrm{rad}$ & N/A & $\mathrm{ft} / \mathrm{in} / \mathrm{sec}^{2}$ & 0.2719 & $\mathrm{ft} / \mathrm{in} / \mathrm{sec}^{2}$ & N/A & $\mathrm{ft} / \mathrm{in} / \mathrm{sec}^{2}$ \\
\hline$R \theta_{T}$ or $R_{\delta p}$ & 97126.41 & $\mathrm{ft}-\mathrm{lb} / \mathrm{rad}$ & N/A & $\mathrm{ft} / \mathrm{in} / \mathrm{sec}^{2}$ & -1.3 & $\mathrm{ft} / \mathrm{in} / \mathrm{sec}^{2}$ & -1.3063 & $\mathrm{ft} / \mathrm{in} / \mathrm{sec}^{2}$ \\
\hline $\mathrm{Nu}$ & -78.04 & $\mathrm{ft}-\mathrm{lb} / \mathrm{ft} / \mathrm{sec}$ & -0.0021 & $\mathrm{rad} / \mathrm{ft} / \mathrm{sec}$ & -0.003813 & $\mathrm{rad} / \mathrm{ft} / \mathrm{sec}$ & N/A & $\mathrm{rad} / \mathrm{ft} / \mathrm{sec}$ \\
\hline $\mathrm{Nv}$ & 837.74 & $\mathrm{ft}-\mathrm{lb} / \mathrm{ft} / \mathrm{sec}$ & 0.0225 & $\mathrm{rad} / \mathrm{ft} / \mathrm{sec}$ & 0.01979 & $\mathrm{rad} / \mathrm{ft} / \mathrm{sec}$ & 0.0195 & $\mathrm{rad} / \mathrm{ft} / \mathrm{sec}$ \\
\hline $\mathrm{Nw}$ & 39.67 & $\mathrm{ft}-\mathrm{lb} / \mathrm{ft} / \mathrm{sec}$ & 0.0011 & $\mathrm{rad} / \mathrm{ft} / \mathrm{sec}$ & -0.007266 & $\mathrm{rad} / \mathrm{ft} / \mathrm{sec}$ & N/A & $\mathrm{rad} / \mathrm{ft} / \mathrm{sec}$ \\
\hline $\mathrm{Nq}$ & 0.00 & $\mathrm{ft}-\mathrm{lb} / \mathrm{rad} / \mathrm{sec}$ & 0.0000 & $1 / \mathrm{sec}$ & -0.5254 & $1 / \mathrm{sec}$ & N/A & $1 / \mathrm{sec}$ \\
\hline $\mathrm{Np}$ & 5593.65 & $\mathrm{ft}-\mathrm{lb} / \mathrm{rad} / \mathrm{sec}$ & 0.1504 & $1 / \mathrm{sec}$ & -0.1801 & $1 / \mathrm{sec}$ & -0.0955 & $1 / \mathrm{sec}$ \\
\hline $\mathrm{Nr}$ & -35827.21 & $\mathrm{ft}-\mathrm{lb} / \mathrm{rad} / \mathrm{sec}$ & -0.9631 & $1 / \mathrm{sec}$ & -1.011 & $1 / \mathrm{sec}$ & -1.0394 & $1 / \mathrm{sec}$ \\
\hline NB1 or $N_{\delta e}$ & 0.00 & $\mathrm{ft}-\mathrm{lb} / \mathrm{rad}$ & N/A & $\mathrm{ft} / \mathrm{in} / \mathrm{sec}^{2}$ & 0.005004 & $\mathrm{ft} / \mathrm{in} / \mathrm{sec}^{2}$ & N/A & $\mathrm{ft} / \mathrm{in} / \mathrm{sec}^{2}$ \\
\hline $\mathrm{NA} 1$ or $\mathrm{N}_{\delta \mathrm{a}}$ & 0.00 & $\mathrm{ft}-\mathrm{lb} / \mathrm{rad}$ & N/A & $\mathrm{ft} / \mathrm{in} / \mathrm{sec}^{2}$ & 0.02299 & $\mathrm{ft} / \mathrm{in} / \mathrm{sec}^{2}$ & 0.0032 & $\mathrm{ft} / \mathrm{in} / \mathrm{sec}^{2}$ \\
\hline $\mathrm{N} \theta$ or $\mathrm{N}_{\delta c}$ & 294705.72 & $\mathrm{ft}-\mathrm{lb} / \mathrm{rad}$ & N/A & $\mathrm{ft} / \mathrm{in} / \mathrm{sec}^{2}$ & -0.08942 & $\mathrm{ft} / \mathrm{in} / \mathrm{sec}^{2}$ & -0.0041 & $\mathrm{ft} / \mathrm{in} / \mathrm{sec}^{2}$ \\
\hline $\mathrm{N} \theta_{\mathrm{T}}$ or $\mathrm{N}_{\delta \mathrm{p}}$ & -465705.47 & $\mathrm{ft}-\mathrm{lb} / \mathrm{rad}$ & N/A & $\mathrm{ft} / \mathrm{in} / \mathrm{sec}^{2}$ & 0.9274 & $\mathrm{ft} / \mathrm{in} / \mathrm{sec}^{2}$ & 1.0023 & $\mathrm{ft} / \mathrm{in} / \mathrm{sec}^{2}$ \\
\hline
\end{tabular}




\section{Appendix C: WVU UH-60 Black Hawk Flight Simulator User Guide}

Start Matlab $6.5^{\circledast}$ from the Desktop. Once the program is ready for use, navigate the Current Directory to the appropriate location containing the folder SimVI.

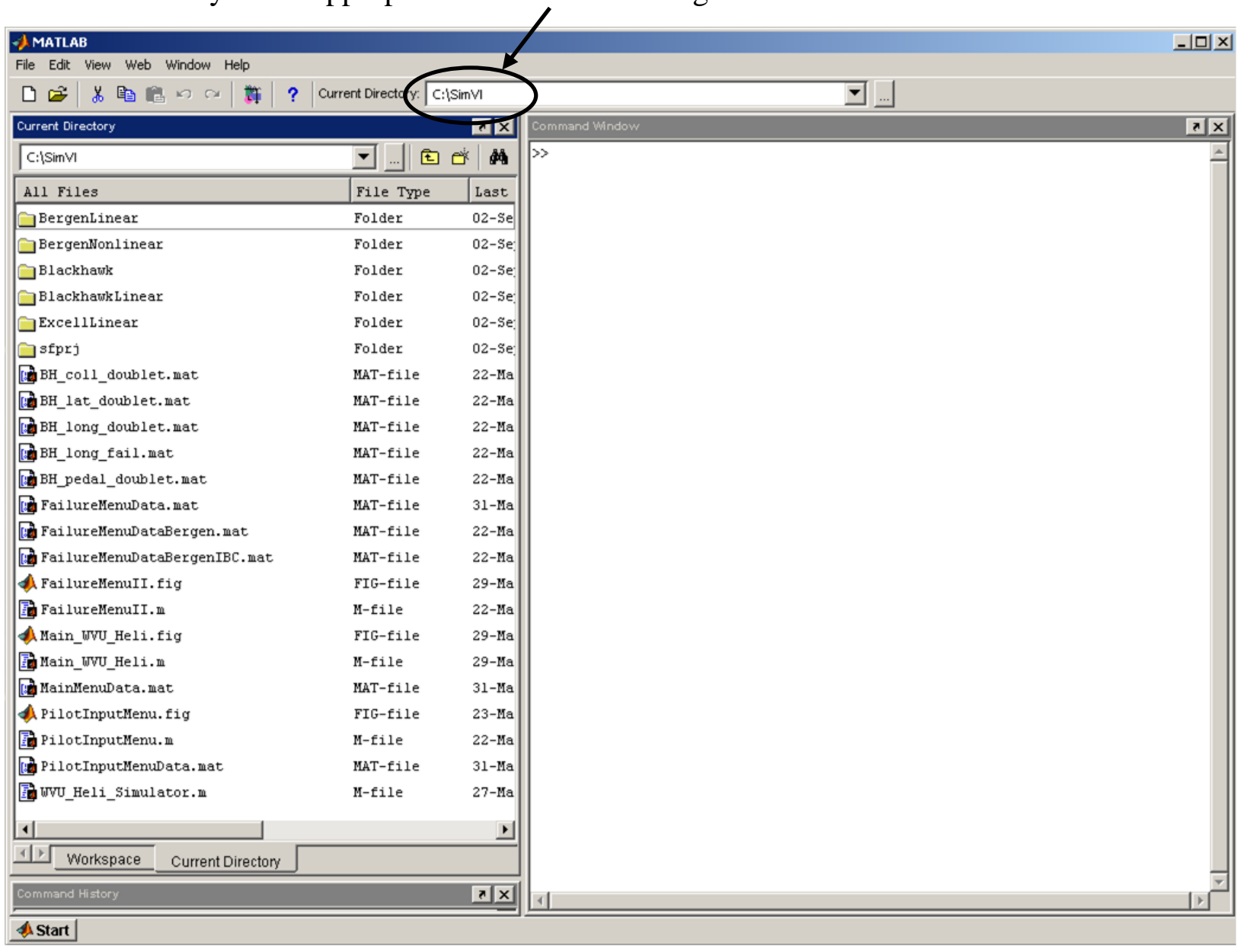

Figure C.1: WVU Helicopter Simulator - Folder Navigation

Type "WVU_Heli_Simulator" in the Command Window and press enter. This will open the WVU Helicopter Simulator Main Menu selection screen. 


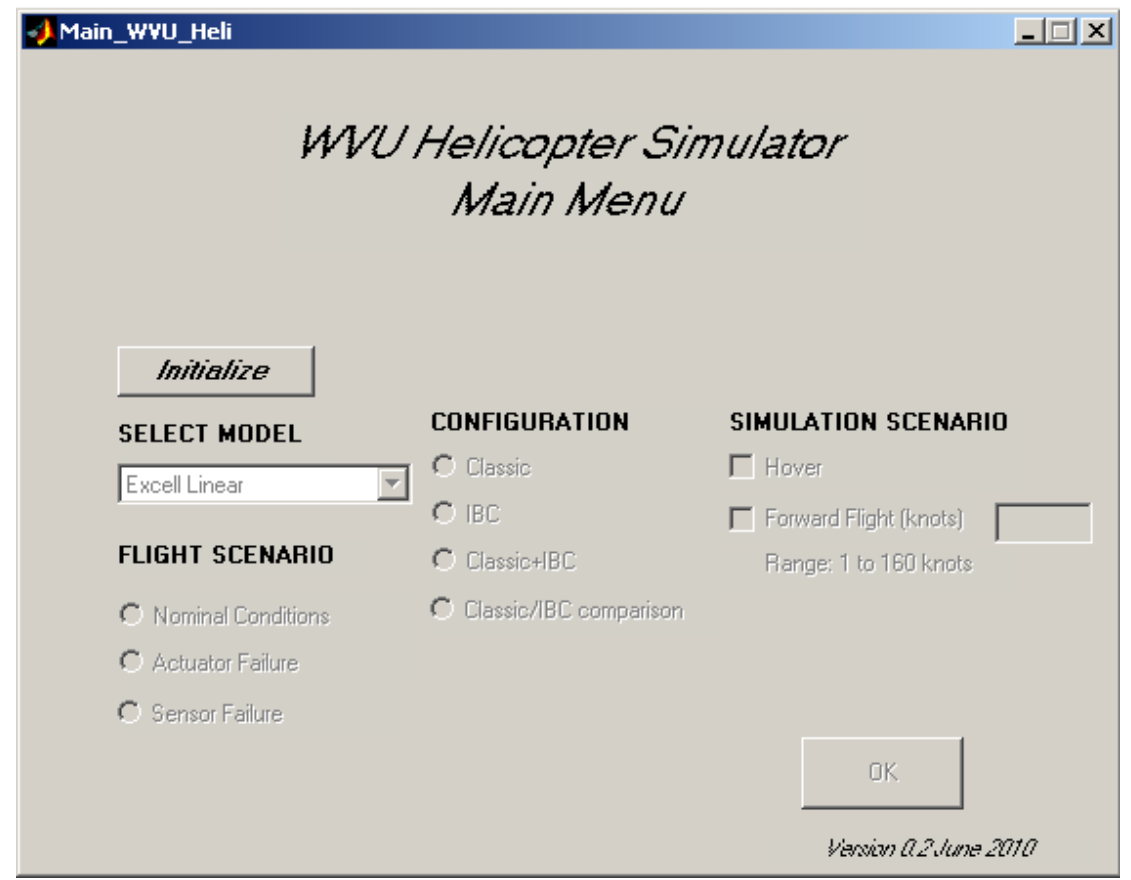

Figure C.2: WVU Helicopter Simulator - Main Menu

By clicking "Initialize," the drop-down menu under "SELECT MODEL" is enabled. The WVU UH-60 linear model can be launched by selecting "Blackhawk Linear" from the dropdown list, as shown in Figure C.3:

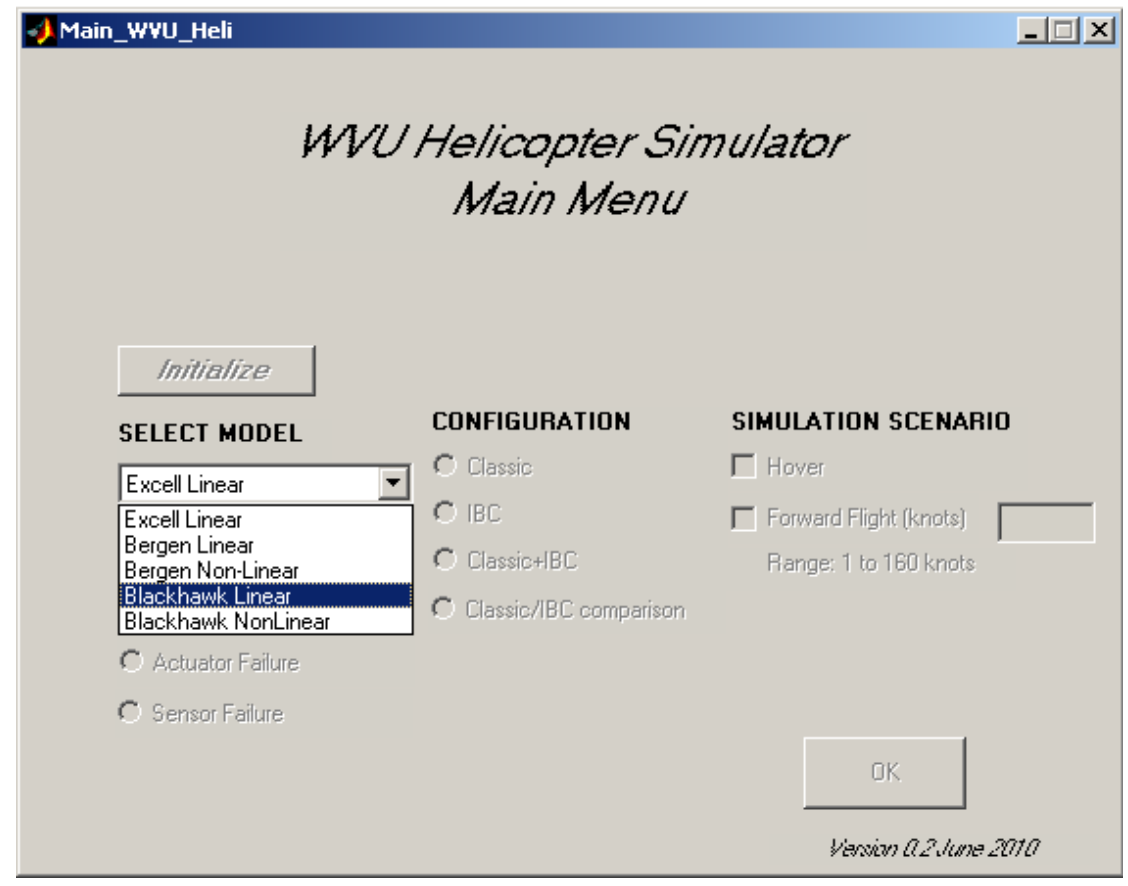

Figure C.3: WVU Helicopter Simulator - Main Menu Drop-Down List 
Next, select a "FLIGHT SCENARIO" and a helicopter "CONFIGURATION." Selecting "Nominal Conditions" runs the simulator at standard sea level altitude, temperature, and pressure with a fully functional aircraft. By selecting "Actuator Failure" the simulator once again runs at standard sea level condtions, but with user defined failure scenarios occuring on the aircraft. A subsequent "ACTUATOR FAILURE MENU" will be presented, if this scenario is selected. Two helicopter configurations are available: Classic (swashplate-based design) and IBC (individual blade control).

Lastly, the linear model is available in two different formats: hover and forward flight. If "Hover" is selected, the UH-60 linear model is solved for trim conditions relating to out of ground effect (OGE) hover. If "Forward Flight" is selected, the UH-60 linear model is solved for trim conditions relating to steady, level forward flight with no sideslip (yaw angle, $\psi$, is initially set to zero). The forward speed can range from 1 to 160 knots.

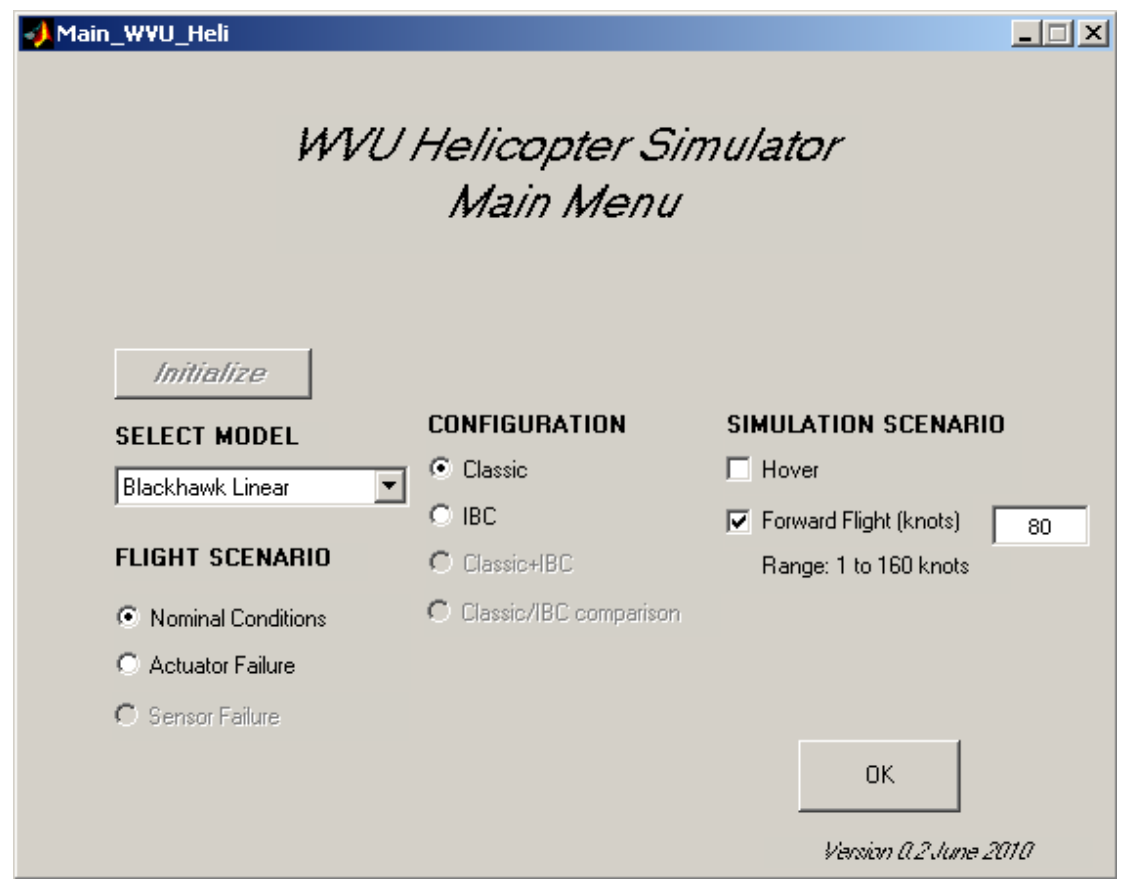

Figure C.4: WVU Helicopter Simulator - Main Menu Simulation Scenarios

By clicking "OK," the parameters are entered into the system and the pilot input menu is displayed to the screen. 


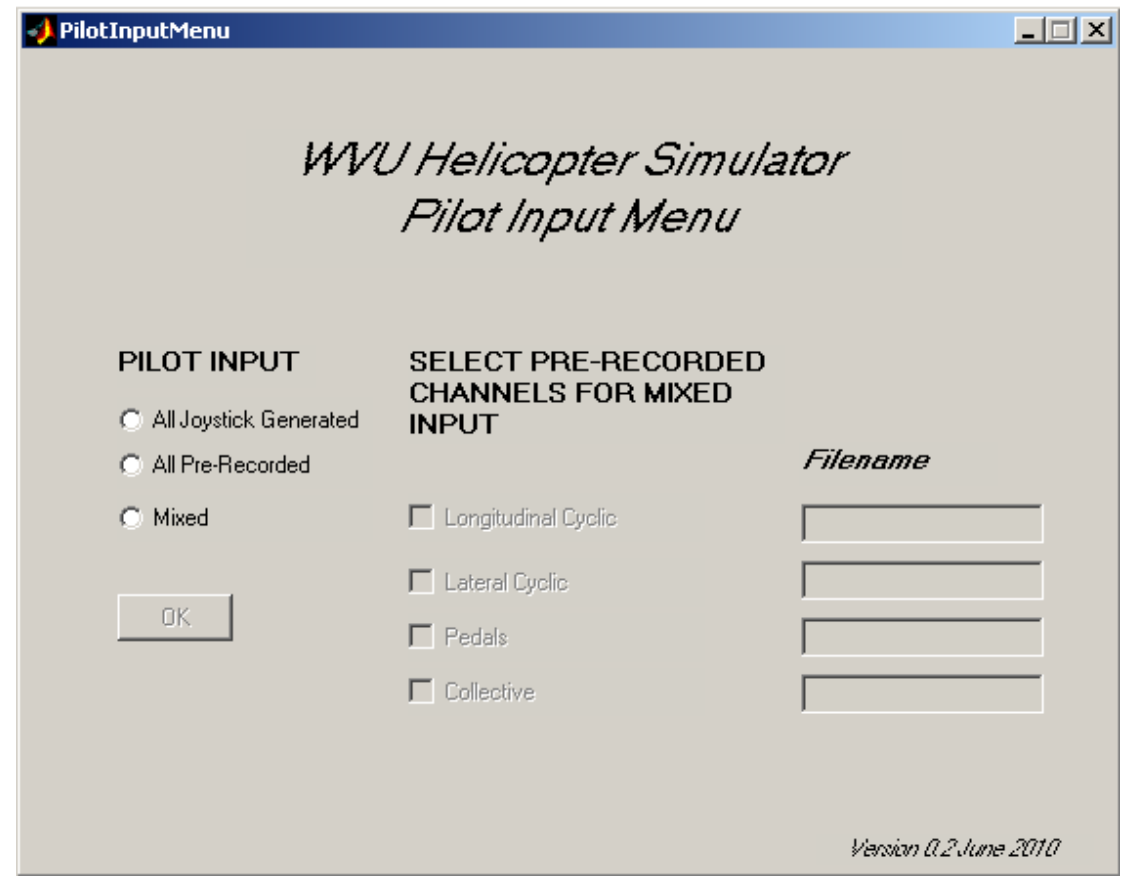

Figure C.5: WVU Helicopter Simulator - Pilot Input Menu

Select one of the three options available under the heading "PILOT INPUT." To use the simulator in real time with a joystick creating control input deflections select "All Joystick Generated" and click "OK." To use pre-recorded control inputs or a combination of prerecorded control inputs and joystick inputs select "All Pre-Recorded" or "Mixed," respectively. 
If any form of pre-recorded control inputs are selected, the user will need to select the appropriate "PRE-RECORDED CHANNEL" and enter the associated filename(s). Examples of pre-recorded input manuvuers can be found within the Current Directory window as .mat files.

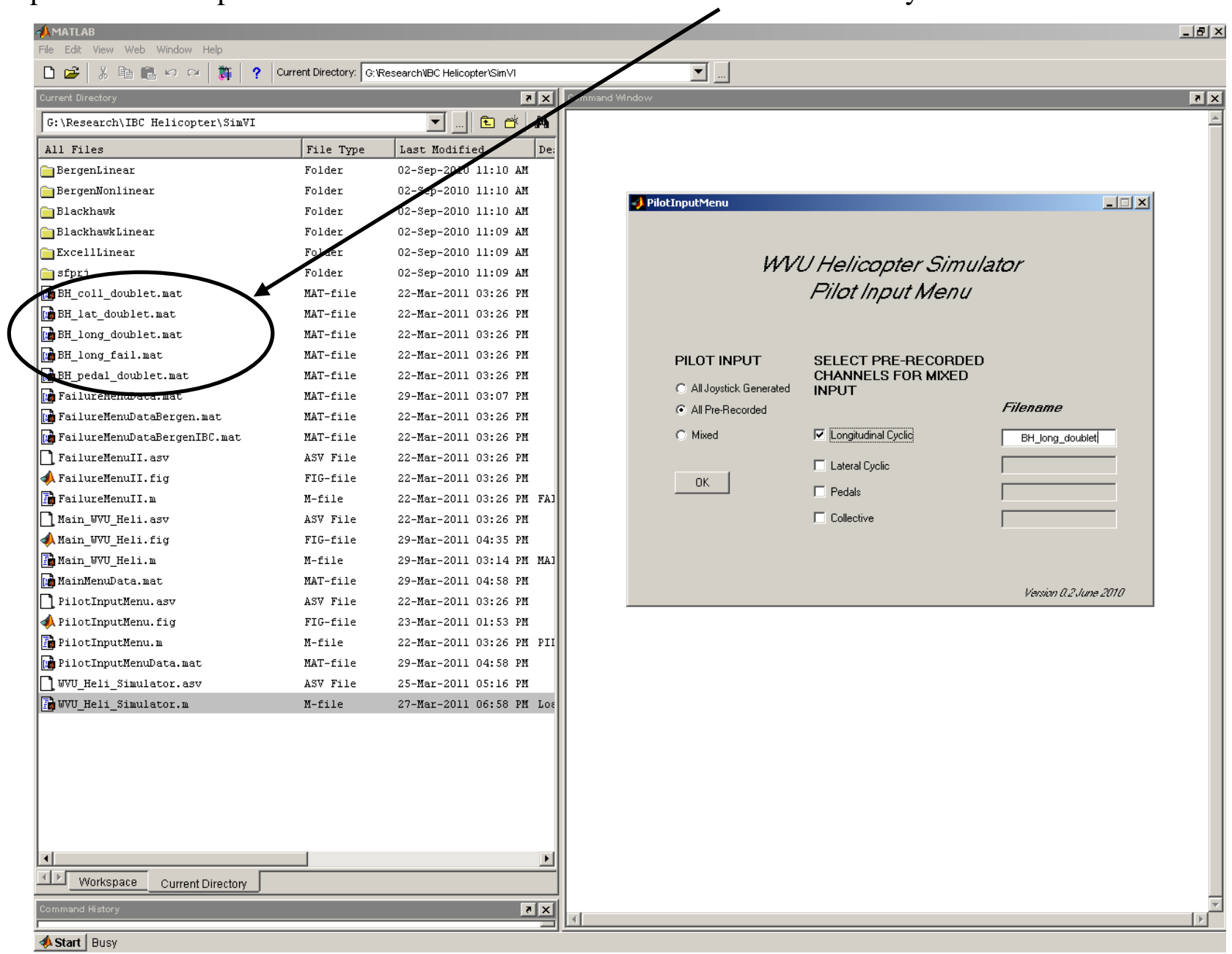

Figure C.6: WVU Helicopter Simulator - Examples of Pre-Recorded Input

Select "OK." Next, if the user selected "Actuator Failure" under the "FLIGHT SCENARIO" heading of the WVU Helicopter Simulator Main Menu selection screen, then the WVU Helicopter Simulator Failure Conditions Menu will appear. If "Nominal Conditions" was selected under the "FLIGHT SCENARIO" heading of the WVU Helicopter Simulator Main Menu selection screen, then SIMULINK will open with some additional windows. Note: SIMULINK may take a few minutes to open, please be patient. 


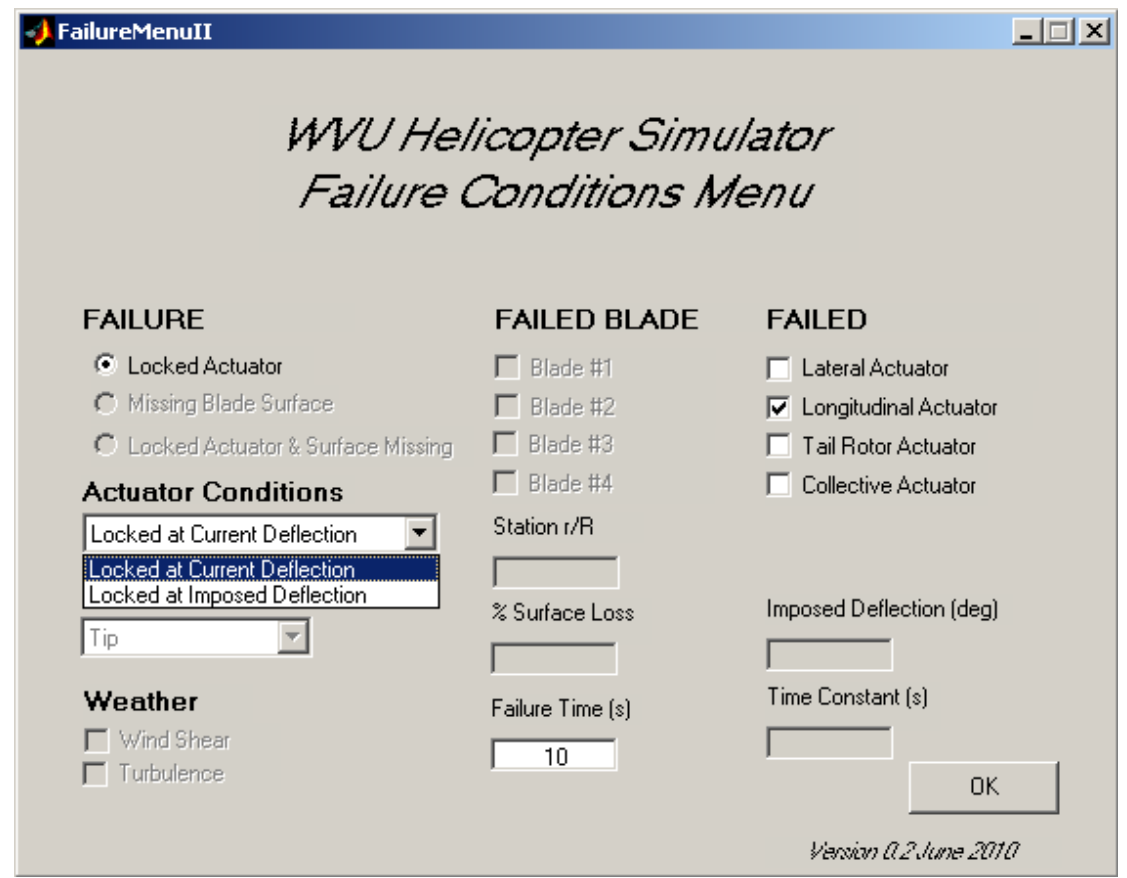

Figure C.7: WVU Helicopter Simulator - Failure Conditions Menu (Current Deflection)

Currently, the UH-60 linear model only has the "Locked Actuator" option available under the "FAILURE SCENARIO" heading. The user can select from two different types of actuator failures the drop down menu. Selecting the option "Locked at Current Deflection" will lock the control input at the current joystick maneuver. In other words, if the joystick is deflecting the longitudinal cyclic at a value of three degrees and the actuator failure occurs, then the longitudinal cyclic will be fixed at three degrees for the remainder of the simulation. This option requires a "Failure Time" to be selected (time that failure occurs), as well as a defined "FAILED ACTUATOR."

If "Locked at Imposed Deflection" is selected, then the control input will move to a user defined value as a first order system. In other words, the failure doesn't happen instantaneously. For example, if the joystick is deflecting the longitudinal cyclic at a value of one degrees and the imposed deflection is set for three degrees (deviation from the current value), then the longitudinal cyclic will gradually move from one degrees to four degrees as a first order system at the time of the failure. The rate that this transition occurs is dependent on the "Time Constant," which is defined as the time it takes the first order system to reach $63 \%$ of its steady state value. 


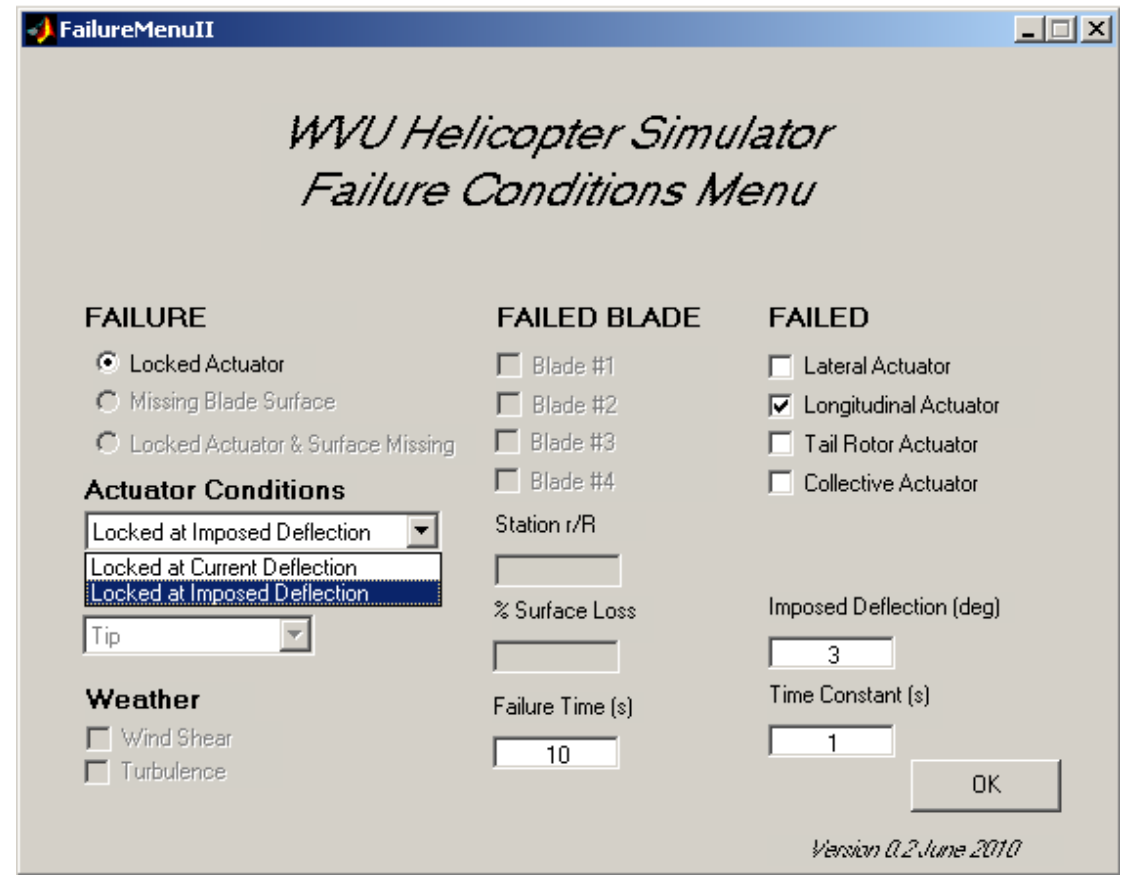

Figure C.8: WVU Helicopter Simulator - Failure Conditions Menu (Imposed Deflection)

Once all of the actuator failure settings have been defined, click "OK." SIMULINK will open with some additional windows. Note: SIMULINK may take some time to open, please be patient. While SIMULINK is opening, eigenvector and eigenvalue information will be displayed to the Matlab ${ }^{\circledR}$ Command Window for the state variable $(A)$ and control/input $(B)$ matrices. These matrices are solved at the defined trim conditions (Hover or Forward Flight). Note that the Current Directory has also been changed. 


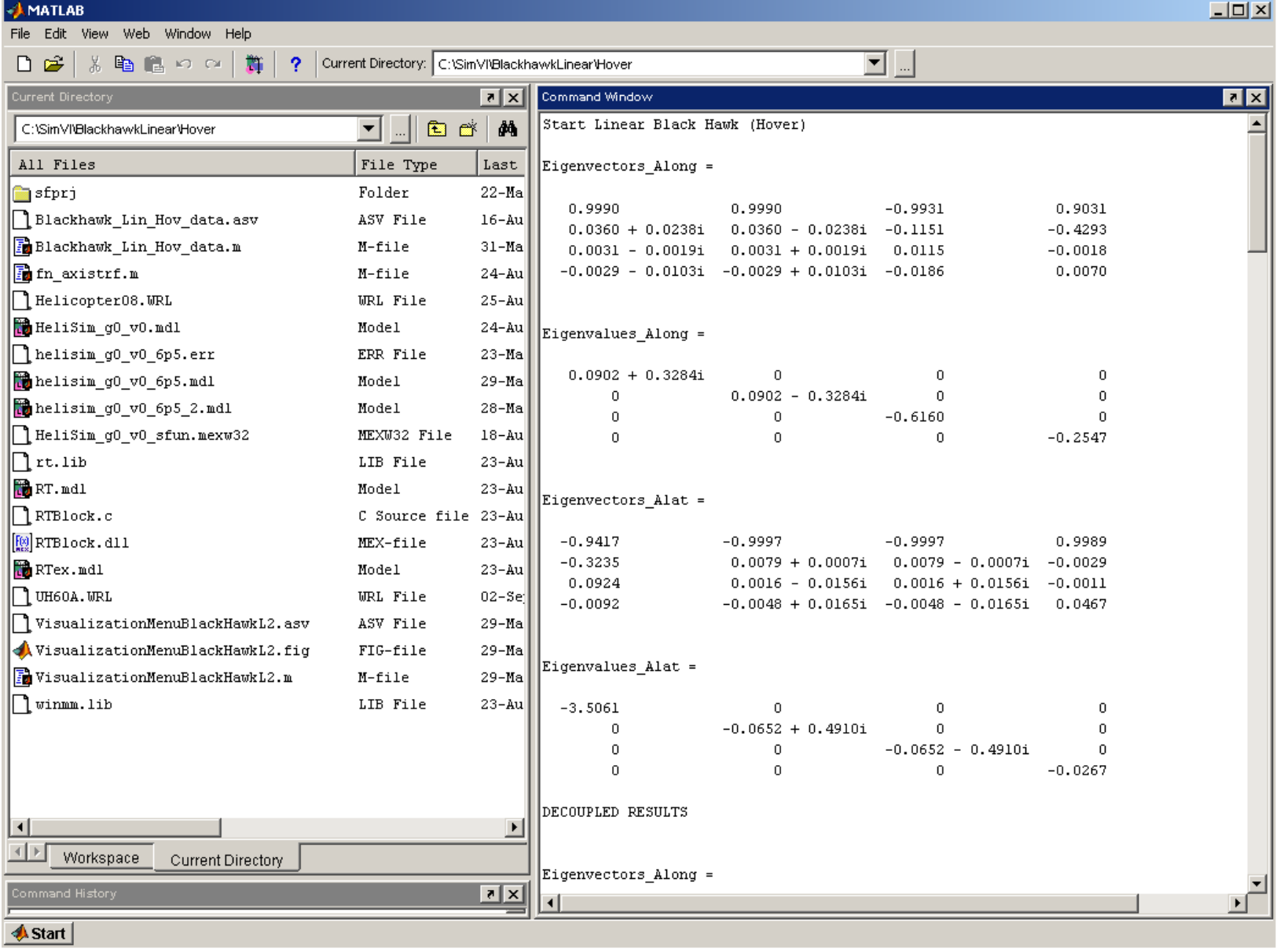

Figure C.9: WVU Helicopter Simulator - Command Window Data 
A SIMULINK model will now open with two corresponding windows:

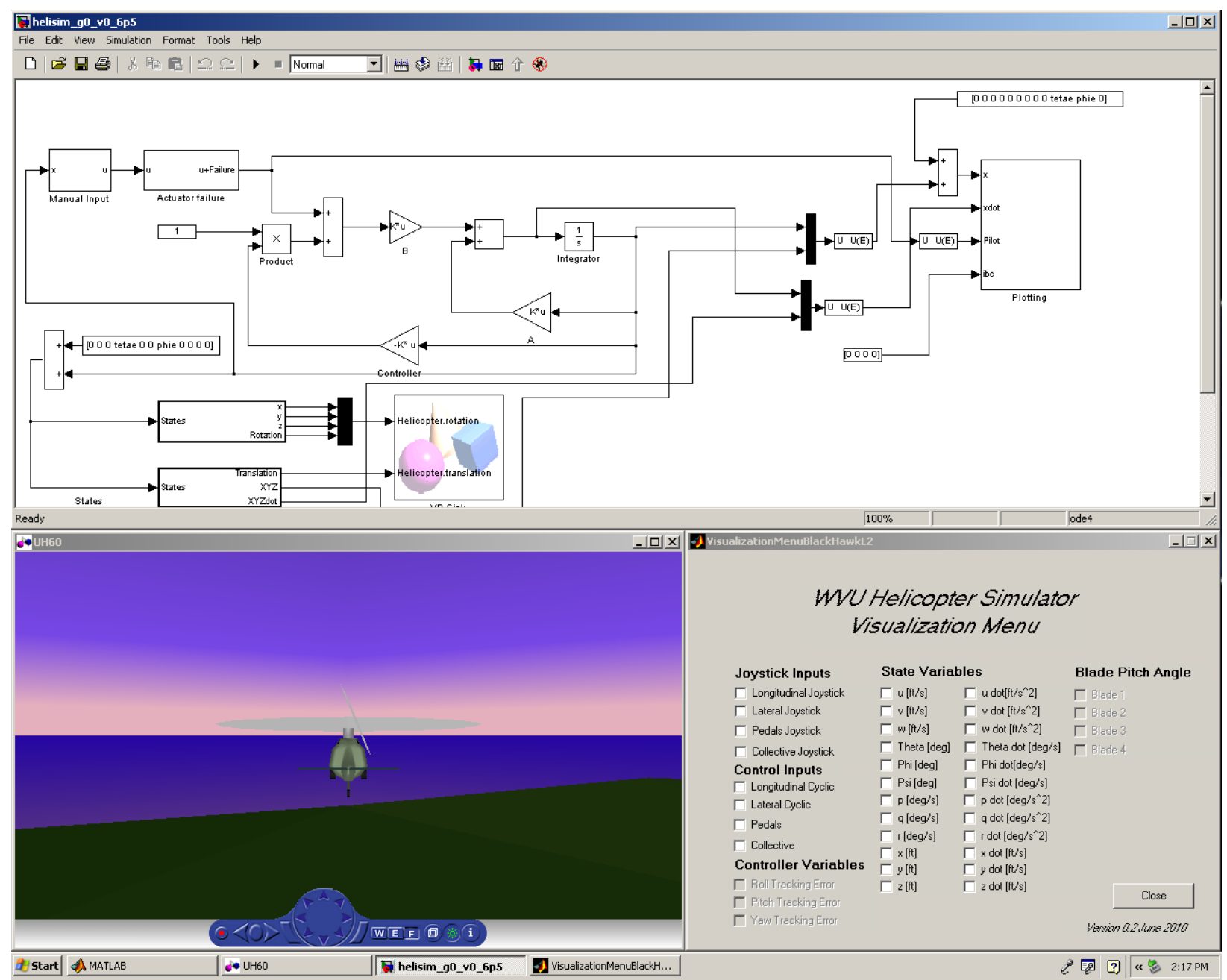

Figure C.10: WVU Helicopter Simulator - Simulation Features 
The first of these two windows is the virtual reality interface, which shows a real time view of a helicopter in flight:

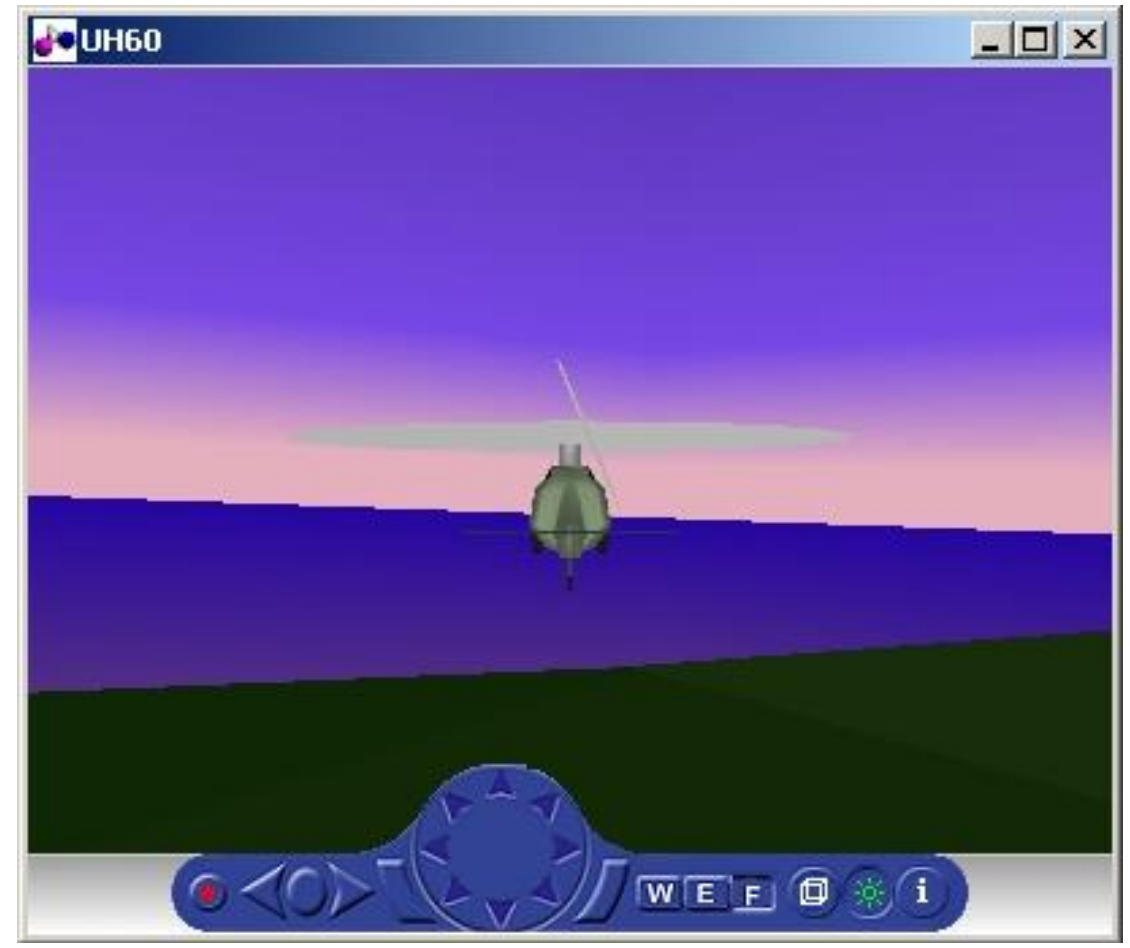

Figure C.11: WVU Helicopter Simulator - VR Interface

The second window is the WVU Helicopter Simulator Visualization Menu:

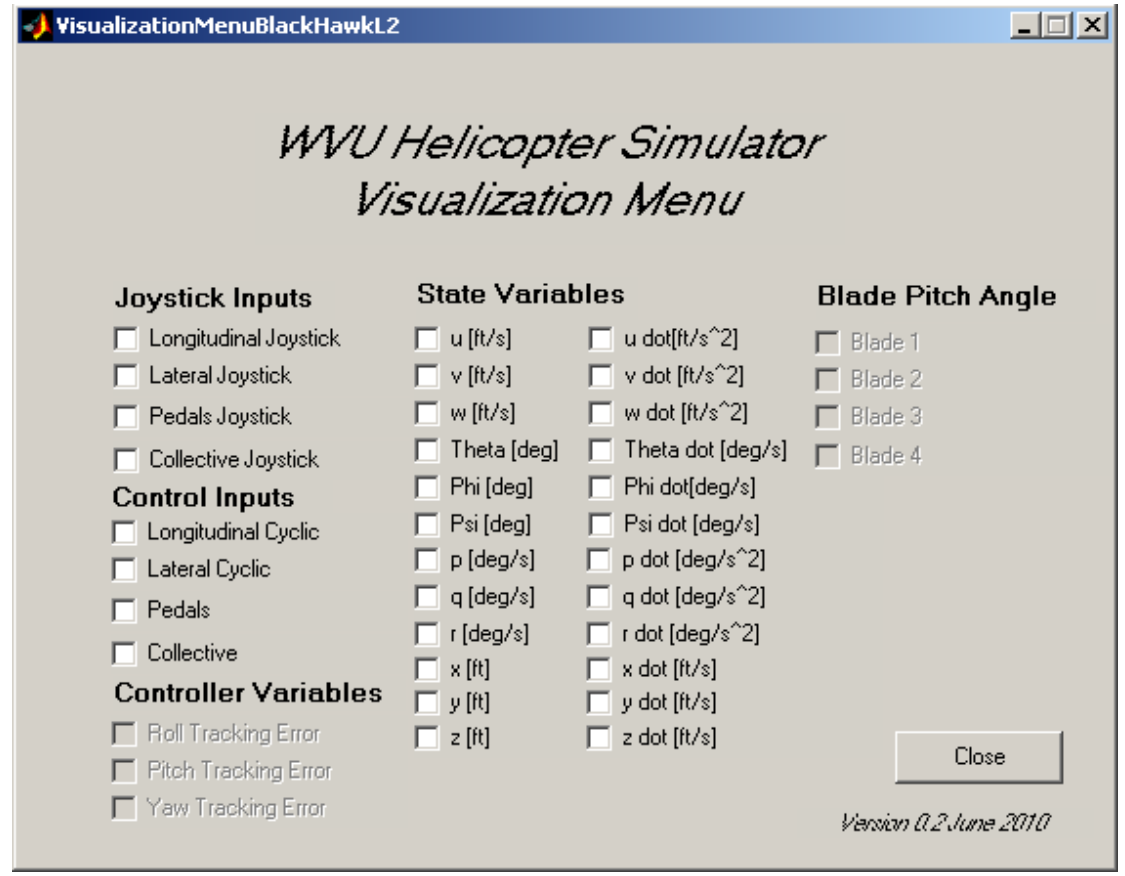

Figure C.12: WVU Helicopter Simulator - Vizualization Menu 
The WVU Helicopter Simulator Visualization Menu can be used to view SIMULINK plots on the screen for a variety of variables and control inputs. By clicking a box, the SIMULINK plot will appear on screen. These plots can be selected before, during, or after the simulation has been run. Click the "play" button at the top of the SIMULINK model to begin a simulation:

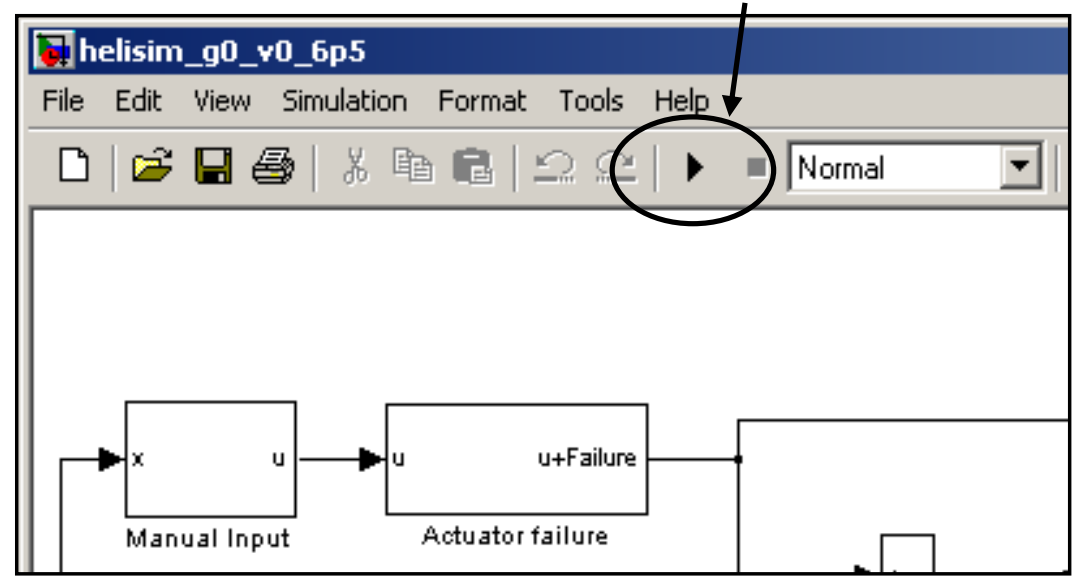

Figure C.13: WVU Helicopter Simulator - Play Button

The virtual reality simulator will now show a real time response of the aircraft, while the plots will show the corresponding effects of control inputs: 


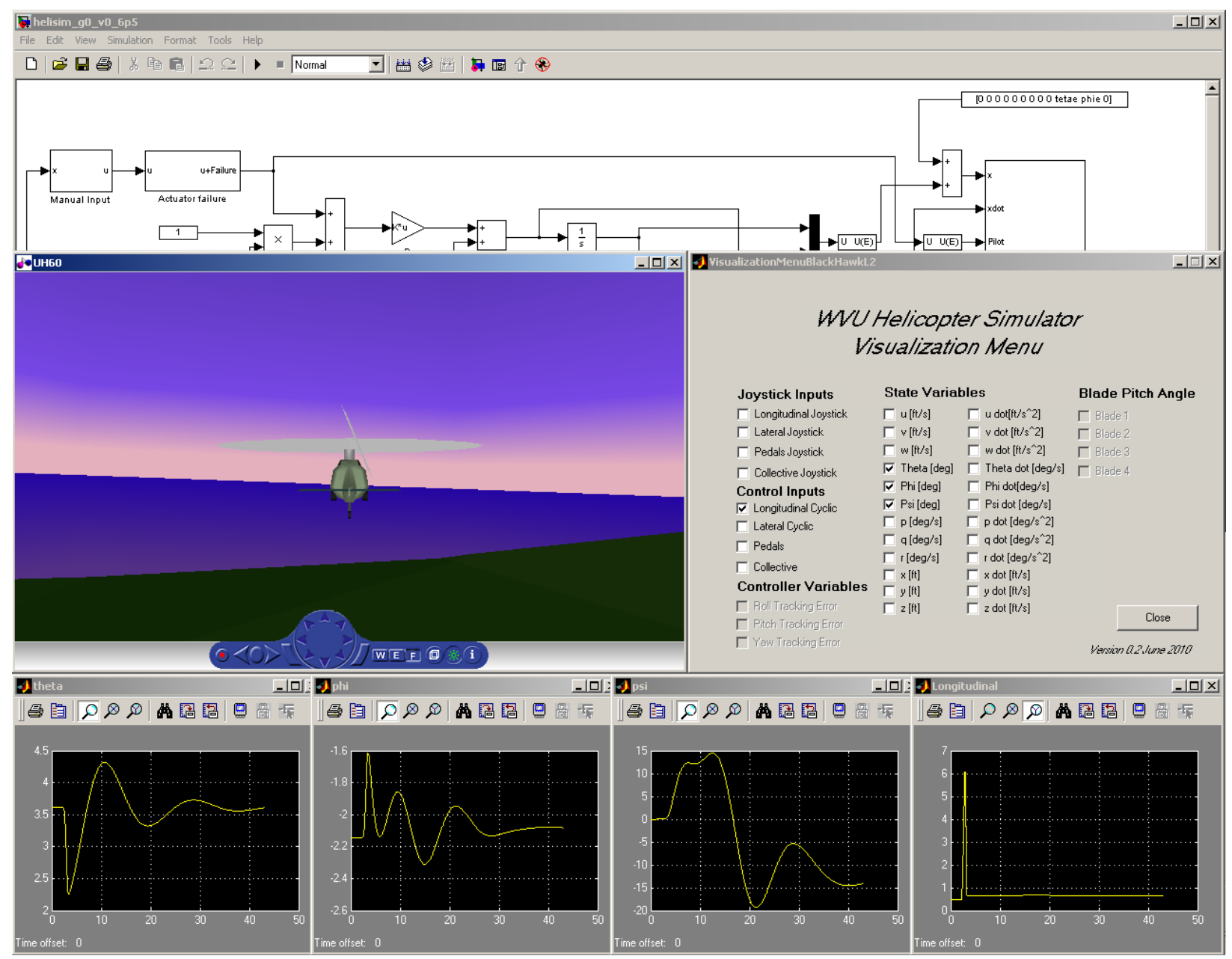

Figure C.14: WVU Helicopter Simulator - Plots

To end the simulation, click the "stop" button (located next to play button). Depending on the computer system, some difficulty main occur in switching between various windows during a simulation. If this is the case, a simple modification can be made within the SIMULINK model. In the SIMULINK model window, open the RTBlock and set the Priority to Normal and the Thread Priority to Normal. This will allow the experiment to run in near-realtime and still allow for adequate flight visualization.

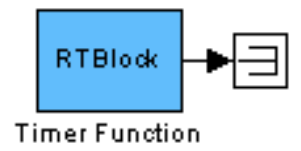

Figure C.15: WVU Helicopter Simulator - RTBlock 


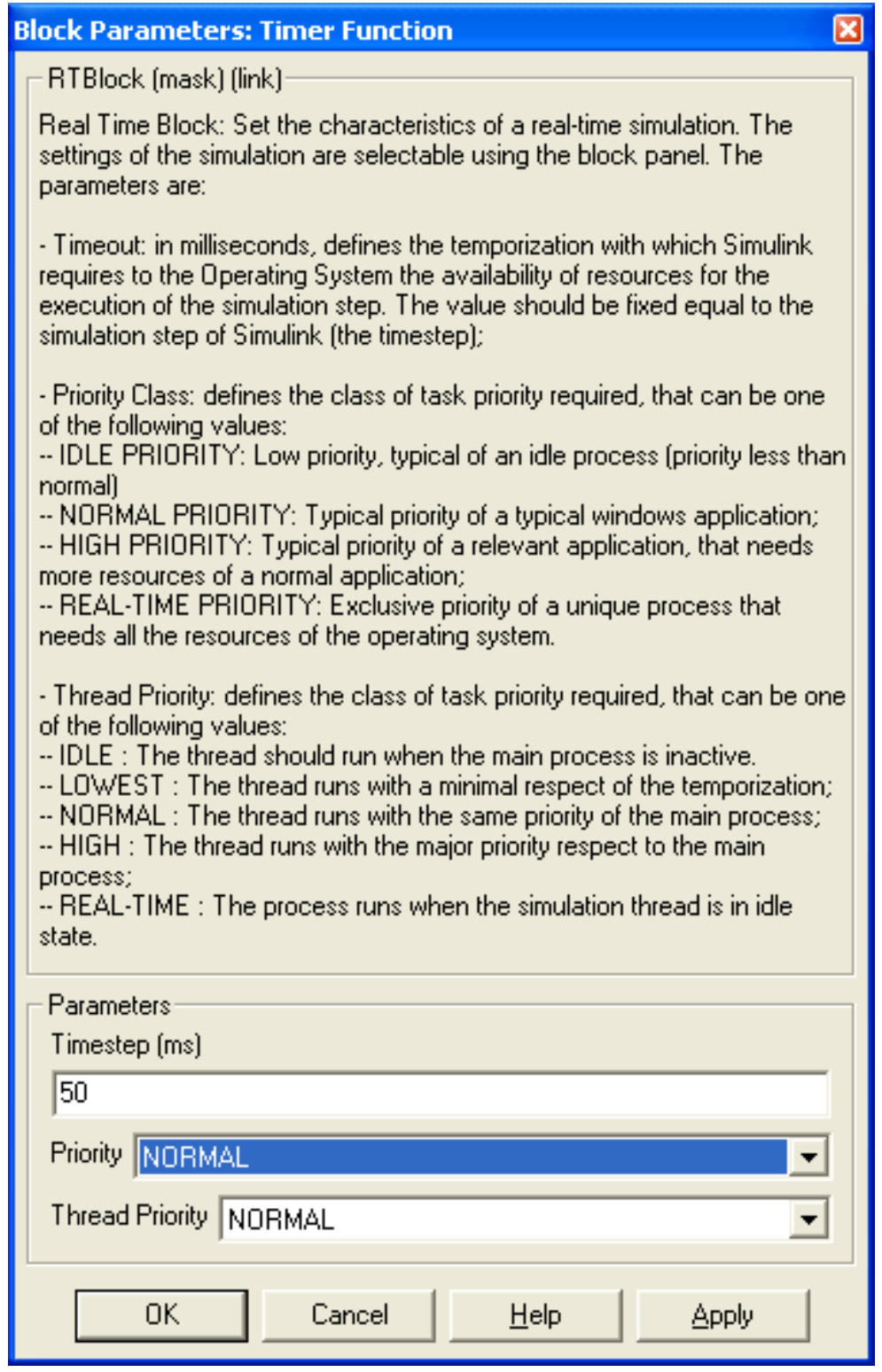

Figure C.16: WVU Helicopter Simulator - RTBlock Parameters

It is also important to remember that the helicopter is operating at trim conditions. Therefore, all control inputs are technically deflections from an original trim position.

To start a new simulation, click "CLOSE" on the WVU Helicopter Simulator Visualization Menu and then close the SIMULINK model. Note that the current directory has reverted back to SimVI on the Matlab ${ }^{\circledR}$ Command Window. Retype "WVU_Heli_Simulator" in the Command Window and press enter to repeat the process. 